



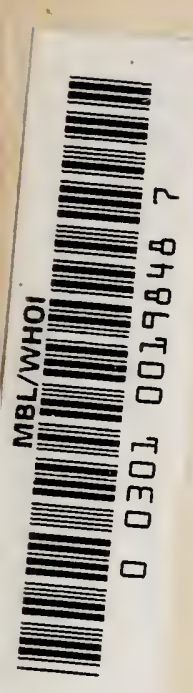





THE ENDOCRINE ORGANS 


\section{WORKS BY THE SAME AUTHOR}

\section{TEXT-BOOK OF MICROSCOPIC}

A NATOMY

With roor Illustrations in the text and 21 Coloured Plates. Royal 8vo. 25 s. net.

\section{THE ESSENTIALS OF HISTOLOGY}

With 645 Illustrations, many of which are Coloured. 8vo. Ios. 6d. net.

\section{EXPERIMENTAL PHYSIOLOGY}

With $8_{3}$ Illustrations.

$8 v 0.4$ s. $6 d$. net.

LifE: Its Nature, Origin, and

Maintenance

Svo. is. net.

\section{A TEXT-BOOK OF PHYSIOLOGY}

By British Authors: in Two Volumes.

Edited by E. A. SCHÄFER. 


\section{THE ENDOCRINE ORGANS}

\section{AN INTRODUCTION TO THE STUDY OF INTERNAL SECRETION}

Sharpey- BV

SIR EDWARD A. SCHÄFER, LL.D., D.Sc., M.D., F.R.S.

PROFESSOR OF PHYSIOLOGY IN EDINBURGH UNIVERSITY

WITH NUMEROUS ILLUSTRATIONS

LONGMANS, GREEN, AND CO.

39 PATERNOSTER ROIV, LONDON FOURTH AVENUE \& 30TH STREET, NEW YORK BOMBAY, CALCUTTA, AND MADRAS

1916 
10503 


\section{PREFACE}

'I'HIs book is founded upon a course of lectures (Lane Medieal Lectures) delivered at Stanford University, California, in the summer of 1913. The lectures were issued in the following year amongst the publications of the University, but in an abbreviated form and without illustrations. It also happened that the proofs, which had been sent for correction, failed to reach me; so that the work as it appeared contained an unusual number of ineidental errors. On these and other grounds, I liave thought it desirable, with the concurrence of the University authorities, to publish the substance of the lectures in a revised form with the addition of the tracings and photographs which were used to illustrate then: thus both enabling the subject to be brought up to date and affording the opjortunity of presenting it to a wider audience.

The time at my disposal for the leetures precluded anything more than a passing mention of some of the many workers who have contributed to our knowledge of this, the newest, development of physiology; and in republishing, it has not been deemed desirable unduly to extend the references to literature, seeing that they are already to be found in such standard works as Biedl's Innere Selinetion, in which the bibliography oceupies more than 250 large octavo pages, and Swale Vineent's Internal Secretions and the Ductless Glands, where they rum to over 2000 titles. Since the appearance of those works much new matter has been added; and more than one long list of literature has appeared in monographs dealing with special internally secreting organs. It is to publications of a comprehensive eharacter such as these that the scientifie worker will turn for detailed information. The aim of this little book is less ambitious : it is designed to supply a concise account of our present knowledge for the benefit of students and practitioners who may be desirous of obtaining more information regarding the internal seeretions than is afforded by the ordinary text-books of physiology, but have not the time or opportunity to peruse extensive monographs or consult original articles.

For a eoneise history of the subject, as well as a eritical examination of the main facts on which the doctrine of internal seeretion is based, the small but masterly compendium Les sécrétions internes, by E. Gley, cannot be too warmly recommended. 


\section{CON'TENTS}

PREFACE

PAGE

CHAP'T'ER I

\section{GENERAL CONSIDERATIONS}

Internal secretions and the organs which furnish them . . . . . 1

'The nature of the active principles of the internal secretions . . . . 4

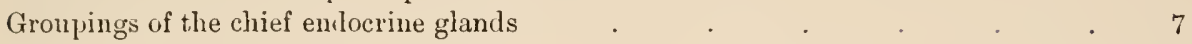

Methods of determining the functions of the endocrine organs . . 8

CHAPTER II

THE THYROID AND PARATHYROIDS

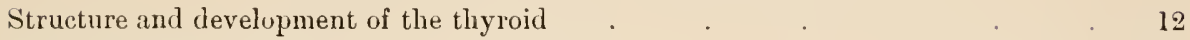

Structure and development of the parathyroids . . . . 16

\section{CHAPTER III}

\section{THE THYROID AND PARATHYROIDS (continued)}

Effects of removal of the parathyroids . . . . . . . . . 22

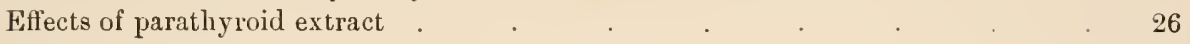

The mode of action and the nature of the parathyroid autacoid _ . . . 27

CHAPTER IV

THE THYROID AND PARATHYROLDS (continued)

Effects of removal aud of atrophic degeneration of the thyroid : hypothyroidism . $\quad 29$

CHAPTER Y

THE THYROID AND PARATHYROIDS (continued)

Effects of increase of thyroid secretion : hyperthyroidism . . . . . 35

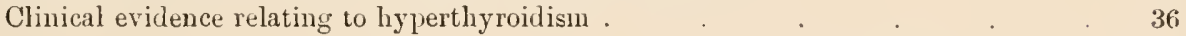

\section{CHAPTER VI}

THE THYROID AND PARATHYROIDS (continued)

The nature of the autacoid substances produced by the thyroid . . . . 40

Interaction of the thyroid with other organs . . . . . . . 41

Influence of the nervous system on thyroid secretion . . . . 44 


\section{CHAPTER VII \\ THE THYMUS GLAND}

Structure and development of the thymus

\section{THE SUPRALENAL CAPSULES}

Morphology

Structure of the cortex .

Functions of the cortex .

\section{CHAPTER IX}

\section{THE SUPRARENAL CAPSULES (continued)}

Effects of suprarenal removal

The nature of the antacoid furnished by the medulla .

\section{CHAPTER X}

\section{THE SUPRARENAL CAPSULES (continued)}

Evidences of the passage of arlenalin into the blood . . . . . 68

Influence of nerves mon the steretion . . . . . . . . . . $\quad 69$

Relations of the snprarenals with other endocrine organs and secreting glands $\quad$. $\quad 70$

CHAPTER XI

THE PITUITARY BODY

Structure of the pituitary

\section{THE PITUITARY BOWY (continued)}

The active principles of the pitnitary

Eflects of extracts of the posterior lobe.

Effects on metabolism and in disease.

Are the various effects obtained from extracts of the posterior lobe due to only one or to more than one autacoid?

THE PITUITARY BODY (continued)

Effects of complete removal 


\section{CHAPTER XV}

THE PITUITARY BODY (continued)

Relations of the pituitary with other endocrine oryans

CHAPTER XVI

THE PINEAL GLAND

Structure of the pineal .

Effects of injecting extracts of pineal

Effects of extirpation. Relations of the pineal witl the sexual glands . $\quad 120$

CHAPTER XVII

THE INTERNAL SECRETIONS OF THE ALIMENTARY MUCOUS MEMBRANE AND OF THE PANCREAS

Secretines

The internal secretion of the pancreas .

The islets of Langerhans

Effects of removal of pancreas. Diabetes

Nature of the pancreatic autacoid

Relation of internal secretion of pancreas with otler endocrine organs

THE INTERNAL SECRETIONS OF THE GENERATIVE ORGANS IN THE MALE

The interstitial cells of the testicle

Effects of castration

The nature and source of the testicular autacoid

Effects of extracts of testicle

THE INTERNAL SECRETIONS OF THE GENERATIVE ORGANS IN THE FEMALE

The interstitial cells of the ovary

The corpora lutea

Effects of removing and reimplanting ovaries.

\section{CHAPTER XX}

THE INTERNAL SECRETIONS OF THE GENERATIVE ORGANS IN THE FEMALE (continued)

Effects of ovarian extracts (hilum ovarii, Graafian follicle-; corpora lutea) . . I41

Metabolic effects produced by corpus luterm . $\quad . \quad$. $\quad . \quad$. $\quad . \quad 145$

Internal secretion of uterus . . . . . . . . . . . . 148

Internal secretion of mammary gland . . . . . . . 150

Internal secretion of placenta . . . . . . . . . 150 



\title{
THE ENDOCRINE ORGANS
}

\author{
AN INTRODUCTION TO THE STUDY \\ OF INTERNAL SECRETION
}

\section{CHAPTER I}

\section{GENERAL CONSIDERATIONS}

\section{Internal Secretions and the Organs which Furnish Them}

MATERIAL which is passed into the blood or lymph from any tissue or organ of the body forms its internal secretion, and organs which are not known to possess any other function than that of passing such material into the blood or lymph are internally secreting or endocrine organs. ${ }^{1}$ This term is not usually extended to organs like the lymphatic glands, of which the material production is of a morphological character, although until recently all such organs used to be included along with the true endocrine glands, the functions of which were at that time unknown, in the general expression of ductless glands. Under this last term were comprised not only the organs to which we now commonly ascribe internally secreting functions, such as the thyroid, parathyroids, the suprarenal capsules or adrenals, the pituitary body or hypophysis cerebri, and the pineal gland or epiphysis cerebri, but also the thymus gland, the tonsils, lymph-glands and lymph-follicles, and the spleen; with these the bone-marrow is associated. Regarding the thymus gland, although some evidence has been adduced that it may yield an internal secretion to the blood which exercises a specific action upon growth and development, and especially the maturation of the generative organs, it appears both developmentally and structurally to resemble the tonsils, which are generally allowed to be structures of a lymphatic nature, and like the tonsils most of its cells are lymphocytic in character. The spleen has been described as furnishing an internal secretion which activates the proteolytic ferment of the pancreatic juice; and the contractions of plain muscular tissue, especially that of the intestines, have been supposed to be stimulated by another substance formed in the organ. But the proof of the existence of such internally secreting functions in connexion with most of these lymphoid structures is so inferior to that which we possess regarding the thyroid,

1 From $\epsilon_{\nu} \delta o \nu$, within, and $\kappa \rho i \nu \omega$, to separate. 
parathyroids, adrenals, and pituitary, and even the pineal gland, that we may, at least provisionally, exclude them from the class of bodies which secrete active chemical agents into the blood for the purpose of influencing other organs. It is to this latter class that I intend to restrict my remarks, and it is to them and them alone that the term endocrine will be applied in these pages.

It follows from what has just been said that by the expression endocrine organ we imply an organ which is known to form some specific chemical substance within its cells, and to pass this directly or indirectly into the blood stream. ${ }^{1}$ The substance thus formed is the active material of the secretion, just as ptyalin is the active agent of the salivary secretion. But while in the case of such glands as the salivary their secretion is conducted by a duct to the exterior, in the case of the endocrine glands the secreted material remains within the body and circulates with the blood; hence the term internal applied to their secretions.

The expression internal secretion was originally used in a sense somewhat different from that in which it is now applied, having been employed by Clande Bernard to describe the grape sugar which, as he showed, is passed from the liver cells into the blood. It has also been used to designate all materials which are contributed to the blood by the tissues. In this sense the carbon dioxide and other products of metabolism which are taken up by the blood in its passage through the capillaries, or are received by it through the medium of the lymph stream, are internal secretions, and every tissue is an internally secreting structure. It is, however, convenient to restrict the term to secretions containing specific organic substances such as the active chemical agents which are produced by certain ductless glands, and this is the sense in which the expression will be employed in this book (see also pp. 5 and 6 ).

It is well known that the production of specific chemical agents which are passed into the blood and carried by it to influence distant structures is not confined to the ductless glands-that an active internal secretion may be produced by other organs than these. A notable example is met with in the pancreas, the more obvious function of which is the production and excretion into the intestine of pancreatic juice; which, by virtue of the ferments it contains, is the most active agent in the digestion of foodstuff's within the alimentary canal. It was shown, however, by v. Mering and Minkowski in 1889, that the pancreas possesses an internal secretory function which is of even greater importance in the economy than its long-recognised external secretory activity. For by totally removing the pancreas in animals, these observers proved that the presence of the gland, and of some substance yielded by it to the blood, is essential to the proper utilisation of carbohydrate material in the tissues, so that when the pancreas is totally removed grape sugar is no longer stored in the liver, to be split up little by

I It must be clearly unclerstood that although this passage of a specific substance into the blood is an essential part of the doctrine of internal secretion, the definite proof of such substances in the blood has only been furnished in very few cases. 
little by the organism into simple oxidisable substances, but is passed out at once into the blood and extracted from the blood by the kidneys, producing glycosuria. It may be added that our present knowledge of the causation of diabetes is based mainly on these observations.

Now it is known that the pancreas possesses, besides the secreting alveoli which form the enlarged and blind terminations of its ducts, a special kind of secreting cells which are massed together into islets of irregular shape and variable number and size, having a special kind of blood supply. These islets, which were first described as a distinct element of pancreatic tissue by Langerhans, have been originally developed from and may retain a comnexion with the ducts of the organ, in this respect resembling the ordinary alveoli. But in the course of growth they have lost all open connexion with the ducts; their cells have acquired specific properties: and their function is without doubt different from the ordinary cells of the gland. With some show of reason the special internal secreting function above mentioned has been ascribed to them, and in support of this it may be stated that in many if not most cases of diabetes these cells are found to have undergone degeneration. They, in fact, form an organ within an organ, and collectively may be regarded as belonging to the group of internally secreting or endocrine glands.

An example of a tissue devoted to the formation of both an external and an internal secretion is found in the epithelium which lines the duodenum. The functions of this epithelium which have been longest known are those of promoting the absorption of digested food materials and of helping to furnish the secretion known as the intestinal juice. But in 1902 it was discovered by Bayliss and Starling that if an extract of the duodenal epithelium is boiled with dilute hydrochloric acid and, after neutralisation, is injected into the blood stream of an animal, a rapid flow of pancreatic juice is determined. It had already been known that the gush of acid gastric juice through the pylorus, or the painting of the mucous membrane of the duodenum with dilute acid, would determine a flow of pancreatic juice, but this flow had been supposed to be brought about as a reflex act by excitation of a local nervous mechanism by the acid. The observations of Bayliss and Starling rendered it clear, however, that this is not the correct explanation of the phenomenon; but that the flow must rather be regarded as due to the absorption of some internal secretion into the blood: the material of this internal secretion being produced in an inactive form by the epithelium cells, and becoming so altered by the dilute acid as to be converted into an agent which, after absorption into the blood stream, excites the secreting cells of the pancreas to activity.

To the active substance which is yielded by the epithelium cells of the duodenal mucosa the name secretine was given by Bayliss and Starling, whilst they termed pro-secretine the inactive material contained within the cells before the action of dilute acid upon them. The active material is obviously of the nature of an internal secretion; it appears, however, 
not to be produced by a special structure, certainly not by a special organ, but, so far as one can tell, by the ordinary cells which line the mucosa and extend into its glands.

A similar but not identical internal secretion was shown by Edkins to be produced by the cells of the mucous membrane of the pyloric end of the stomach. When rendered active and absorbed into the blood, this secretion, which is termed gastrine, stimulates not the cells of the pancreas, but those of the fundic glands of the stomach itself.

A yet more remarkable example of the coincidence of external and internal secretory functions in the same organ is supplied by the generative glands (ovary and testicle). It has been known from time immemorialthe experiment is repeated daily for commercial purposes in thousands of animals, and is still practised upon man for domestic reasons in certain Oriental countries-that the removal of the generative glands in the young male animal usually entirely prevents the development of the accessory generative organs, such as the prostate, and of the features which characterise the male sex externally. These changes may be prevented by successfully grafting a testicle in the castrated animal.

Again, removal of the ovaries in the young female exerts a profound influence over the organism and prevents the development of many female characteristics. In some cases, even in the adult, removal or atrophy of the ovaries has been noticed to lead to the development of male characters. Instances of this have been often recorded in birds. In young mammals removal of the ovaries is followed by arrest of development of the uterus. This may be prevented by successfully transplanting the ovaries, or by grafting an ovary from another animal of the same species into the peritoneum or elsewhere. It seems clear, therefore, that the result of removal is due in both male and female to the absence of the internal secretion of the generative gland.

\section{The Nature of the Active Principles contained in the INTERNAL SECRETIONS}

We have compared the active materials of the internal secretions, which are formed within cells and passed out into the blood, to the active agents of the ordinary secretions, which are directed on the exterior by means of a duct. But the comparison cannot be pressed. In the case of the external secretions, the active agents when present are always of the nature of a ferment. They belong to the class of bodies which are known as enzymes. The conditions and modes of action of these bodies are for the most part familiar to the biologist. They occur not only in secretions, but in the bioplasm of most if not of all cells ; indeed the chemical activity of the cell in most cases depends upon its contained enzymes. Although far simpler in chemical nature than the bioplasm by which they are produced, and in no sense endowed with life, enzymes are very probably of a protein nature, 
and they are readily destroyed by heat in presence of water. The active materials of the endocrine organs, on the other hand, are for the most part not rendered inactive even by prolonged boiling, and are certainly of a much simpler chemical constitution than enzymes. They are dialysable; and although most of them have not yet been isolated in a crystalline form, due probably to the fact that it is difficult to obtain them free from impurities, some of them have been so obtained, and at least one-the active material of the adrenal medulla-has been prepared synthetically. Many of them act instantly; their action, as Starling has pointed out, being similar to that produced by the active principles of drugs, especially those of organic, i.e. of vegetable, origin. These also operate by immediate chemical action, being conveyed to the parts which they influence in solution in the circulating blood. But while some of the materials of the internal secretions produce their effects upon the tissues immediately, others operate more slowly, so that the results of their action may only become apparent after a prolonged period of time. The latter class usually exert their influence upon the growth and nutrition of special organs or of the body generally: they are accordingly termed by Gley morphogenetic. ${ }^{1}$ None of the substances we are dealing with are known to cause the production of antibodies when introduced into "foreign" blood. Their action is similar in all animals, however different from the animal yielding the secretion.

As with drugs, some of the principles yielded by the endocrine organs act by stimulating or exciting cell-functions : this is notably the case with the principle obtained by the action of acid on the duodenal epithelium. Others depress or inhibit those functions: an example of this is met with in extract of placenta, which when injected into the blood-vessels tends to prevent the secretion of milk. To such stimulating principles as that contained in the extract of duodenum after treatment with acids the term lormone (from o $\rho \mu^{\prime}\left(\omega\right.$, to stir up) was originally applied by Starling, ${ }^{2}$ and the expression has been extended to include the active principles of all internal secretions. So long as only exciting agents were known, there could be no objection to this extension of the term, but since agents which produce depression or cessation of function have been shown also to be produced in the body - and their number will probably become considerable as the nature of the internal secretions is more fully examined-it is advisable to employ an expression which will discriminate between these and the stimulating agents. On this account I propose to distinguish the action of the depressants from that of the excitants by the use of the term chalone ( $\chi \alpha \lambda \alpha^{\prime} \omega$, to make slack). A chalone may therefore be defined as an endocrine product which inhibits or diminishes activity, as distinguished from a hormone, which excites to increased activity. ${ }^{3}$

1 He suggests the name harmozones for them ( ${ }_{\alpha}^{\alpha} \rho \mu \delta \zeta \omega$, to govern).

2 Verhandl. d. Naturforscher-Versammlung, Stuttgart, 1906.

3 The original expression employed by Bayliss and Starling (Journ. Physiol., xxviii., $1903)$ in their paper on secretine was chemical messenger. This is more appropriate as a general term than hormone, because it includes all chemical agents which produce 
Starling does not, however, confine the use of the term hormone to organic principles of an endocrine nature. His definition is much wider. "By the term 'hormone," " he says, "I understand any substance normally produced in the cells of some part of the body and carried by the blood stream to distant parts, which it affects for the good of the organism as a whole" (Proc. Roy. Soc. Med., 1914, vol. vii., Therap. and Pharm. Sect., p. 29). He then proceeds to give as examples of hormones, secretine, adrenalin, and carbonic acid-the last, which is produced by the tissues in general and more especially by muscular tissue, stimulating the respiratory centre to activity. Obviously this definition would include many substances normally present in the blood, such as water, urea, glucose, and inorganic salts, which are produced in various parts of the body and affect distant organs such as the kidneys; indeed it may be supposed that most circulating materials will, when we know more about their history, come into the definition. The expression hormone has not been hitherto employed by physiologists and clinicians in this extended sense; the term has usually been restricted to the active organic principles of the internal secretions. But it will perhaps be best to employ the term hormone in the sense in which it was used by its inventor, i.e. to denote any substance in the blood which excites cells of the body to activity, and to express by a special term those specific substances which are produced by the organs of internal secretion for the purpose either of exciting or of restraining the activity of other organs. Since the most characteristic feature of the action of these substances is the resemblance to the action of drugs, such as the vegretable alkaloids, I propose to employ for these specific substances the general title autacoid substances, or, simply, autacoids (áviós, self, and "̈̌ as a specific organic substance formed by the cells of one organ, and passed from them into the circulating fluid to produce effects upon other organs similar to those produced by drugs. Such effects are either in the direction of excitation, in which case the endocrine substances producing them are excitatory autacoids and would come under the expression hormones, or in the direction of restraint or inhibition, in which case they are restraining or inhibiting autacoids and would be classed as clualones. The action of an autacoid may therefore be described as hormonic or chalonic, according to the kind of effect it produces.

Some autacoid substances appear to prodnce opposite results in different parts. Thus the adrenalin of the suprarenal medulla causes contraction of the plain muscle

an effect at a distance, whether such effect be excitatory or inhibitory. If, in place of hormone, the expression hermone ('E $\rho \mu \hat{\eta} s$, Nercury) had been selected, the difficulty which is caused by the use of the term hormone, which implies excitation, for agents which act in exactly the contrary manner, would not be felt. Biedl uses the expressions erregende Hormonen and hemmende Hormonen, i.e. excitants which excite and excitants which prevent excitation! It is true that he regards the one class as exciting katabolic changes and the other as exciting anabolic clianges, but this is purely thenretical, and it is, to say the least, improbable that these agents operate in the manner thus indicated. 
of the blood-vessels and inhibition of that of the intestines. But in both cases the action may be regarded as that of a hormone or exciting agent, for both effects are prodnced by stimulation of the end substance of the sympathetic nerves. In extreme dilution ( 1 to several millions) in mammals, and in a less dilute form in birds, adrenalin is said to cause inhibition instead of contraction of the muscle of the blood-vessels. But this again may be produced by excitation of inhibitory nerve fibres by the more dilute solution, and if so, the action would still be hormonic. Nevertheless, the possibility of the same autacoid substance acting under some circumstances as a hormone or excitant, and under other circumstances as a chalone or depressant, must be borne in mind. This, indeed, serves to illustrate the drug-like nature of these principles, for such inversion of action under difference of circumstance is known to occur with some drugs.

Noël Paton (Regulators of Metabolism, 1913) takes a view of the action of the principles of the internal secretions different from that usually adopted. He regards them as playing the same sort of part in the metabolism of the various organs they influence as Sydney Ringer showed to be the case with the salts of blood in maintaining the activity of the heart. "A certain minimum amount of each seems to be essential, and some proportion between the amounts of each must be maintained if the metabolism is to continue in its normal course. . . . It seems to me that such a conception is more in accordance with the facts which we possess than that of a series of hormones or excitors directly calling forth the activity of the various tissues."

\section{Groupings of the Chief Endocrine Glands}

Most of the purely endocrine glands can be grouped under the three main heads of thyro-parathyroid apparatus, suprarenals, and pituitary. It is noteworthy with regard to these groups that each of the organs forming the group is compounded of two distinct but usually closely intergrown parts. Thus the thyro-parathyroid group is composed of thyroid proper and parathyroids; the suprarenal of cortical and medullary portions ; the pituitary of epithelial and epithelio-neural parts. And in each case the functions of the two portions, so far as is known, appear to be in no way similar, difficult as it is to believe that tissues so closely connected anatomically should have no sort of functional connexion. The close anatomical connexion is, however, sometimes absent, as with those parathyroids which are altogether detached from the thyroid, and as with the paired bodies and the interrenal body of Elasmobranch fishes. A close anatomical relationship without any apparent functional bearing is, however, not without examples in other organs, e.g. in the frog there exists a very intimate anatomical connexion of the suprarenal with the kidney, although there is no particular reason to believe that any special functional relationship obtains between the two.

It is further noticeable that in each of the above groups one of the two parts has a more evident, and in a sense a more active, function than the other. Thus the removal of the parathyroids occasions symptoms which are far more acute than those produced by the corresponding operation on 
the thyroid. And extracts of the medullary substance of the adrenals and of the posterior or epithelio-neural part of the pituitary have an immediate and striking effect on various tissues and organs when injected into the blood-vessels, whilst similar extracts of the cortical substance of the adrenals or of the anterior or epithelial part of the pituitary are without any inmediate action. There is, however, in the case of the thyroid, direct experimental as well as clinical evidence, and, in the case of the suprarenal capsules and pituitary, the testimony of much clinical observation, to furnish reason for the belief that the parts of these glands which at first sight appear less active may exercise, if a slower, yet a no less potent influence upon the organism than the portions the activity of which can be more immediately demonstrated.

\section{Methods of Determining the Functions of the Exdocrine Organs}

Two general methods are employed for this purpose, the one being the observation of the changes which result from partial or complete surgical removal of the organ in man and animals, or its destruction by disease; the other, observation of the changes which result from the administration of watery or saline extracts prepared from the organ. As has been already stated, the active principles of the endocrine glands are not destroyed by boiling with water or with Ringer's solution, at least for a short time. Advantage is taken of this to prepare extracts which are free or almost free from protein or nucleo-protein, since the introduction of these substances into the blood might tend to mask the effect of the autacoid which is being tested. Solutions obtained in this way may be kept, after sterilisation, in hermetically sealed receptacles almost indefinitely. Preserved in the dry condition the autacoids also appear to undergo no diminution of their activity. In these particulars animal autacoids resemble extracts of plants containing active medicinal principles of an organic nature, with the action of which, as has already been indicated, the effects they produce bear a close comparison.

As with drugs, the extracts can be administered by the mouth, or by subcutaneous, or intramuscular, or intraserous, or intravenous injection. Or isolated organs and tissues may be perfused with or immersed in the extract the action of which is to be examined. The intravenous method was first employed by Oliver and myself to investigate the physiological action of such extracts in 1894, and led immediately to the discovery of the active principles of the suprarenal capsules and the pituitary body.

Administration by the Mouth.- This is well known to be effective in the case of the thyroid, and the fact is taken advantage of in cases of hypothyroidism such as occurs in endemic goitre, cretinism, and myxœedema. On the other hand, thyroid juice or the substance of the gland given freely with the food in normal individuals produces symptoms which are interpreted as due to excess of the thyroid autacoids in the blood. With smaller 
doses effects are produced upon metabolism, including an increase of $\mathrm{N}$ secretion and an increase of $\mathrm{O}_{2}$ intake and of $\mathrm{CO}_{2}$ output, with reduction of body fat. Buccal administration of pituitary extracts or pituitary gland substance is also stated to yield beneficial results in cases of deficiency of pituitary secretion, although in normal individuals no effect may be apparent. Similarly, buccal administration of suprarenal extract gives little, result in normal individuals, but both in Addison's disease and in certain other affections beneficial effects have been recorded.

Administration by Subcutaneous or Intramuscular Injection.-As with drugs, the effects of administering the animal autacoids by hypodermic injection are usually more rapid and more marked than with buccal administration, although in some cases the difference is not striking. But Meltzer and Auer have shown that if extract of the medulla of the suprarenals, or of the posterior lobe of the pituitary body, are administered by intramuscular injection-absorption being promoted by gentle massagethey rapidly cause their characteristic effects. Probably the reason why these extracts when given by hypodermic injection produce little general result-although the local effects in causing vasoconstriction may be very marked-is that the autacoid is rapidly destroyed in the body; so that when absorbed slowly it is got rid of before any excess is able to accumulate in the blood. This applies only to moderate doses and to the immediate effects. Secondary effects may be seen with large doses, and these may be of a marked character.

Intruvenous Injection.-The immediate effects-if any-of the animal autacoids are, as with drugs, unfailingly exhibited as the result of the injection into a vein of the extracts containing them. In this manner can be shown the action of extract of thyroid in causing a marked but evanescent depression of the blood-pressure: the various effects of extract of suprarenal medulla; such as contraction of blood-vessels with raising of blood-pressure, acceleration of pulse, sometines preceded or followed by retardation, flow of saliva, erection of hairs, dilatation of pupil, retraction of third eyelid, and protrusion of eyeball, contraction of uterus, vas deferens, and seminal vesicles, inhibition of gastric and intestinal movements and of the bladder : as well as those produced by extracts of the posterior lobe of the pituitary, such as contraction of the blood-vessels with slowing of the heart, increase of secretion from the kidneys, outflow of milk from the mammary gland, contraction of the uterus, of the intestines, and of plain muscle in general.

A caution must be entered against the too hasty conclusion that a particular effect obtained in injecting an organ extract is a specific effect due to an autacoid substance. Especially is this warning necessary in experiments in which the bloodpressure is employed as the gange of activity. For there are few organs which yield extracts that are absolutely inert when tested by intravenous injection. This applies to many glandular and lymphatic structures, extracts of which generally cause a rapid fall of blood-pressure, usually speedily recovered from. The depressor effect is not dependent upon the presence of mucleo-proteins in the extract, as was 
at one time supposed, nor upon the presence of choline; but seems to be caused by an organic material of a specific nature which varies in different organs, the extracts producing in each case a specific form of blood-pressure curve.

Extracts of animal tissues-if unboiled-are liable to produce intravascular clotting. If this is general, instant death is the result; if localised, it may manifest itself by serious interference with the functions of the nervous system or of other organs: and the result of such injection might erroneously be set down to a specific action of the extract injected, although it would only represent the result of an accident. A similar caution applies, although in a minor degree and for a different reason, to effects which may be obtained as the result of buccal and hypodermic administration of animal-extracts. Such effects may (unless they are otherwise proved to be specific) be produced by variations in amount of such organic substances as nucleo-proteins, which, when added to the ordinary diet of animals, are eapable of affecting growth and metabolism.

It is a perfectly legitimate criticism regarding the employment of extracts of organs, that we are not justified in assuming that because we obtain evidence of the presence of active substances in such extracts they are necessarily preformed in the organ, and still less that they are passed out from it into the blood. In fact, as we have seen, actual chemical evidence of the presence of such substances in the circulatory fluids is almost entirely lacking. Nevertheless, the action of extracts of certain of the ductless glands is quite specific, which is not the case with extracts of other organs; and since the active principles contained in such extracts are always readily soluble in water and diffusible, it is difficult not to believe that they are formed with the object of producing their specific action after being passed into the blood, in greater or less quantity according to the needs of the organism. The criticism that with many such extracts an amount of material may be necessary to produce a visible effect which is altogether out of proportion to the size of the endocrine organ the action of which is being studied, loses force if we remember that these organs are extraordinarily vascular and probably proportionately active, so that within a short tine a larger amount of active substance may be formed and passed into the blood than is present at any given moment in the cells of the organ. Nor need the action, under physiological circumstances, be so striking as we endeavour to obtain it under conditions of experiment; indeed it is not improbable that in many cases the functions of the internal secretions under normal circumstances are rather facilitating than active.

The terms substitution therapy, onganotherapy, opotherapy, and autotherapy are employed to denote the effects produced by administration of organs and their extracts-especially the endocrine organs-with the view to combat symptoms which are believed to be caused by a deficiency in the blood of the autacoids which are produced by those organs. The fact that such extracts have come into extensive therapeutic use emphasises the essentially drug-like action of the active substances they contain. Harrower (Practical Hormone Therapy) has collected a large number of observations bearing upon this subject. 


\section{THE THYROID AND PARATHYROIDS}

THe thyro-parathyroid group of endocrine glands consists (1) of the thyroid proper, which takes the form of two lobes situated on either side of the larynx and windpipe; and often united by an isthmus over the trachea (fig. 1); (2) of the parathyroids: generally two on each side-one, the upper (parathyroid IV), which is usually in contact with the corresponding lobe of the thyroid near its upper and dorsal aspect, whilst the other, the lower (parathyroid III), lies either in contact with the corresponding lobe of the thyroid near its lower and mesial aspect or is removed a greater or less distance from it, sometimes as low down as the thymus. Both upper and lower parathyroids are usually supplied with blood by branches of the inferior thyroid artery, with which they are anatomically closely connected. But there is a good deal of variation in this, as well as in their position relatively to the thyroid and to one another (Halsted and Evans, Geis). In many animals (dog, cat, rabbit, monkey) the upper parathyroid is deeply embedded in the substance of the thyroid (Kohn), and it has on that account then been termed the "internal" parathyroid, the lower being designated "external." The expressions parathyroid III and parathyroid IV, which indicate the source of each gland, are on the whole the least ambiguous and ought if possible to be employed.

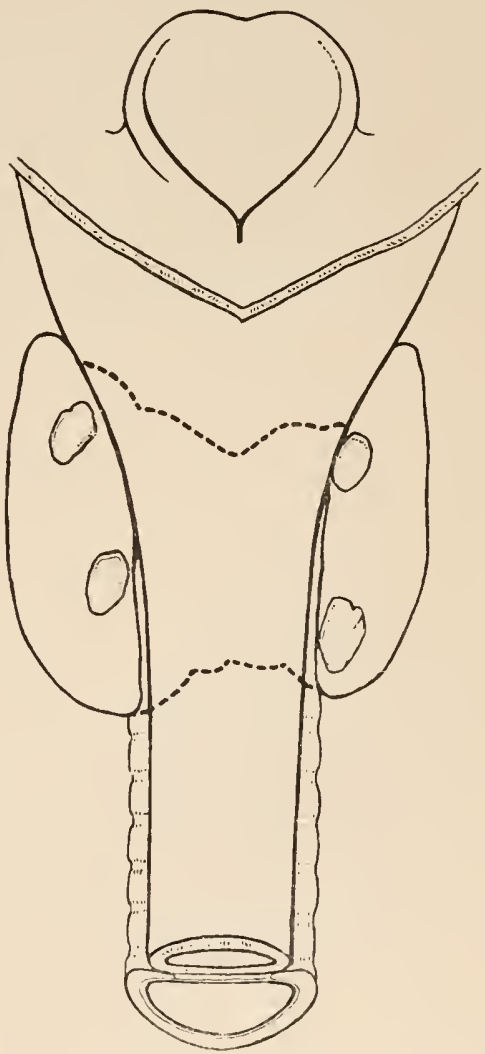

Fig. 1.-Sketch of a preparation of human larynx and oesophagus from the dorsal aspect, showing the thyroid and parathyroids.

The thyroid may also contain a portion of tissue resembling thymus gland, and, like that, containing lymphocytes and corpuscles of Hassall. Such portion of thymus tissue is developed from the same branchial pouch (IV) as the upper parathyroid, whereas the main thymus is developed 
from pouch III, which gives origin to the lower parathyroid (fig. 2). Accessory thyroids, usually quite small, occasionally occur in the tissues of

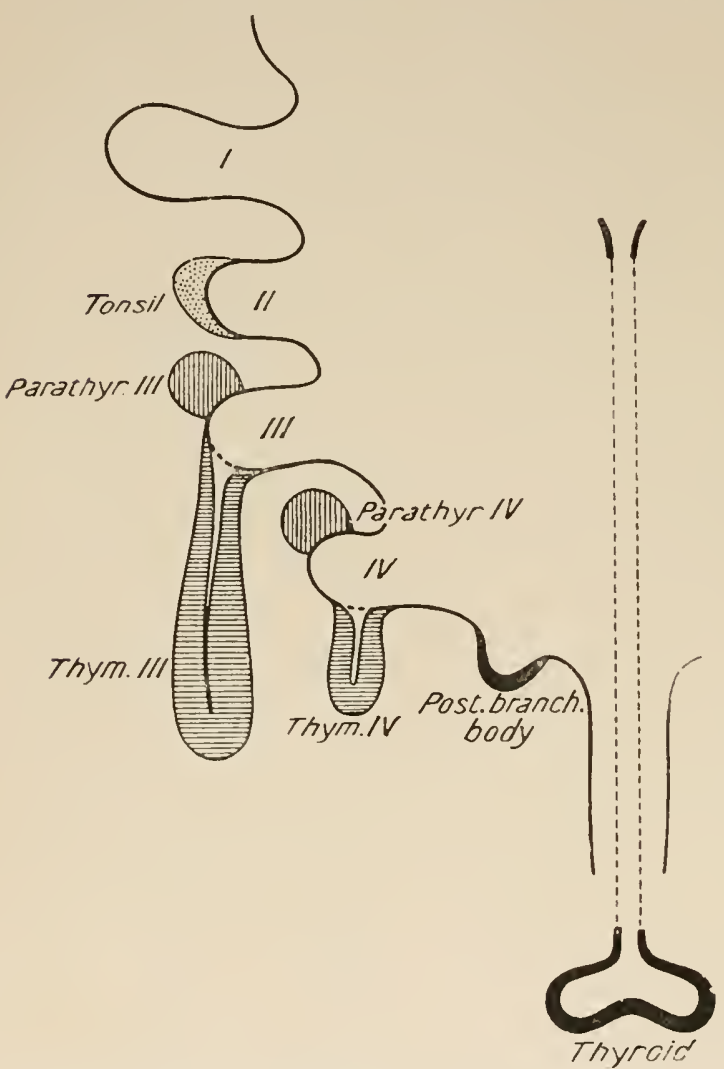

Fig. 2.- Diagram to illustrate the origin of the cleft organs (thyroid, parathyroids, thymus, etc.) in the mammalian embryo.

$I, I I, I I I$. II, branchial pouches; Parathyrii, origin of lower parathyroid from cephalic aspect of third pouch ; Jurathir.iv, origin of upper parathysoid from cephalic asject of fourth pouch: Thym.iii,iv, orixin of thymus from callial aspect of third and fourth pouches (Thym iv usually forms the part associated with the thyroid); Post.branch.body, post-branchial lody, which forms a separate organ in tower Vertebrata, but in mammals either disappears or is incorporated with the thyroid.

with the state of distension of the vesicles. the neck and in the anterior mediastinum. Accessory parathyroids also occur; they are common in the rabbit, and are in this animal often found to a considerable number embedded in the thymus. This is also the case with the rat.

In the rat, monse, and guinea-pig only the parathyroid III is ordinarily present, and this varies greatly in position relatively to the thyroid.

The thyroid is represented in all Vertebrates. In Amphioxus and Ammocnetes it retains an open connexion with the pharynx. Parathyroids do not occur below Amphibia. ${ }^{1}$

\section{Structure and Develop- MENT OF THYROID}

Structure.-The thyroid proper is an organ consisting of small closed resicles (fig. 3) of varying size and shape, but for the most part irregularly spheroidal. Each vesicle is lined by epithelium, the cells of which are columnar, cubical, or flattened in accordance There is no definite basement membrane separating the epithelium from the connective tissue and blood-vessels. The vesicles are generally filled by the so-called "colloid," a viscid fluid in the fresh organ, which is coagulated into a

1 For the structure and morphology of the thyroid and prarathyroids, the praper by the late Mrs F. D. Thompson in the Phil. Truns. for 1910 may be consulted. Thie following works deal with the whole subject:-Leopold-Lévi, Physio-pathologie du corps thyrö̈de, 1908 ; L. Lannoy, Thyrö̈des, Parathyroïdes, Thymus, 1914. For the parathyroids, see D. A. Welsh, Journ. Anat., 1898 ; D. Forsyth, Trans. Path. Sric., 1907 ; and Guleke, Chirurgue der Nebenschilddriisen, 1913. 
solid substance by fixative reagents. The interresicular substance is areolar tissue, containing in parts many small cells. Some of these are

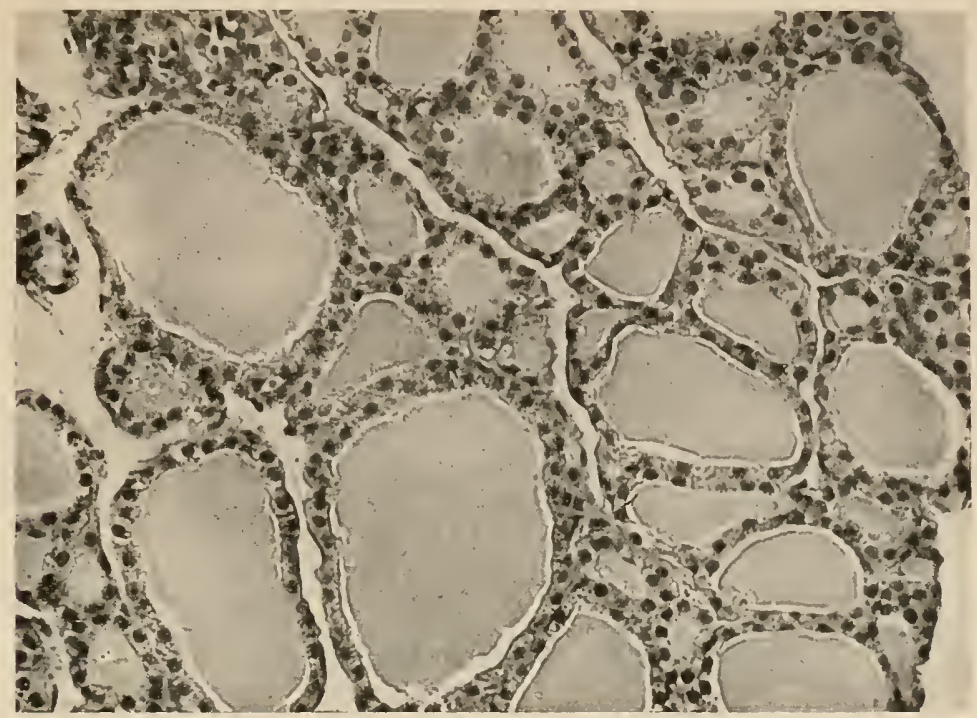

Fig. 3.-Section of thyroid (cat). Magnified 300 diameters.

lymphocytes, whilst others are not unlike those of the parathyroids, although the identity has not been established. There are also very numerous blood-vessels, the thyroid being one of the most vascular organs in the body; it receives in proportion to its size more than five times as much blood as the kidneys. The capillaries form a close network around each vesicle, giving a characteristic appearance to an injected specimen (fig. 4): they come into immediate contact with the vesicular epithelium (fig. 5). There are numerous lymphatics within the organ, and "colloid" like that of the vesicles is occasionally seen within them. The gland receives nerves from the sympathetic and from the superior and inferior laryngeal : they are distributed both to the bloodvessels and to the secreting epithelium.

The vesicles of the thyroid do not always

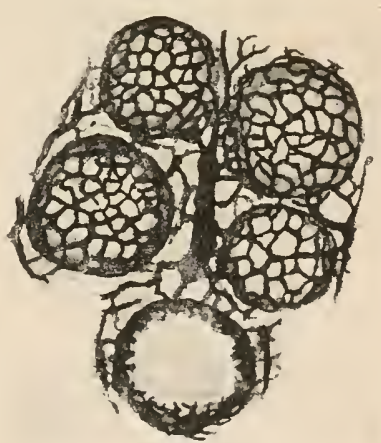

FIG. 4.- Thyroid of dog injected, low power. present the appearance above described. Sometimes they are smaller or irregular, with projections into their cavities, and the lining epithelium cells are pronouncedly columnar. In these circumstances there is usually little or none of the typical colloid material in the vesiclesalthough the appearance of the cells is suggestive of secretory activity. It may be inferred that the secreted material finds in these cases a 
ready exit from the vesicles, and thus fails to accumulate within them; it is possible that it may also be different in consistence and quality. So far as can be ascertained, these differences of appearance are seen in animals which are otherwise normal. A glandular structure of this type, but more pronounced, is noticeable in the thyroid in cases of exophthalmic goitre in man. It is usually there interpreted to indicate the production of excess of secretion (hyperthyroidism). The epithelium cells of the vesicles contain fatty granules which are said to increase in number with age; they are most numerous near the free border. The

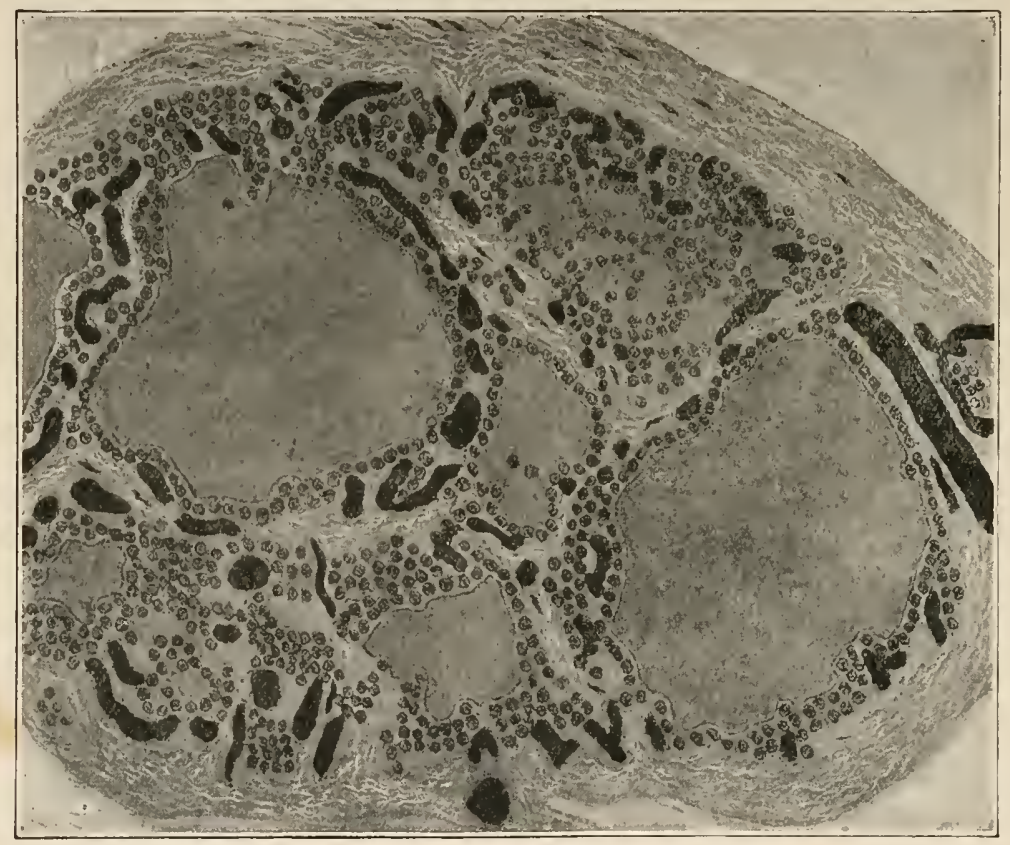

Fig. 5.-Section of thyroid, human, injected. (IIajor.) Highly magnified. The close relation of the capillaries to the vesicles is shown.

colloid is insoluble in alcohol, water, or ether; when coagulated it is readily stained by eosin, less easily by hæmatoxylin. In fixed sections it often appears shrunken away from the epithelium. It is believed to be formed from granules which are produced within the cells, and which become changed and dissolved on extrusion. Doubtless it contains the active principles of the secretion, and probably forms a storehouse whence they can be extracted as required by the organism.

A close relationship exists between the size and structure of the thyroid and the state of general nutrition of the animal. The effect of variations of diet upon the thyroid has been studied in rats by Chalmers Watson (see figs. $6 \mathrm{~A}$ and $6 \mathrm{~B}$ ), who has shown that all transitions from an active or superactive organ with highly developed columnar epithelium and irregular 
large vesicles and without any great accumulation of colloid, to a gland

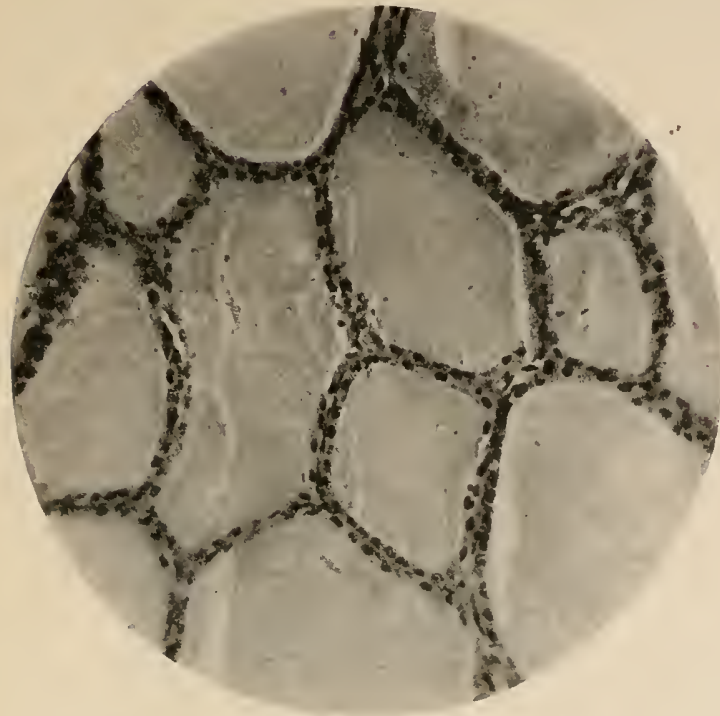

FIG. 6A.-Section of thyroid of wild rat. Magnified 250 diameters. The vesicles are seen to be distended with colloid and the cells flattened. (Chalmers Watson.) with flattened epithelium and vesicles greatly distended by colloid are exhibited under the influence of different nutritive substances in the diet: the former conditions being, in the rat, typically seen when the animals have been fed upon a mixed food such as bread and milk; the latter when the diet has been composed of lean meat. Prolonged feeding of rats with lean meat led eventually to a shrinking in size of the vesicles and of the whole organ, these changes being associated with dryness of skin, falling off of hair, and other evidences of ill-health; in carnivora results of this kind were not observed.

Development.-The thyroid is originally developed like an ordinary secreting gland by a median outgrowth from the entoderm lining the floor of the pharynx at a level between the first and second branchial pouches (fig.2). It appears very early and grows backwards as a solid column of cells, bifurcating at the upper end of the trachea into two lateral portions. The solid column becomes hollowed out into a duct (ductus thyreoglossus), which presently becomesobliterated, usually completely; itsoriginal opening is marked throughout life by the forctmen ccecum at the back of

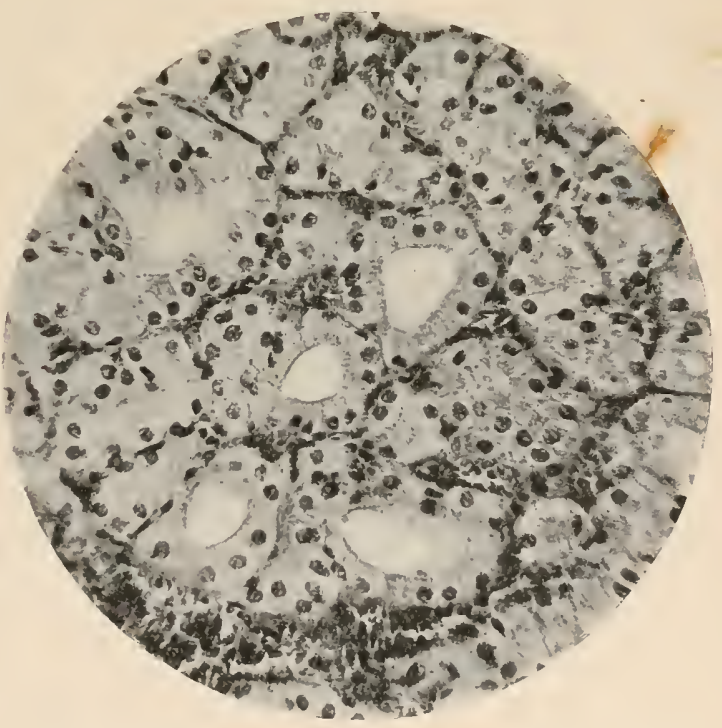

F1G. 68.-Section of thyroid of anotlier wild rat. Magnified 250 diameters. The vesicles contain little or no colloid ; the epithelial cells are columnar. (Chalmers Watson.)

the tongue. The lateral parts into which the caudal end divides, branch 
again and again to form a system of hollow epithelium-lined tubes, and later these become cut up into the closed vesicles which are characteristic of the gland. The thyroid bud is joined by outgrowths from the ventral

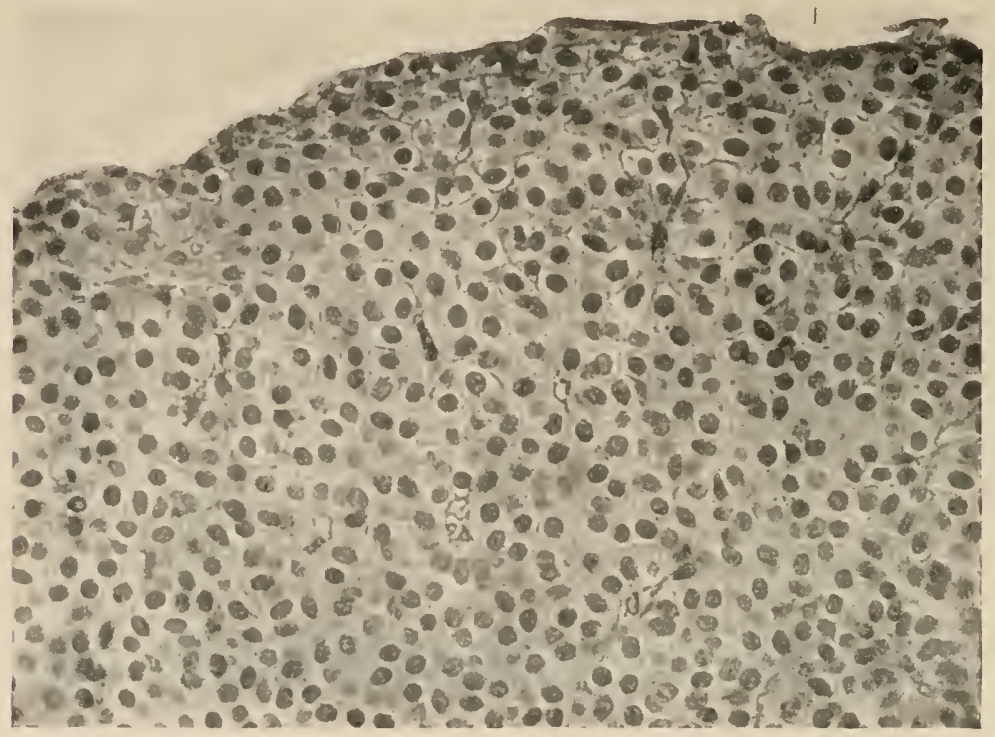

FIG. 7.-Section of parathyroid (cat). IIagnified 400 diameters. This is a good illustration of the compract type of gland.

wall of the pharynx on each side behind the fourth branchial pouch (postbranchial bodies); these may be involved in the thyroid, but it is doubtful if they contribute to the formation of its vesicles.

\section{Structure and Developaleyt of Parathyrolds}

Structure.-The parathyroids (fig. 1) are four minute organs averaging 6 to $7 \mathrm{~mm}$. in length, 3 to $4 \mathrm{~mm}$. broad, and 1.5 to $2 \mathrm{~mm}$. thick (Welsh). Each weighs about 0.03 gramme (half a grain). Rarely there are more than four, sometimes fewer. As already stated, one (the lower) may occur altogether detached from the thyroid, ${ }^{1}$ but usually in man both are closely attached to it. The upper of the parathyroids may be completely embedded in the substance of the thyroid (fig. 13).

The parathyroids were described by Sandström in 1880. Their physiological independence and distinction from the thyroid proper was first recognised by Gley in 1891, and confirmed by Vassale and Generali in 1896 , but is not fully accepted by Forsyth, Vincent, and some other authorities.

1 This is constantly the case, as Gley pointed out, in the rabbit, and partly accounts for the fact that when thyroidectomy is performed in that animal, two parathyroids being left behind, tetany does not occur until these are removed. Even then tetany sometimes fails to show itself ; this may perhaps be accounted for by the presence of accessory parathyroids in the thymus. 
The parathyroid is composed of epithelium-like cells (figs. 7 to 13), which either form a compact mass (fig. 7 ) or are divided up into lobules or

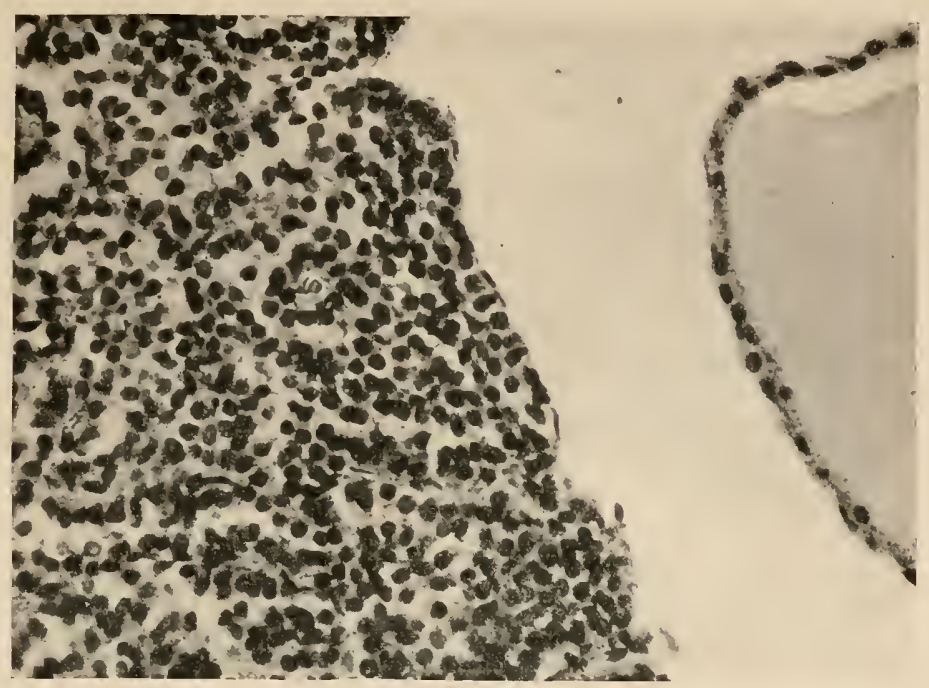

FIG. 8. - Section of parathyroid of dog. Hagnified 400 diameters. This shows a looser arrangement of the trabecule than the gland represented in fig. $\overline{7}$. On the right is part of one of the vesicles of the thyroid.

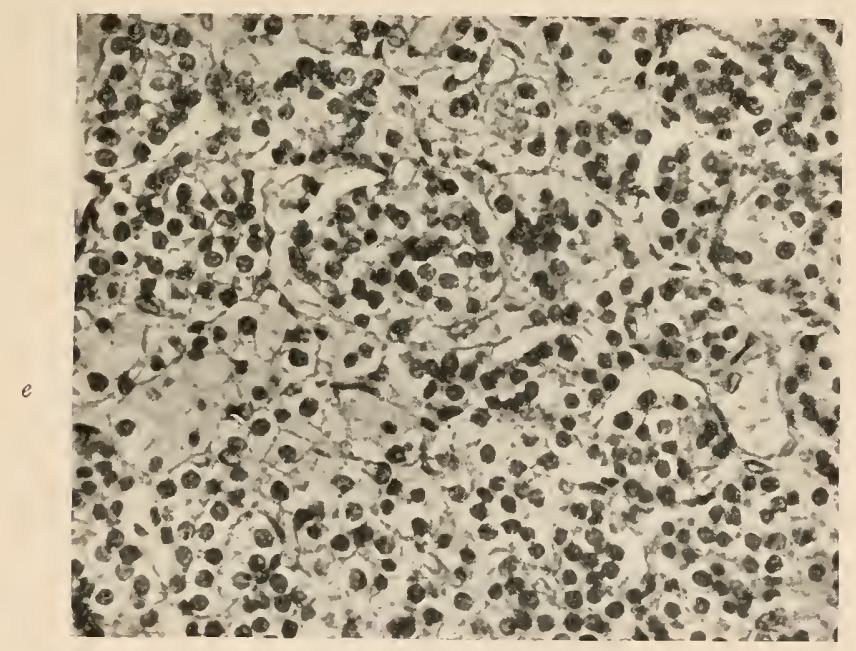

FIG. 9. - Section of parathyroid of man. Magnified 400 diameters. On the left is a strand of eosinophil cells (e). (Figs. 8 and 9 are from specimens prepared by Dr Kojima.)

trabeculæ (fig. 8) by strands of connective tissue. These differences of structural appearance may sometimes be observed even in different parts of the same gland. The interstitial connective tissue conveys the vessels, 
which mainly take the form of sinus-like capillaries. There is a capsule of areolar tissue sending in processes to join the interstitial tissue of the organ:

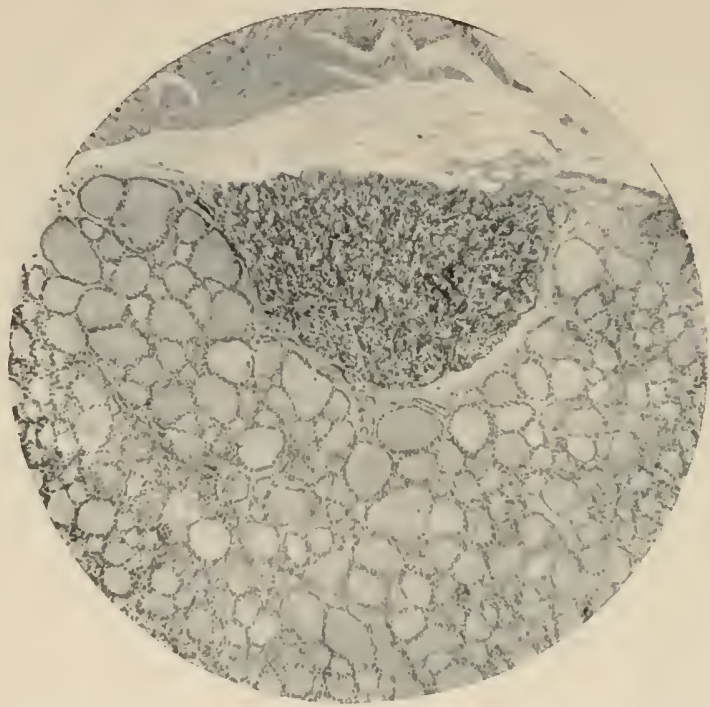

FIG. 10.-Section of parathyroid and adjacent thyroid tissue (rat). Magnified 50 diameters. The vesicles of the thyroid are filled with colloid. The parathyroid is of the reticular type, consisting of loosely arranged trabeculæ.

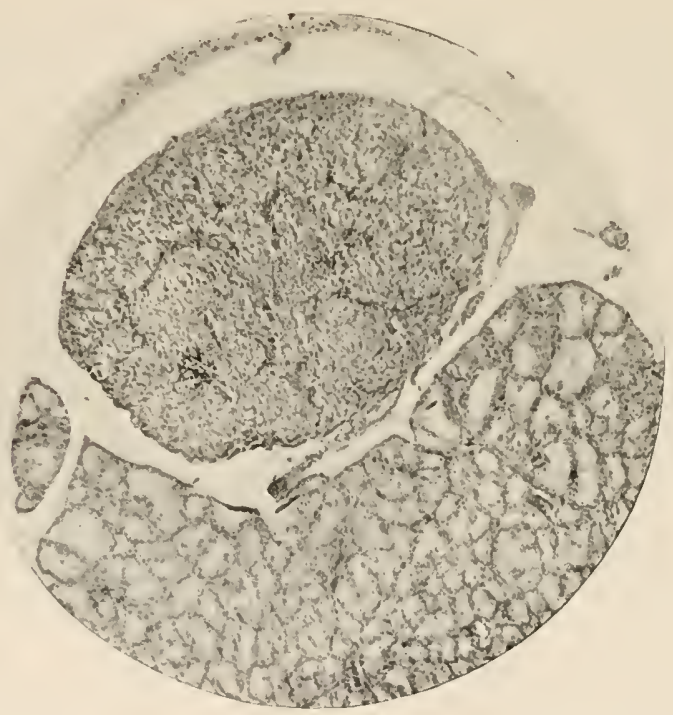

FIG. 11.-The same, from another preparation. The thyroid vesicles are kempty and their cells columnar.

plain muscle cells have been described in this; it may also contain fat-cells. Besides the ordinary or principal cells of the gland-which are small and 
either clear or somewhat granular-others occur which are considerably larger and contain oxyphil granules, staining with eosin (Welsh): these only

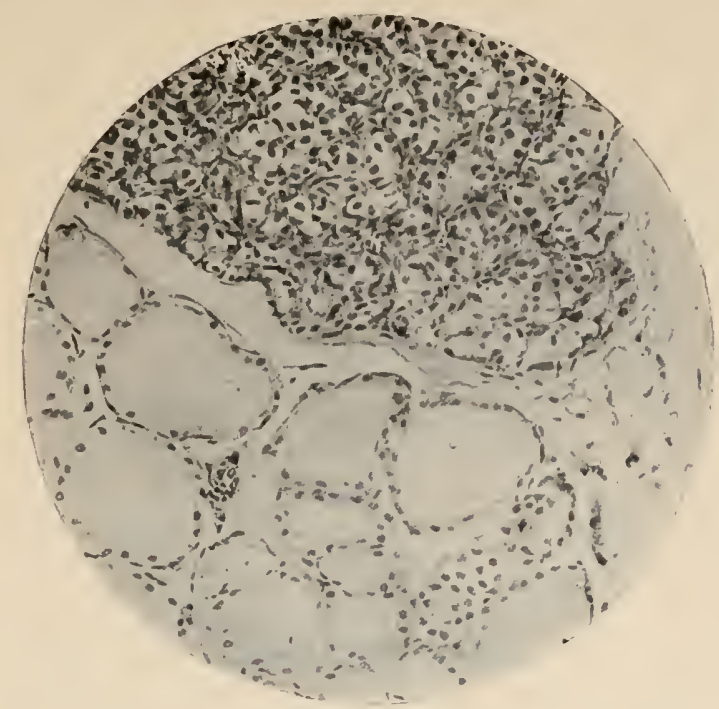

Fig. 12. - Part of a section of thyroid and parathyroid (rat). Magnified 200 diameters. In this gland the vesicles of the thyroid are distended with colloid; the parathyroid is of the reticular type.

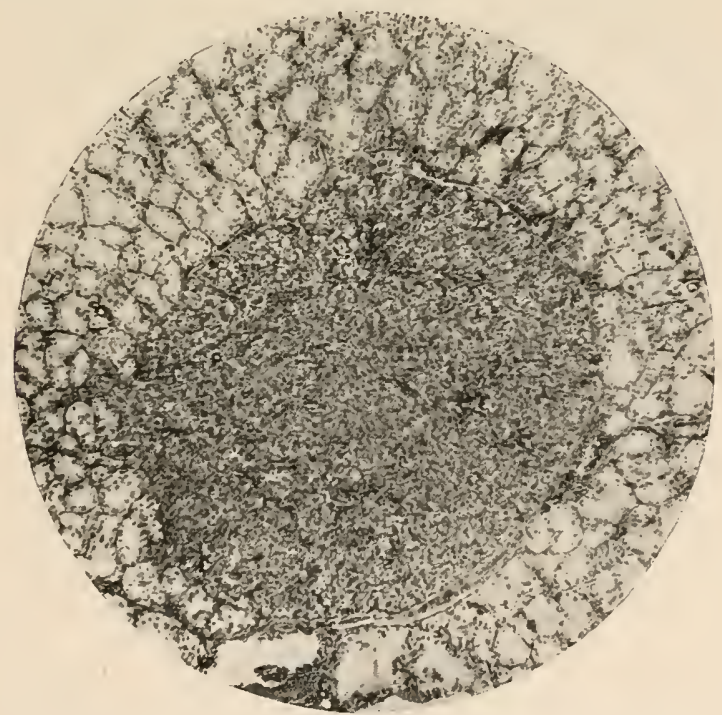

Fis. 13.-Section of an interual parathyroid (1at). Magnified 50 liameters. (An internal parathyroid is rarely to be found in the rat, although common in many animals.) The vesicles of the thyroid are empty of colloid in this preparation.

appear after the tenth year in man. Probably they represent a functional stage of the ordinary'cells, since transitional forms occur. Both kinds of cell 
contain fatty granules, which increase in number with age; glycogen has also been detected both in the cells and in the interstitial spaces of the gland.

Vesicles containing colloid material similar to those of the thyroid, but usually smaller, are frequently found in the parathyroids. They usually

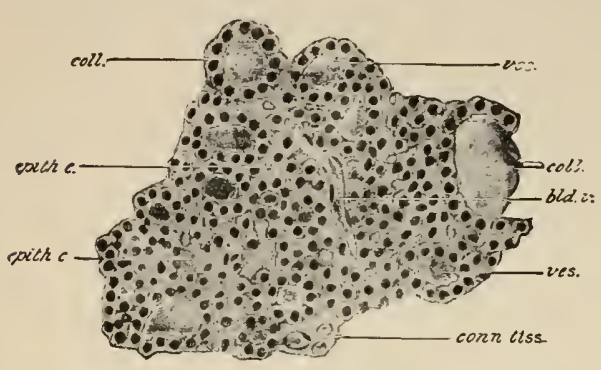

FIG. 14. - Section of parathyroid of cat after previous removal of thyroid. (Vincent and Jolly.) Vesicles which contain colloid are developed within the gland. increase in number with age, and occasionally the colloid is found between the cells, not enclosed within a vesicle. Whether it is of the same chemical nature as that of the thyroid is not established, but it is probably different, as it appears to contain no iodine. After complete removal of the thyroid, in the parathyroids which had been left colloid-containing vesicles were found by Vincent and Jolly in considerable number and of some size (fig. 14). This observation has been confirmed by Halpenny and Thompson, who found that if the animal survives a sufficient time the vesicles become large and irregular (fig. 15), ${ }^{1}$ presenting a certain resemblance to those of a thyroid

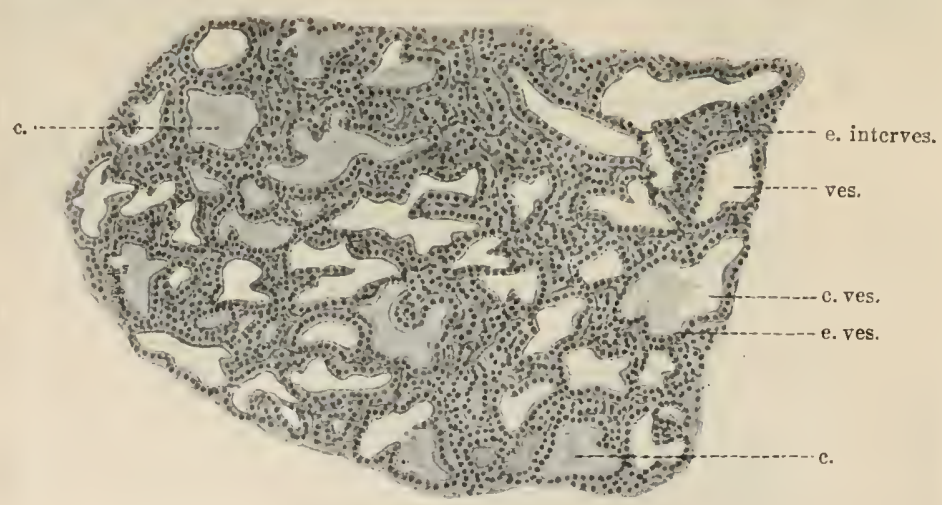

FIr. 15. - Section of parathyroid of dog, eighty-three days after thyroidectomy. (Halpenny and Thompson.) The gland now contains a large number of irregular vesicles and exhibits signs of hypertrophy and increased activity.

e.ves., epithelium of vesicles; e.interves., epithelium between vesicles; c., colloid; c.ves., cavity of vesicle.

in exophthalmic goitre (fig. 26, p. 38). The same observers state that after removal of all the parathyroids the vesicles of the thyroid tissue

1 It is suggested by Guleke that the author's were here dealing not with a parathyroid but with an accessory thyroid. The parathyroids usually remain unaltered in myxœedema : Forsyth has, however, described one case which was an exception to this rule (Trans. Clin. Soc., 1907). Biedl has also recorded the development of colloid-containing vesicles in the parathyroid in a case of atrophy of the thyroid in man. 
itself take on a similar appearance, becoming large and irregular (tig. 16). In this case there is also seen a multiplication of intervesicular cells, which the authors believe to be of the same nature as the cells of the parathyroids. The conclusion they arrive at is that the tissues of the two organs are largely intermixed, at least in birds and mammals. In lower Vertebrates, however, Mr's Thompson found the two to be completely separate both developmentally and structurally.

The parathyroids are amongst the most vascular organs in the body. They are supplied each by a special branch of the inferior thyroid artery

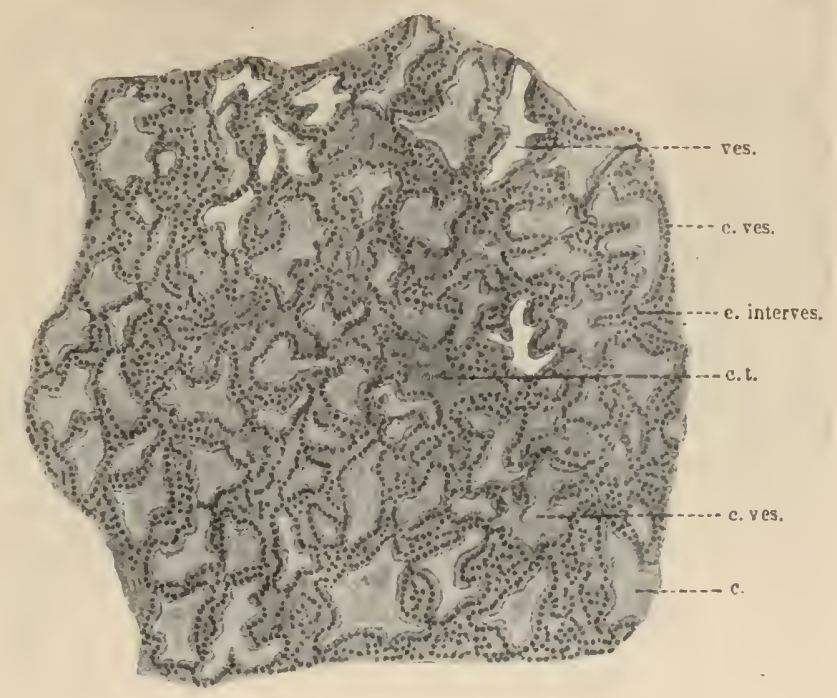

FIG, 16. - Section of thyroid of dog, thirty-two days after removal of all the parathyroids. (Halpenny and Thompson.) The appearance is singularly like that of the parathyroid shown in fig. 15 , and somewhat resembles the thyroid of exophthalmic goitre (fig. 26).

ves., vesicle ; e.ves., epithelium lining vesicle; e.interves., intervesicular tissue; c.t., connective tissue.

The sinus-like capillaries come into close relationship with the epithelial cells of the gland.

The nerves of the parathyroids, like those of the thyroids, pass both to the vessels and to the secreting cells. Some evidence has been adduced which seems to show that the cell-activity is controlled by the nervous system.

Development.-The parathyroids are developed as outgrowths of the IIIrd and IVth visceral pouches on each side (fig. 2), that from the IIIrd pouch giving rise to the upper, and that from the IVth to the lower parathyroid. From the same pouches the thymus is also derived; occasionally, as already mentioned, one or more outgrowths from the thymus rudiments pass into the thyroid. On the other hand, parathyroid and even thyroid tissue occasionally occurs within the thymus; in some animals constantly. 
CHAPTER III

\section{THE THYROID AND PARATHYROIDS (continued)}

\section{Effects of Removal of the Parathyroids}

Parathyroidectomy.-If the operation is complete-i.e. if it includes all four parathyroids-most animals die as the result of the removal; some within a few days, others within a few weeks. The most acute symptoms are exhibited by carnivora such as dogs, cats, foxes, and wolves (Vincent), and the young of herbivora (v. Eiselsberg, Sutherland Simpson), and are of a nervous nature. For the first day or two there are no symptoms, other than some loss of appetite. There then supervenes marked exaltation of reflexes, which leads to the occurrence from time to time of fibrillar contractions of muscles, and later cramp-like and clonic contractions, with eventually convulsive fits; these may be of considerable violence and alternate with intervals of depression. The limbs in progression and the tail are stiff and exhibit quiverings. The irritability of the peripheral nerves to both electrical and mechanical stimuli is markedly increased. The pulse is quickened and the heart-beat becomes greatly exaggerated. There is profuse salivation. The body temperature may rise two or three degrees centigrade during the fit. The paroxysms are usually accompanied by rapid gasping respirations which may be synchronous with the heart-beats; sometimes by vomiting and diarrhea. There is considerable wasting. The hair tends to be shed. In the rat, Erdheim found that the growing incisors fail to be properly calcified. Deficient calcification of the teeth has also been found by Fleischmann to occur in children affected by tetany. Death may occur within a few days, or the affection may last a long time and spontaneous recovery may occur. The fits are sometimes frequent, but more often occur at long intervals; the animal, if it fails to recover from the effects of the removal, usually succumbs during a convulsion.

In man the contractions of muscles tend rather to take on a tonic character: this is also observed in rats and puppies. In most animals they are clonic. The tonic contractions are usually associated with diminution of respirations and of frequency and force of heart-beats, and with fall of body temperature: the clonic with increase, as above described. The meaning of these differences is not clear.

The syndrome is usually spoken of as "tetany" (tetania parathyreopriva); this is in no way synonymous with "tetanus." It may be acute 
or chronic: in the former clonic, in the latter tonic contractions of the muscles tend to manifest themselves.

Tetany is without doubt due to deprivation of the parathyroids, for it will occur when these alone are removed. It varies greatly in severity and often takes on an intermittent character. The symptoms may remain latent for a considerable time, and only show themselves as the result of some unusual condition such as pregnancy. The effect is on the lower neurones, for according to Horsley it is not arrested by ablation of cerebral cortex. Lanz and Biedl state that it is increased on the side of the ablation; with cerebellar lesion they find an increase on the opposite side. According to Mustead, section of dorsal roots does not affect it. After spinal transection it disappears below the level of the lesion. Tetany is relieved by injection of parathyroid extract, and in many cases by administration of thyroid substance: it is uncertain if this last result is due to included parathyroid. When tetany is produced by total extirpation of all parathyroid tissues it can apparently only be cured by a successful graft of a parathyroid from an animal of the same species. The condition has been found to occur after complete removal of the thyro-parathyroid apparatus in man, and may be sufficiently serious to threaten life, unless suitable measures are taken to combat the effects of parathyroid loss. ${ }^{1}$

In order to prevent the accession of tetany in operations for removal of thyroid tumours it is usually necessary to leave at least two of the four parathyroids. In one dog experimented on by Edmunds, he found that a single parathyroid was sufficient to prevent the onset of tetany (the three others and both lobes of the thyroid having been removed): on extirpation of the remaining parathyroid the animal speedily developed tetany.

Animals with insufficient amount of parathyroid tissue may not suffer from tetany under ordinary circumstances, but the symptoms may come on under special conditions. Thus Vassale observed, in a bitch from which three of the four parathyroids had been removed, that the animal was especially subject to fits of tetany during pregnancy ${ }^{2}$ and lactation. The character of the food also influences the onset of the symptoms, flesh foods being much more apt to bring on the condition than a vegetable or milk diet.

1 A case in which all possible remedies, and grafts from various animals, including a monkey, were tried without avail, but which was rapidly and completely cured by the implantation into the subcutaneons tissue of paratlyroids obtained fresh from the deadhouse, is described by W. H. Brown in the Anuals of Surgery, vol. liii., 1911. In experiments on animals it has been almost universally found that to ensure the success of a graft of parathyroid it must be derived from the same animal from which the parathyroids have been removed (Halsted and others).

2 This is contrary to what might be expected, considering that the mother wonld have had the parathyroids of the foetuses to draw upon. It seems, however, to be confirmed by the results of other experiments on dogs, and also by those of Adler and Thaler upon partially parathyroidectomised rats. Animals which have suffered complete paratliyroidectomy do not become pregnant. 
The most satisfactory explanation of the nervous results of the removal of the parathyroids is the assumption that they yield to the blood a special autacoid-presumably of a chalonic or restraining nature-which tends to prevent over-excitation or discharge of nerve-cells. It has been suggested that the over-excitation, since it occurs most markedly in carnivora, is induced by products of protein metabolism. Some species exhibit no symptoms whatever-at least when the operation is performed on the adult. Horsley stated that this is the case with birds and rabbits; but, according to Gley, the latter are affected if care is taken to find and remove all parathyroids. Doyon and Jouty obtained typical tetany in hens which had been parathyroidectomised. Vincent and Jolly found that rats and guinea-pigs do not seem to suffer from removal of their parathyroids, but Christiani and Erdheim both readily obtained tetauia parathyreopriva in rats, although in them it takes much longer to produce a fatal result than in most animals; and Pfeiffer and Meyer obtained it in mice. According to Vincent and Jolly, badgers are totally unaffected by complete removal of both thyroids and parathyroids.

It is possible that insufficient attention has been paid to age by many who have experimented on the subject. For it is certain that-with the exception of puppies, which are less susceptible than adult dogs-young animals are much more susceptible both to thyroidectomy and to parathyroidectomy than adults. This is strikingly exemplified in experiments by v. Eiselsberg and by Sutherland Simpson on sheep and lambs. They found, as had been done by others, that sheep show no symptoms whatever as the result of complete removal of thyroids and parathyroids, while lambs exhibit both symptoms of tetany and arrest of development with supervention of cretinism (fig. 17). Adult goats, on the other hand, may exhibit well-marked tetania parathyreopriva. In monkeys this condition has often been missed, but it occurs if the removal of parathyroids is complete.

As already mentioned, Halpenny and Thompson describe changes in the thyroid (of dogs) following parathyroidectomy (fig. 16) which resemble the changes met with in exophthalmic goitre in man (see p. 37), and are usually interpreted to mean increased activity of the gland. If this interpretation is correct, we must regard the parathyroids as exercising an inhibitory influence upon the thyroid, and some at least of the symptoms of parathyroidectomiy as due to the removal of this restraining influence. Rudinger has upheld the view that there is reciprocal antagonism between thyroid and parathyroids.

Various clinical symptoms are associated with pathological changes in the parathyroids, and have been referred (1) to atrophy or diminished secretion (hypo-parathyroidism), (2) to enlargement or increased activity (hyper-parathyroidism), (3) to altered secretion (dys-parathyroidism). To the first condition must be ascribed manifestations resembling those of tetania parathyreopriva. These occur under various circumstances, e.g. 
during pregnancy, in the course of infectious diseases, and in new-born infants. In some such cases degenerative changes or hæmorrhages have been observed in the parathyroids. But other cases have been recorded in which changes of a similar character have been found post-mortem in the parathyroids without symptoms of tetany having been noticed during life. Various attempts have been made to associate conditions showing increase of response to reflex or to cortical stimuli, e.g. such as occur in Thomsen's disease and in paralysis agitans, with a condition of chronic deficiency of parathyroid secretion. It is stated by Berkeley that cases of puralysis ugitans are benefited by administration of parathyroid. The

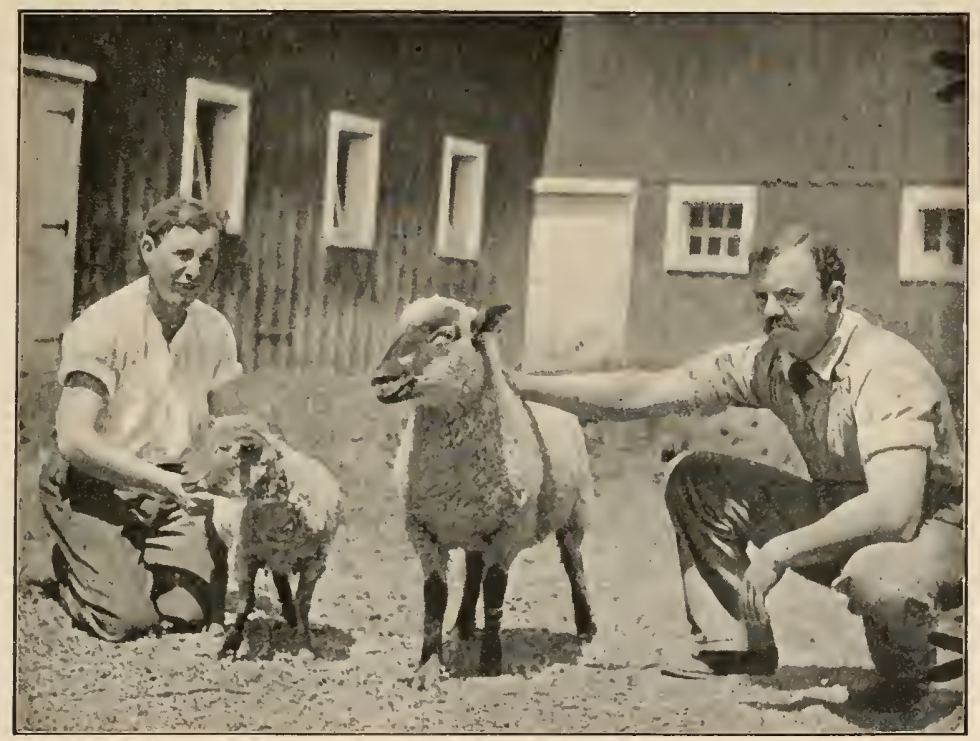

FiG. 17. - Photograph showing a thyroidectomised cretin lamb about fourteen montlis old and a normal sheep of the same age. The thyroids (with the parathyroids) had been removed from the cretin about twelve months previously. (Sutherland Simpson.)

gland has also been recommended in chorea, epilepsy, and eclampsia. On the other hand, it has been suggested that pseudoparalytic conditions, such as those which are found in myotonia paralytica and myasthenia gravis, are due to chronic increase of the secretion. But the evidence in support of the view that these affections are related to abnormalities of the parathyroids is not at present convincing.

Effects of Parathyroid Removal on Metabolism.-Chronic parathyroid tetany is always accompanied by rapid diminution in weight and general emaciation, indicating that the nutrition of the body as a whole is seriously affected. The emaciation is however due, at least in part, to incidental circumstances such as loss of appetite and the supervention of diarrhoea. These conditions may appear, even in the absence of actual tetany, with insufficiency of parathyroid secretion, such as occurs when the vessels 
of the parathyroids are ligatured (Thompson, Leighton and Swarts). An observation which has frequently been made after parathyroidectomy is the occurrence of changes in the hair and nails, and also in the growth and structure of the bones and teeth. These changes are, of course, only seen if the animals survive the operation for some time. As Erdheim has shown, the calcification of the teeth is delayed and imperfect, and they are unusually brittle. In the skeleton the bones remain smaller than in the controls; also the healing of fractures is delayed. If these changes are the direct result of the removal of the parathyroids, there is obviously reason for believing that the parathyroids influence calcium metabolism in some way which is not understood; a further foundation for this is met with in the fact that more than one observer has described an increase of calcium excretion in parathyroidectomised animals. In connexion, however, with this subject, other facts appear to point in the opposite direction, since many cases of osteomalacia have been found to be associated with hyperplasia (adenoma) of one of the parathyroids, and therefore presumably with a condition of hyperparathyroidism.

MacCallum and Voegtlin found that the effects of parathyroidectomy could be removed by injection of extract of parathyroid. The extract has also been used with some success in man by Halsted. Extract of pituitary is said by Ott to have a similar effect. The same result was obtained by MacCallum from the administration of calcium salts, both subcutaneously and by the mouth; he regards tetany as caused by a diminished calcium content of the blood. According to Biedl, however, these salts do not prolong life after the operation; and in my own experience they may altogether fail either to prevent or alleviate post-operative tetany. According to Carlson and Jacobson, the action of calcium salts, when it occurs, is merely like that of other substances which decrease the excitability of the nervous system.

In man, cataract is often found to be associated with chronic tetany.

\section{Physiological Effects of Parathyroid Extract}

Probably largely owing to the difficulty of obtaining enough material, very few observations have been made on the physiological effects of injections of parathyroid extracts. Ott finds that when injected intravenously they have an entirely different effect from those of thyroid (see p. 35). He states that the blood-pressure is first raised, then lowered; that the rate of respiration is increased; that they are diuretic, acting directly on the renal epithelium, and that in large doses they have the effect of lowering the body temperature. Also that applied locally the extracts increase the extent of the contraction both of intestines and uterus, and dilate the pupil. These statements await confirmation. 


\section{The Mode of Action and the Nature of the Parathyroid AUTACOID}

The theory that the parathyroids serve the purpose of destroying poisonous products of metabolism which are elaborated in the main thyroid -apart from its a priori improbability-has received no support from the results of experiment. If the removal of the parathyroids were to be explained in this manner, simple parathyroidectomy should produce much more acute symptoms than total removal of the whole thyroid and parathyroid apparatus, but Biedl states that there is no difference in the acuteness of the symptoms. It is, however, possible that, as already stated, the symptoms of tetany may be produced by the presence in the blood of a special toxin-for which the term tetany toxin has been proposed-and that the parathyroids may have the function of destroying or neutralising such a toxin; in this ease they need possess no power of producing an internal secretion. It has also been suggested that there may occur in tetany an accumulation in the blood of toxic intermediate products of protein metabolism, such as appear when the metabolic functions of the liver are interfered with, and that the parathyroids produce an autacoid of hormonic nature which excites some other organ (e.g. the liver) to complete the metabolism of proteins. But the simplest theory to explain the phenomena is that already suggested, which assumes the production of a chalonic autacoid serving to diminish the excitability of nerve-cells. This hypothetical autacoid-which it must be understood has nerer been isolated-may provisionally be termed parathyrine. We shall see that there is reason to believe that the thyroid produces an autacoid with an opposite tendency.

The explanation which is often given of parathyroidectomy, as of extirpation of other endocrine glands, that it produces disturbances of the chemical correlation between the blood and organs affected, is merely another way of stating the problem to be explained.

The production of a special antacoid which tends to regulate the deposition of calcium in the tissues is not proved, and we must bear in mind that any changes which seriously interfere with general nutrition are especially liable to affect the process of ossitication.

\section{Relation of the Parathyroids with Other Endocrine Organs}

Although some authors believe the parathyroids can functionate vicariously for the thyroid, the generally received and most probable opinion seems to be that they are independent in function, or, if anything, antagonistic. They usually show no enlargement in congenital atrophy of the thyroid, and although certain experiments by Vincent and others have appeared to indicate that there may be enlargement and colloid formation after thyroidectomy, it must be borne in mind that it is by no means difficult for errors to creep in in experiments of this kind. 
There seems, however, to be no doubt that cases of tetany benefit by the administration of thyroid extracts, although the tetany cannot be cured by such administration. It is unlikely that the effect is due to the minute proportion of parathyroid substance in these extracts.

Mrs Thompson has described the development of colloid vesicles in the pars intermedia of the pituitary after parathyroidectomy, and has concluded that this is a vicarious effect-but it must be remembered that there are great individual variations in the number of such vesicles in the pituitary, and that some animals exhibit a very large number even normally. Most other author's have failed to substantiate any change in the pituitary after parathyroidectomy alone, although there are marked changes after thyroidectomy.

Very little that is definite has been substantiated regarding the relations of the parathyroids with the suprarenals, or with the internal secreting functions of the pancreas or the generative glands. It has, however, been affirmed (Guleke) that removal of the suprarenals prevents the appearance of tetany after parathyroidectomy, but only when the thyroid is included in the removal. And, on the other hand, that adrenalin injection will bring on a fit of tetany in a parathyroidectomised animal. These effects are produced no doubt through the nervous system, and point to a certain antagonism between suprarenal and parathyroid.

Gozzi has described degenerative changes in the liver-cells as a result of parathyroidectomy, but regards them as secondary to the general effects on the organism as a whole. 


\section{CHAPTER IV}

\section{THE THYROID AND PARATHYROIDS (continued)}

\section{The Effects of Surgical Removal and of Atrophy or Degeneration of the Thyroid: HypothyroIdisu}

Thyroidectomy.-Schiff, who.had previously (1856) performed the operation in various animals with incomplete results, was led in 1884 to again investigate the effect of thyroidectomy in animals: he was also the first to attempt to combat the resulting symptoms by implantation of thyroid from an animal of the same species. Schiff's extirpations probably in most instances, as the symptoms he records show, included the parathyroids. Gley drew attention to the importance of leaving at least two of these in order to study the effects of thyroidectomy alone. Subsequent observations on the subject are numerous, although some are contradictory. This is due mainly to the fact that differences are found with animals of different species, and that age introduces a material factor into the result; young animals being much more susceptible to thyroidectomy than adults, as they are also to parathyroidectomy.

When positive results are seen in adult animals they take the form of thickening and drymess of the integument, with a tendency to loss of hair. Adiposity may supervene later, although there is at first usually some wasting. The muscles lose tone and are weaker than in the normal animal. Regeneration of tissues is retarded. Anæmia is usually present. The body temperature is low; the power of heat regulation by means of the skin is diminished (Lorraine Smith). The sexual functions are interfered with. The limit of assimilation of carbohydrates is raised. The nervous system is markedly affected, dullness and apathy being prominent symptoms. Many nerve-cells, especially those of the cerebral cortex, exhibit a shrunken appearance and present a strong contrast with those of the normal animal. A myxœdematous condition of the integument was described in monkeys by Horsley, Murray, and Edwards, but others (H. Munk, Kishi, Tincent and Jolly, Halpenny and Gumn) have not seen this.

Similar symptoms are observed in cases of spontaneous atrophy, or degeneration of the gland in children (fig. 18, A). There is arrest of growth, especially of the skeleton, the cartilage bones long remaining incompletely ossified ; development of the generative organs is much delayed; the integument is swollen; the surface of the skin is dry; the hair tends to fall out and becomes thin; the face is pale and puffy; the abdomen swollen; the nose depressed; the hands and feet are podgy. The fontanelles of the skull 
remain open. The muscles are limp and weak. Deaf-mutism is common.

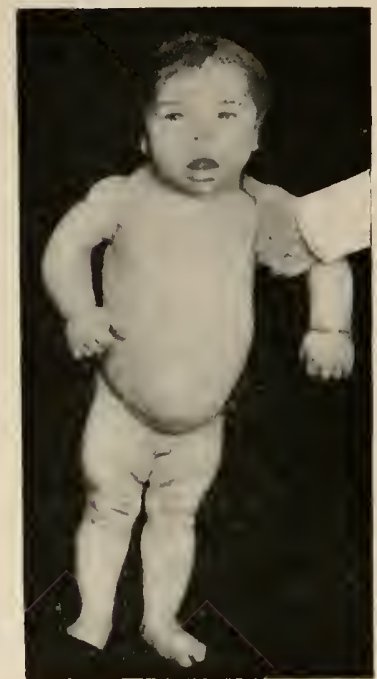

A

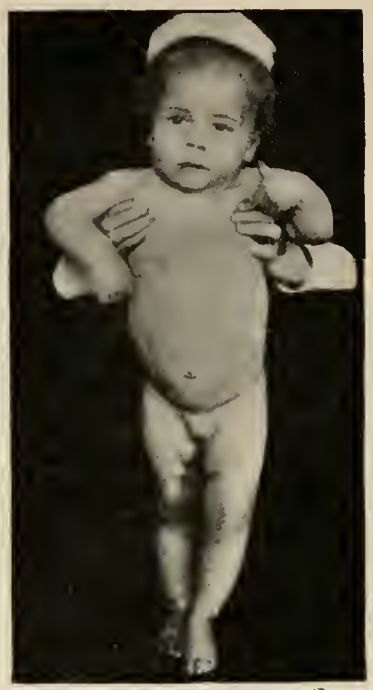

B

Fig. 18. - Myxcedema of child (A) before and (B) after treatment with thyroid. (Byrom Bramwell.)

The highest functions of the nervous system remain undeveloped, the child becoming idiotic: this seems to

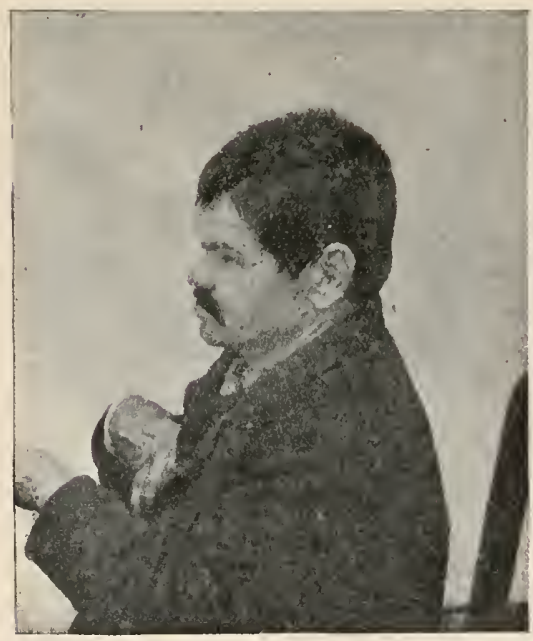

FIG. 19.-Photograph of a case of eudemic cretinisin. (E. Bircher.) The characteristic depression of the root of the nose is well seell. be due to an arrested development of cells of the cortex cerebri.

The above combination of symptoms forms the condition known as cretinism. This may be either sporadic or endemic. The former is generally associated with absence or early atrophy of the thyroid; the latter with goitrous degeneration. Of endemic cretinism, according to M'Carrison, there are in the Himalayan valleys two types, the myxœedematous and the nervous: the latter is presumably associated with changes in the parathyroids; whilst in the former the parathyroids are unaltered. This is the type chiefly met with in Europe (fig. 19).

The symptoms do not show themselves until some little while after birth, in spite of the absence of a thyroid. The absence appears to be compensated, for a time at any rate, by autacoids conveyed from the 
mother's thyroid to the child; before birth through the placenta, after birth through the milk. When the atrophy is congenital it usually takes the form of complete lack of development of the thyroid proper-the parathyroids are generally present and well developed - the condition of cretinism and all the above symptoms being well marked.

If in the adult subject either thyroid atrophy occurs or such degenerative changes take place in the gland as materially affect its functions, the condition known as myxoedema (or myxœedema adultorum to distinguish it from the corresponding affection of the child) becomes manifested (fig. 20). This condition, which is much more common in females than in males, was described by Gull in 1873 , and recognised by him to be a

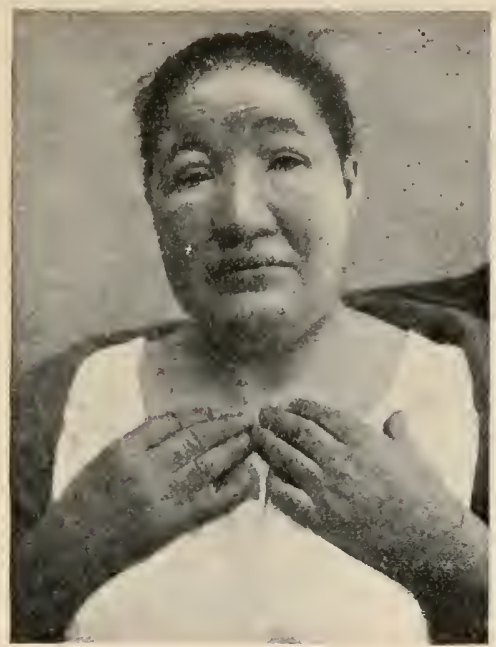

A

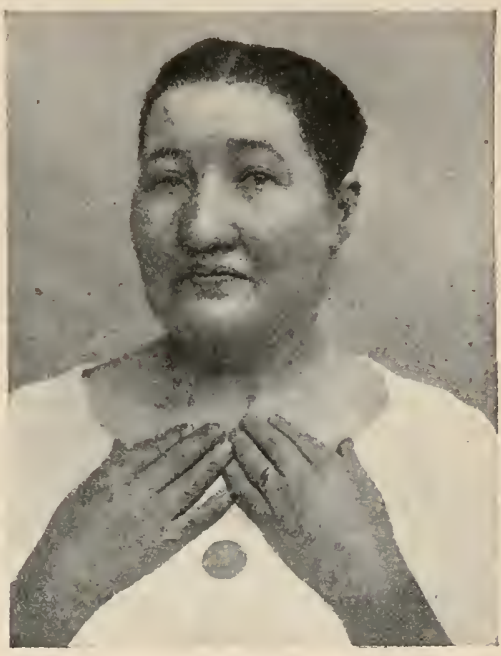

B

FIG. 20.-Myxcedema of adult (A) before and (B) after treatment with thyroid. (Andersson.)

cretinoid condition of adult life; and subsequently, in 1877, by Ord, who gave the name to the disease and showed that it is associated with changes in the thyroid. It is characterised by thickening and swelling of the integument, which pits on pressure, the pitting disappearing on relaxing the pressure; by the skin becoming dry and the hairs falling out; by a low body temperature; and by mental dullness and general impairment of sensibility. In cases of myxœedema in the human subject, Brun and Mott have found general chromatolysis of nerve-cells of subacute character. Both in spontaneous and in operative myxœdema the metabolic processes are diminished in activity, so that although less food is taken the body weight may increase. Regenerative changes also occur more slowly. There is usually a considerable deposition of fat, especially under the skin. The activity of the sexual functions is diminished in both sexes. There is a diminution in the amount of oxygen consumed and in the amount of nitrogen excreted. There is increased tolerance for sugar, so that a con- 
siderably larger amount than usual (as much as 300 grammes) may be taken without producing glycosuria. Nevertheless, glycosuria occurs sometimes, but it is not excessive. ${ }^{1}$

Symptoms similar to those of myxœdema are produced as the result of surgical removal of the thyroid in man (fig. 21). This was first apparent as the result of the effects of operation for goitrous tumours (J. L. and A. Reverdin, Th. Kocher). The Reverdins spoke of the condition as postoperative myxadema; Kocher terned it cachexia strumipriva. It begins to show itself at a variable period after operation-from a few days to months or even years-and is more readily produced in young than in

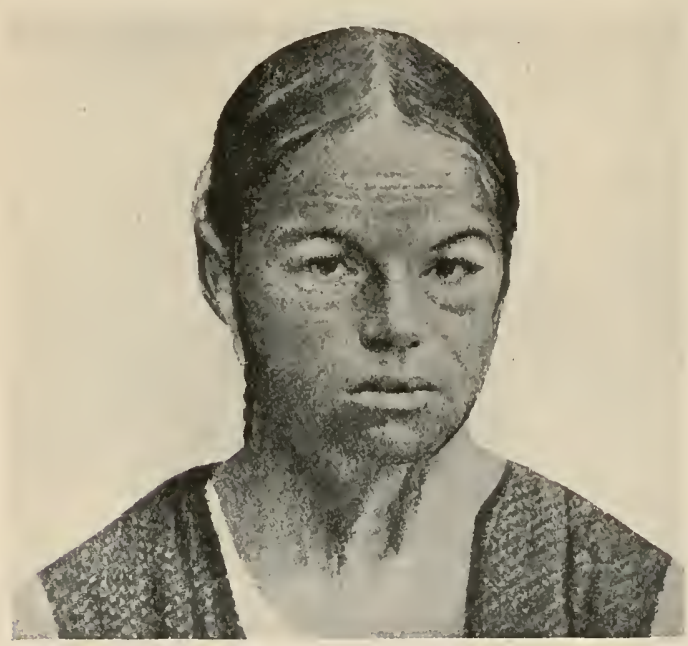

FIG. 21.-A case of post-operative myxœdema (cachexia strumipriva) in a 26-year-old woman. (v. Brun.) older subjects. It is sometimes accompanied by symptoms of tetany: when present, these symptoms are presumably referable to involvement of parathyroids. According to Kocher, the patients rarely survive the complete loss of the thyroid for more than seven years. To prevent ultimate ill-effects at least onefourth of the organ must be left.

The above symptoms, whether due to congenital atrophy or to operative removal, can be allayed or entirely removed by successful implantation of pieces of thyroid (Schiff)-an operation which has, however, rarely succeeded in man - or by administration of thyroid substance or extract either hypodermically (G. Murray) or by the mouth (Mackenzie and Fox). Patients suffering from the effects of loss of thyroid secretion, whether this take the form of cretinism, myxcedema, cachexia strumipriva, or endemic goitre, can be completely restored to health and kept normal for apparently any length of time by buccal administration of the gland or its extracts (see figs. 18, 20, 22). If the treatment is intermitted the symptoms almost at once begin to reappear. The effects are therefore obviously due to the loss of an autacoid contained in the internal secretion. This autacoid in some way affects the metabolic processes of the body, either directly or indirectly promoting the nutrition of the connective tissues and influencing the functions of the cells of the nervous system, particularly those of the cerebral cortex.

I The alterations in metabolism in myxoedema and the effect of thyroid treatment upon them have been studied in Tigerstedt's laboratury by J. A. Andersson (Hygiea, 1898). 
Enlargement of the thyroid such as occurs in endemic goitre (fig. 22), in spite of a great increase in volume of the gland, is commonly attended

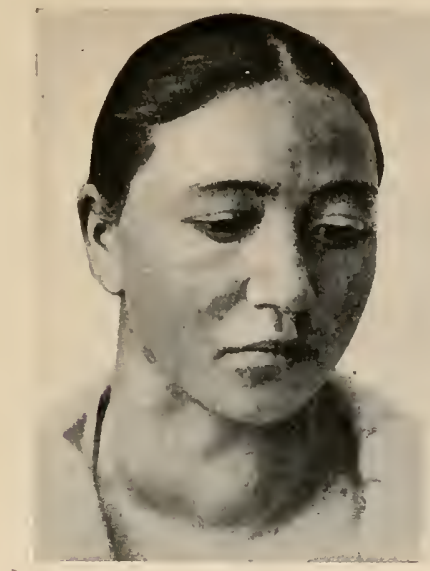

A

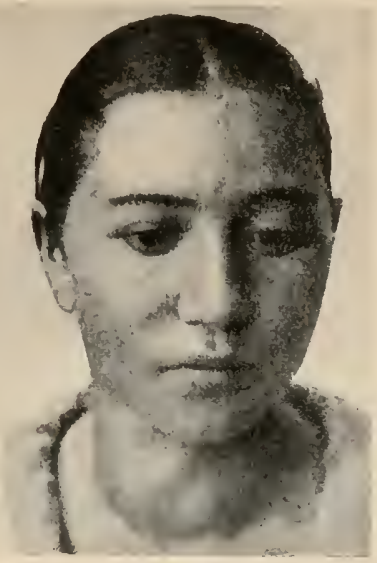

B

Fig. 22. - A case of endemic goitre (A) before and (B) after treatment with thyroid. ( $r$, Brun.)

by symptoms of hypothyroidism; not, as might have been expected, by those of hyperthyroidism. But when the enlargement is the result of malignant cell-proliferation (carcinoma or sarcoma), the functions of the organ may still be carried on. It is indeed a significant fact in connexion with the genesis of malignant tumours, that when in such cases the whole of the thyroid is removed by the surgeon, should there be any metastatic growths elsewhere, e.g. in the liver, the usual symptoms of cachexia strumipriva do not show themselves.

The enlargement of the gland in endemic goitre generally takes the form

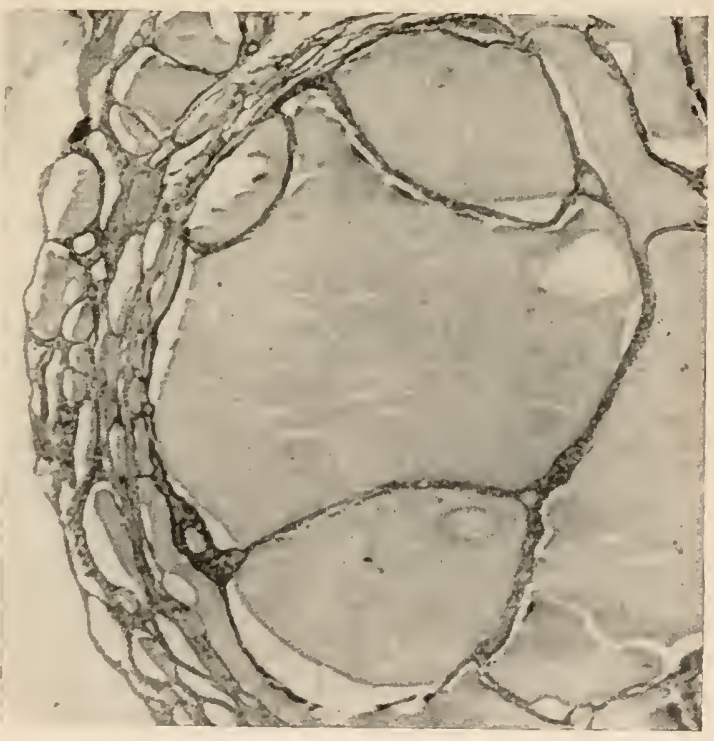

FIG. 23.-Section of thyroid from a case of endemic goitre. Magnified 50 diameters. Notice the enormous size of some of the colloid-filled vesicles.

of a diffuse hypertrophy: the follicles enlarge and their epithelium proliferates: new follicles may also become formed. There is nearly always a 
tendency for colloid to accumulate. This ultimately causes enormous distension of the vesicles and flattening of their epithelium (fig. 23), which may eventually undergo almost complete degeneration. A characteristic degeneration of the arteries of the gland has also been described.

Whilst the above are the usual changes found in endemic goitre, many exceptions are met with. One would expect the enlarged gland to yield an excessive amount of secretion to the blood, but this appears not to be the case, although endemic goitre is occasionally characterised in its early stages by symptoms suggestive of hypersecretion and resembling some of those seen in incipient exophthalmic goitre (p. 37). More often these symptoms of hyperthyroidism are absent: generally from the first and always eventually, the appearances which show themselves are unquestionably symptomatic of hypothyroidism. This must mean that even if the secretion is being produced in abundance it is not of a normal character, the normal autacoid being either absent or deficient in quality. Perhaps the enlargement of the gland represents an attempt by nature to compensate for such deficiency. 


\section{THE THYROID AND PARATHYROIDS (continued)}

\section{Effects of Ixcrease of Thyroid Secretion : Hyperthyroidism}

THE effects of a too great amount of the thyroid autacoids in the circulating blood can be investigated either by their introduction directly into the circulation or indirectly by other channels, such as the alimentary canal; or by studying the symptoms of affections in which there is reason to believe that an excess of these autacoids is being secreted by the gland.

\section{Effects of Administration of Thyroid Extract or Juice}

The iminediate result of intravenous injection (fig, 24) is to produce a marked but evanescent fall of blood-pressure, which is mainly due to dilatation of the peripheral vessels. This effect is probably specific,

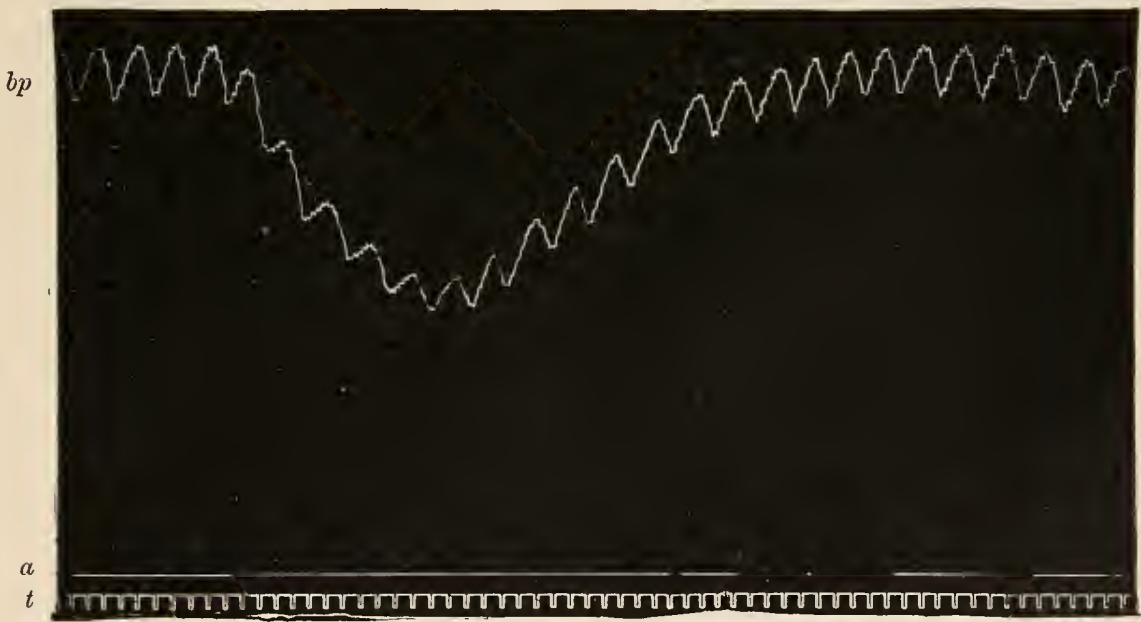

FIG. 24.-Effect upon the blood-pressure of injecting thyroid extract intravenously. $b p$. , arterial pressure; $a$., 'abscissa ; $t$., time in one-second intervals. (From the British Medical Jourual, Aug. 10, 1895.)

although somewhat similar results are obtained with extracts of many other organs (see pp. 9, 10).

The fall of blood-pressure caused by thyroid extract is often preceded by a slight rise. 'The fall is just as well marked after administration of atropine as before: it is therefore not due to vagus action. 
Asher states that the fall of blood-pressure does not occur in the rabbit. I have, however, occasionally obtained it in that animal, but usually the fall is absent and a slight rise alone apparent.

Asher and Flack found that the prior injection of thyroid extract in the rabbit increases the excitability of the cardiac vagus and of the depressor. I have not been able to confirm this result either in the rabbit or in the cat or dog, although, in the last two, if depressor fibres are stimulated at the same time that thyroid extract is injected into a vein the fall of blood-pressure is greater than with either of these by itself. This is, however, an effect of summation, as is shown by the circumstance that in those cases in the rabbit in which a slight rise is produced by thyroid extract instead of a fall, the combined effect of depressor and thyroid extract is less than that of the depressor alone.

Given by the mouth in the human subject thyroid extract produces lowering of the blood-pressure. ${ }^{1}$ Large doses are followed by tachycardia (rapid pulse), often with some irregularity; nervous excitability; flushing of the skin, with feeling of heat; increase of perspiration; and increase of nitrogen metabolism. If long continued the fat of the body is diminished and glycosuria may be caused. Alimentary glycosuria is also more easily produced than normally. There is considerable wasting, although the appetite is increased. There are often digestive disturbances. In extreme cases there may be exophthalmos and other effects referable to cervical sympathetic excitation, such as dilatation of the pupil and (in animals) retraction of the third eyelid; psychical excitement; sleeplessness; tremors of the limbs; in short, most of the symptorns of exophthalmic goitre. The addition to the food of animals of even a small amount of thyroid gland has the effect of increasing nitrogenous metabolism, as shown by the increase of nitrogen in the urine. This is accompanied by a corresponding increase in food consumption. Some of the additional nitrogen thus ingested is retained in the body, but this is compensated for by increased fat consumption, so that the difference in growth curve of the thyroid-fed animals and the controls is but slight. With large doses of thyroid there soon ensues marked loss of weight, due both to increased nitrogen elimination and loss of fat. There is also an increased respiratory exchange.

The colloid contents of the thyroid vesicles are augmented by the ingestion of much thyroid substance.

\section{Clinical Evidence}

Exophthalmic Goitre.-This affection, first described by Parry (1825) and connected by him with the thyroid, is also associated with the names of Graves (1835) and Basedow (1840), both of whom called special attention to the symptoms. The name exophthulmic goitre expresses its most prominent signs (fig. 25). The disease is usually accompanied by considerable enlargement of the thyroid. According to Moebius and Greenfield

1 In diabetic subjects it is said to cause the opposite result-an effect lasting for several days. 
the enlargement is accompanied by hypersecretion which is the direct cause of the symptoms, this opinion being founded on the facts that, (1) as has just been mentioned, some of the symptoms of the disease can be produced by excessive administration of thyroid, and (2) that the symptoms are for the most part opposite in character to those which are known to be produced by atrophy or diminution of function of the gland. Thus there is a rapid and often irregular pulse; nervous and psychical excitation, with muscular tremors; a feeling of warmth in the skin, and throbbing of cutaneous vessels, often accompanied by profuse sweating; shallow respiration; markedly increased metabolism (especially nitrogenous), with abnormal appetite and loss of body fat; a decreased assimilatory power for carbohydrates; an anxious, restless expression; prominence of the eyeballs; wide palpebral aperture, often with dilatation of pupils. The enlargement of the thyroid may involve only one lobe. The enlarged gland pulsates, and gives a murmur on auscultation.

Exophthalmic goitre is far more common in the female than in the male (as 4.6 to 1 ), a fact which may be related to the enlargement of the gland which usually occurs in the female at puberty and during pregnancy. It is generally associated with a persistent thymus, which has by some authors been credited with the production of certain of the symptoms of the disease. About 13.5

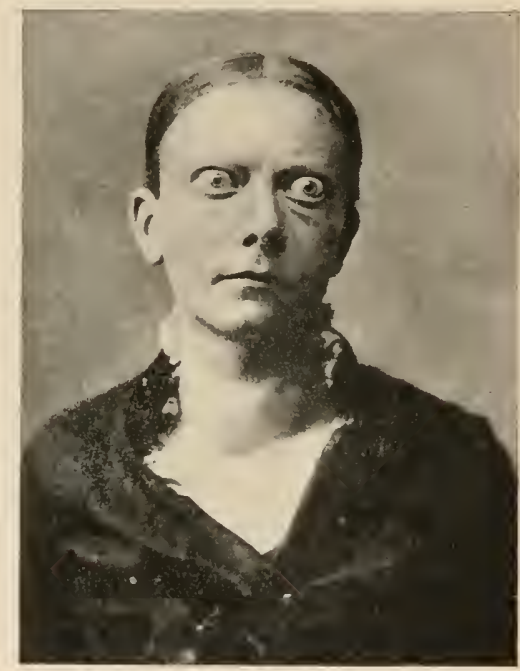

Fig. 25.-Case of exophthalmic goitre. (Byrom Bramwell.) per cent. of cases have polyuria without sugar. Only 2 per cent. have permanent glycosuria, although alimentary glycosuria is not uncommon. Albuminuria is present in about 11 per cent.

The histological appearances (figs. 26, 27) are conformable with the theory of a hypersecretion. The gland is greatly enlarged, and the individual vesicles are irregular and tend to run together. The interstitial tissue is increased in amount and assumes a lymphoid appearance, sometimes with characteristic germinal centres. The follicle wall tends to grow into the interior of the conjoined follicles in the form of projections, thus increasing the surface for secretion and giving the cavities a still more irregular aspect. In some parts the follicles are smaller than usual, and may even disappear. The cells lining the follicles tend to acquire a columnar form: in later stages they may undergo degeneration and become set free within the follicles. The contents of the follicles are more fluid than in the normal thyroid, and in sections show little or no coagulated colloid. 
Direct proof of hypersecretion of the thyroid is thought to be furnished

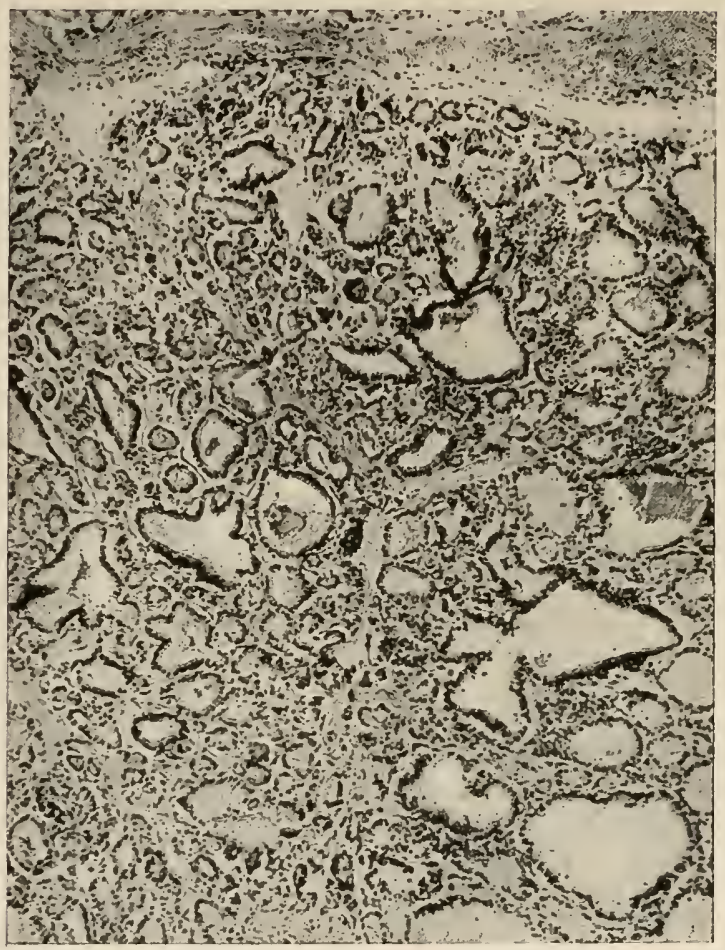

FIG. 26. - Section of thyroid from a case of exophthalmic goitre. Magnified 75 diameters.

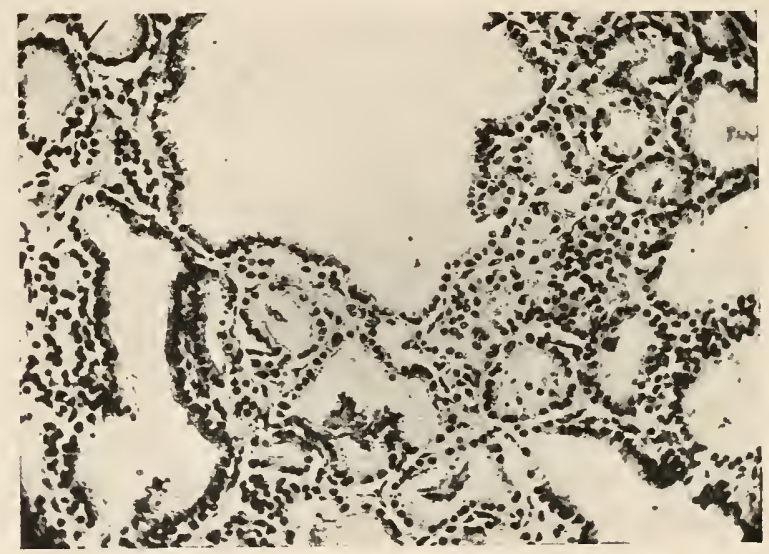

FIG. 27. - Part of the same section, magnified 200 dianseters. Notice the irregularity in size and shape of the vesicles, and the fact that they are mostly empty of coagulated colloid.

by the experiments of Reid Hunt, who found that the blood of a person aftlicted with exophthalnic goitre increases the resistance of mice to the 
poisonous effects of acetonitrile; an effect he had previously found to result from injection of thyroid extract. Some observers have stated that injection of blood-serum from cases of exophthalmic goitre produces effects in animals similar to the symptoms of that disease in man. Others, on the contrary, have obtained different results, and state that, although in dogs small doses of extract from an exophthalmic goitre may cause increased rate of heart-beat and some rise of blood-pressure, this is soon followed by the opposite condition. They therefore hold that the symptoms are produced not by excess of normal thyroid secretion circulating in the blood, but as the result of the production of a perverted secretion (dysthyroidism). This view is not, however, that generally taken, either by physiologists or clinicians, most of whom are disposed to regard the hypersecretion theory as more probable. The favourable results which ensue in many cases from surgical removal of a large portion of the hypertrophied gland or ligature of some of its ressels point in that direction. 


\section{THE THYROID AND PARATHYROIDS (continued)}

\section{Nature of the Autacoid Substances produced by the Thyroid}

THE active principle of the thyroid which is concerned with metabolism has been usually assumed to be represented by the non-proteid nitrogenous material known as iodo-thyrin, or by the compound of this with protein (iodo-thyro-globulin). The former was prepared from thyroid by Baumann (1895), and found by him to contain a marked amount of iodine $(0.3$ to 0.9 per mille of dry substance). In confirmation of this assumption, the experiments of Reid Hunt, Marine, and others show that the production of the autacoid is promoted by administration of iodides, and that there is a certain relation between the physiological activity of the gland and its iodine content. But the fact that even when the desiccated thyroid contains a considerable amount of iodine it is sometimes found to have no action suggests that Baumann's substance may not be the actual autacoid, although it may be associated with it. We are, in fact, still in the dark as to the true nature of this autacoid, and it seems better to express our ignorance by a term which implies no theory, leaving the question of its identity with iodo-thyrin or iodo-thyro-globulin open. I propose, therefore, provisionally to apply the word thyrine to denote the active principle, whether it be identical with or contained in the iodo-thyrin of Baumann or not.

As we have already seen, the autacoid of the parathyroid (parathyrine) is probably of chalonic, i.e. of inhibitory nature, serving to keep in check the activity of certain tissues, especially of nerve-cells. On the other hand, the autacoid of the thyroid (thyrine) acts like a hormone in increasing their excitability. This increase of excitability is especially well marked in connexion with the sympathetic. The question arises: Is this a direct effect on the sympathetic system or is it indirect through the adrenals, which are stimulated to increased secretory activity by excess of thyroid in the blood? The answer is not easy. But it may be stated that although certain symptoms of hyperthyroidism are similar to those produced by excess of adrenalin in the blood, others are not so. This is the case with the flushing of the skin, which is due to vascular dilatation; whereas adrenalin ordinarily produces vasoconstriction. Further, excess of adrenalin in the blood leads to glycosuria, which is not as a general rule seen in exophthalmic goitre, nor is glycosuria a necessary result of 
administration of thyroid. Moreover, it is undoubtedly the case that the administration of adrenalin exercises a beneficial effect in some cases of exophthalmic goitre: a fact which would be inexplicable on the theory that the results of hyperthyroidism are simply due to excitation of the suprarenals and the production of an excess of adrenalin.

But although many of the effects of thyroid feeding and of hyperthyroidism otherwise produced can be explained by the presence of excitatory or hormonic autacoids, it is not possible to explain the results produced by thyroid deprivation, or hypothyroidism, upon the body generally, and certain organs in particular, merely by assuming the absence of these excitatory substances. For loss of the thyroid is followed by increased growth and presumably increased activity of certain other organs. This is the case with the pituitary; and although it has been suggested that this is an instance of vicarious increase of size associated with the performance of similar functions, the similarity of the functions of the two glands is far from obvious. A more probable explanation is that besides a hormone which excites some cells, the thyroid secretes an autacoid of chalonic nature which restrains the activity of others: on removal of the thyroid this restraint is abolished, and over-activity is the result.

The thyroid autacoids affect the growth of the thymus gland, which has been found to undergo an increase in size in fœetal animals after thyroid feeding of the pregnant mother (guinea-pigs); on the other hand, the suprarenal capsules (cortex) and the thyroid itself are said to undergo a diminution in weight under these circumstances. Hoskins, who furnishes this observation, ascribes the effect upon the growth of the thymus to stimulation by a hormone furnished by the thyroid; if this is so, the opposite results on suprarenal and thyroid should be ascribed to an autacoid of opposite sign. To carry out this line of reasoning to its logical conclusion, the diminished growth of the skeleton and of the generative organs which follow thyroid removal in young animals would be explained by the absence of a hormone which promotes their development. We must, however, be on our guard in assuming that every effect obtained is due to a direct action upon the organ affected (see below).

\section{INTERaCtion OF THE THYroid with Other Organs}

With the Generative Organs.-The important influence exerted by the thyroid secretion on nutrition generally is no doubt responsible for the fact that hardly any organ in the body remains unaffected as a result of its complete removal or atrophy. But the secreting organs with which it may be regarded as being more specifically associated are few. Among them are the generative glands. In the female the thyroid becomes enlarged at puberty, during the menses, and during pregnancy. In the young thyroidectomised subject the generative glands are only slowly or imperfectly developed, the resulting condition being characteristically one of 
sexual infantilism. In the adult animal ( $\mathrm{dog})$ Alquier and Theuveny found diminished activity so far as production of spermatozoa is concerned, but less distinct evidence of change in the ovary; although the animals appeared to come on less completely in heat and to conceive with difficulty.

With the Liver and Pancreas.-Other effects, of a more or less specific character, are produced upon liver-glycogen. Krause and Cramer find that in the cat and rat, fed with thyroid, glycogen disappears from the liver; but there is no glycosuria, the sugar having been conveyed to the tissues and oxydised. Parhon has obtained a similar result with the rabbit. The thyroid therefore produces mobilisation of carbohydrates. Thyroid feeding also tends, as we have seen, to diminish the limit for the assimilation of sugar. This may be due either to an increase in the secretion of adrenalin or to a direct inhibitory effect on the internal secretion of the pancreas.

After thyroidectomy the assimilation limit for sugar is markedly raised; and according to some observers adrenalin-glycosuria is greatly diminished or fails to show itself. This statement, however, is contradicted by Underhill. If the parathyroids are included in the removal, the assimilation limit for sugar is lowered and adrenalin produces a stronger glycosuria than in the normal animal. The influence of the thyroids and parathyroids is therefore antagonistic in this as in some other respects. According to Lorand, if a dog deprived of pancreas and exhibiting glycosuria is thyroidectomised, the sugar disappears from the urine. Lorand further states that extirpation of the pancreas has the effect of increasing the amount of colloid in the thyroid vesicles, and that thyroidectomy causes a marked increase in the amount of islet tissue in the pancreas. But both these statements are difficult to accept on account of the differences which are normally present, both in amount of colloid in the thyroid and in number of islets in the pancreas. If substantiated, they would show a direct correlation between the thyroid and the pancreas, the internal secretion of the thyroid being restrained by that of the pancreas and the internal secretion of the pancreas by that of the thyroid, so that when either gland is extirpated, the internal secretion of the other either becomes more active or increased in amount.

With the Suprarenul Capsules.-There is an indirect way in which the internal secretion of the pancreas can be influenced by thyroid secretion, and that is by the effect which this produces upon the action of the secretion of the suprarenal medulla. This effect appears, as Asher and Flack have shown, to be in the direction of increase of excitability of those tissues which are amenable to the action of adrenalin. On the other hand, when the thyroid is extirpated the activity of the secretion of the suprarenals is diminished. And the phenomena which are normally produced by sympathetic stimulation are similarly affected. Further, with hyperthyrosis, such as occurs in intense thyroid feeding, most of the symptoms are those of over-excitation of the sympathetic, and are similar to those caused by adrenalin. There is, moreover, some evidence that the 
amount of adrenalin in the blood is increased in hyperthyroidism. 'Thus, Ott and Scott got increase of adrenalin in the blood after intravenous injection of thyroid extract: they obtained, however, a similar result after injection of other organ extracts. With regard to exophthalmic goitre, Krause observed dilatation of the pupil of the excised frog's eye when placed in blood-serum of patients affected by this disease, although blood-serum of normal individuals does not give this reaction. Krause has further obtained chemical evidence of the presence of excess of adrenalin in blood after injection into animals of the juice of thyroid gland from cases of exophthalmic goitre, and its presence has also been demonstrated in such cases by physiological tests (Fraenkel with the uterus; Trendelenburg and Bröking with the frog's blood-vessels). It may therefore be assumed that the secretion of the thyroid in exophthalmic goitre acts as a direct stimulant to the suprarenal capsules, causing them to yield adrenalin to the blood in larger quantity; a result which is also obtained with thyroid feeding. But the fact that some cases of exophthalmic goitre benefit by the exhibition of adrenalin is difficult of explanation on this hypothesis, for this treatment should cause an exacerbation of the symptoms. Moreover, it must be borne in mind that most of the physiological tests which have been used for adrenalin would also be given by pituitrine.

Incidentally, it may be mentioned that F. Mlunk noticed a diminution of lipoids in the cortex of the suprarenals in animals fed with thyroid gland.

With the Pituitury Body.-As has been pointed out above, a very striking effect is caused by removal or atrophy of the thyroid upon the pituitary body: which not only undergoes general enlargement, but also exhibits well-marked indications of increased secretion. These changes will be described when the pituitary is dealt with.

What part, if any, concomitant removal of parathyroids may take in promoting the changes in the pituitary is not certainly known. According to Halpenny and Thompson, some of the alterations which have been described in the pituitary occur if the parathyroids only are extirpated. But other observers have failed to find any changes in the pituitary after parathyroidectomy.

With the Thymus Gland.--Reference has already been made to the anatomical and developmental relationship between thymus and thyroid, to the effect of thyroid feeding of a pregnant animal upon the growth of the thymus of the foetus, and to the supposed effect of the thymus in assisting to produce the symptoms of exophthalmic goitre: indeed its removal by operation has been recommended and even practised in that affection. In view of these circumstances some authorities believe that there exists a mutual relationship between the two organs, and that they exercise-by their internal secretions-an excitatory influence upon one another. In conformity with this it has been stated that increase or diminution in size of the two organs frequently go hand in hand. But 
this can only be early in life, for under normal conditions of growth and development the thymus is undergoing retrogression whilst the thyroid is becoming more active in its functions. Moreover, the normal variations in both organs are so considerable, and at present, in spite of many observations, so little is accurately known regarding the conditions under which they occur, that it will be wise to reserve judgment as to their mutual relations.

\section{Influence of the Nervous System on Thyroid Secretion}

It was shown by Cyon that vasodilator nerve-fibres pass from the recurrent laryngeal nerves to the thyroid gland. Ossokin showed the gland to be supplied by both superior and inferior laryngeal, and also by pharyngeal branches of the vagus. Vasoconstrictors pass to it by way of the sympathetic. H. Wiener found extirpation of the inferior cervical ganglion to be followed by atrophy of the gland and diminution of thyro-globulin in the thyroid of the same side. Asher believes that the internal secretion of the thyroid is directly influenced by the nerve-fibres which pass to the gland by the superior and inferior laryngeal nerves. But he used as a test of the outpouring of secretion the increase of excitability of certain nerves (depressor and cardiac vagus), which he states is also produced by injection of thyroid extract into the blood. This, however, I have not found to be the case, and therefore, although it is not improbable that the secretion is under the influence of either the vagus or sympathetic, or both, further evidence is necessary before we can regard this as a proven fact. It has been stated that the iodine content of a thyroid lobe is diminished as the result of excitation of the vagus of the same side, but this also needs confirmation.

The view which was at one time held that the function of the thyroid is merely that of a destroyer of toxic substances circulating in the blood is no longer tenable. The same may be said for an old idea-resuscitated by Cyon-that the organ serves as a kind of shunt to regulate the flow of blood in the cranial cavity. This, indeed, has nothing to support it beyond the extreme vascularity of the gland and its position in close comnexion with the carotids. 


\section{CHAPTER VII}

\section{THE THYMUS GLAND}

\section{The Structure and Development of the Thymus}

RELATIVELY to the rest of the body the thymus is largest at birth, but it remains well developed during childhood. It is essentially an organ of early life. After puberty it generally undergoes retrograde changes; these consist in diminution in volume of the proper gland substance accompanied

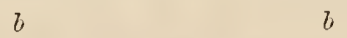

$b$

$b$

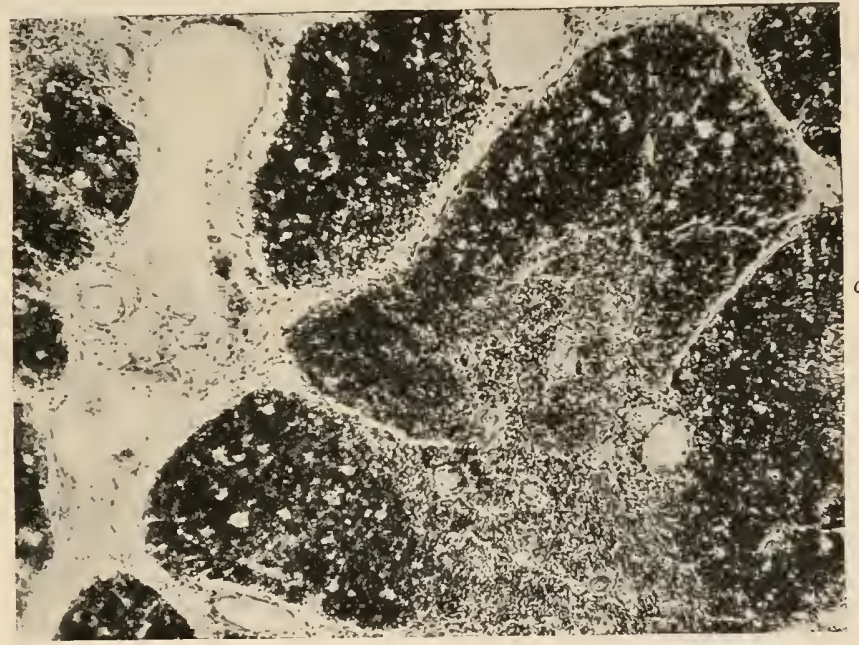

$m$

FIG. 28. - Part of lobule of the thymus of a child. IIagnified 60 diameters. $c$. , cortex ; m., medulla ; $b ., b$., large blood.vessels in connective tissue trabeculæ.

by an increase in connective tissue, the whole organ becoming smaller and often embedded in a mass of fat. Occasionally it remains fully developed; such cases are generally associated with an unusual development of lymphatic tissue in the body, the condition being termed status lymphaticus.

In its developed condition the thymus consists of two main lobes, one on each side, the lobes themselves being subdivided into lobules and the whole strung together in an irregular manner along a strand of connective tissue which sends offisets into the lobes, subdividing the lobules from one another and sending partial septa into the individual lobules. The con- 
nective tissue conveys blood-vessels, lymphatics, and nerves to and from the organ.

Each lobule is composed of a cortex which is very dark in stained sections

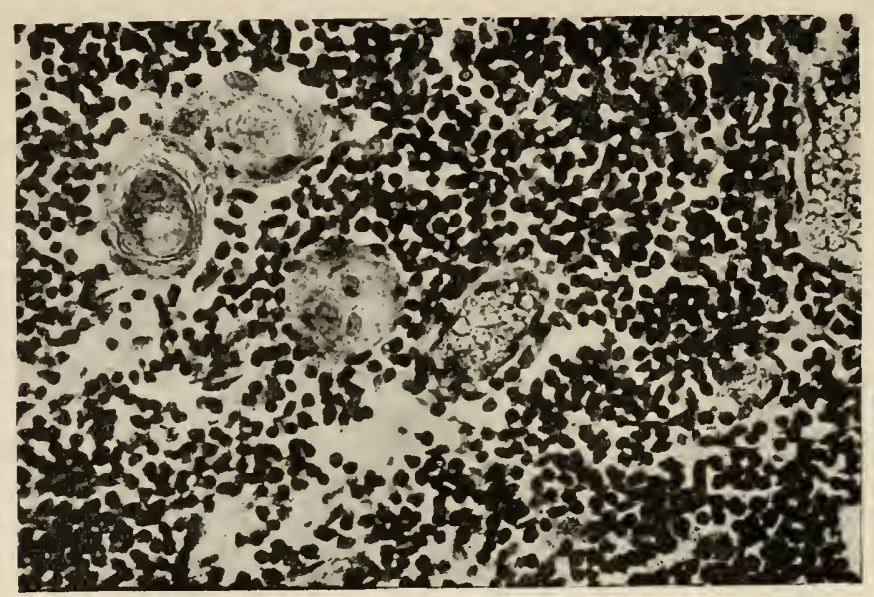

FIG. 29. - Medulla of thymus of child. Magnified 300 diameters. The small darkly stained cells are lymphocytes. The preparation shows two or three concentric corpuscles, and blood-vessels.

and a medulla which is lighter (fig. 28). The difference is due to the large number of lymphoid cells in the cortex, which is densely packed with

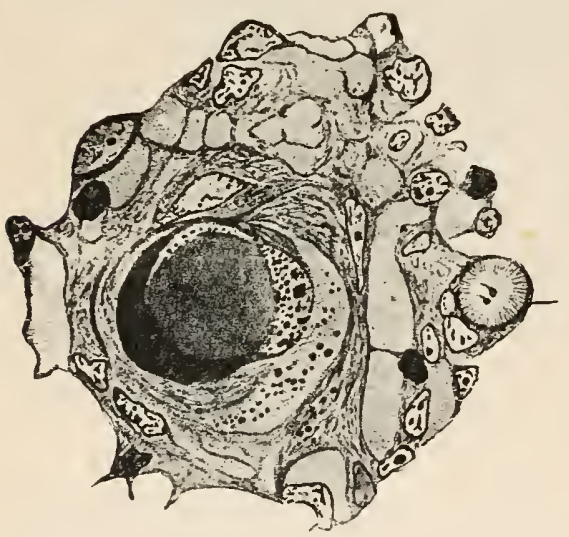

Fig. 30.-A concentric corpuscle of the thymus with a part of the adjoining reticulum. (Hammar.)

c., a ciliated vesicle. them. The medulla is formed of a cell-reticulum as a basis, in the meshes of which are a considerable number of lymphoid cells; and in addition the characteristic "concentric corpuscles of Hassal," which are formed by nests of epithelium cells surrounding one or more cells which occupy the centre of the nest (figs. 29, 30). Some of the concentric corpuscles are compound, having more than one centre. Occasionally the medulla is found to contain small ciliated cavities, and rarely striated muscle-fibres are seen within it.

The thymus is developed in the embryo from sprouts of the epithelium of the third branchial pouch on each side (fig. 2). These unite to form a single median column of cells which becomes hollowed out and tubular, and ultimately branched. Eventually lymphoid nodules forming the cortex of the lobules appear in the 
walls of this branching tube (fig. 31), and its epithelium becomes broken up and modified to form the reticulum and concentric corpuscles of the medulla. In Petromyzon the thymus retains its original connexion with the branchial clefts, but in all other vertebrates this connexion becomes lost, and in mammals the organ takes up a position either in the neck or in the anterior mediastinum. In birds it forms a series of isolated masses on each side of the neck. Small portions of thymus tissue are frequently found embedded in the thyroid, these having developed from the sprouts of the fourth branchial pouch; on the other hand, an accessory thyroid is often met with in the substance of the thymus.

The thymus is singularly susceptible to the effects of inanition; even a short period of fasting produces a considerable diminution in its size.

\section{Functions of the Thymus}

The functions of the thymus are more obscure than those of most of the endocrine organs: indeed there is room for question whether it should be included amongst these bodies. But the mutual relations which appear to be established between it and the generative glands in

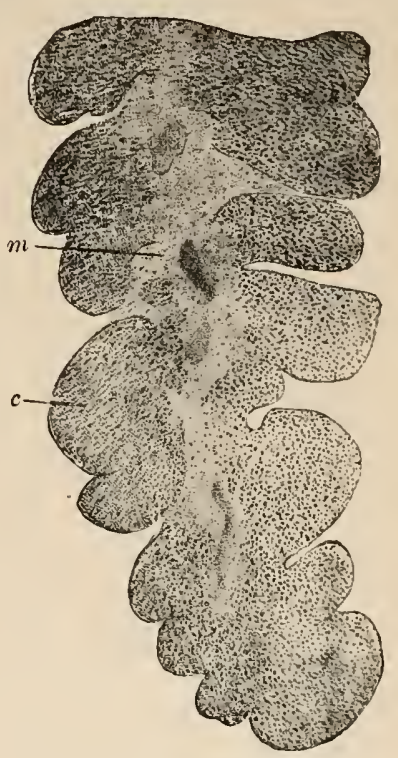

Fig. 31.-Section of developing thymus. (From Prenant, Bouin, and Maillard.)

c., cortex; m., medulla. At this stage the medulla is continuous throughout the gland. the male sex perhaps entitle it to occupy a place amongst them.

Injection of extracts of the gland seems to have no specific effect. The results of feeding with the thymus appear also to be non-specific; such as are obtained seem to be dependent upon the large amount of nuclein it contains. But according to Gudernatsch, tadpoles which are fed with thymus do not undergo metamorphosis, although they increase greatly in size: the same observer describes exactly the opposite effect as the result of thyroid feeding. Noël Paton and Goodall, who removed the thymus in a number of guinea-pigs, were not able to establish any relation of the gland to the rate of growth of these animals, which apparently suffered no deleterious effects from loss of the organ. Other observers (Basch, Klose and Vogt, Matti), who for the most part employed kittens and puppies for experiment, have described certain positive results of thymectomy; especially softening of the bones with increased excretion of ealcium salts, muscular weakness often with tremors, and diminution of intelligence. Compensatory increase in amount of the splenic follicles has been described. The symptoms were not alleviated by grafting or by feeding with thymus.

Klose and Vogt also obtained an increase in rate of development of both the testicles and ovaries. As regards the testicles, this result has been 
confirmed by Noël Paton, who finds that the converse is also true, viz., that castration in the guinea-pig is followed by increase in size of the thymus. In castrated cattle also the thymus is nearly double the size that obtains in uncastrated beasts (J. Henderson). In all castrated animals the involution of the gland is retarded.

Noël Paton has also found that removal of both thymus and testicles has a marked effect in delaying the rate of growth of guinea-pigs, whilst this result is not obtained by removal of thymus or testicles alone.

In the female no such relationship has been established between the generative glands and the thymus. 


\section{CHAPTER VIII}

\section{THE SUPRARENAL CAPSULES}

THE suprarenal capsules or adrenals have received special attention, both from clinicians and physiologists, since Addison (1855) described the symptoms of the disease which bears his name and which he associated with degeneration of these organs. Addison's disease is characterised by great languor and general debility, with weakness and diminution of tone, not only of the skeletal but of the vascular and visceral musculature, feeble action of heart, loss of appetite, disturbance of the digestive tract, severe abdominal pain, and extreme emaciation. Anæmia, which is an occasional accompaniment of the disease, was regarded by Addison, when it occurs, as symptomatic; but it is probably the result not of the destruction of the capsules, but of the intercurrent affection (generally tuberculosis) which has produced their destruction. The most striking characteristic of the disease as described by Addison was undoubtedly the pigmentation (bronzing) of the skin, which occurs as a diffuse colouration upon the face and hands and other exposed parts, and is increased in regions where there is some pigmentation normally present, such as the areolæ of the nipples and the external genital organs. It is also found on the mucous membrane of the mouth and on that of the conjunctiva. Sometimes the bronzing does not occur; these cases are usually the more acute. The disease is fatal. Its course may be prolonged, "even to six or ten years. In rare instances recovery has taken place, and periods of improvement lasting many months may occur" (Osler). Some cases are markedly benefited by administration of suprarenal extract per os or hypodermically; others not at all.

The cause of the excessive formation of pigment is not understood, but it has been suggested (by Adami and others) that adrenalin may be derived from the same source as the melanin of the skin, and that if the formation of adrenalin is interfered with an excess of melanin is formed and deposited. Meirowsky states that in portions of skin removed from patients who have died of Addison's disease an increase of pigment occurs as long as five days after death if the pieces are kept in a warm, moist chamber, but that this does not occur in skin from those who have died from other causes. He suggests that a colourless precursor of the melanin is present in the skin, and supposes this to become transformed under the influence of light. Somewhat similar observations have been made by Königstein, and by Biedl and Hofstätter, on the skin of dogs deprived of their suprarenal 
apparatus; but negative results were obtained with rabbits and other rodents. In epinephrectomised animals pigmentation of the skin is not seen; it therefore probably requires a gradual destruction, such as occurs in chronic disease of the capsules in man, a condition which has not hitherto been successfully imitated in animals. Some observers have described obscure pigmentation of the skin and mucous membranes in animals as the result of removal of the adrenals, or as the effect of removal of one and injury of the other, but the evidence that the pigmentation was produced by the operation is inconclusive.

\section{MORPHOLOGY}

It is well known that the suprarenals consist of two parts, cortex and

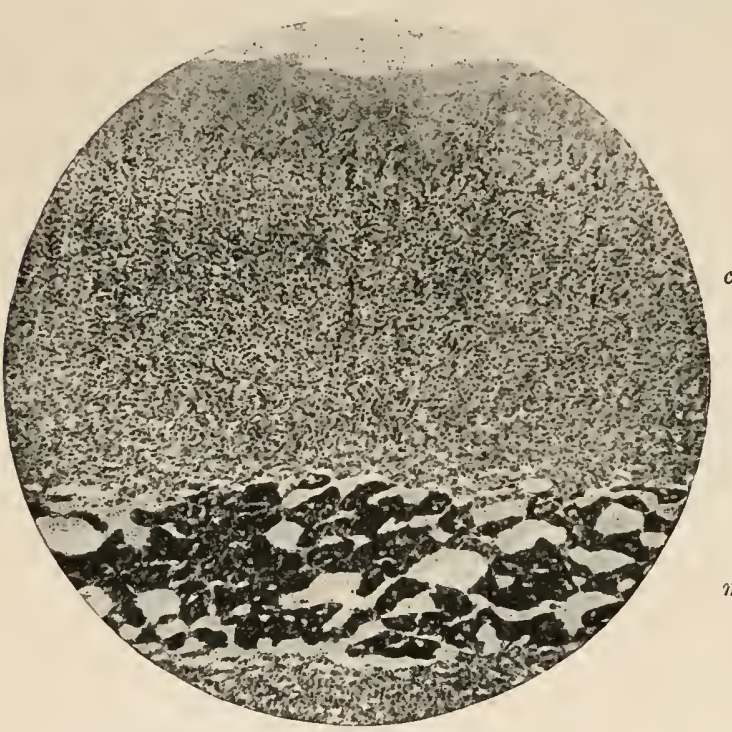

FIG. 32.-Section of suprarenal, low power. c., cortex; m., medulla. medulla (fig. 32), which, although anatomically united in many animals, are morphologically distinct and are developed from different embryonic formations; the cortex being formed from mesoderm-cells of the genital ridge, whilst the medulla is developed from cells which belong to the same neuroblast-masses as give rise to the nerve-cells of the sympathetic ganglia. The cells of the medulla are characterised by the brown colour which they strike with chromic acid and its salts (chromaphil reaction) (figs. 32, 34).

This reaction is due to the presence of adrenalin (see p. 58).

In fishes these two parts remain separate, but in all higher vertebrates they are united into one organ, which is generally attached to the kidney on each side. In birds and reptiles and amphibia the renal and adrenal tissues interlock. It is only in mammals that the same condition is found as in man, viz., a central medulla with an enclosing cortex.

Accessory suprarenals are not infrequent. They consist either of cortical substance alone or of medullary substance alone, or of the two combined. They occur most commonly between the kidneys and along the lower part of the abdominal aorta as far as its bifurcation. In the male rat such an accessory gland is almost constantly seen close to the epididymis. They are relatively longer and more frequent in the new-born 
animal than in the adult, in which they may be missed altogether. The possibility of their presence must, however, be borne in mind when considering the results of the extirpation of the adrenals in animals.

Those accessory glands which have a structure and derivation similar to the medulla of the suprarenal capsules also contain cells which are coloured brown by chromic acid. Such bodies have been termed paraganglia by Kohn, chromaphil bodies by Vincent, chromaffine bodies by most other authors.

The carotid gland is of this nature. The coccygeal gland is different. It contains no chromaphil cells and appears to represent an arteriovenous anastomosis which is met with in certain lower mammals. Paraganglia invariably occur in close morphological and developmental connexion with sympathetic nerves and ganglia (Stilling).

Chromaphil cells have been found in almost all vertebrates, even in Petromyzon. They have also been described in the epithelium cells of the mantle of a gasteropod (Purpura lapillus) by Roaf. In Annelids they occur, according to Sommet and Pol, in some of the nerve-cells of the segmental ganglia. This is well seen in the leech, the blood-vessels of which react to adrenalin like those of vertebrates. The development of chromaphil cells is, according to J. F. Gaskell, correlated with that of a muscular vascular system.

Abel has made the interesting observation that certain patches of skin glands in a large American toad (Bufo aqua) furnish a white, pasty secretion containing a large proportion of adrenalin.

\section{Structure of the Cortex}

The cortex of the suprarenal is composed of polygonal epithelium-like cells arranged mainly in columns (zona fasciculata), but near the medulla as a network of trabeculæ (zona reticularis). Towards the surface the cell-columns end in rounded and sometimes hollowed-out terminations forming the so-called zona glomerulosa, the cells of which, in some animals, tend to have a columnar form. Those of the zona fasciculata are usually larger than in the other parts. Characteristic of the cortical cells is the presence of lipoid granules, which may impart a yellowish colour to this portion of the capsule. The zona reticularis also contains pigment granules which in some animals give it a distinct brownish colour. The human foetus has unusually large suprarenal capsules. It has been shown that this is almost entirely due to a great development of an innermost part of the cortex lying at the boundary with the medulla (boundary zone of Elliott and Armour (fig. 33)); this is not to be confounded with the intermediate zone of Virchow, a very thin layer, pigmented in old age, lying at the junction of the cortex and medulla.

The cells of the boundary zone differ from those of the rest of the cortex in having no lipoid granules. After birth they undergo a fatty change 
and the layer gradually disappears, so that it is no longer distinguishable after the first year. At birth what will be the cortex of the adult gland consists only of a thin peripheral layer of cells containing lipoids; these cells multiply, and the layer enlarges pari passu with the disappearance of

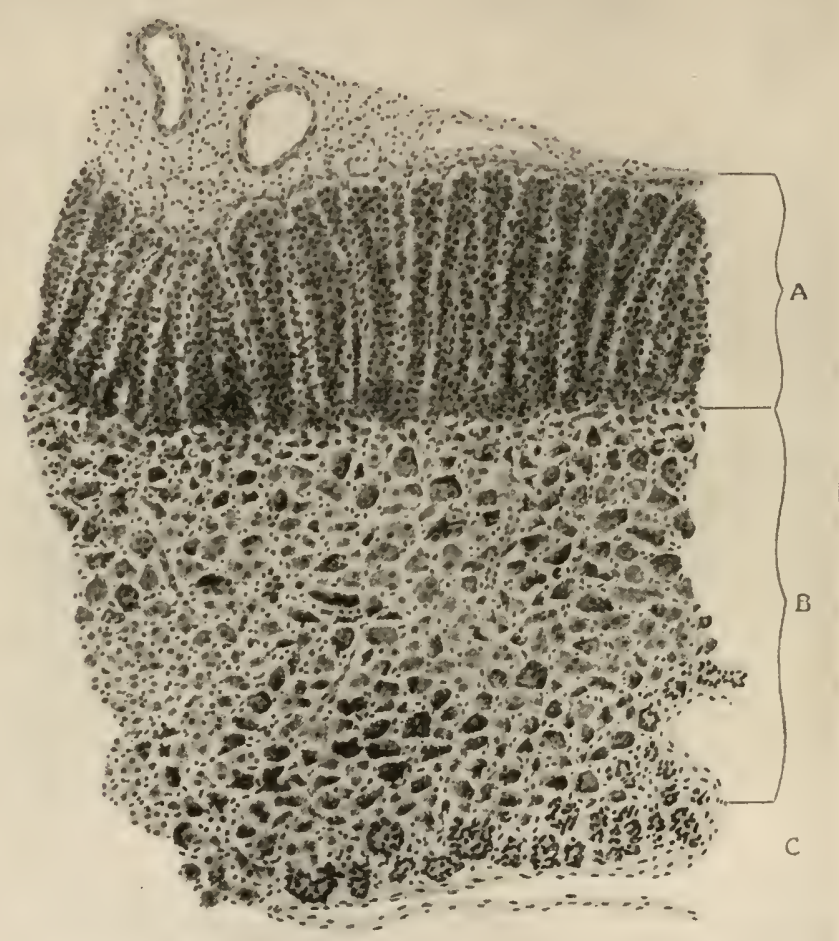

Fig. 33. - Section of suprarenal of child twelve days old, low power. (Elliott and Armour.)

A, outer part of cortex; B, large cells forming boundary zone of cortex ; $\mathbf{C}$, thin layer of medulla : just below is the central vein.

the boundary zone. A remarkable fact pointed out by Elliott and Armour is that in the anencephalous foetus the boundary zone is absent and the suprarenal resembles that of other foetal mammals.

\section{Functions of the Cortex}

Little is known regarding the functions of the cortex. Its anatomical relation in mammals to the chromaphil part and the fact that its blood passes directly into the medulla suggests that its cells may be concerned in the production of materials which are utilised by the medulla; but, as has been above mentioned, this relation fails in many vertebrates. It has been stated by Abelous and others that the cortex contains a precursor of the adrenalin of the medulla, and that if left standing for twenty-four 
hours in an incubator a considerable amount of a substance giving the reactions of adrenalin accumulates within it. But according to the investigations of Bayer the results obtained are not ascribable to adrenalin, but to products of protein decomposition. The facts that the cortex becomes enlarged during pregnancy and is small in cases of deficient sexual development, and that changes have been described (in the guinea-pig by Kölmer) in the cortical cells accompanying the phases of the ostrous cycle, seem to afford evidence of some relationship between the functions of the cortex and the generative glands; but whether this is direct, or operates through other ductless glands-such as the thyroid and pituitary-is not known. The occurrence of a connexion between the development of the sexual organs and that of the suprarenal cortex has been especially insisted upon by Glynn, who is of opinion that the cortex is concerned with the differentiation and growth of the sexual cells.

It has also been suggested that a function of the cortex may be to neutralise deleterious products which are formed in the processes of metabolism or which are introduced from outside. But this supposition has received no support as the result of experiments.

One of the most striking facts connected with the cells of the cortex is their richness in lipoids and fats. These have been chemically investigated by many workers. In an analysis by Biedl the suprarenals of the pig yielded 74.61 per cent. of water and 25.39 per cent. of dry residue. Of the latter, 61.12 per cent. consisted of proteins, etc., and 38.88 per cent. of lipoids-besides some insufficiently distinguishable extractives. In this analysis the medulla was included; as this is poor in lipoids the lipoid contents of the cortex must have a much higher value-far higher than any other non-nervous tissue.

Besides globules of what appear to be fat, a doubly refracting substance is found in the cortical cells of most animals-varying in amount and in its position in the cortex in different species. In some it takes the form of doubly refracting crystals. Elliott and Tuckett regard both the fatty and the doubly refracting substance as products of secretion of the cells. They find that the doubly refracting substance increases in amount during rest and diminishes as the result of muscular activity. In the guinea-pig there are numerous brown-coloured granules in the cells-chiefly in the zona reticularis-and Elliott and Tuckett state that these also accumulate during rest and quickly disappear with muscular work, fatty globules taking their place. The doubly refracting lipoid substances seem to consist mainly of lecithin and cholesterol-the latter in the form of esters. Rosenheim and Tebb extracted from the suprarenal cortex of the ox varions fatty acids, cholesterol esters, and phosphatides, such as sphingonyelin; but not free cholesterol.

The suggestion that the suprarenal cortex may be a seat of manufacture of the lipoids of the body and may especially be related to the formation and development of the myelin of the medullated nerve-fibres is attractive. 
And the fact that in the human foetus and infant so large a development of suprarenal cortex occurs-which is missed in the anencephalous monster - seems to indicate a connexion between the development of the substances formed in the cortex and those constituting the cerebral hemispheres. But against this idea we have the observation of Elliott and Armour that the superadded part of the suprarenal cortex in the fœetus does not contain the doubly refracting lipoid substances which are characteristic of the ordinary cortical cells. Nor does the doubly refracting lipoid matter occur in all animals : in many species it is absent. This is the case with all adult ruminants examined, although it occurs in some in the young state. In both man and animals where normally present it tends to disappear in various diseases; whilst during pregnancy lipoids are said to increase in amount, not only in the suprarenals but in all the organs of the body.

The cortex increases in proportion to the growth of the body more than

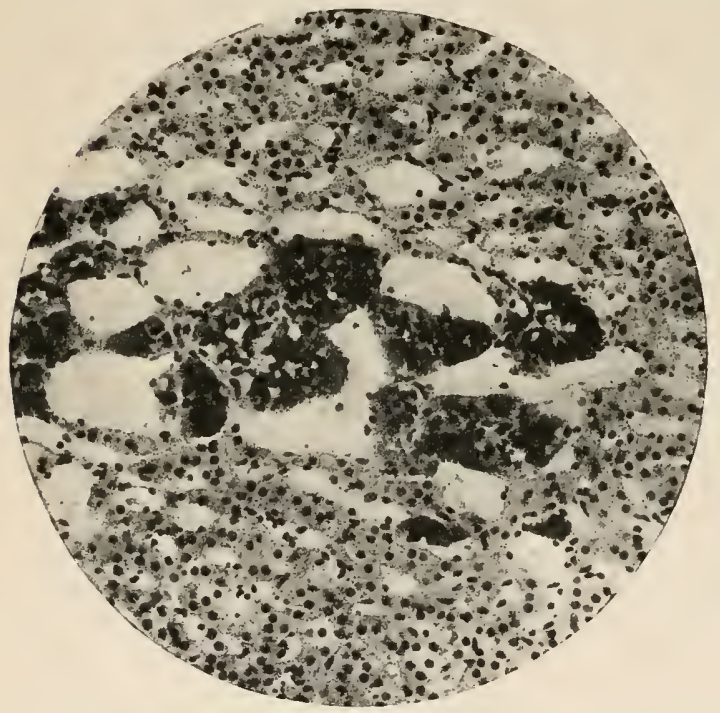

Fig. 34. -Section of suprarenal at thin part of medulla. Magnified 150 diameters. In this section as well as in that shown in fig. 32 the cells of the medulla are stained brown with bichromate of potassium. They contrast strongly with the cells of the zona reticularis of the cortex. The blood-sinuses of the medulla are seen to he continuous with those of the zona reticularis.

the medulla. It becomes augmented in size with the activity of the sexual glands in animals; nevertheless, castration is followed by its hypertrophy. There is no evidence that any kind of active autacoid substance is produced by the cortical cells, and it is probable that their function is associated with the building up of metabolic products which are to find employment in other parts of the organism.

\section{StRuCture of THE Medulla}

The medulla is composed of cells which have a different form and structural appearance from those of the cortex. They are arranged in what appear in section like irregular anastomosing columns with large blood-spaces between. But in point of fact the medulla is better described as a solid cell-mass permeated by sinus-like blood-vessels (fig. 34 ) with the cells compactly arranged between and around them. The cells of the medulla are irregularly polygonal in form, but where they abut on the sinuses they often assume a nore columnar aspect. There can be little doubt that the materials they secrete find their way directly into the blood within the blood-spaces. 
The cell-protoplasm contains granules which vary in size and amount in different cells (Carlier). Some of these granules are stained brown with chromic acid and its salts (adrenalin or chromaphil reaction), and this gives a yellowish-brown colour to the medulla when the suprarenals are fixed in any solution containing these salts. Occasionally the colouration is more diffuse. A similar reaction is sometimes given by the blood and lymph in the vessels of the medulla in sections of the organ.

Besides the chromaphil granules above mentioned, others are found, somewhat coarser, soluble in water and alcohol but not in ether, and staining with difficulty. Lipoid and pigment granules may also occur. The relationship of these various granules to one another is not known.

\section{Vessels and Nerves of the Suprarenals}

The blood-vessels are very numerous. The arteries enter at the surface and give off branches to supply the cortex with a rich capillary network. The blood-vessels do not penetrate the cell-columns of the zona glomerulosa and zona fasciculata of the cortex, but run in the connective tissue septa between them. In the zona reticularis the vessels become large, take on a sinus-like character, and come into close relationship to the cells. They pass into the sinuses of the medulla. According to Neumann, the bloodsupply of the suprarenal is more abundant than that of any other organ in the body, viz., as much as 6 to 7 c.c. per gramme and per minute (with a blood-pressure of $130 \mathrm{~mm} . \mathrm{Hg}$ ). This is even higher than that of the thyroid, which comes next with 5 c.c. per gramme and per minute. The respiratory exchange is also very high (Baumann).

In birds and reptiles the suprarenals have a venous blood-supply as well as an arterial-mblood being conveyed to each gland by a "portal" vein which is usually formed by the junction of two or three intercostal veins.

The connective-tissue septa of the cortex contain lymphatics, which pass directly into lymph-vessels of the medulla.

The suprarenals are very richly supplied with nerves. Each receives no less than thirty-three nervous filaments (Kölliker), derived in part directly from the splanchnic, in part from the suprarenal plexus, which is itself constituted by branches from the celiac, phrenic, and renal plexuses. After forming a network in the connective-tissue investment of the organ, the nerves penetrate into the cortex, partly supplying its blood-vessels, partly its cell-columns. But most of the nerves extend to the medulla, where they form a dense plexus from which filaments pass to end between the secretory cells. Groups of sympathetic nerve-cells are occasionally found both in the medulla and in the deeper parts of the cortex. 


\section{THE SUPRARENAL CAPSULES (continued)}

\section{Effects of Suprarenal Removal: Epinephrectomy}

AdDison's account of the disease he described and which he termed idiopathic ancemia led Brown-Séquard to test the effect of the removal of the suprarenal glands in animals. The operation, which was performed upon a number of animals of different species (rabbits, guinea-pigs, dogs, and cats), was followed in every case of double extirpation by a fatal termination within thirty-seven hours of the removal. But a fatal result was produced also in all or nearly all the animals in which the lesion was unilateral, although subsequently Brown-Séquard succeeded in keeping some animals alive for a few days when only one capsule was removed. Since it is now well established that careful removal of one capsule under aseptic precautions is not fatal, ${ }^{1}$ there can be little doubt that BrownSéquard's results were in considerable measure the consequence of shock and sepsis, and that they could not be relied on as a proof that the suprarenal capsules are essential to life. This is indeed the opinion which was formed by most of his contemporaries. Nevertheless, looked at in the light of our present knowledge, it is certain that death must have been either caused or greatly accelerated by the removal of both capsulessince this is now known to be in most animals the invariable result of the double operation and to occur within a few days. There are, however, exceptions, especially in some species of animals: among which the white rat may be particularly mentioned. These exceptions are probably associated with the occurrence of accessory bodies, but whether these must be of cortical or medullary nature-or both-is not determined.

No effect of the extirpation-especially if the operation is performed on the two glands at an interval of a few days-is at first apparent. For some days there is little sign of anything wrong. Presently the animal becomes less lively and exhibits signs of muscular weakness. The body temperature also becomes lowered, but the blood-pressure is fairly maintained. Ultimately the weakness becomes extreme, the pulse feeble, the blood-pressure low, and the respiration dyspnœic. Death soon follows, sometimes immediately preceded by convulsions.

1 An exception must be made for the guinea-pig, in which unilateral extirpation is frequently followed by death. It may be remarked that the suprarenals of the guinea-pig are larger in proportion to its size than are those of any other animal. 
Experiments on adrenal transplantation have for the most part led to negative results. The graft almost invariably undergoes rapid necrosis and disappears, although Haberer and Stoerk obtained some success by implantation into the dog's kidney. Administration of suprarenal extract is unable, either in Addison's disease or in the cachexia produced by extirpation, to prevent the usual fatal termination, although this may be somewhat deferred. The muscular weakness characteristic of Addison's disease nay for a time tend to disappear with the administration, so that the ergographic record may again approach the normal. But such administration cannot, as in the case of cachexia thyreopriva, take the place of the internal secretion of the gland, and until measures are found to induce grafts to take in man, Addison's disease will probably continue to terminate fatally. With the progress of surgery the possibility of successful implantation seems less hopeless than was the case only a few years ago.

After extirpation of one gland only there is a compensating hypertrophy of the other, and also of the accessory bodies. Castrated animals were found by Hultgren and Andersson to live much longer after the complete operation than normal individuals. This is also stated to be the case if the complete operation is performed in two stages, first the capsule of the one side and then that of the other being removed. The result is perhaps due to the fact that time is thus given for a process of hypertrophy of accessory bodies. With regard to the total amount of suprarenal substance that must remain in order to maintain life, Biedl found in cats, dogs, and rabbits, that if one-eighth of the whole suprarenal substance is left the animals always survive. He further found that if the interrenal body alone is removed in the skate the animal dies in two or three weeks, becoming progressively weaker and refusing food. In one skate in which a small portion was left, these symptoms were absent. He concludes, after a survey of all the experimental evidence on the subject, that it is abundantly proved that the suprarenals are not only important but are essential to life, and that it is probable that this is due to some material yielded by the cortex-although the loss of the adrenalin which is supplied by the medulla may be contributory.

It appears that in other diseases than Addison's the functions of the suprarenal capsules to a great extent become suppressed. In diphtheria and after injection of diphtheria-toxin in animals, it has been found that the amount of adrenalin yielded by the medulla of the suprarenals is much diminished, and may even in extreme cases disappear altogether. In cholera also the amount is greatly diminished; it is stated that in this disease subcutaneous administration of adrenalin is markedly beneficial. If this diminution in the amount of adrenalin formed should prove to hold good in other acute infectious disorders, it would seem probable that interference with the functions of the suprarenal capsules is in large measure responsible for the cardiac weakness and general loss of tone which are prominent symptoms in such affections. 
The Nature of the Autacoid furnished by the Medulla

All the physiological effects which are about to be described as yielded by suprarenal extracts are obtainable from extract of medulla alone: intravenous injection of extract of cortex gives no appreciable result. In Teleostei, where the cortex is represented by the corpuscles of Stannius, and in the Elasmobranchs, in which the cortex is represented by the interrenal body and the medulla by the entirely separate "paired bodies" of Balfour, it has been shown by Vincent that the latter yield an active extract, whilst extracts of the interrenal body are inactive. It was proved by Moore that the action of the extract of medulla is due to the material within the cells which becomes stained with chromic salts, and which, as Vulpian showed, is readily oxidised by various reagents, giving characteristic colour reactions with ferric chloride, chlorine water, and caustic alkalies. A similar reaction was obtained by Vulpian with a material contained in the blood of the suprarenal vein. With phospho-tungstic acid a blue colour is yielded even in extreme dilution.

This chromaphil substance of the suprarenal medulla, after being partly isolated by Fraenkel, was prepared in a condition approaching purity by v. Fürth, and by Abel, and eventually in a crystalline form by Takamine and by Aldrich. It has received various names, such as suprarenin (v. Fiirth), epinephrin (Abel), udrenalin (Takamine), the last being that by which it is most widely known. ${ }^{1}$ It has been estimated by Batelli that the suprarenal capsules contain about 1 part of adrenalin per 1000 of the whole gland, but as it only occurs in the medulla, which forms less than a fourth of the gland, the proportion in this would be considerably greater.

Adrenalin can be prepared synthetically, methyl-acetyl-pyrocatechin being first obtained. This when reduced gives a racemic salt which can be split into $d$-adrenalin and $l$-adrenalin. The latter appears to be in all respects identical with the natural product, while the racemic salt and $d$-adrenalin are much less active physiologically.

Chemically adrenalin is ortho-dioxyphenyl-ethanol-methylamine:

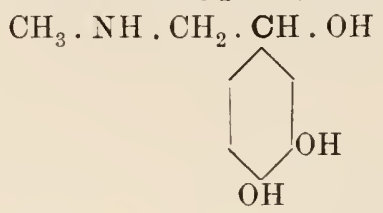

and is related to tyrosine (oxyphenyl-amino-propionic acid).

\section{Effects of Intravenous Injection of Suprarenal Extracts}

If an extract or decoction of the medulla-made with water or Ringer's solution-is injected into a vein, an immediate and marked rise of bloorpressure is produced. This is caused by contraction of the peripheral

1 This name has been adopted in the Pritish Pharmacopcia and will therefore be employed in this work. 
arteries. Along with the vascular contraction a slowing of the heart's action (or even complete stoppage of auricular beats) may occur, due to an effect on the cardio-inhibitory centre, and this may somewhat limit the rise of blood-pressure (fig. 35). But if the vagi are cut or paralysed by atropine, the heart-beats become enormously accelerated and also augmented in force (primarily by the action of the autacoid on the auricles, but also somewhat on the ventricles), ${ }^{1}$ and this greatly increases the rise of blood-pressure (fig. 36). There is some diminution in the depth of the respirations, and

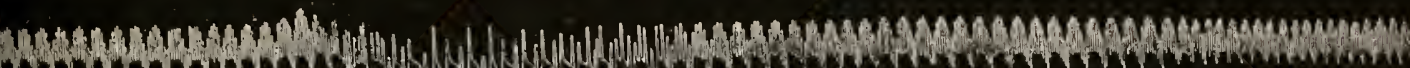

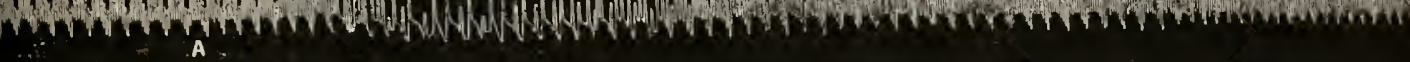

8

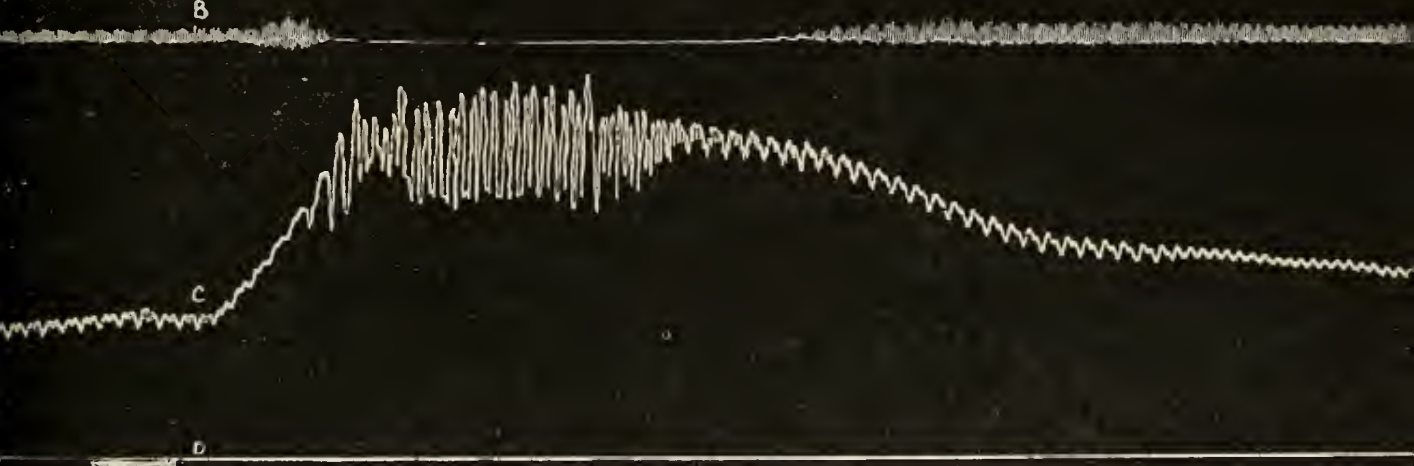
E

Fig. 35.-Effect upon heart and blood-pressure of injecting suprarenal extract into a vein, with vagi intact (dog). (This figure, as well as figs. 36 and 38 , are from Oliver and Schäfer, Journ. Physiol., 1895, vol. xviii.)

$A$, ventricle ; $\mathrm{B}$, auricle ; $\mathrm{C}$, arterial pressure ; $\mathrm{D}$, signal ; $\mathrm{E}$, time-marking in seconds. The tracings in this and the next three figures have been reduced to rather less than half the size of the originals.

occasionally a temporary cessation of breathing, especially in the rabbit. ${ }^{2}$ But this disappears long before the effect on the blood-vessels has ceased to show itself. The effect upon the vessels lasts a few minutes, gradually passing off; after its passage the blood-pressure is usually a little lower than before. The arteries which are most affected are those of the splanchnic area (fig. 37): those of the limbs and trunk rather less, although the cutaneous vessels are usually strongly contracted: those of the pulmonary system and of the brain only very slightly if at all, while those of the coronary circulation are unaffected: indeed, in some animals these last are

1 In birds, as Noël Paton has shown, the augmentation is confined to the auricles.

${ }^{2}$ Garrelon and Langlois find that in the dog either diminution or increase of respirations may occur, these effects depending upon the condition of the respiratory centre at the time. 


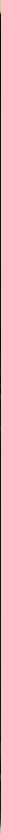

FIG. 37. - Effect upon blood-pressure, kidney volume, and flow of urine of injecting suprarenal extract into the vein of a dog. (From Schäfer and Herring, Phil. Trans., 1906.)

$A$, blood-pressure tracing; B, kidney volume change (oncograph): the frll extent of the shrinkage is not recorded; C, drops of urine marked by magneto-electric signal; $\mathrm{D}$, tine in ten-second intervals; $\mathrm{E}$, abscissa of blood.
pressure and signal of injection.

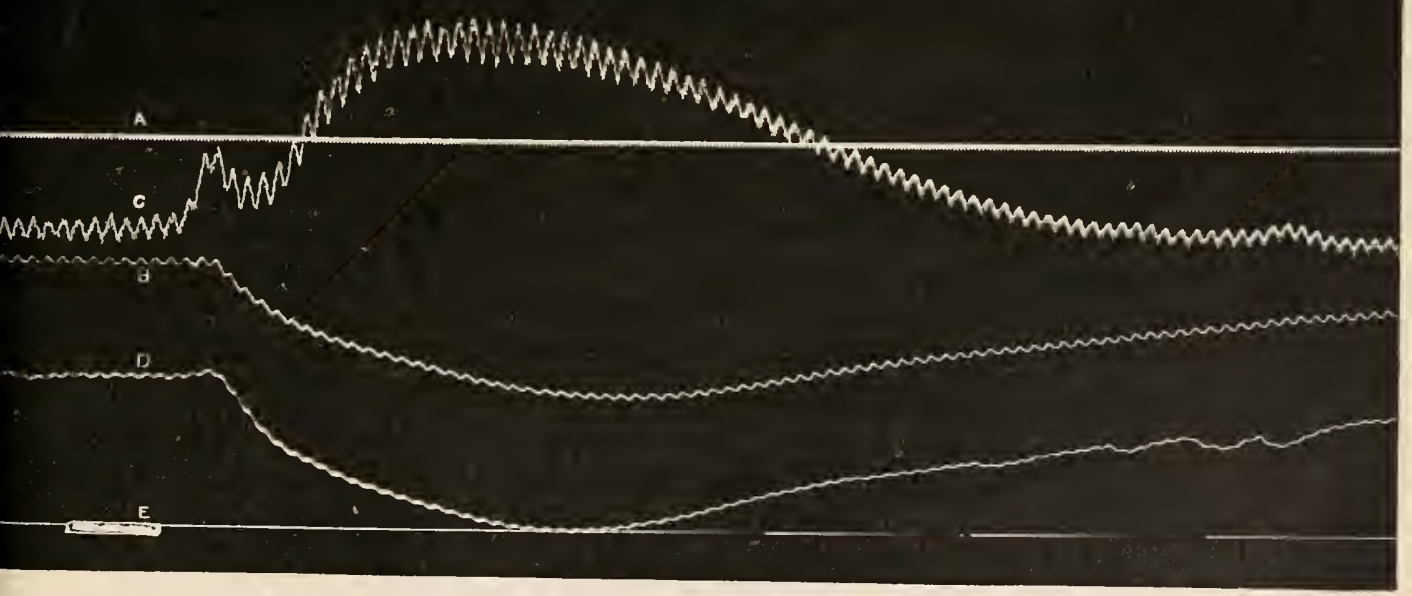

FIG. 38. - Etfect upon blood-pressure and limb rolume of iujecting suprarenal extract into a vein $(\operatorname{dog})$.

A, time-marking (seconds); C, arterial pressure; B, volume changes of left fore limh, nerves intact; D, volume changes of right fore limb, brachial plexus cut; $\mathrm{E}$, signal; the line records abscissa of blood-pressure. 
arterial pressure (J. D. Cameron). Moore and Purinton found that with very minute doses a fall of pressure may be obtained instead of a rise. If the amount injected is considerable, the rise of blood-pressure caused by vascular contraction and heart acceleration may be enormous - three or four times the normal-and the amount of strain put on the heart is correspondingly great. Sometimes the heart muscle is unable to respond properly under these circumstances and the ventricular action becomes fibrillar-delirium cordis being produced, generally leading to instant death. This seems especially liable to occur in a particular phase of early chloroform anæsthesia (Levy).

As a general rule a number of successive injections can be made into a vein, and each one will produce an amount of rise of blood-pressure proportionate to the amount of autacoid in the extract: the activity can in fact be gauged by this method. Other modes of testing the activity of suprarenal extracts are (1) by

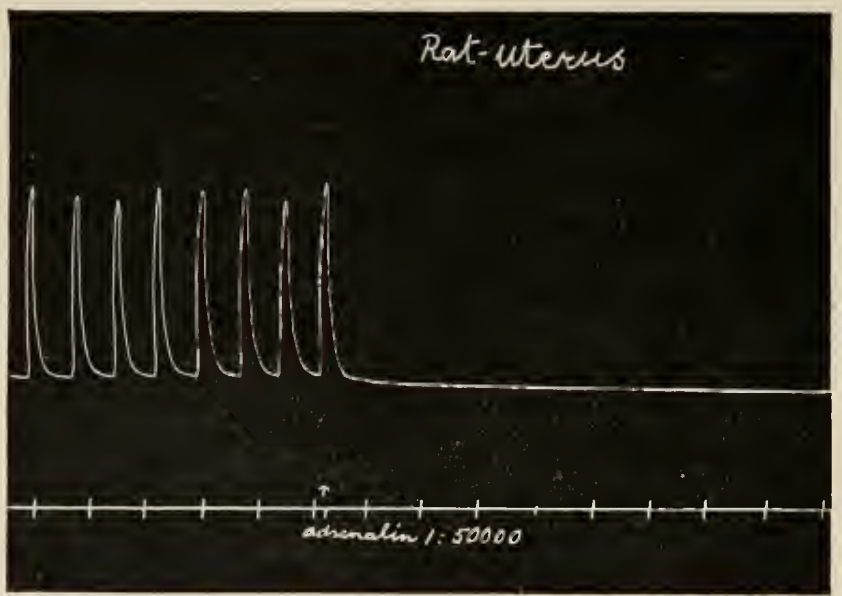

Fig. 39. - Effect of solution of adrenalin upon an isolated portion of uterus of rat. The contractions are inhibited.

their action when added to Ringer's solution perfused through the blood-vessels of a frog the central nervous system of which has been destroyed, (2) by the effect produced upon the pupil of the excised eye of a frog when immersed in Ringer's solution to which a definite amount of the extract is added, (3) by immersion of the excised uterus of a rat in a similar solution kept aerated by a stream of oxygen and maintained at body temperature, (4) the same, using a piece of intestine instead of uterus, and (5) the same, using strips of artery cut transversely.

The effect of suprarenal extract upon the heart and vessels is not the only action upon plain muscle, although it is the most obvious. Other involuntary muscular tissue supplied by sympathetic fibres is also affected. This may be in the direction of increased contraction (sphincters of pylorus and of ileocæcal valve, spleen, vagina, uterus, ${ }^{1}$ vas deferens, retractor penis),

1 Cushny finds that the uterus of a pregnant cat is contracted by adrenalin, whilst the non-pregnant uterus is usually inhibited. In the rat inhibition is the usual effect (fig. 39), but in the rabbit (fig. 40) and most animals contraction is produced. 
or of inhibition (intestine (fig. 41), stomach, œesophagus, gall-bladder, urinary bladder). Certain of the plain muscles of the orbit and globe of the eye are excited when suprarenal extract is injected intravenously, so that the

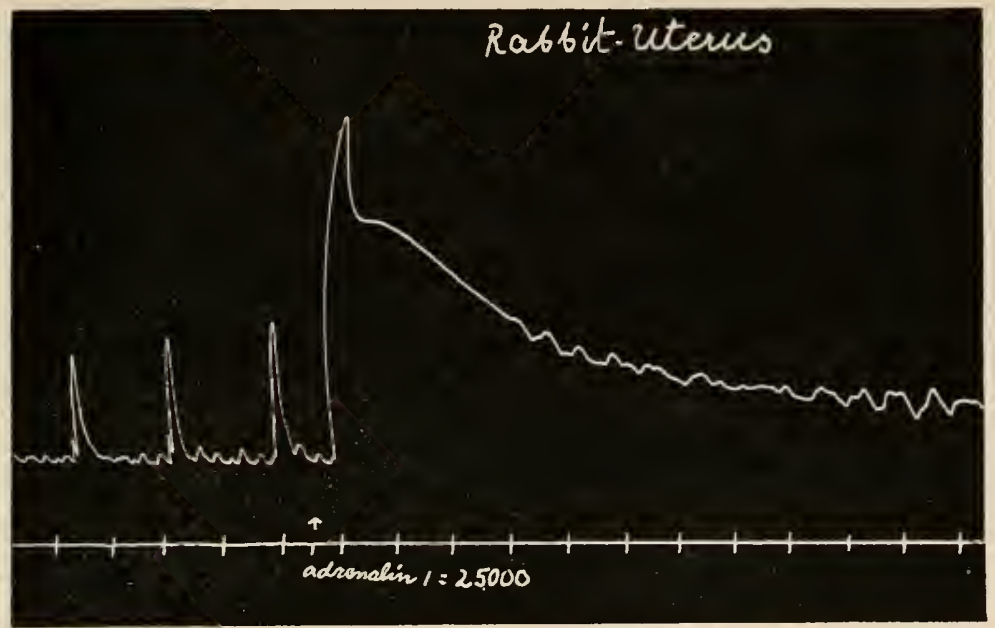

Frg. 40.-Effect of solution of adreualin on cornu uteri of rabbit, the contraction of which is yc.. fincreased. I am indebted to Dr M. Itagaki for the tracings shown in figs. 39 and 40.

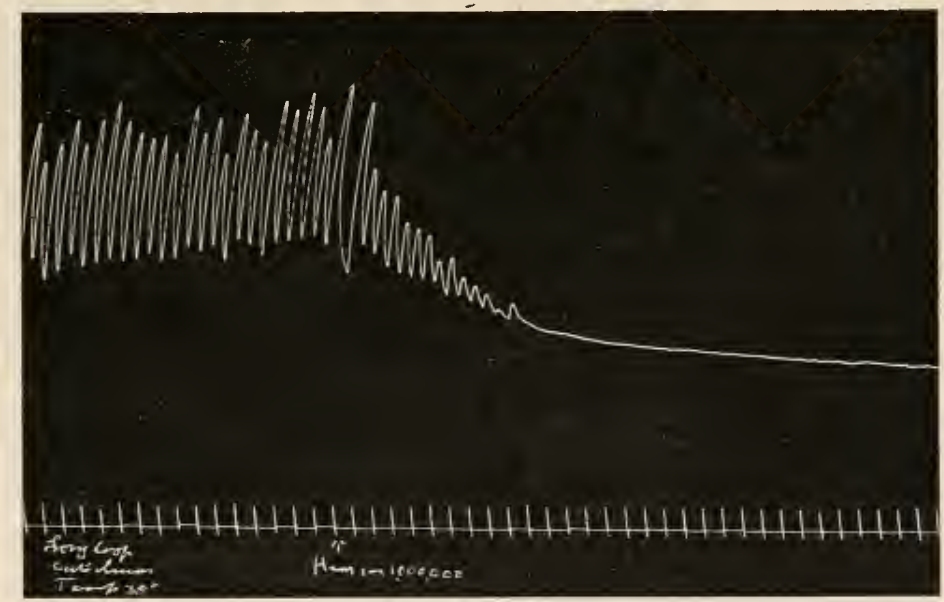

FIG. 41.-Effect of immersing a strip of the longitudinal coat of the ileum of a cat in one-in-a-million solution of adrenalin. (A. W. Young.)

eye tends to protrude and the palpebral fissure becomes large, the third eyelid is retracted and the pupil widely dilated (Lewandowsky). ${ }^{1}$

${ }^{1}$ Dropping a solution of adrenalin into the conjunctival sac does not produce dilatation of the pupil inless the superior cervical ganglion of the sympathetic has been previously removed on that side. The removal causes the dilatator pupillæ to be more sensitive to the action of the autacoid (see p. 60). It is stated by Löwi that in diabetes produced by extirpation of the pancreas, the pupil will react to the instilled solution of adrenalin without such removal of the ganglion. 
A flow of saliva similar to that caused by excitation of the cervical sympathetic is also produced, and is accompanied by contraction of the vessels of the glands: the flow of saliva is little apparent in the dog, but it is well marked in the cat, in which animal, as is well known, excitation of the sympathetic in the neck provokes an abundant flow from the salivary glands. The lacrimal glands are caused to secrete as wêll as the mucous glands of the mouth, throat, and windpipe. These effects are accompanied by pallor due to vasoconstriction, followed shortly afterwards by flushing. There is increase of flow of gastric juice and bile, but not of pancreatic juice. The sweat glands are said to be stimulated in the guinea-pig, but not in the cat. The skin glands of the $d o g$ are caused to secrete. The mammary secretion is unaffected. The flow of urine is increased by subcutaneous but diminished by intravenous injection. The blood-flow is increased in the suprarenals themselves.

The autacoid has further been found to defer the onset of fatigue of muscle and to assist its recovery. The arrectores pilorum, especially those of certain parts, contract. Adrenalin also causes contraction of the pigment cells both of the skin and retina of the frog. It is noteworthy that sympathetic stimulation also produces this effect; at least this is so for the pigment cells of the skin. In birds some of the effects are different from those obtained in mammals. Noël Paton and Watson found that in the duck the effect of adrenalin is to cause decrease in the strength of the ventricular beats, which may more than compensate for the arterial contraction simultaneously produced, so that a fall of blood-pressure may result. 'There is also contraction of the intestine instead of inhibition.

Although the rule is perhaps not entirely without exception, it may be stated as a general principle that the result of suprarenal injection is identical with that of stimulating the endings of the sympathetic nerves throughout the body (Langley).

As has already been pointed out, the above results are obtained even if the sympathetic nerves have been divided and allowed to undergo degeneration. It has, therefore, been concluded that under the influence of these nerves the tissues produce, either at the junction of nerve and muscle ("myo-neural junction" of Elliott) or throughout the cell-protoplasm, a material ("receptive or excitable substance" of Langley) which reacts with adrenalin, and not only with it but also with drugs, such as those alkaloids which have a pronounced physiological action. And, further, that this receptive substance increases either in amount or sensitivity after the action of the nerves is withdrawn by their severance.

Abolition of the effect of adrenalin in producing contraction of plain muscle (and the same applies to the effects of sympathetic excitation) can, as Dale has shown, be obtained by administering ergotoxine-an amine base obtained from ergot, and also obtainable from the products of breaking down of histidine. Ergotoxine does not, however, paralyse the inhibitionproducing effect of adrenalin (nor the inhibition caused by sympathetic 
excitation). Therefore, if, as sometimes happens, both contraction and inhibition can normally be brought about through the sympathetic and also by adrenalin, when the contraction effect is abolished by ergotoxine, the inhibition effect alone appears, and this may produce a reversal of the norinal action. Thus after a sufficient dose of ergotoxine, adrenalin produces vasodilatation in place of vasoconstriction, and inhibition of uterine contractions instead of increased contraction. In the ferret the urinary bladder is contracted by suprarenal extract if ergotoxine is previously administered (Elliott), although it is usually inhibited. This corresponds with the effect of administering the same drug prior to stimulating the sympathetic nerves passing to that viscus. Ergotoxine doubtless acts, like adrenalin, on the junctional or receptive substance. Dixon obtained like results with apocodeine.

The action of adrenalin upon the terminal apparatus of the sympathetic system is common to a number of primary and secondary amines: the action has been termed sympatho-mimetic by Barger and Dale. The more nearly the structure of the amine approaches that of adrenalin the more marked is this action. A knowledge of these facts has led to the production of various synthetic drngs having similar properties. The chemical history of adrenalin furnishes, indeed, a striking illustration of the drug-like character of autacoids.

Repeated intravenous injections into the ear-vein given at intervals of a few days produce (in the rabbit) degenerative sclerosis of arteries (Josué). This action is not specific to the suprarenal autacoid, but is the result of prolonged abnormally high blood-pressure, however produced.

Applied directly to the smaller blood-vessels, the suprarenal autacoid produces marked contraction of the muscular coat, and it is therefore of value in surgery as a styptic for arresting hæmorrhage from small arteries.

It was found by Oliver and myself (and confirmed by other workers) that the contractions of skeletal muscle are prolonged under the influence of suprarenal extract. The effect we obtained nust, however, have been due to something in the extract used other than adrenalin, for I have since failed to get any effect with small doses of that substance. In larger doses adrenalin has a paralysing action on muscle somewhat similar to that produced by excess of potassium salts (Takayasu). Nevertheless, administration of suprarenal by the mouth has been shown to be favourable to muscular action, fatigue being less easily produced: this was found by Langlois to be the case in Addison's disease (fig. 42). Lucien and Parisot find postponement of fatigue in frog muscle to be an effect of the autacoid.

Effects of Subcutaneous and Buccal Administration.-Subcutaneous injection of the extract does not produce the rapid effect on involuntary muscle which is so characteristic of intravenous injection-although, as Meltzer and Auer have shown, intramuscular injection may show this result. But large doses of the extract, or of the separated autacoid substance of the medulla, produce in rabbits and some other animals serious or even fatal symptoms. 
After a preliminary period of excitement, with rapid pulse and respirations, a period of depression supervenes. Accompanying this depression the muscular movements are first slowed; there is then paralysis of the limbs and later of the respiratory muscles, with asphyxial convulsions. The body temperature becomes lowered some little while before death. The paralysis is central. Post-mortem a general hyperæmia of the viscera is evident, and abundant hæmorrhages are seen to have occurred in various parts. If a first dose is not fatal, a certain amount of immunity may be produced to a subsequent dose (Vincent).

Subcutaneous injection of adrenalin was found by Blum (1901) invariably to produce hyperglycæmia and glycosuria. This occurs even if the animal had been fed on a diet free from carbohydrates (Noël Paton); it is then accompanied by increased excretion of nitrogen. This observation

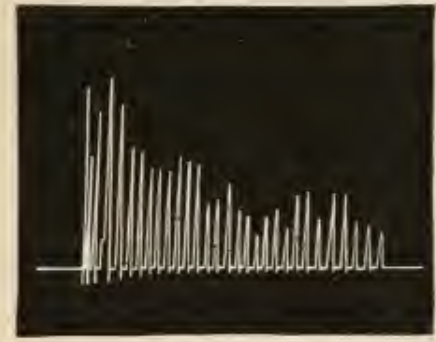

A

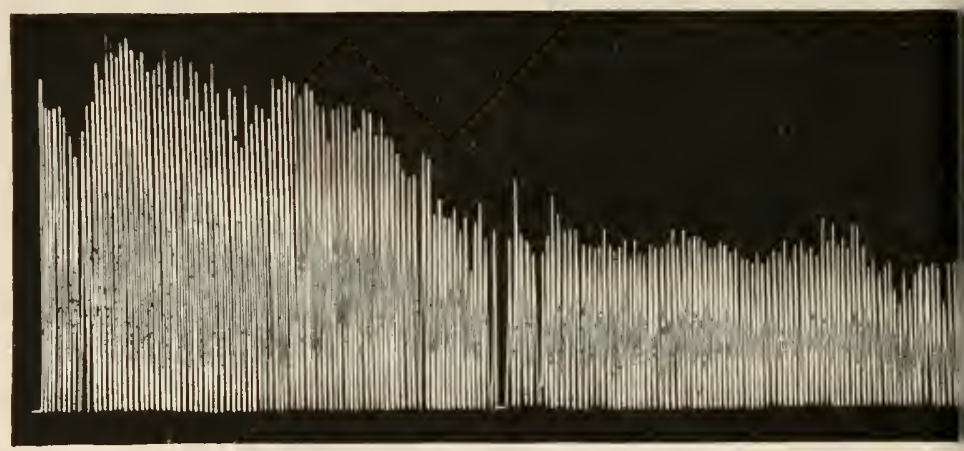

B

FIG. 42.-A, ergograph tracing from a person suffering from Addison's disease. B, tracing from the same person after six weeks' administration of suprarenal. (Langlois.)

$A$, natural size ; $B$, reduced to one-half.

seems to indicate that under these circumstances the sugar is formed from protein, but according to the observations of Herter and Richards glycosuria does not occur if the liver glycogen has been got rid of by the combined effects of fasting and phloridzin injection. Pollak states, however, that in rabbits the liver of which has been rendered glycogenfree by fasting and administration of strychnine, adrenalin may, in addition to producing glycosuria, cause glycogen to be again stored in that organ.

The effect of adrenalin in producing glycosuria appears due in part to an action on the liver nerve-endings, in part to an effect on the pancreas; for Herter and Wakeman found that the direct application of the autacoid to the pancreas will cause glycosuria. This will be again referred to in considering the influence of the suprarenal on other organs, and also in connexion with the internal secretion of the pancreas.

Several observers have found the administration of adrenalin to cause increase of metabolism both of fats and proteins. 
Considerable amounts of the extract can be taken into the stomach without producing any immediate physiological result such as is caused by intravenous injection. This is probably due to the fact that the active material, although not destroyed by gastric juice, is absorbed but slowly and becomes destroyed in the tissues as fast as it is absorbed. That such destruction is readily produced is obvious from the fact that even when large doses are injected into a vein the effects pass off within a few minutes. Where the destruction is effected is not known, although it has been conjectured that it may be in the tissues generally, especially the muscles and liver. It was found by Oliver and myself that adrenalin is not destroyed by prolonged contact with blood, nor is it eliminated by the urine. Meltzer finds that it is destroyed by cerebro-spinal fluid. Since it has been shown (W. Cramer) that the autacoid is rapidly inactivated in vitro by dilute formaldehyde, it may well be that the inactivation in vivo is brought about by this substance, which is believed to be one of the intermediate products of protein-metabolism. 


\section{THE SUPRARENAL CAPSULES (continued)}

\section{Evidences of the Passage of Adrexalin into the Blood}

That the passage of adrenalin into the blood is always proceeding in sufficient amount appreciably to raise the tone of the blood-vessels seems somewhat doubtful. It was found by Oliver and myself that even in the blood of the suprarenal vein there is not always enough of the autacoid to cause a rise of blood-pressure when a few cubic centimetres are injected into a vein. But it is possible by employing more delicate physiological tests-e.g. the dilatation of the pupil which occul's in the enucleated eye of the frog, or by passing extracts of dried and deproteinised mammalian blood through the vessels of the frog-to obtain evidence in some animals of its presence not only in the blood of the suprarenal vein, but to a less degree in the blood generally. The amount is, however, normally very small, even in the suprarenal vein: not more than about one part in a million, according to Hoskins, $\mathrm{I}^{\prime} \mathrm{C}$ Clure, and O'Connor, whilst Fraenckel estimates it at very much less. This indicates that the rate of passage into the blood is usually slow: probably it varies at different times. If only a very small percentage is present, the blood-pressure may be lowered instead of raised: we cannot, therefore, assume that the normal tone of the vascular system depends on the presence of adrenalin in the blood, although, that the maintenance of vascular tone is in some animals assisted in this manner, is shown by the experiment of compressing the suprarenal vein. Such compression is followed by a gradual fall of blood-pressure, which quickly recovers, and, indeed, more than recovers, its former height on relieving the compression. Temporarily compressing the abdominal aorta produces somewhat similar results. It is possible that the partially resumed tone of peripheral vessels which comes on after section of their nerves may be due to a compensatory increase of adrenalin in the blood, perhaps assisted by an increase of the pressor autacoid of the posterior lobe of the pituitary. The circumstance that after section of its nerves plain muscular tissue becomes more sensitive to the influence of adrenalin must be borne in mind in considering this question.

Trendelenburg estimated the amount of adrenalin in the blood of the suprarenal vein of a cat, and found that on the average $.003 \mathrm{mg}$. was passed out of the two organs per minute. From the data thus obtained he reckons that about $5 \mathrm{mg}$. per kilo. body weight is formed in twenty-four hours. After draining off a large quantity of blood and thus causing a considerable fall of blood-pressure, the amount of 
adrenalin passed per minute was not increased. G. N. Stewart states that massage of the suprarenals leads to the passage of an increased quantity of adrenalin into the blood: when the massage is light a depressor effect is caused, when vigorous a pressor effect; but, according to Hoskins and $\mathrm{M}^{\circ} \mathrm{Clu}$ e, there is never so large a pressor effect as with "ordinary therapeutic dosage."

Hoskins and Rowley find that administration of adrenalin does not increase the excitability of the vasomotor nerves to faradisation, but rather tends to depress it.

With regard to the amount of adrenalin required to produce a physiological effect upon plain muscle, it may be mentioned that Cannon obtained inhibition of a strip of intestinal muscle with a solution containing 1 in 20 millions, and Janeway and Park observed inhibition of a strip of coromary artery of the sheep witl a solution of 1 in 50 millions.

\section{The Influence of Nerves upon the Secretion}

It was shown by Biedl that stimulation of the splanchnic nerves is accompanied by increased blood-flow through the organ. The result is even better marked when these nerves have been cut and allowed to degenerate for two or three days so that only the vasodilators are acting. Tscherboksaroff, in confirmation of an observation by Dreyer, found that during excitation of the splanchnic in a dog the blood passing from the suprarenal capsule by its vein produces a greater effect in raising the bloodpressure of another dog than the bloor of the suprarenal vein under ordinary circumstances, and concluded that adrenalin is passed into the traversing blood under the influence of impulses conveyed by this nerve. He also obtained a larger amount of adrenalin from the suprarenal capsule as the result of such stimulation. But the actual proof of secretion under the influence of nerves is most satisfactorily furnished by the experiment of Asher, who found that after ablation of the stomach, intestines, and all the other abdominal organs, in order to eliminate the direct effect which would be obtained on their blood-vessels, stimulation of the splanchnics still causes a marked rise of blood-pressure, which fails if the suprarenal blood-vessels are compressed. Elliott and Tuckett were able to exhaust the suprarenal of its adrenalin by stimulation of its nerves.

Section of the splanchnics diminishes the amount of adrenalin which is passed into the blood: according to Elliott, it is only the reflex secretion which is affected; an automatic solution goes on all the time. Pende found that section of the splanchnics leads eventually to atrophy of the medulla.

Von Anrep noticed that stimulation of the splanchnic produces a double rise of blood-pressure; he ascribes the first to direct stimulation of the vasomotors, the second to the outpouring of adrenalin into the blood. This latter phase fails to appear if the suprarenals are extirpated (figs. 43, 44). In the cat Cannon found that the dilatation of the pupils and upstanding of the fur which accompany sudden alarm or excitement are associated with an increased outpouring of adrenalin into the suprarenal veins, and he has drawn attention to the fact that many of the phenomena 
which characterise violent emotional states (both in animals and man) are similar to those which are produced by excess of the suprarenal autacoid in the blood.

It is conjectured that the hyperglycæmia and glycosuria which result from Bernard's sugar puncture are accompanied by and probably largely due to stimulation of the suprarenals through the splanchnics causing the passage of an excess of adrenalin into the blood, which in turn produces increased
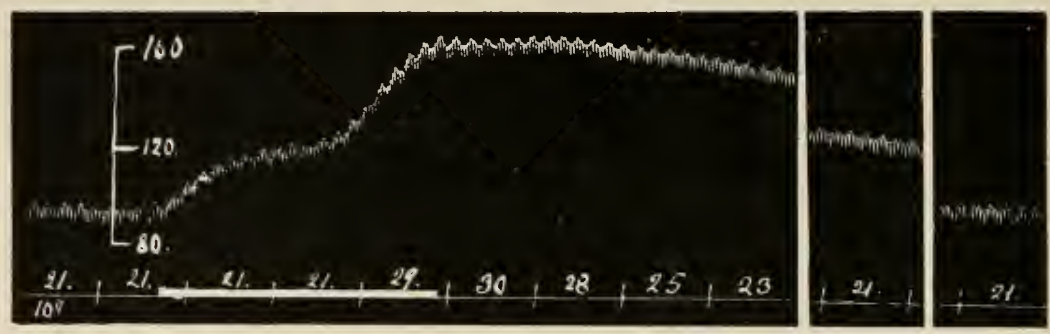

Fig. 43.-Effect on blood-pressure of stimulating the splanchnic nerves. The first rise in bloodpressure is caused by constriction of the vessels of the splanchnic area, the second by outpouring of adrenalin into the blood. 'T'he numbers above the abscissa denote the number of pulse beats in ten seconds. (v. Aurep.)

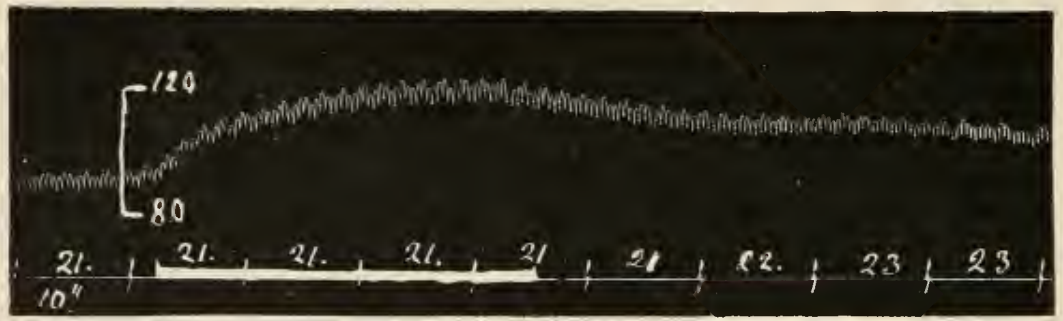

FIG. 44.-The same as in fig. 43 , but with the suprarenal capsules removed. Only the rise of blood-pressure caused by the direct effect of the stimulation on the vessels of the splanchnic area is now seen. (v. Anrep.)

transformation of the liver glycogen into glucose. This will be referred to more fully in the next section.

Dale has suggested that certain alkaloids (e.g. nicotine and pilocarpine) exert their action on involuntary muscle, not directly, but by stimulating the suprarenals to increased activity. This has also been shown to be probably true for morphia, chloroform, and ether by Elliott; the effect appears to be brought about through the splanchnic nerves.

\section{Relations of the Suprarenals with Other Exdocrine Organs and Secreting Glands}

Ott and Scott state that various organ extracts, viz., thyroid, parathyroid, pituitaly, thymus, pancreas, testicle, and ovary, produce an increased 
secretion of adrenalin into the blood. The variety of these does not, however, indicate specific relationship. On the other hand, the secretion of the suprarenal medulla has an influence upon many diverse organs and glands-including most of the other ductless glands; this is probably due to the fact that adrenalin activates sympathetic nerve-endings throughout the body.

With the Sexual Glands.-A direct relationship between the development of the sexual glands and that of the suprarenals may be regarded as well established, although the nature of the relationship-whether through the nervous system or, as is more probable, through chemical agencies-is not precisely known. The connexion appears to be more with the cortex of the adrenals than with the medulla. During pregnancy the whole gland undergoes enlargement: the cortex much more than the medulla. Whilst hypertrophy of the cortex is stated to occur as the result of castration, various observers have found that increase is also associated with sexual precocity. Further, in diseased conditions resulting in hypoplasia of the adrenals, changes in the testicles, especially in their interstitial cells, have been noted.

Elliott and Tuckett do not admit any special connexion between the suprarenals and the sexual glands. They associate the cortex more particularly with the development of the muscular system. They also point out that the lower the animal in the vertebrate, or at any rate in the mammalian series, the greater is the relative development of the cortex.

With Externally Secreting Glands.-Injection of suprarenal extract was found by Langley (in the cat) to produce an active secretion of all the salivary and mucous glands of the mouth, gullet, and trachea. The secretion is not arrested by small doses of atropine and is similar to that produced by sympathetic excitation. The lacrimal glands are also stimulated to active secretion: and this is said to be the case also with the gastric glands.

With the Liver.-The secretion of bile is increased by adrenalin. But the most noteworthy effect on this organ is upon its glycogenic function, for the autacoid of suprarenal medulla even in small doses produces a rapid conversion of the liver glycogen into sugar, which passes into the blood and eventually into the urine. The effect is similar to that caused by Bernard's sugar puncture of the medulla oblongata and by excitation of the splanchnics It will be remembered that after section of the splanchnics Bernard found that puncture of the medulla oblongata fails to cause glycosuria. The effects on the liver are probably in large measure, if not entirely, due to reflex or other excitation of cells in the nerve-centre. These give origin to nerve-impulses travelling along sympathetic fibres to the suprarenals, and thus cause the outpouring of an excess of adrenalin into the blood; this again excites the terminal apparatus of the sympathetic nerves in the liver-cells. Kahn noticed that if one suprarenal is left, its medulla shows indications of over-activity and far less adrenalin is stored within 
it than normally. He states that in the guinea-pig the blood can be shown to contain an excess of adrenalin after the sugar puncture. A. Mayer found that Bernard's puncture is not effective after removal of the suprarenals. Macleod and Pearce observed that adrenalin produces hyperglycæmia even after division of the hepatic plexus (which is not the case with the hyperglycæmia caused by stimulation of the splanchnics), and that only when the suprarenals are intact is it possible to produce hyperglycæmia by stimulation of the nerves of the liver. Adrenalin is therefore in some way necessary to the activity of these nerves: possibly by rendering them more sensitive. It is stated that the effect of adrenalin on the liver glycogen can be prevented by atropine (Doyen and Gautier). Ergotoxine also antagonises this action of adrenalin (see p. 64).

As already stated, if the liver is rendered free from glycogen, adrenalin injection will not only produce hyperglycæmia and glycosuria as before, but may, even in fasting animals, cause glycogen to be stored: this is associated with the fact that the metabolism of proteins is increased under the influence of adrenalin, and the protein is in this case the source of the carbohydrate which is formed (Noël Paton). On the other hand, O. Schwarz found the liver glycogen to disappear in rats in which the suprarenals had been removed, although it could be restored by liberal feeding with glucose and cane sugar (but not by lævulose or starch). If the glycogen of the liver is got rid of by phloridzin, administration of adrenalin does not increase the glycosuria (A. I. Ringer).

With the Pancreas.-Pemberton and Sweet found removal of the suprarenals to cause a flow of pancreatic juice which is stopped by injection of adrenalin, although under normal conditions the flow of pancreatic juice seems not to be affected by the intravenous injection of adrenalin, at least in moderate doses. But it is the internal secretion which is mainly affected by this hormone. Herter and Wakeman found that the mere swabbing of the exposed pancreas with adrenalin solution provokes intense glycosuria, comparable with that produced by extirpation of the organ. The glycosuria and the hyperglycemia caused by pancreatic extirpation is, however, increased, as several observers have found, by adrenalin, so that the whole of its effect on carbohydrate metabolism is not exerted through the pancreas, but part must be directly on the liver. We have, in fact, already seen that adrenalin has a direct effect on the glycogen storage of the liver. But this again is influenced by the internal secretion of the pancreas. Thus Zuelzer failed to get adrenalin glycosuria when he injected pancreas extract at the same time as the adrenalin; on the other hand, he states that tying the suprarenal veins is effectual in preventing glycosuria pancreatopriva. These experiments show that carbohydrate metabolism is in some way regulated by the interaction of the suprarenals and pancreas upon the liver-cells. Graham Lusk, however, from a study of the respiratory quotient in a glucose-fed dog to which adrenalin was administered, comes to the conclusion that this 


\section{Relations of the Suprarenals with Other Endocrine Organs 73}

autacoid does not act on carbohydrate metabolism by specifically inhibiting the internal secretion of the pancreas, but that its effect on carbohydrate metabolism is related to its vasoconstrictor action. The subject will again come up for discussion when the internal secretion of the pancreas is dealt with.

With the Thyroid and Pituitury Body.-The mutual relations of the thyroid and suprarenals have already been discussed under the former organ. Those of the pituitary and suprareuals will be considered when the functions of the pituitary are dealt with.

A concise account (with bibliography) of the structure and functions of the suprarenals is to be found in Lucien and Parisot, Glandes surrénales et organes chromafinnes, 1913. 


\section{CHAPTER XI}

\section{THE PITUITARY BODY (HYPOPHYSIS CEREBRI)}

THE next of the endocrine glands to claim our attention is the pituitary body. The study of this organ has sprung into prominence within quite recent years. Although somewhat vaguely connected with growth phenomena, and shown (1887) to be related to certain forms of abnormal development of the body, and especially of the skeleton, it was not until 1895 that it was suspected of having an active function: by most it was regarded as a rudimentary structure having some morphological interest but little or no physiological importance. Now, on the contrary, it is known that from one part of the gland autacoid principles can be extracted which exert an active influence upon some of the most essential organs of the body; whilst from another part it seems probable that principles are furnished to the blood which serve as chemical regulators of nutrition and growth. Moreover, by most of those who have worked at its functions it is thought to be essential to life. Like most of the other special endocrine organs it is found, with very few exceptions, throughout the whole series of Vertebrata, and these exceptions may ultimately prove only apparent.

\section{Structure of the Pituitari}

The pituitary body is in man a small organ about the size of a hazelnut without the shell, weighing a little more than half a gramme. It lies at the base of the brain in the sella turcica of the sphenoid bone. It is connected with the floor of the third ventricle by a short, hollow, funnelshaped stalk-the infundibulum. This stalk is composed of nervous tissue, and expands in the interior of the gland into what is known as the nervous portion-pars nervosa-which when examined by appropriate methods is found to be mainly composed of neuroglia fibres and cells (Herring). In some animals the cavity of the infundibulum with its lining of ependyma is prolonged in the form of a blind canal far into the pars nervosa, but in man this canal has become obliterated, although it existed in the early embryo.

In front of and partly surrounding the pars nervosa the organ is formed of a mass of epithelium cells, granular in appearance. This constitutes the pars anterior seu glandularis. It is highly vascular. In the middle of the organ the pars anterior is separated from the pars nervosa by a cleft lined by columnar, cubical, or flattened epithelial cells and filled with glairy 
fluid. In the adult human subject the cleft is generally found to be obliterated or broken up into isolated cysts containing a colloid-like material. The cleft is all that remains of the original tubular structure of the pars glandularis, which in the early embryo was formed by a pouchlike outgrowth of the buccal ectoderm (Rathke's pouch) communicating at first with the cavity of the mouth, although ultimately the communication has become obliterated.

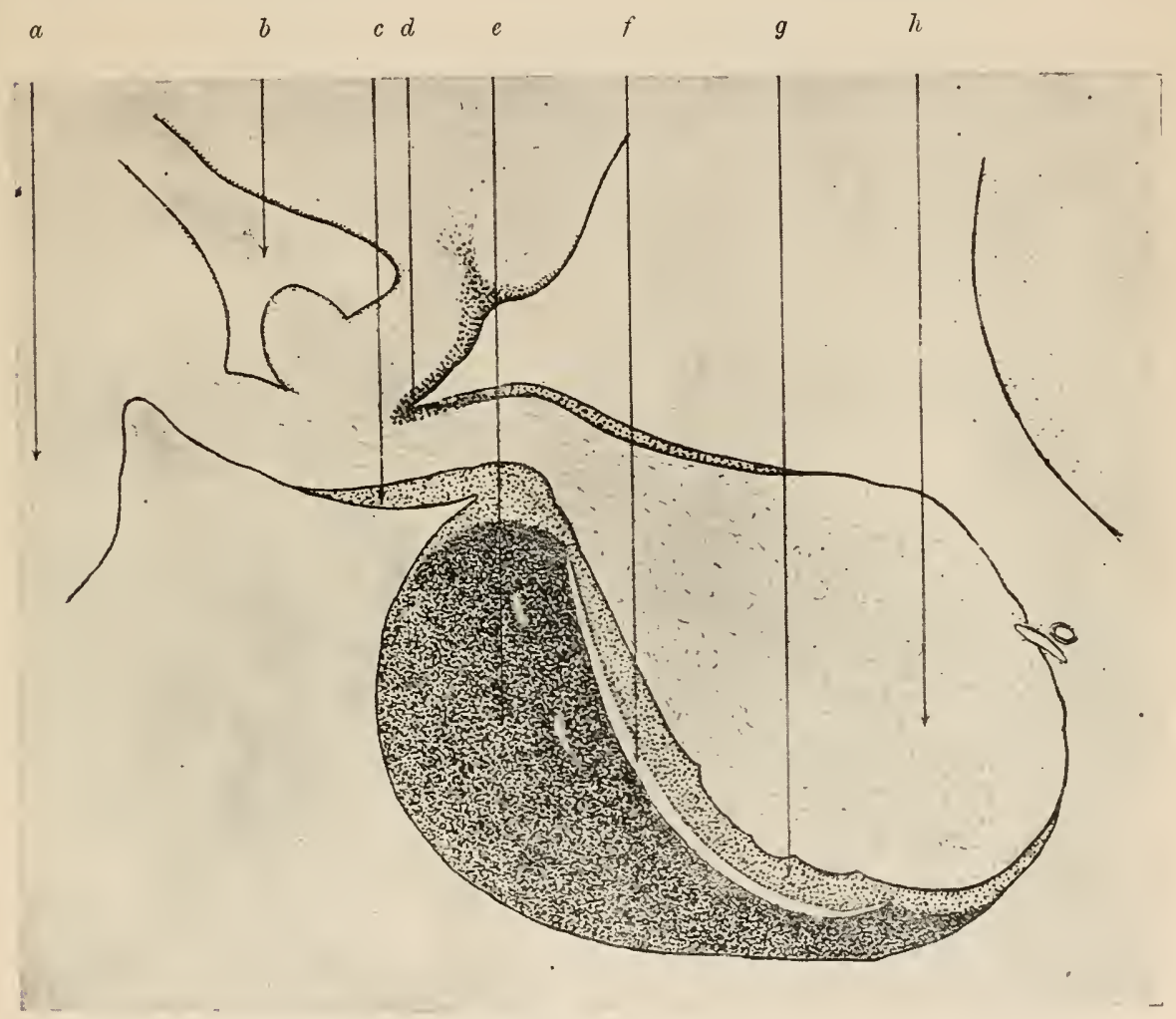

FIG. 45. - Mesial sagittal section through the pituitary body of an adult monkey (semidiagrammatic). (Herring.)

$\alpha$, optic ehiasma ; $b$, third ventricle (infundibulum); $c, d$, extension of pars intermedia round neck of pituitary $e$, pars anterior seu glandularis ; $f$, intraglandular cleft; $g$, pars intermedia; $h$, pars nervosa.

Traces of the original connexion with the buccal ectoderm may persist in exceptional cases even in the adult, as the so-called pharyngeal hypophysis. Another vestigial structure-the parahypophysis-has been described as occurring in the dura mater lining of the sella turcica, and other small accessory bodies similar in structure to the anterior lobe have also been described. It is possible that these may undergo hypertrophy after extirpation of the main gland and partly supply its function.

But the pars nervosa does not actually abut against the intra glandular 


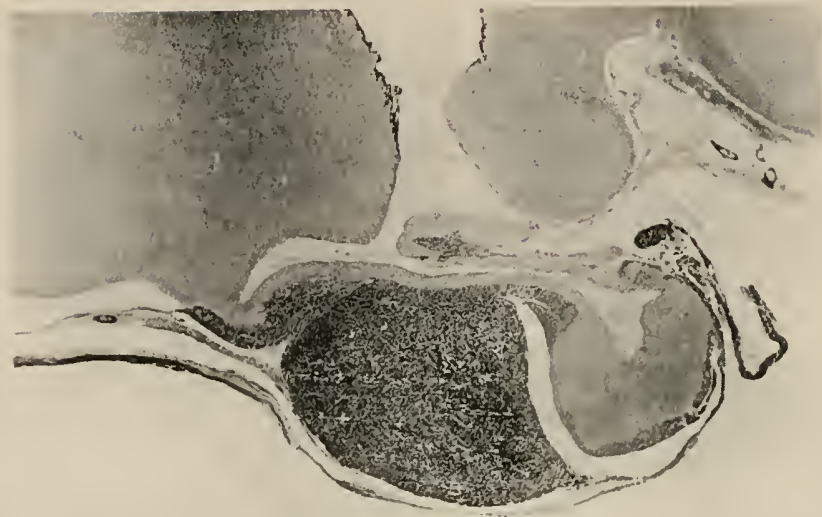

FIG. 46. - Mesial sagittal section through the pituitary body of an adult cat. Photograph. (Herring.) The intraglandular cleft is accidentally broken open in the section. Notice the extension in the cat of the infundibulum into the middle of the pars nervosa.

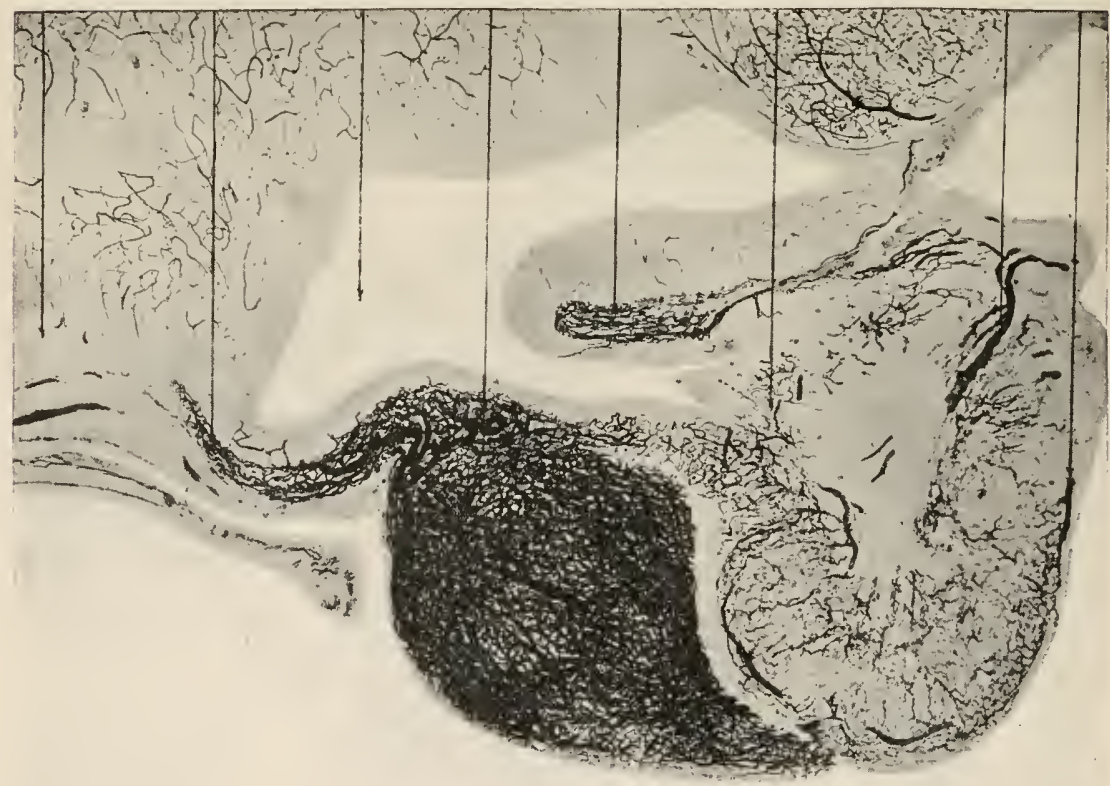

FIG. 47. - Sagittal section of pituitary of adult cat. Blood-vessels injected. Photograpl. (Herring.)

$a$, optic chiasma; $b$, tongue-like ar,terior process of pars intermedia ; $c$, third ventricle; $d$, pars anterior: $e$, extension of pars interniedia round neck of gland; $f$, points to pars intermedia; $g$, larger blood.vessels entering pars nervosa; $h$, posterior limit of gland. 
cleft. It is separated from it by a layer of epithelial tissue of varying thickness, which although also originally derived from the epithelium of Rathke's pouch, differs in certain respects from the par's anteriorits cells being less granular and its blood-vessels much less numerous. This portion of the gland is known as the pars intermedia since it lies between the pars anterior and the pars nervosa. From the former it is separated by the cleft just described: from the pars nervosa there is not always a well-defined line of separation-indeed cells of the pars inter-

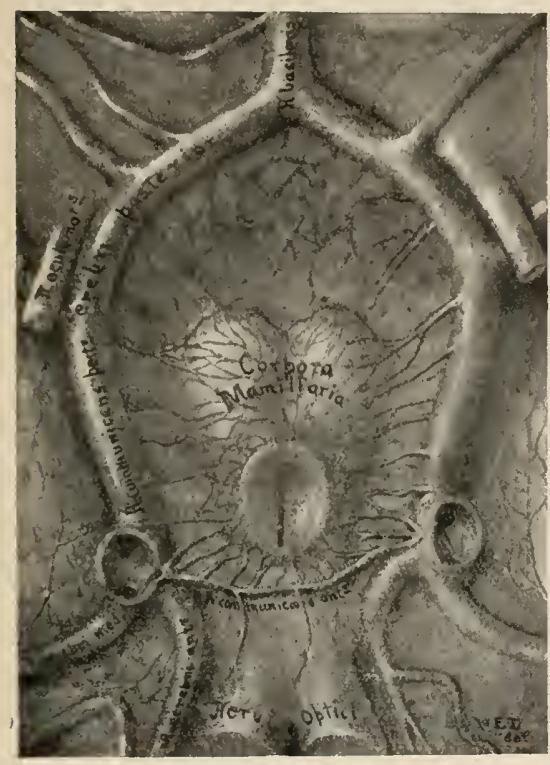

$\Lambda$

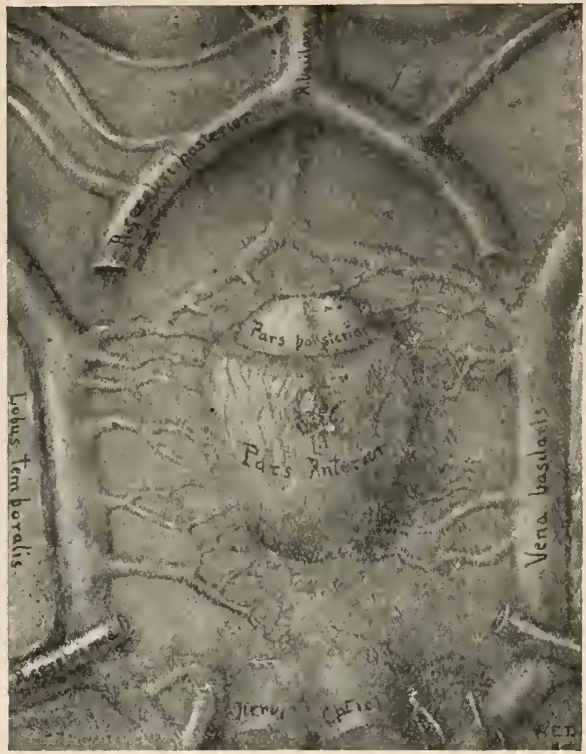

B

FIG. 48.-Blood-supply of the pituitary hody. (Dandy and Goetsch.) A. Arterial blood-supply, seen from the ventral aspect. A large number of small arteries are seen converging from the circle of Willis to the neck of the gland, which has itself been removed. B. Venous blood-supply. The principal veins are shown passing from the pituitary to a venous circle, which roughly corresponds with the arterial circle of Willis. Both figures show the parts somewhat magnified.

media may extend for some distance into the pars nervosa between its neuroglial fibres; they impart to it an important functional significance, which will be referred to later in considering the mode of secretion of the pars intermedia. It is not difficult to split the gland across the middle in the situation of the intraglandular cleft, thus separating the larger pars anterior from the combined pars nervosa and pars intermedia. When such a separation is effected the term posterior lobe has been given to pars nervosa plus pars intermedia, the pars anterior being termed in contradistinction anterior lobe.

Pars anterior seu glandularis.-As already mentioned, this is formed of trabecular masses of epithelium-like cells between which are very numerous sinus-like blood capillaries lying in intimate relation to the cells, 
which are indeed sometimes set closely round the blood-spaces. So abundant are the blood-vessels that a photograph of a section of this part of the injected organ appears almost black (fig. 47): the contrast with the pars intermedia and pars nervosa being marked. The pars anterior is supplied with blood by about eighteen to twenty small arterioles which converge towards the infundibulum from the circle of Willis and pass into it along the stalk (Dandy and Goetsch). They open into the sinus-like channels which in this part take the place of capillaries; the blood from
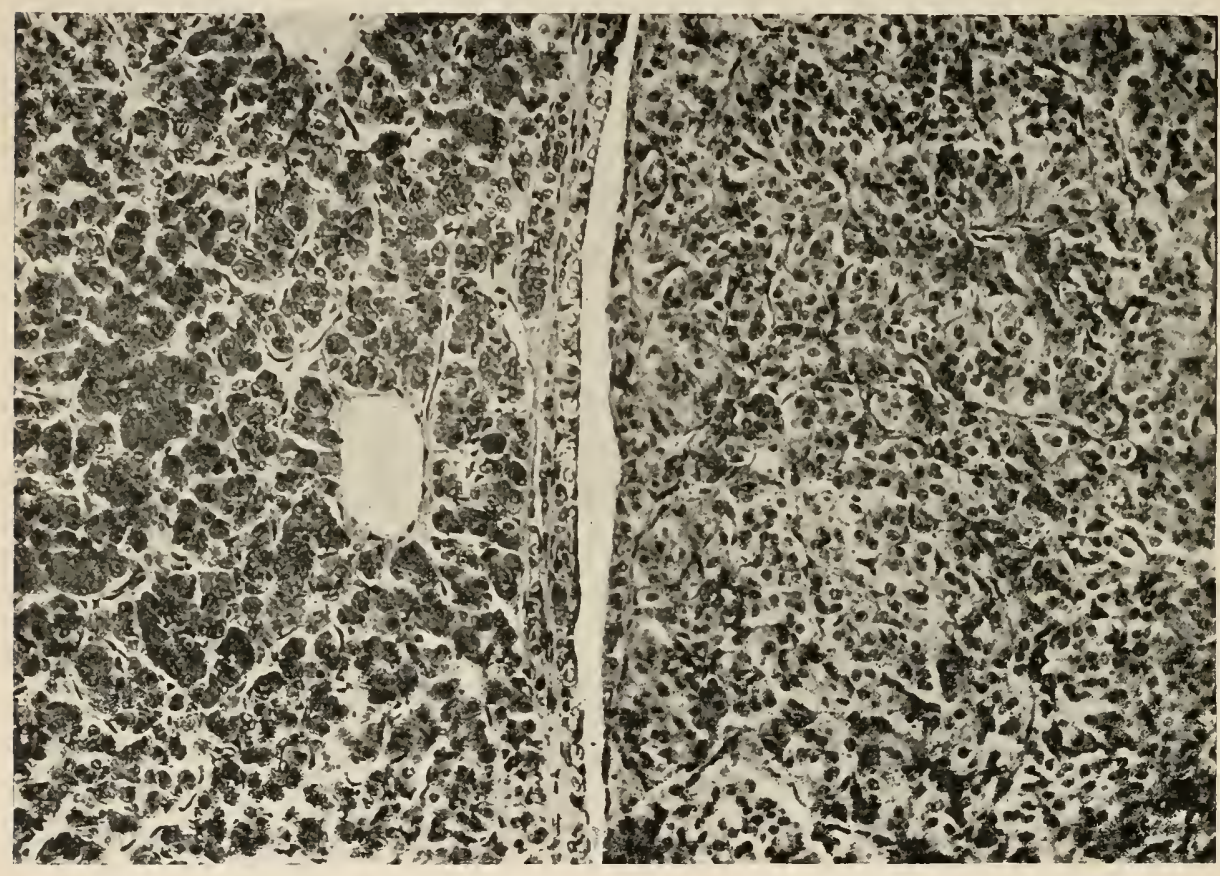

$\alpha$

$b$

$c$

FIG. 49. - Section of ox pituitary at intraglandular cleft (b), showing on left side $(a)$ a portion of the highly vascular pars anterior, and on right side (c) a portion of pars intermedia. Magnified 200 diameters.

these passes away by corresponding venules (fig. 48). The pars anterior of the pituitary constitutes one of the most vascular organs in the body.

The cells of the pars anterior appear as two varieties, viz., clear, nonstaining (chromaphobe), and granular, staining (chromaphil): and the granular cells are again divisible into oxyphil and basiphil, i.e. those staining with acid and basic dyes respectively, the oxyphil cells being normally by far the more numerous. It has been suggested that these three types of cells represent different stages of the same cell; this is probably only true for the chromaphobe cells and for the cells with oxyphil granules. The last-named cells are very distinct (figs. 49 and 50, $a$, and fig. 51). They may sometimes be seen placed around the blood-sinuses like 
the cells of an ordinary secreting gland around the lumen of the alveolus. In some animals all the cells of the pars anterior are set like a columnar epithelium round blood-sinuses-this is strikingly shown in Elasmobranch fishes such as the skate. In the tortoise columnar cells surround closed vesicles containing a colloid material. The basiphil cells are, when present, mostly found near the periphery of the trabecular masses. In pregnancy

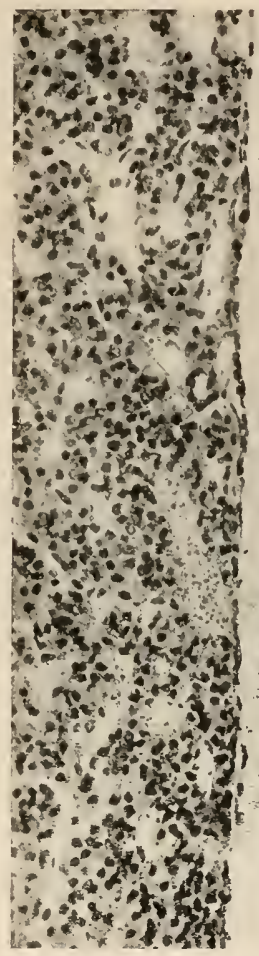

$a$

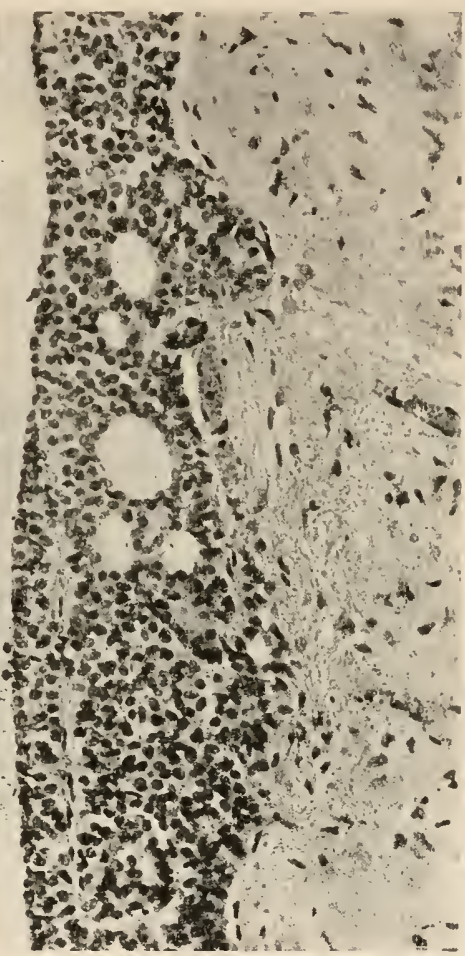

$d$

FIG. 50.- Section of pituitary of cat at intraglandular cleft $(b)$, showing on the left side $(a)$ the highly vascular par's anterior, and on the right side of the cleft the pars intermedia $(c)$, in which several vesicles are seen, and which abuts on the pars nervosa $(d)$. Magnified 200 diameters. (Figs. 50, $\mathbf{5 2}$, and $\mathbf{5 4}$ are from sections prepared for me by Dr M. Kojima.)

large, finely granular oxyphil cells are observed in unusual number (Erdheim and Stumm): these cells have been designated pregnancy cells. Oxyphil cells are also unusually abundant in the enlarged gland of acromegalic subjects, where they form adenoma-like masses. Most of the cells also contain numerous fine fatty globules.

There is a small amount of reticular connective tissue between the cells. A few nerves have been traced into the pars anterior from the pars nervosa.

Under certain circumstances in man and mammals, especially in cases of thyroid absence or insufficiency, a product of secretion of the anterior 
lobe cells which has the appearance of colloid appears to accumulate between the cells. These in some parts come to be arranged round the colloid in the form of vesicles which are not very unlike those of the thyroid gland. Even normally this appearance may be observed in the pars anterior (fig. 52), although it is more characteristically seen in the pars intermedia (figs. $50, c, 53,54$ ).

Pars intermediu.-As has been stated, the pars intermedia, although well provided with blood-vessels, is far less vascular than the pars anterior. At the circumference of the intraglandular cleft these two parts are continuous into one another without a sharp line of demarcation, although it is

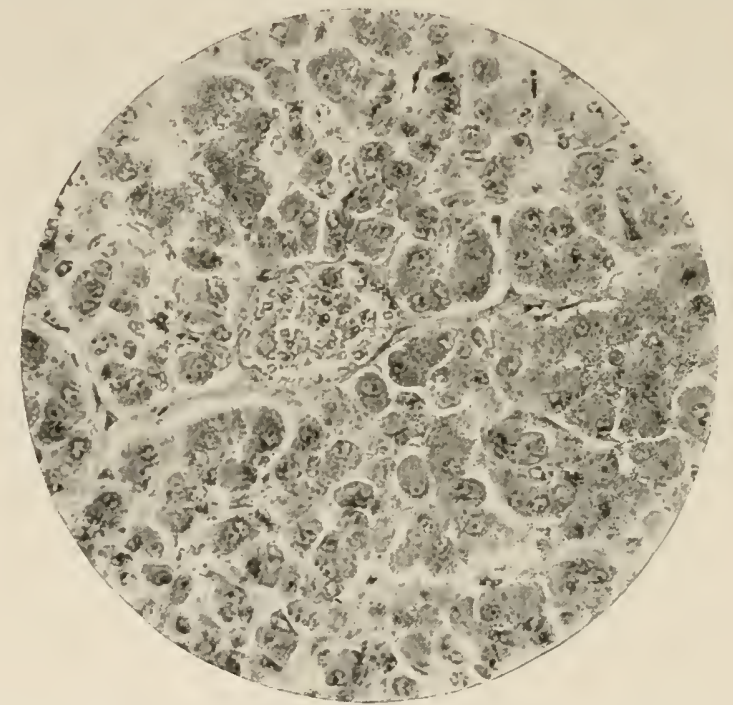

FIG. 51.-Portion of pars anterior of ox pituitary. Magnified 300 diameters. A large bloodvessel is seen near the middle of the field. Nearly all the cells are oxyphil.

possible to distinguish them by the character of their cells. Behind the intraglandular cleft the pars intermedia forms a well-marked layer of varying depth (figs. 49, 52); it also extends as a thin stratum over the surface $_{n}$ of the pars nervosa, as well as over the neck of the gland which connects the pars nervosa with the infundibulum. The cells of the pars intermedia have not the coarse oxyphil granules which are characteristic of the granular cells of the pars anterior, but they contain fine neutrophil granules staining neither with acid nor with basic dyes. They often surround well-defined vesicles occupied by an oxyphil colloid material: occasionally these vesicles are unusually large and numerous, especially in the neighbourhood of the intraglandular cleft (fig. 52). In addition to these colloid masses, some of the cells of the pars intermedia may often be seen in different stages of conversion into globular hyaline bodies, their protoplasm and nucleus becoming swollen: the latter may have become indistinct or have disappeared. Some of the globules thus produced are 
granular in character rather than hyaline. In both cases the cells ultimately break down, setting free the hyaline or granular substance.

As has already been mentioned, the pars intermedia is by no means everywhere sharply marked off from the pars nervosa, for strands of the cells of the pars intermedia may extend a variable distance between the fibres of the pars nervosa. The hyaline and granular globules which have been derived from its cells also pass into the substance of the pars nervosa and

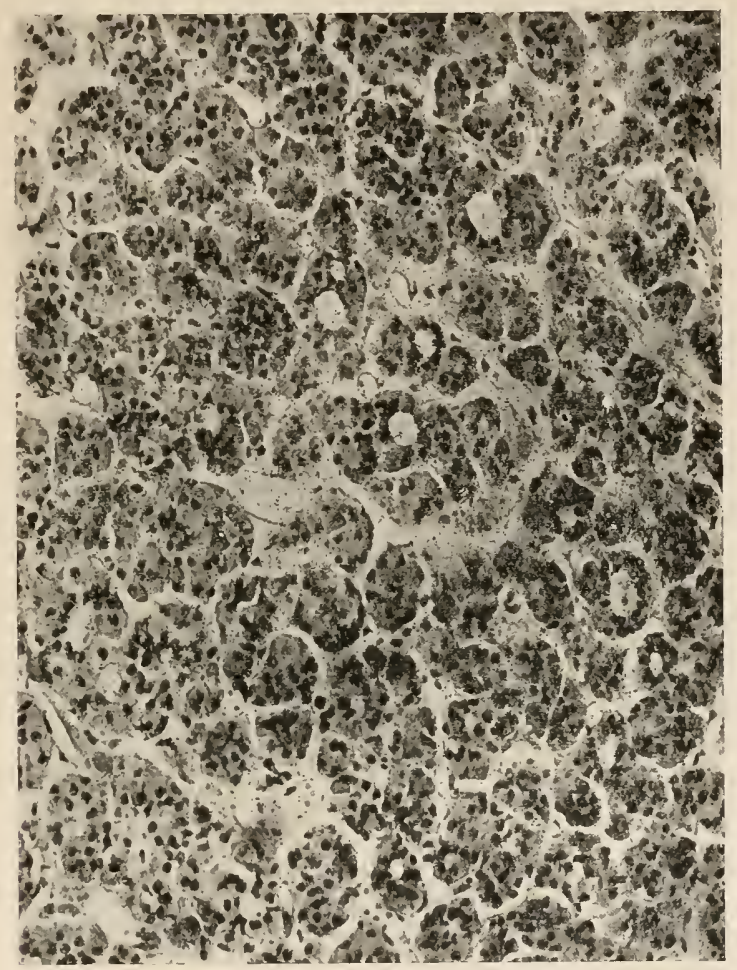

FIG, 52.-Portion of pars anterior of cat's pituitary, showing the groups of oxyphil cells with vascular spaces between the groups. Several vesicles, surrounded by cells, are included in the section. Magnified 400 diameters.

are seen between its fibres: they can, in fact, be traced as far as the continuation of the third ventricle into the stalk. This fact was pointed out by Herring, who concluded that the hyaline and granular substances which are produced by conversion and breaking down of the cells of the pars intermedia form the secretion of this portion of the pituitary, and that this secretion passes into the cerebro-spinal fluid. In confirmation of Herring's conclusion, evidence that the active principle of the posterior lobe of the pituitary is present in cerebro-spinal fluid has been obtained by Cushing and Goetsch, although their results have been traversed by Carlson. It has, however, been shown by Cow that intravenous administration of 
duodenal extract indubitably causes the appearance of the pituitary

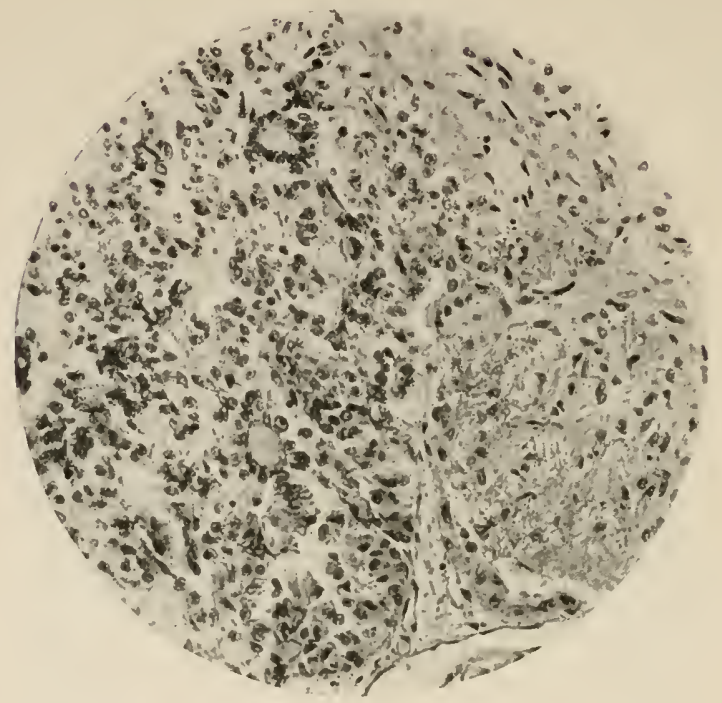

FIG. 53. - Section of pars intermedia of ox pituitary where it abuts on pars nervosa.

Two colloid resicles are seen amongst the cells. Magnified 200 diameters.

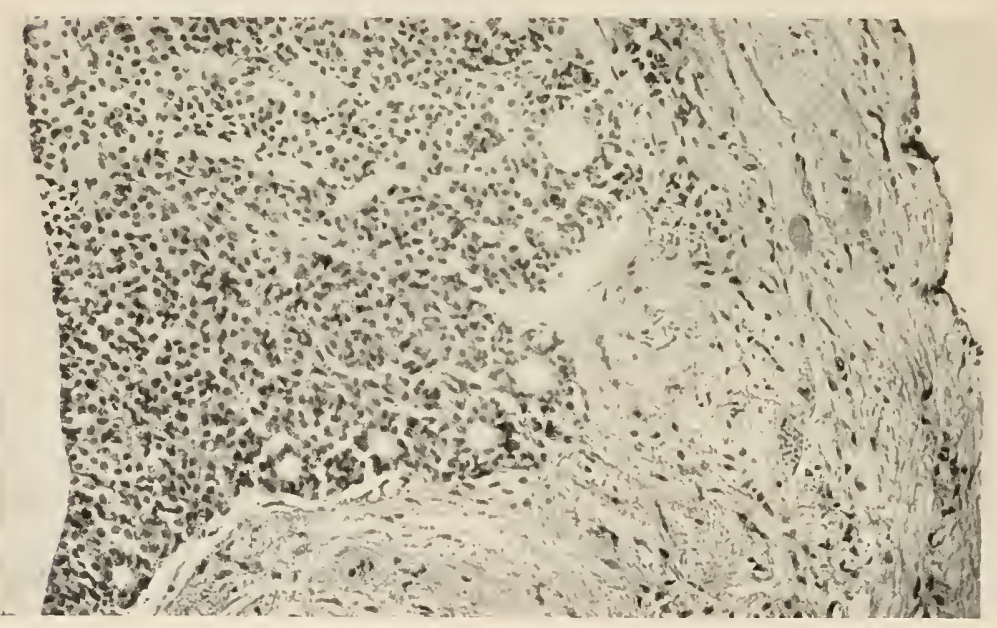

FIG. 54. - Section of cat's pituitary, showing on the left a thickened portion of pars intermedia, with several vesicles amongst its cells, and on the right pars nervosa with two hyaline masses amongst its fibres. The sharp edge of the pars intermedia on the left forms part of the boundary of the intraglandular cleft; the free edge on the right of the pars nervosa is part of the boundary of the extension of the third ventricle into the gland.

autacoids in the cerebro-spinal fluid; a fact which makes it evident that they must normally be passed to some degree into that fluid. The hyaline 
globules are greatly increased as the result of thyroidectomy (Herring). Cushing states that this increase also results from extirpating the pancreas, and that it occurs as the result of section of the infundibular stalk.

Pars nervosa (also known as the neuro-hypophysis or infunctibular body). - This is formed almost entirely of neuroglia fibres with neuroglia cells scattered amongst them. Many of the fibres arise from these cells, others from the ependyma cells of the infundibulum and of its extension into the gland. Between the neuroglia fibres, especially in the neighbour-

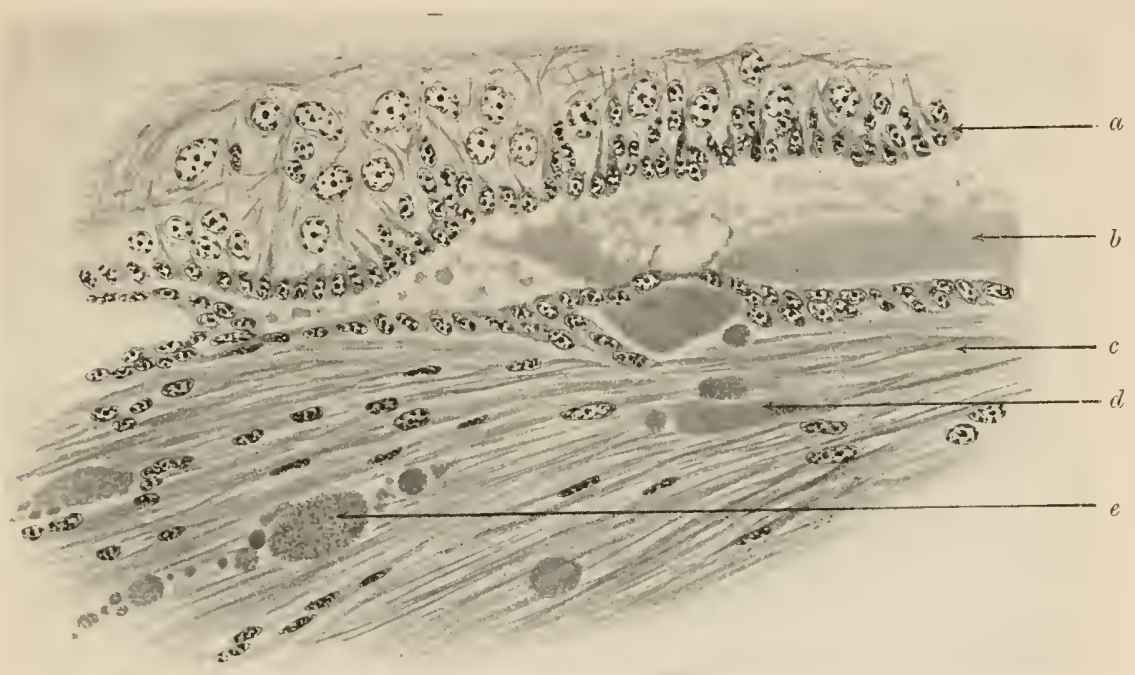

FIG. 55. - Section of posterior lobe of pituitary of cat, including a portion of the central cavity which is continuous with the infundibulum of the third ventricle. (Herring.)

$a$, ependyma of central cavity; $b$, colloid or hyaline matter in central eavity: some of it is seen passing through the ependyma of the pars nervosa ; $c$, ependyma fibres; $d$, hyaline masses; $e$, a granular mass in pars nervosa.

hood of the stalk, but also in other situations, is to be seen the hyaline and granular matter already referred to; sometimes in the form of swollen cells such as have been described in connexion with the pars intermedia, sometimes as amorphous masses; these masses are traceable, as already mentioned, to the infundibulum, where they may be seen passing through the ependyma into the cavity of the ventricle (fig. 55). There can be little doubt that the physiological activity of extracts of the pars nervosa is connected with the presence of this substance within it, since extracts of ordinary nervous and neuroglial substance have not the same action. Some authors have described nerve-cells within the pars nervosa-but according to Herring these do not occur, and there are very few nerve-fibres. The pars nervosa is the least vascular portion of the pituitary, its blood-vessels being comparatively few in number. 


\section{CHAPTER XII}

\section{THE PITUITARY BODY (continued)}

\section{The Active Principle or Principles of the Pituitary}

VARIOUs attempts have been made to isolate the active principles of this organ, and more than one investigator has succeeded in obtaining from extracts of the posterior lobe a crystallisable material which produces the stimulation of plain muscle characteristic of such extracts. Clear, proteinfree, sterilised solutions containing the active principles are met with in commerce under the names pituitrin, hypophysin, etc., but it is not claimed that these represent pure chemical substances. There is reason to believe that, unlike the suprarenal medulla, the posterior lobe of the pituitary body yields more than one active autacoid (see p. 96). On the other hand, no active principle has been extracted from the pars anterior. This, however, does not negative the idea to which we are led by the evidence of many experimental and clinical observations, that the pars anterior forms a substance or substances which pass into the blood and exercise important effects on metabolic processes in various organs.

\section{Effects of Extracts of the Posterior Lobe}

Effects on Plain Muscle.-The announcement in 1895 that extracts of pituitary, as well as those of suprarenal, have a remarkable influence upon the vascular system, producing a great rise of blood-pressure with contraction of vessels and increase in force of the heart-beats (fig. 56), led to the attention of physiologists being drawn to this gland, which had until then been neglected by them. Howell (1898) found that the action is confined to extracts of the posterior lobe-which, as we now know, includes pars intermedia and pars nervosa--and it has since been shown that it is yielded by extracts of either pars intermedia or pars nervosa alone, but rather more distinctly by the pars nervosa than by the pars intermedia (Herring). The effect of the extract upon the blood-vessels is a direct one, and is not due, as in the case of the suprarenal hormone, to its stimulant action on sympathetic endings. The effect on the heart was also shown by Howell to be different from that of adrenalin; for whereas-with the vagi cut or paralysed-adrenalin causes a marked acceleration of the heart (sympathetic stimulation), the pituitary autacoid causes slowing with increase in force of the individual beats. In the bird it augments both auricular and ventricular contractions, whereas adrenalin affects the auricles only 
Effects of Extracts of Posterior Lobe of Pituitary

(Noël Paton and Watson). Moreover, while adrenalin either produces no action on the coronary vessels or, in some cases, causes them to dilate,

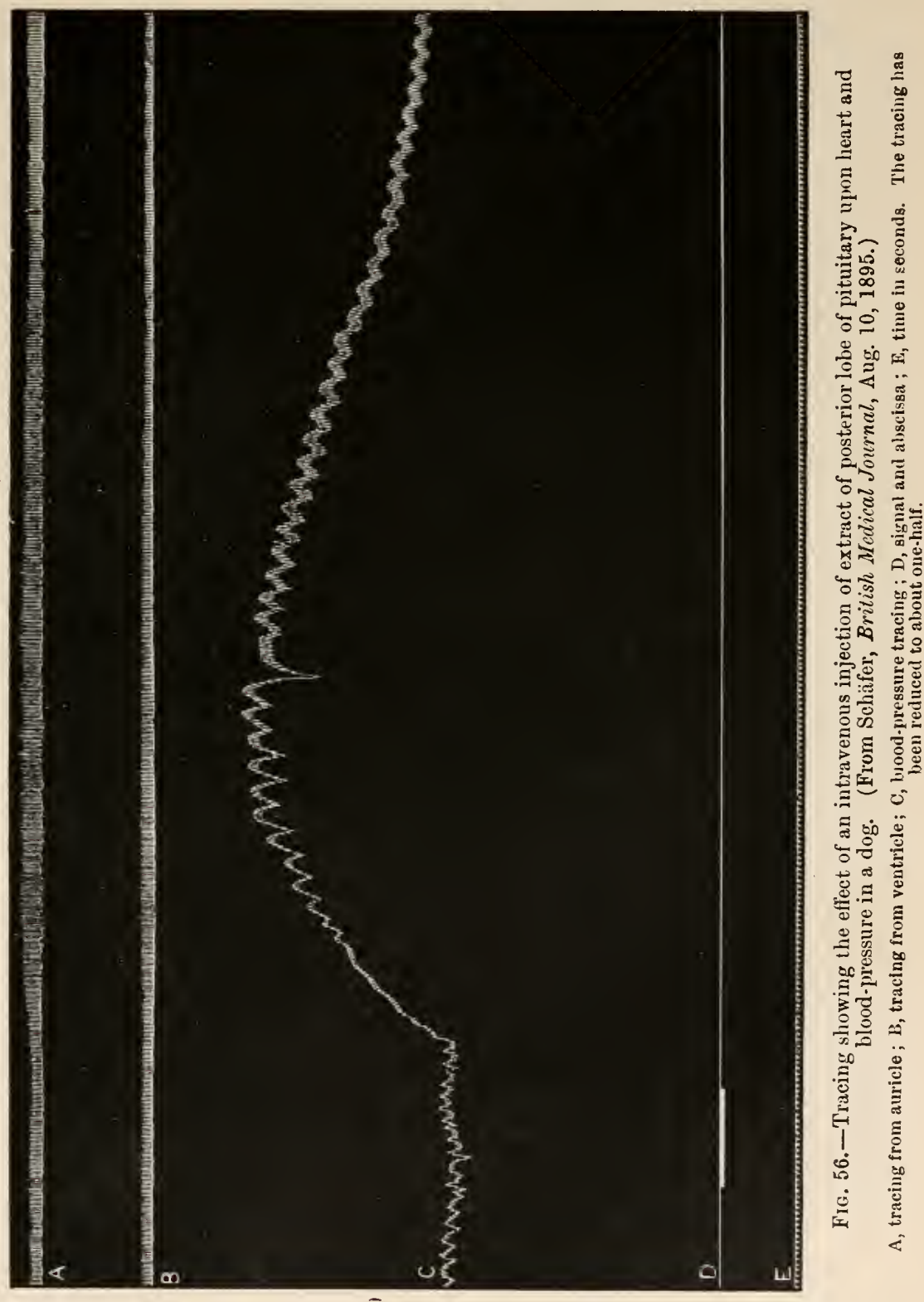

the autacoid of the pituitary constricts them as it does most other systemic arterioles; this is true also for the pulmonary ressels. The pressor hormone also has the peculiarity that the effect of a second dose administered a short interval (thirty minutes or less) after the first usually causes 
no effect (tachyphylaxis ${ }^{1}$ ); or, if any, not a rise but a fall of blood-pressure which may or may not be followed by a slight rise (fig. 57). Frequently
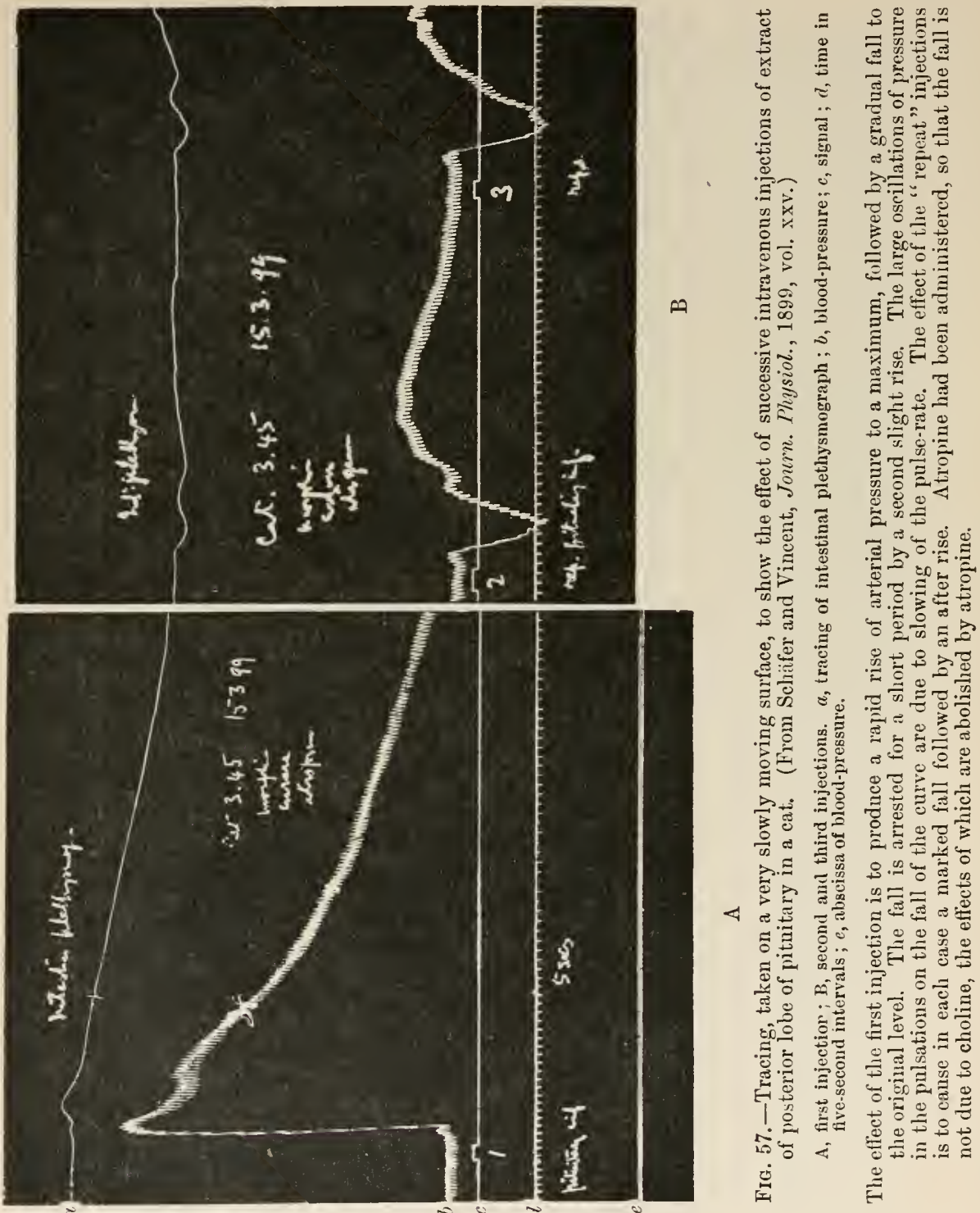

a preliminary fall precedes the rise produced by the first dose. Probably, therefore, there is present in the extract a second autacoid which is antagonistic to the first and should be classed with the chalones or inhibitory autacoids. The substance which causes the fall of blood-pressure is not choline, although the curve obtained resembles that caused by 
choline, for it is not affected by atropine. In birds only dilatation of vessels is produced, and this is antagonised by atropine (Noël Paton and Watson).

On the heart's action the repeat dose has the same effect as the first dose, i.e. the beat is strengthened (Biedl). The effect on the uterus (see below) is also repeated if administration of the autacoid is repeated. The pressor effect and the effect on the heart produced by the stimulating (hormonic) autacoid usually lasts a considerable time (a quarter to half an

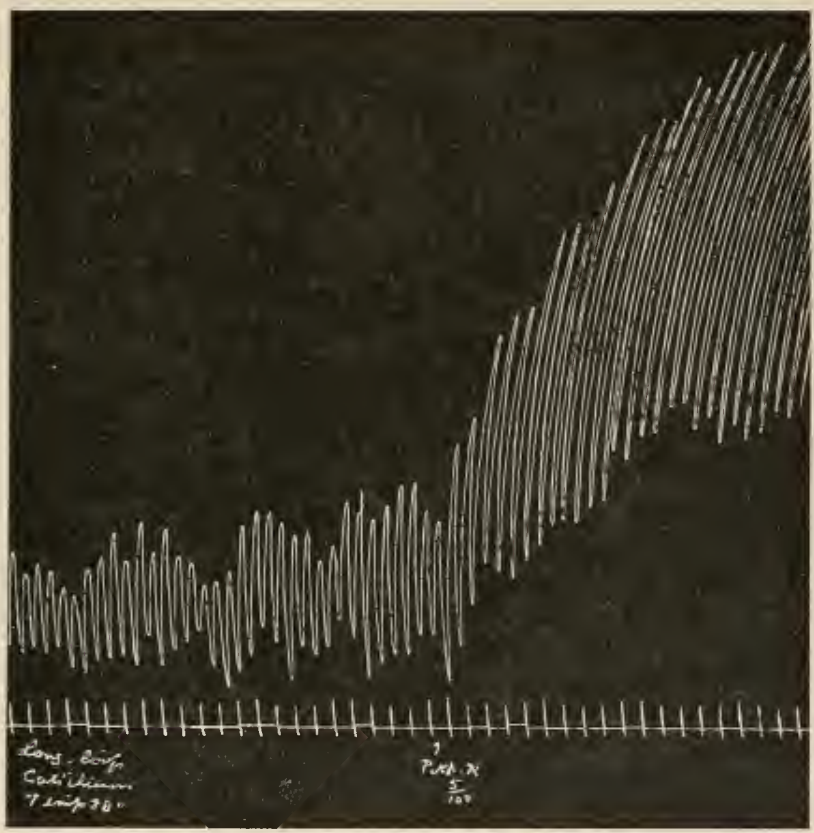

Fig. 58. - Tracing to show the effect of the addition of extract of posterior lobe of pituitary body to Ringer's solution in which a longitudinal strip of intestinal muscle was suspended. (A. W. Young.) Notice both the increase in force of the individual contractions and the increase in tone of the muscle.

hour or more), varying, however, with the dose; the depressor effect of the chalonic autacoid has a much shorter period of activity.

The extract of pituitary acts upon other plain muscular tissue besides that of the blood-vessels. Thus it powerfully affects the bladder and intestine (fig. 58) (Blair Bell and Hick), the stomach (Houssay), ${ }^{1}$ the uterus (fig. 59) (Dale), ${ }^{2}$ even in minute doses; it also produces dilatation of the pupil

1 Houssay states that the secretion of gastric juice is at the same time increased ; this is perhaps the result of setting up contractions in the muscularis mucosæ.

2 The uterus is also rendered more excitable to influences reaching it through its nerves. Accorling to Dale, pituitary extract acts on plain nusscle more by increasing its sensitiveness to normal stimuli than by acting as a direct excitant. Thus when administered in pregnancy before the commencement of parturition it produces no effect; whereas its action during parturition is well established. Engeland and Kutscher claim to have isolated an autacoid which affects the uterus only. 
of the excised eye of the frog (W. Cramer). In some of these actions it resembles adrenalin, but the stimulating autacoid of the pituitary is certainly different both chemically and in its physiological reactions from that of the suprarenal. For it does not specifically stimulate structures innervated by the sympathetic as does adrenalin; moreover, neither apocodeine nor ergotoxine affect the results obtained with it. Probably it acts as a direct stimulus upon the contractile substance of the cells which it influences.

Effects on Kidney.-The renal arteries form an exception to the constrictor effect produced by pituitary extract, since they dilate as a consequence of the addition of the extract to the circulating blood (fig. 60): the dilatation is correlated with an increase of secretion of urine (figs. 60 ,

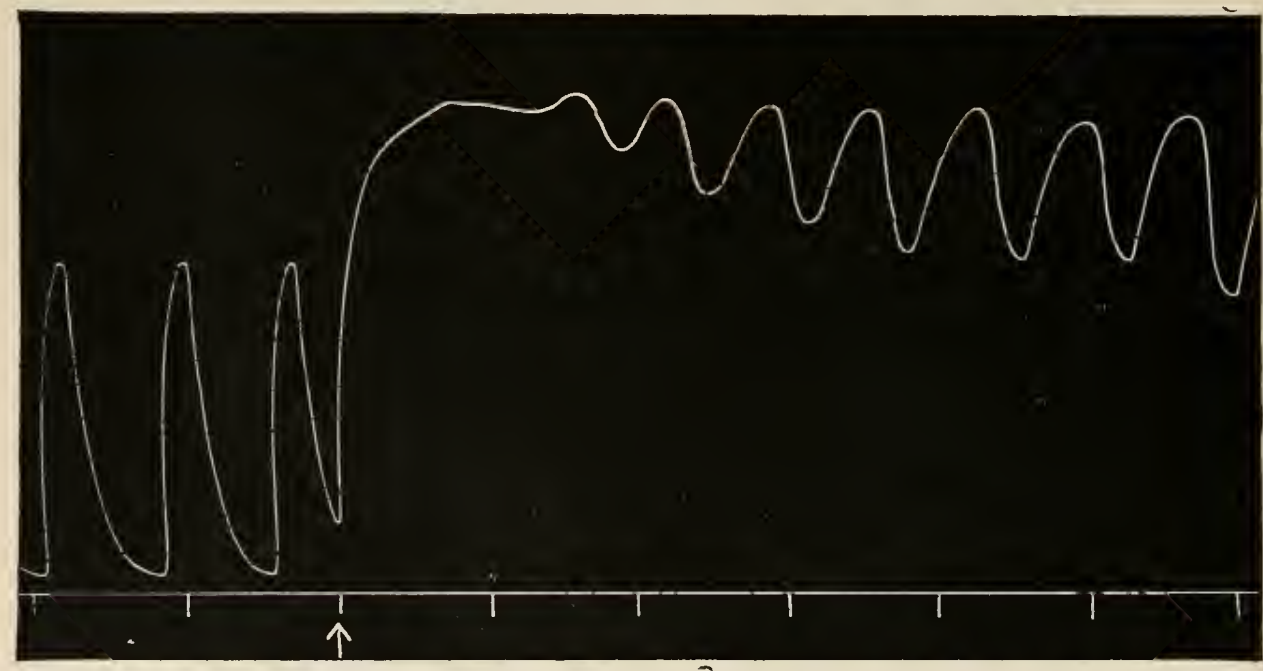

FIG. 59. - Tracing showing the action on an isolated cornu of rat's uterus suspended in Locke's solution, of the addition of extract of posterior lobe of ox pituitary to the solution. (M. Itagaki,)

$61,62)$ : it is often preceded by a slight contraction, and the increase of urine by a temporary diminution. The increased secretion may be in part brought about by the increased flow of blood through the kidney vessels, due to the circumstance that they undergo dilatation, while all the other systemic arteries are contracting; but that it is to a certain extent caused by a specific effect of one of the pituitary autacoids is probable from the fact that it may occur in the absence of any obvious arterial change.

Moreover, an increased rate of flow is maintained after the blood-pressure has come back to the level at which it stood before the injection. And the effect of a second and subsequent doses of the autacoid administered soon after the main result of the first dose has passed off is again to produce an increase in the urine flow (fig. 62), although the blood-pressure as the result of these after-doses does not rise, or falls instead of rising, and although the kidney volume may now be unaffected. This experiment clearly 
demonstrates that the autacoid affects not only the blood-vessels of the organ, but also its secreting cells, which it renders more active (or more

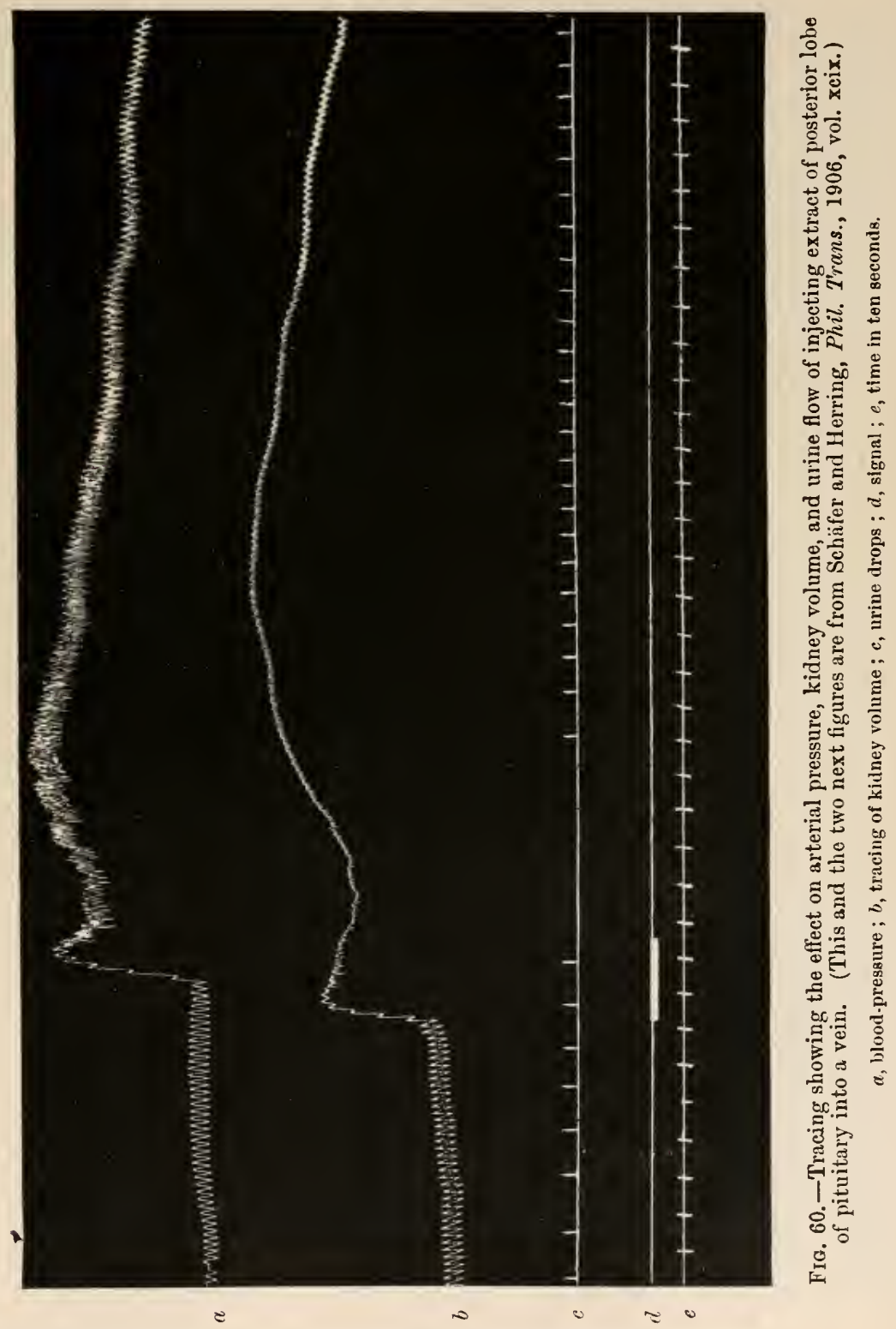

permeable). The secretion must therefore in these circumstances be induced by a direct chemical excitation of the renal cells by the autacoid, which thus bears the same relation to the kidneys as is borne by the secretine of the duodenum to the pancreas. In this respect also the action of the auta- 
coid of the pituitary is comparable to that of those drugs which act as specific diuretics upon the secreting cells of the kidney, as distinguished

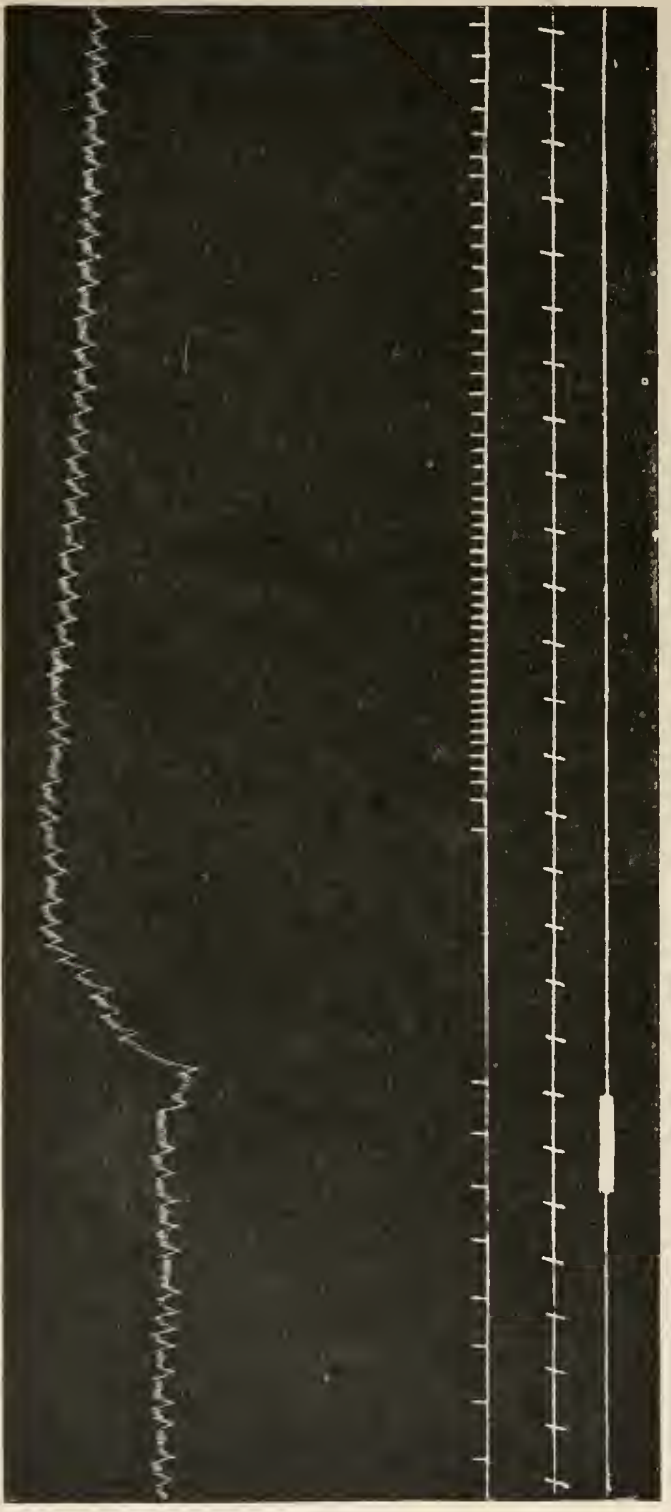

8

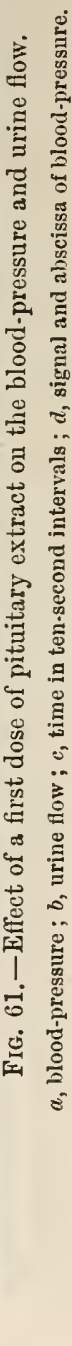

from those which produce diuresis by increasing the water content of the blood or by merely increasing the general blood-pressure.

The diuretic action of the pituitary autacoid is not antagonised by atropine. This may be taken as a sign that it does not act through nerves or nerve-endings, but directly upon the kidney cells; in this respect also it resembles the action of secretine upon the pancreas.

Effect on Secretion of Cerebro-spinal Fluid.It has been shown by Weed and Cushing that extracts of posterior lobe also contain an autacoid which stimulates the flow of cerebro-spinal fluid (fig. 63). This is not dependent on increase of blood-pressure, for it may be accompanied by a fall instead of a rise of pressure, and by an increase in depth of the respirations: the increased flow of cerebrospinal fluid seems to be independent of these circumstances.

Effect on Mill Secre-

tion.-It was found by Ott and Scott that in the goat an injection of pituitary extract into a vein greatly increases the quantity of milk which can be drawn from the udder in a given time after the injection, as compared with that which could be obtained in a similar period immediately 
before. This galactagogue action of pituitary extract was confirmed in lactating cats by Mackenzie and myself. The method we employed consisted in canalising or incising the nipple of one or two of the mammæ so as to allow any milk which was secreted to run out. The milk was conducted to the side and registered by allowing it to fall upon an electrical drop recorder. This modus operandi permits the conditions of the experiment to be controlled and the results accurately recorded. It can in this way be shown that even a very minute dose of the pituitary autacoid -whether the same hormone as that which affects the muscular tissue of the blood-vessels and viscera, cannot certainly be saidwill cause milk which has accumulated in the gland to be immediately poured out (fig. 64), whilst a somewhat larger dose will produce complete emptying of the alveoli. If the nipple is not canalised or incised, the resistance which is afforded in the passage through its ducts, controlled as they are by the plain muscle tissue which abounds in the nipple, does not permit of this emptying, and no actual outpouring of the

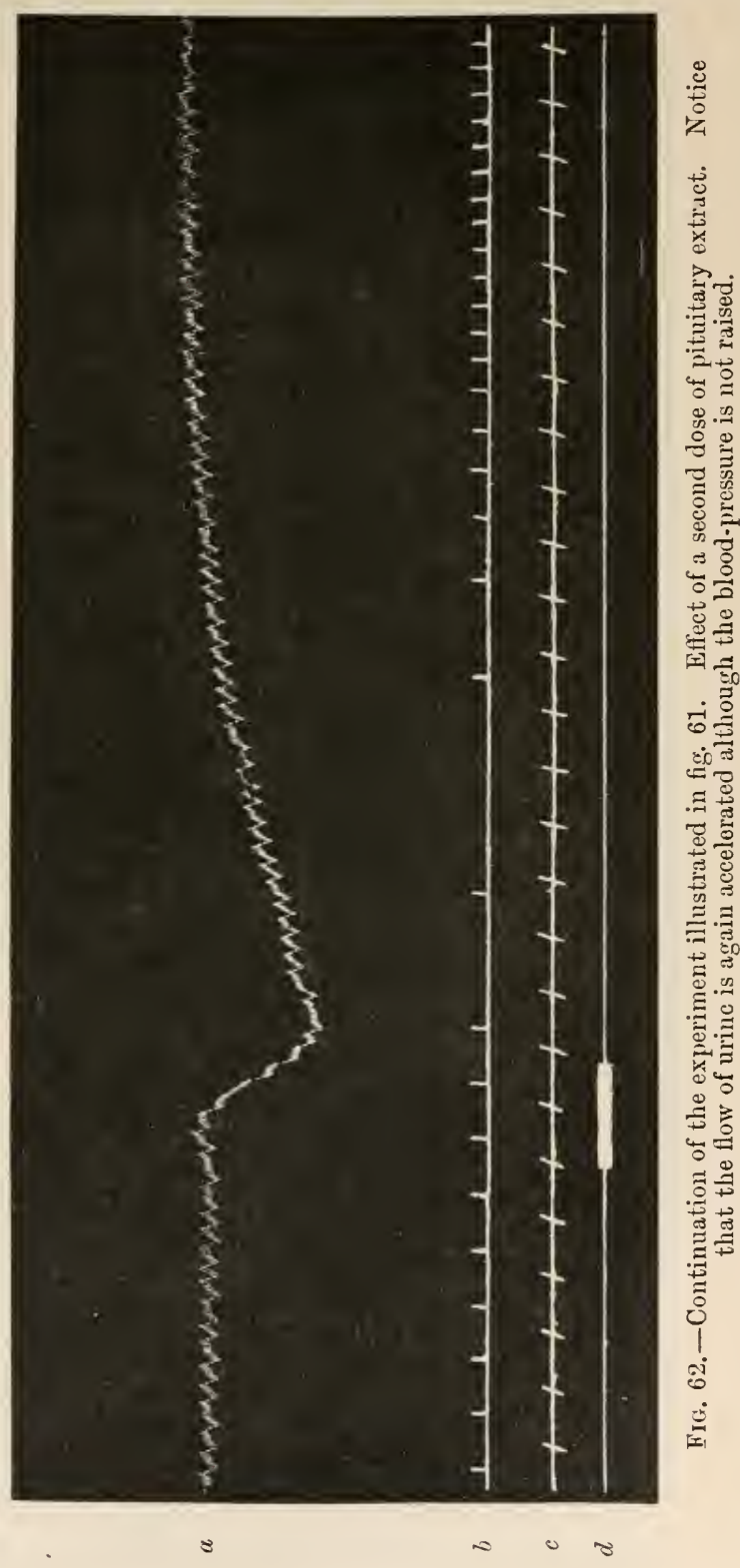
secretion takes place. If an intramuscular injection of pituitary extract is made in the arm of a nursing woman, a feeling of tingling is felt in the mamma and a sensation of milk flowing towards the nipple is experienced like that which occurs when the child is put 


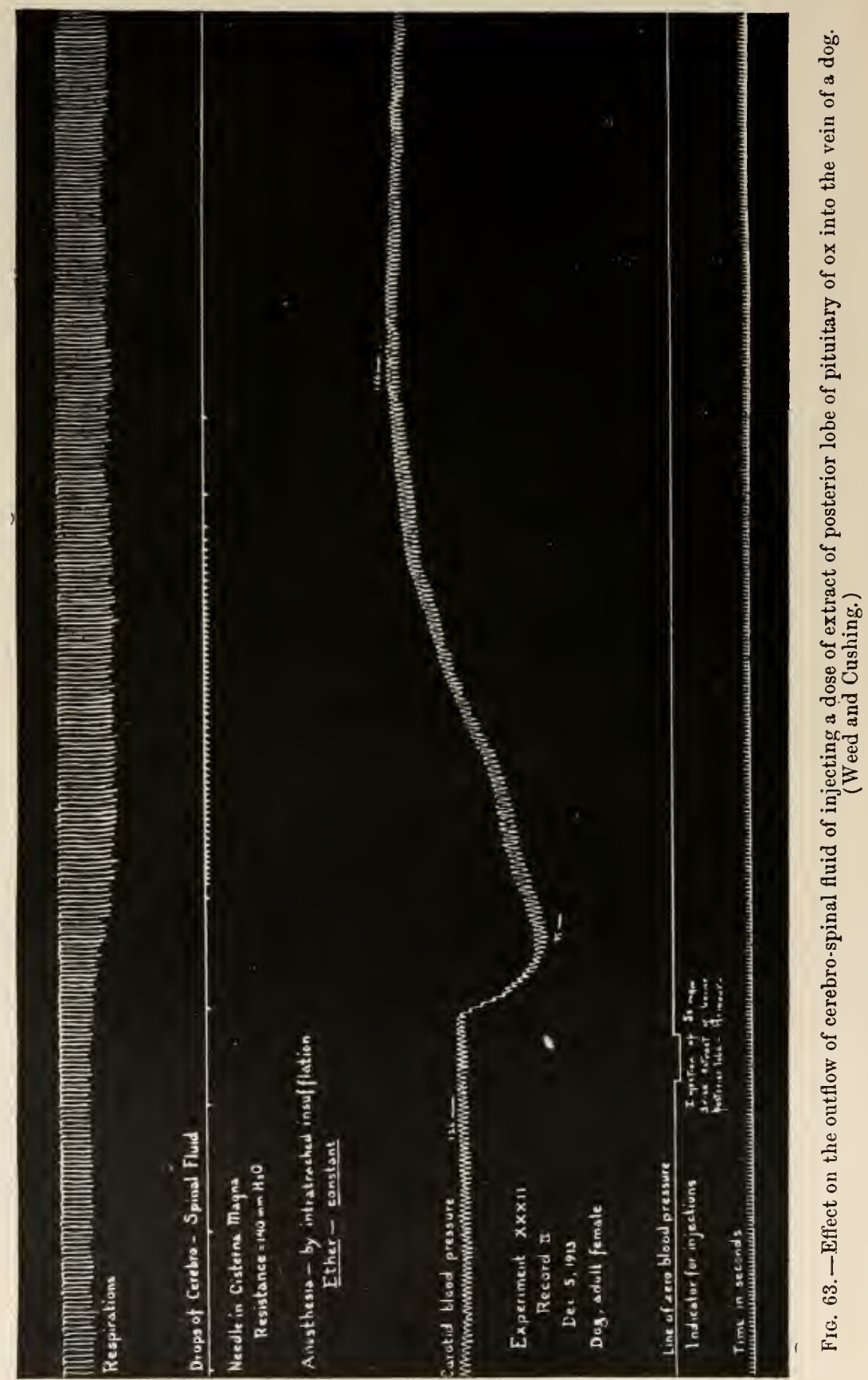


to the breast, although there may be no actual outpouring of the secretion.

If in the experiment upon the cat the animal is killed immediately after one of its glands (with nipple incised) has been emptied by an intravenous injection of extract of posterior lobe in the manner above described, and if a portion of tissue comprising parts of two adjacent mammæ-one emptied

$a$
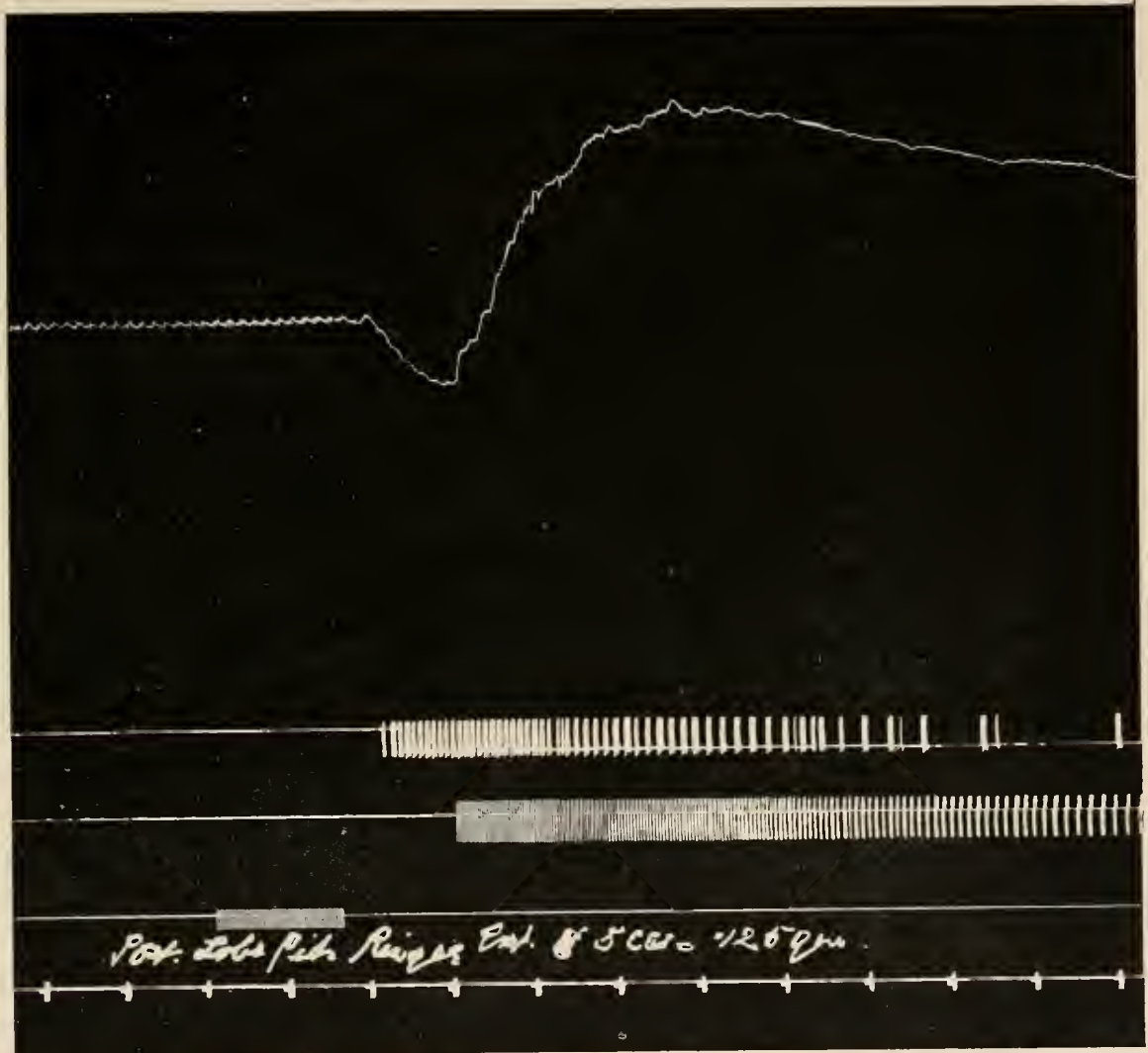

Fig. 64.-Effect on blood-pressure and mammary gland of a lactating cat of injecting extract of $0.125 \mathrm{~g}$. of posterior lobe of pituitary. (From K. Mlackenzie, Quart. Journ. Exper. Physiol., 1911, vol. iv.)

$a$, tracing of blood-pressure: notice that the main rise is preceded by a preliminary fall; $b$, drops of milk exuding from a fine cauula introduced into one of the lactiferous ducts; $c$, drops of milk exuding from incised gland; $d$, signal ; $e$, time in ten seconds.

of its secretion as the result of the injection, the other with its alveoli still full of milk-is fixed and sections are made passing through both full and empty mammæ, the contrast in appearance is remarkable (fig. 65). In the one, where the alveoli are distended with secretion, they are large and rounded and the lining cells are flattened against the limiting membrane, whilst in the other, from which the secretion has been discharged, the alveoli are irregular, shrunk, and empty, their walls are folded, and the lining cells stand prominently out from the limiting membrane. 
If after a first full dose of pituitary extract has been given, a second dose succeed it at a short interval, no further flow of secretion from the exhausted mamma can be produced. ${ }^{3}$ The effect of the autacoid, therefore, is not-at any rate immediately-to cause the cells to form and secrete milk, but only to cause the alveoli to empty themselves of the milk which has been previously formed and secreted within them. The simplest manner in which one can conceive this to occur is by contraction of (plain) muscular tissue around the alveoli. In support of this conception, I have

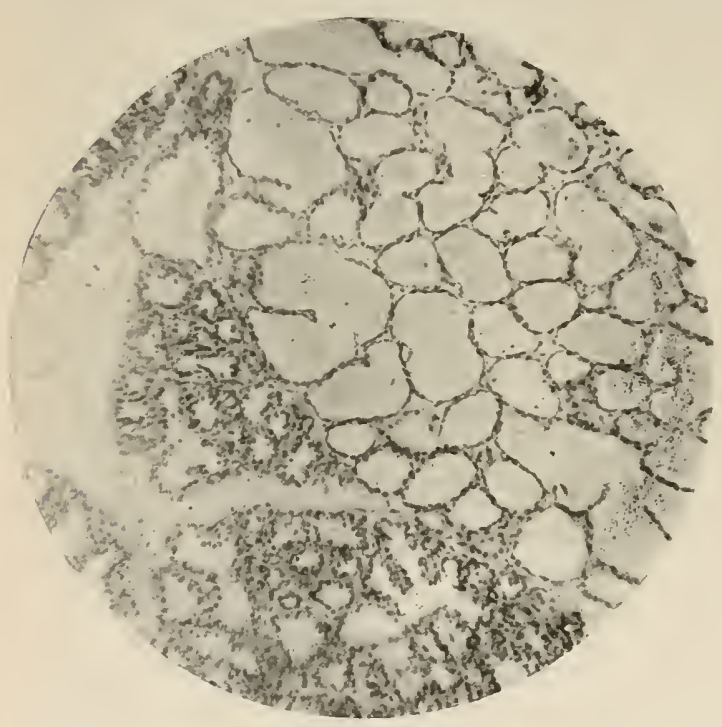

Fig. 65.-Section including the adjacent parts of two mammary glands of a lactating cat. One of them had discharged the whole of its milk as the result of an intravenous injection of pituitary extract, the nipple having been excised to allow the milk to flow out freely. In the other the alveoli are distended with milk. Low power. succeeded in detecting in the walls of the mammary alveoli long, rod-shaped nuclei immediately external to the epithelium. These nuclei exactly resemble those of involuntary muscle-cells, and probably belong to a thin muscular layer which is situated, like the muscular tissue of the sweat glands, between the basement membrane and the epithelium of the alveoli. The action of pituitary extract upon milk secretion differs therefore from its effect upon the secretion of urine in the fact that in the last-named case there is an actual stimulation of the renal cells to abstract fluid from the blood, whilst in the mammary gland there occurs merely a contraction of the walls of the alveoli and discharge of fluid previously secreted.

Apart from the pouring out of the contents of the alveoli-which, when the gland is intact, shows itself as a tendency of the alveoli to empty themselves towards the nipple,- - the pituitary galactagogue has little or no effect on the total production of milk. This at least is the result which was obtained in the goat by Findlay, and in cows by Gavin. Later observers (Hammond, Sutherland Simpson) have obtained a slight increase in the diurnal yield of both goats and cows; and also a slightly increased amount of fat in the milk produced under the influence of the autacoid.

Mackenzie found (in the cat) that atropine does not arrest the flow of milk obtained as the result of pituitary injection (an observation which has

1 This is not an instance of tachyphylaxis, but is due to the fact that there is now no milk left in the alveoli. 
been confirmed for the cow by Houssay). He obtained, however, an inhibitory action from extract of placenta, which, when injected into a vein just previously to the injection of pituitary extract, prevents the effect of the latter from influencing the mammary gland. It is reasonable to conclude from this that placenta extract contains a chalonic autacoid which restrains the outpouring of the secretion of the mamma and antagonises the hormonic action of the pituitary autacoid.

Galactagogue autacoids are also contained in extracts of other organs than the pituitary, viz., the corpus luteum of the ovary, the involuting mucous membrane of the uterus after parturition, the lactating mammary gland itself, and to a slight extent the pineal gland. Their effect on the mamma is exactly like that of the pituitary galactagogue, but the effects
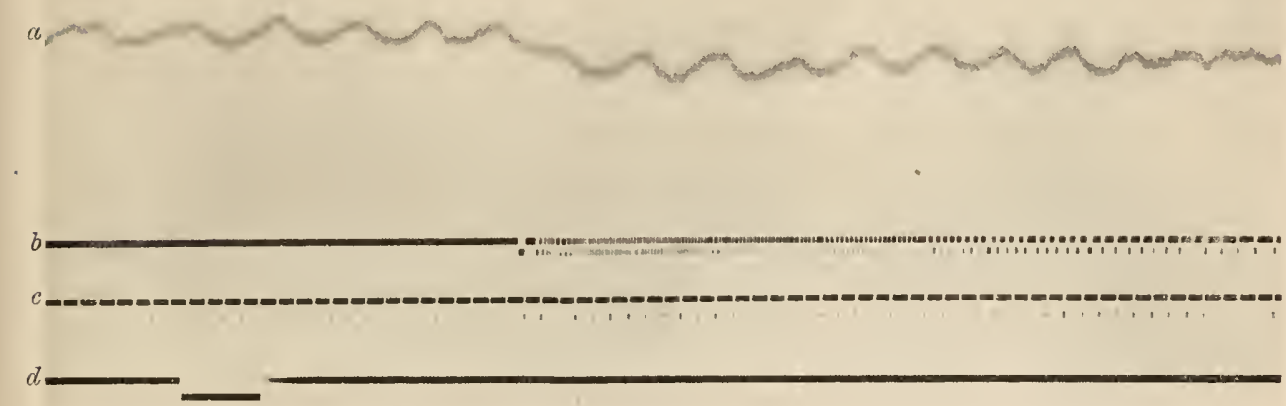

F1G. 66.-Electric change accompanying the flow of milk from the mammary gland under the influence of a dose of pituitary extract administered intravenously.

$a$, record of string galvanometer : each millimetre of ordinate $=20$ microvolts ; $b$, record of drops of milk ; $c$, time in seconds; $d$, signal of injection. The waves on $a$ are respiratory.

on blood-pressure are either nil or are different from that of pituitary extract. Their galactagogue action will be described later.

The blood, even in non-lactating animals, sometimes contains enough galactagogue autacoid to provoke the mammary secretion of a lactating animal, although the other effects of pituitary extract are not seen. In one experiment performed by me, as little as 5 c.c. of the blood-serum of a guinea-pig injected into a lactating cat provoked a marked secretion from a mamma the nipple of which had been incised, without producing any effect on the blood-pressure.

The action of pituitary and other extracts in causing secretion from the gland is accompanied by a change in the electric potential of the organ (fig. 66), so that the alveoli tend to become negative to the duct. This change is somewhat similar to that which is produced in other secreting glands which have been investigated.

From what has been stated regarding the mammary gland, it is obvious that this is an organ which is singularly under the influence of autacoids circulating in 
the blood. It is, moreover, well known that its secretion is not directly under the influence of the nervous system. Excitation of its nerves produces no effect on the secretion, which continues normal after all nerves are cut (Eckard). Even a gland which has been transplanted to a totally different situation will secrete milk (Ribbert). The case of the pyophagus twins, Rosa-Josepha Blazék, who are united by a common sacrum, with anus and vulva in common but with two uteri and vaginæ, is particularly interesting in connexion with this question. For when one of the twins became pregnant the mammary glands in both underwent hypertrophy and eventually secreted milk. The well-known effects of nervous conditions (emotions and the like) upon milk secretion must therefore be produced through the internal secretions of organs such as the pituitary.

\section{Effects on Metabolism and in Disease}

It is found, as with adrenalin, that the autacoids of the posterior lobe of the pituitary have an important influence upon carbohydrate storage. When injected either into a vessel or subcutaneously they cause disappearance of glycogen from the liver. They also facilitate the production of alimentary glycosuria by lowering the limit of assimilation of sugar (Borchardt).

Subcutaneous and intramuscular injections-especially the latterproduce effects similar to those caused by intravenous administration, although less rapidly. ${ }^{1}$ On the other hand, buccal administration has little or no effect on the blood-vessels, heart, and plain muscle. This is not due to destruction of the active material by the gastric juice, but probably to its slow rate of absorption from the alimentary canal. Addition of the gland substance to the food of growing animals, or its administration by subcutaneous injection, has been stated to check growth and delay ossification (especially in males), but this statement appears not to be of general application. In white rats the growth is not obviously affected by the addition of small amounts of pituitary to the ordinary food, nor is any obvious effect produced upon nitrogenous metabolism. In animals in which the gland has previously been experimentally removed or injured (see below), Cushing has described amelioration of the symptoms as the result of adding large amounts of the gland substance to the food. Pituitary extracts and derivatives from them have been administered in a variety of disorders, including surgical shock, intestinal inertia, uterine inertia, amenorrhœa, vesicular inertia, deficiency of milk secretion, hæmoptysis, exophthalmic goitre, hay fever, rheumatoid arthritis, rickets, and osteomalacia, but it is only in the first three that they have proved of distinct value.

Are the Various Effects obtained from Extracts of the Posterior LOBE DUE to ONLY ONe OR TO MORE Thax ONE AUtacoid?

Whether all these effects are produced by one and the same active principle has not yet been definitely determined. For example, in the case

1 Large doses administered subcutaneously are fatal to rabbits, the symptoms being similar to those caused by adrenalin (see p. 65). 
of the kidney we may be dealing with the action of a single autacoid which acts as a chalone upon the blood-vessels of the organ, producing inhibition of their tone, and as a hormone upon the secreting cells, stimulating them to increased activity; or two separate autacoids may be concerned, one of which atfects the blood-vessels and the other the cells of the organ. The latter view was taken by Herring and myself, but was combated by Dale, who adduces other examples of the action of drugs in which the same active substance produces a double result. If Dale's contention is correct, we are, so far as the action upon the kidney and its vessels is concerned, dealing with a single autacoid capable of acting either upon both tissues, viz., blood-vessels and secreting cells, or, under certain
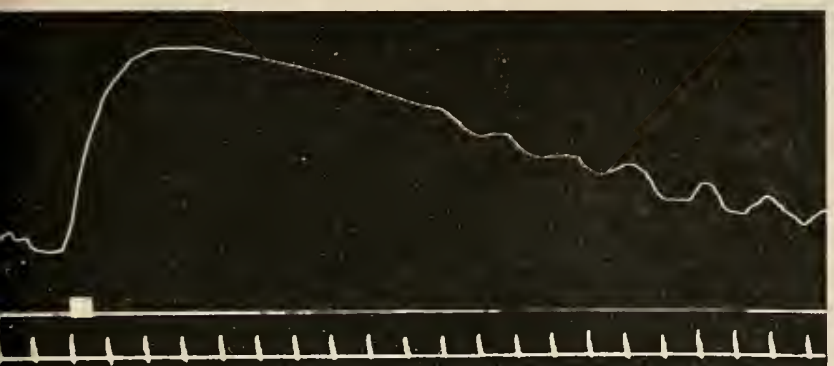

A

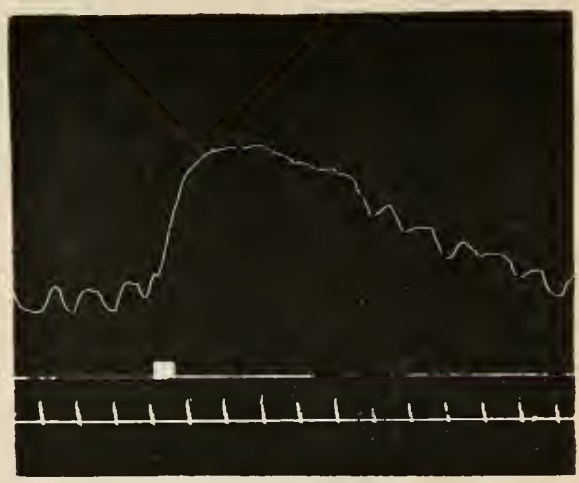

B

FIG. 67.-A. Tracing showing the effect of extract of pars nervosi of ox pituitary on isolated muscular tissue of rat's uterus. (Herring.) The strip was acted npon by the extract during the period marked by the signal. $B$, this tracing was made from the same preparation as that employed to obtain the last tracing. It shows the effect produced by an equivalent amount of extract of pars intermedia. The resulting contraction is smaller and less prolonged.

circumstances, upon one only. When its action is produced upon one only this may be interpreted to mean that the other is temporarily insensitive to its action: when, for example, in the action of pituitary upon the kidney the diuretic action (upon the cells) fails to be produced whilst the vascular effects are pronounced, or vice versê. But even if this were valid for the kidney, there are strong reasons for the belief that the posterior lobe of the pituitary yields more than one autacoid. For there is distinct evidence that a specific hormone affects the secretion of milk; quite possibly the effect upon the uterus is due to another; while there is very little doubt that the fall of blood-pressure produced by a second dose of pituitary extract is due to a chalonic agent entirely different from the hormone causing the initial rise. Bayer and Peter have also produced evidence that there are two autacoids which act upon intestinal muscle, one producing inhibition and the other contraction.

Important observations bearing upon this question have been made 
by Herring, who finds well-marked differences of effect according as extracts are prepared from pars intermedia or pars nervosa. ${ }^{1}$ Thus pars

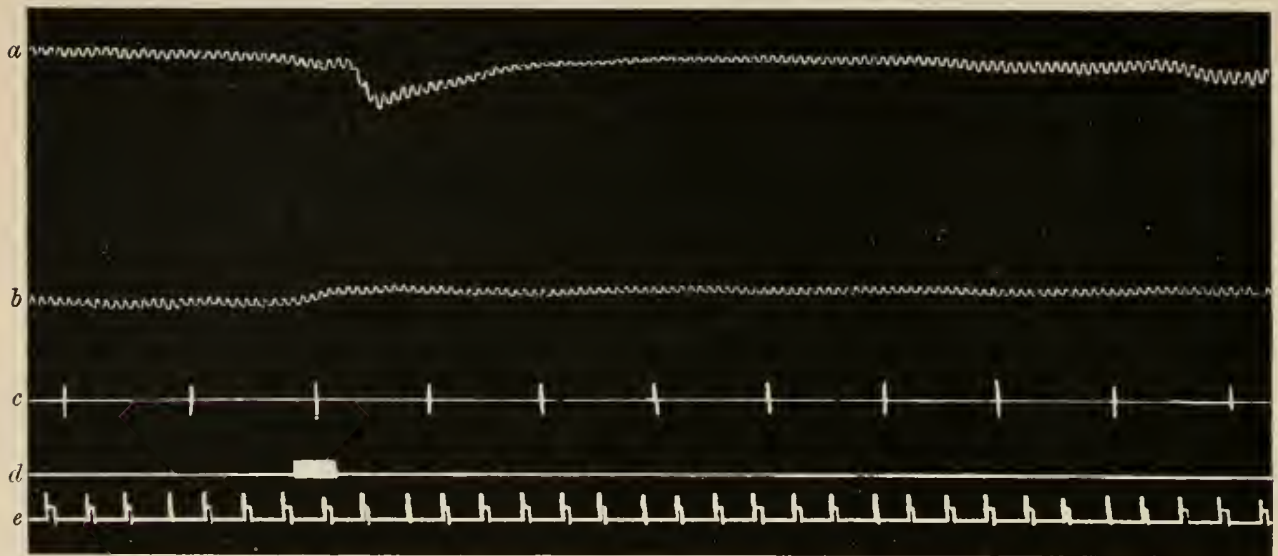

Fig. 68. - Effects on blood-pressure and kidney volume of injecting 3 c.c. of a 2 per cent. extract of pars internedia of fresh $o x$ pituitary into the jugular vein of a cat. (Herring.)

$a$, blood-pressure ; $b$, kidney volume ; $c$, urine drops; $d$, signal ; $e$, time in ten-second intervals.

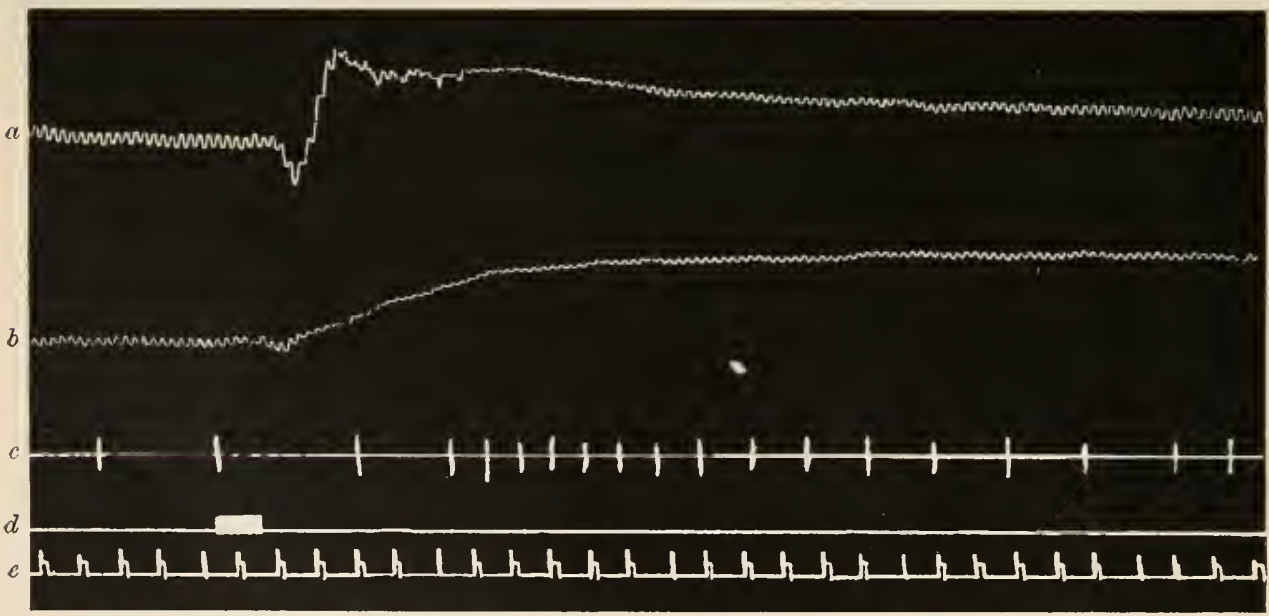

Fig, 69.-Effects on blood-pressure and kidney volume of injecting 3 c.c. of a 2 per cent. extract of pars nervosa of fresh ox pituitary into the jugular vein of the same cat. This injection was made eight minutes later. (Herring.) Lettering as in fig. 68.

nervosa of the ox excites the uterine muscle much more powerfully than does pars intermedia, whilst pars intermedia excites both uterine muscle and mammary gland more easily than it excites the plain muscular tissue

1 Most workers have employed extracts of the whole posterior lobe, which contains both parts. 
of the blood-vessels; in this respect it differs from pars nervosa. Further, extract of pars intermedia seems not to exhibit the specific effect on the kidney and urine which are so marked with extracts of the whole posterior lobe-nor do repeat doses show any lessened effect, or prevent extracts of pars nervosa from producing the usual results on blood-pressure, kidney, uterus, and milk secretion.

Herring has also found that extracts of the pituitary of the skate injected into mammals, although they affect the uterus and mammary gland, have no influence on blood-pressure or kidney.

These observations appear to indicate that there are at least two specific autacoids of the posterior lobe, both of which are present in the pars nervosa of the ox and only one in the pars intermedia (and in the whole pituitary of the skate). These autacoids are irrespective of that which produces a fall of blood-pressure, the specific nature of which, although probable, is less certain. 


\section{CHAPTER XIII}

\section{THE PITUITARY BODY (continued)}

\section{Effects of Complete Removal: Hypophysectomy}

A LARGE number of experiments have been made with the view of determining the nature of the symptoms which follow removal of the pituitary. The results of these have been somewhat conflicting in character -due in some measure to the differences of method employed to arrive at the position of the organ, which is obviously a difficult procedure, deeply placed as it is at the base of the brain. Thus, while one set of operators (e.g. Horsley and Handelsmann, and Aschner) have preferred to approach it (in animals) through the buccal cavity and basis cranii, in order to avoid disturbance of the brain, others (e.g. Paulesco, Cushing, Biedl) have not hesitated to attack it through a large aperture in the side of the skull, another similar aperture being made on the opposite side so as to enable the hemispheres to be pushed over in order to obtain a good view of the gland; in some animals, such as the dog, the organ can be got at without much difficulty by this procedure. The former method has the disadvantages (1) that the operator is working at the bottom of a deep pit from the walls of which blood is constantly oozing so as to obscure the parts, and (2) that it is impossible to secure asepsis. By the use of the lateral method these disadvantages are for the most part avoided, but it has been alleged that the serious results which are described as following removal of the organ by this operation are due to shock and paralysis caused by the unavoidable insult to the brain.

Effects of Complete Removal.-Paulesco was the first to state definitely that complete removal is in every case sooner or later fatal. This result was obtained with animals from all classes of Vertebrata. Most of the hypophysectomised mammals died within two or three days. He also found that mere severance of the stalk connecting the pituitary body to the base of the brain is fatal. Paulesco's statements were confirmed by Harvey Cushing and his fellow-workers, who for the most part restricted their experiments to dogs. They found that adult animals usually succumb after total deprivation in from two to five days, whilst puppies survive longer (ten to thirty days); they ascribe this difference to the greater functional adaptability of accessory glandules which are probably present in the roof of the pharynx in young animals. In all cases of long survival a fragment of the gland, including some of the anterior lobe, was found 
post-mortem, and they attribute the survival to such a remnant. On the other hand, they obtained no definitely recognisable symptoms by severance of the infundibular stalk, a procedure which, as we have seen, Paulesco alleged to be fatal. Removal of part only of the anterior lobe leads to certain definite changes in metabolism, which are considered by Cushing to be due to deficient secretion, a condition to which he has given the name hypopituiturism. Similar results to those of Paulesco and Cushing have been obtained by Biedl, and recently by Ascoli and Legnani.

The symptoms of complete removal or apituitarism (cachexia hypophyseopriva) are described by Cushing as follows: "On the day after the operation the animal (dog) usually appears normal, with fair appetite and no characteristic signs of loss of secretion. Gradually it becomes lethargic, refuses food and responds slowly or not at all to the voice. Later the respiration becomes slow and the pulse both slow and feeble, the musculature limp, often with tremors and fibrillar twitching; the back is arched, and the temperature subnormal; finally, often within forty-eight hours, the auimal becomes comatose and dies in this condition." According to Cushing, immediate reimplantation of the removed gland in some other structure causes an abatement of the symptoms and prolongs life; but whether indefinitely or not is uncertain, and would doubtless depend upon whether the graft underwent subsequent degeneration. In Cushing's later experiments extirpation of the gland seems to have been less certainly fatal or longer delayed, the animals exhibiting the symptoms rather of hypo- than of a-pituitarism. This may be due to small portions of the gland having been left behind, or to the employment of younger animals, or to the vicarious activity of some other organ or organs. The fact is interesting because Aschner, who has performed a large number of extirpations mainly by the inferior operation (through the base of the skull), has not found the gland to be essential to life-or at least has obtained very considerable prolongation of life after its entire removal. It must, however, be regarded as doubtful if it is possible to effect complete removal by this operation. Aschner himself, who admits the difficulty, regards the small residue as unimportant. In all his cases symptoms of hypopituitarism showed themselves. His animals, if young, remained small: their milk teeth were retained and also their lanugo hair: their epiphyses did not ankylose. The thyroid was enlarged, the thymus persistent, and the cortex of the suprarenal thickened. The development of the sexual organs was markedly retarded. The animals laid on fat. In the adult the chief effect of the removal was the putting on of fat. The secretion of carbonic acid was found by Benedict and Homans to be diminished. In pregnant animals Aschner found removal of the pituitary to be always followed by abortion.

The experiments of others have yielded different results. Thus Horsley and Handelsmann, who attempted complete extirpation in a number of animals, chiefly by the operation through the base of the skull, state that although a large proportion of their cases died within forty-eight hours, 
they consider this was due to causes incidental to the operation (shock, hæmorrhage, infection). Those that survived showed none of the symptoms above described as characteristic of apituitarism. But in view of the results of clinical observations on the effects of destructive disease of the pituitary, it must be regarded as doubtful whether the removal of the gland has been as complete in these cases as in those described by Paulesco and Cushing, the operative method employed by whom seems less open to objection than that in which the gland is reached through the basi-sphenoid.

\section{Effects of Partial Removal and Injury}

The results of lesions which involve only partial removal are even

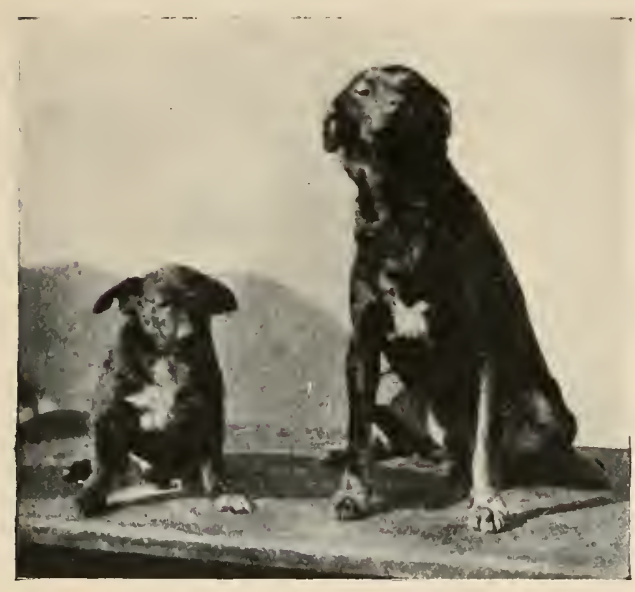

FIG. 70.-Twelve-months'-old hypophysectomised dog (left) and control of same litter (right). (Aschner.) The operation was performed at eight weeks. more interesting than those in which the extirpation is complete and the symptoms more acute. The most striking effects are obtained in young animals. Retardation of growth after hypophysectomy has been described by various authors, and that this is a characteristic of diminished amount of pituitary substance and concomitant diminished secretion of autacoids by the gland has been established by the experiments of Cushing and of Biedl. The work of Aschner, which has already been alluded to, also obviously has an important bearing upon this point, although Aschner himself be-

lieves that in most of his operations the removal was complete and that the condition was one of apituitarism. The retardation in development shows itself in a general diminution in size, in the ossification process, which is imperfect, and in the sexual organs, which long retain their infantile condition. Mental dullness has also been generally noted.

In spite of retardation in development, there is a marked tendency to fat formation, so that the actual weight of the operated animal may exceed that of the control. Even in adult animals a tendency to obesity is a characteristic feature after partial hypophysectomy. Accompanying this tendency, and possibly acting as a causative agent, is a high tolerance for sugars, the limit of alimentary glycosuria being markedly raised. This is the contrary effect to that produced by injection of posterior lobe extract, and is doubtless the result of deficiency of posterior lobe secretion, which in Cushing's opinion "is essential to effective carbohydrate metabolism." 
It was found by Cushing (in conjunction with Goetsch and Jacobson) that immediately after the operation of partial hypophysectomy a temporary glycosuria would at first usually ensue. This result is perhaps due to a dislodgemnt of accumulated secretion and irritation due to the injury. The effect, however, soon passes off, and is followed by the permanent condition of increased tolerance for sugar. Animals which have acquired this tolerance will suffer loss of the pancreas without becoming diabetic. Injury to the posterior lobe or even its manipulation is, probably for the same reason (release of accumulated secretion and possibly temporary irritation due to the injury), often immediately followed by marked glycosuria and also by polyuria, which may persist long after the glycosuria has disappeared or may be present from the first without glycosuria (diabetes insipidus). In one case of such injury to the pituitary in a dog operated upon by me the amount of urine rose from 40 c.c. per diem to 230 c.c., and during the following nineteen days remained at an average of 119 c.c. In another it rose from 110 c.c., the average of eleven normal days, to 182 c.c., the average of the eleven days immediately succeeding the operation. It was, however, much higher than this on the third, fourth, and fifth days, averaging 266 c.c. Mere exposure of the pituitary was found to have no such effects. A case in man has been recorded by Simmonds in which there was a malignant tumour of the pars nervosa extending to the pars inter-

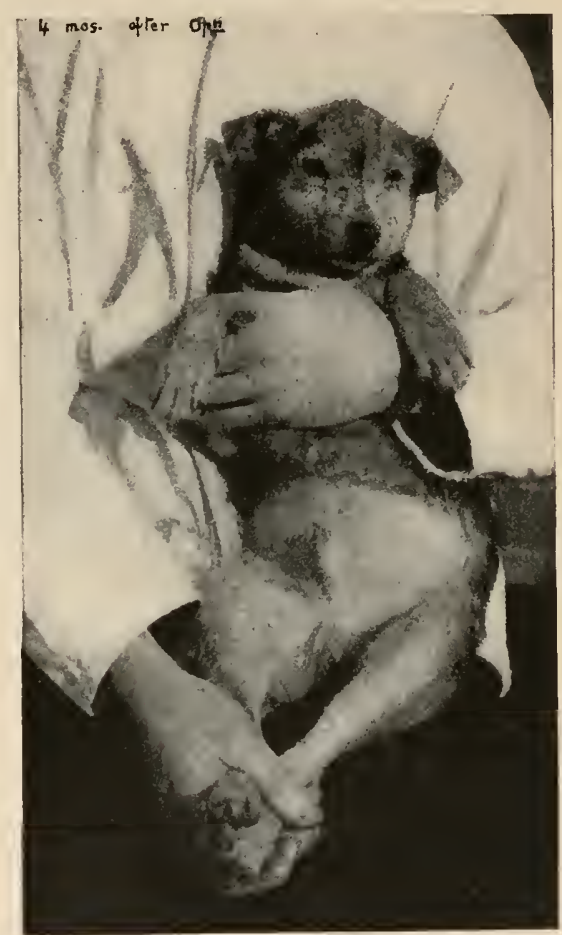

FIt. 71.-Young dog, eight months old, four months after removal of the greater part of the pituitary body. (Cushing.) Notice the tendency to adiposity, and the deficient development of the sexual organs. media, with marked diabetes insipidus (10 to 19 litres of urine per diem). This is probably a case of the cells of a malignant tumour assuming the functions of the tissues they are growing from (see p. 33).

It has been found by Cushing that stimulation of the cervical sympathetic or of its superior ganglion causes diuresis; he considers this is brought about by provoking the secretion of the posterior lobe, since stimulation of the superior cervical ganglion produces no effect if the pituitary be first removed. He therefore concludes that secreting nerves pass through this ganglion to the pituitary. Cushing also states that excision of the posterior lobe or separation of the stalk is sometimes followed 
by prolonged polyuria : this may be caused by irritation of portions of pars intermedia which remain. According to Weed, Cushing, and Jacobson, puncture of the pituitary gives as definite results regarding glycosuria as Bernard's puncture of the fourth ventricle. In both cases there must be
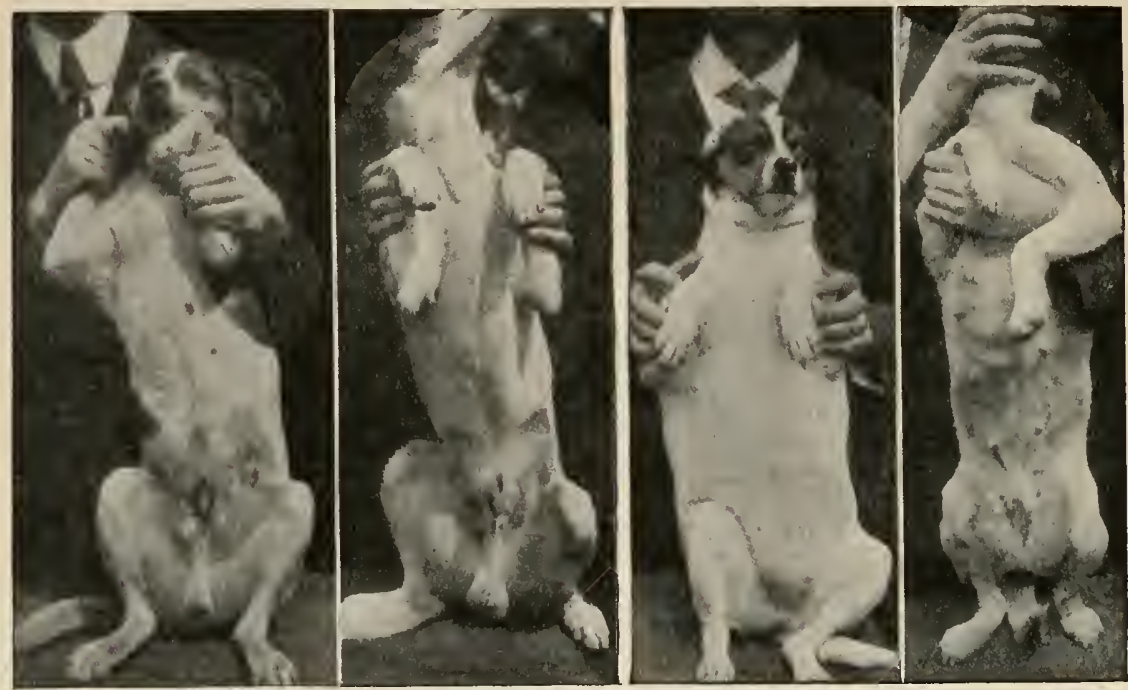

Fig. 72.-Adult dogs, male and female, some months after removal of the greater part of the pituitary body. In each case a control of the same litter is shown on the right of the operated animal. (Cushing.) The tendency to adiposity is well marked in both sexes.

"available" glycogen present, i.e. glycogen resulting from recent ingestion of carbohydrates. Both this and Bernard's puncture are ineffective after section of the cord at the fourth thoracic level.

\section{Effects of Grafting and Feeding with Pitultary}

Many attempts have been made to increase the internal secretion of the pituitary-especially of the pars anterior-by grafting the organ or portions of the organ from an animal of the same species into various parts of the body; but these have always so far resulted in failure, the graft disappearing, or at any rate undergoing degeneration, in the course of a few days. In white rats, rabbits, and guinea-pigs I have repeatedly implanted the organ as a whole or in small pieces under the skin of the groin, in the peritoneal cavity, in the kidney substance, in the spleen, and in the substance of the brain, but always with no result or with only a temporary effect upon the amount of urine secreted, which has obriously been due to the autacoid of the posterior lobe. Only after extirpation of the animal's own gland did Cushing and his fellow-workers succeed in occasionally getting a graft to take (for at least a month). A. Exner seems to have obtained something like a positive result in rats without previous removal of the 
animal's own gland, for he states that he was able to observe a temporary increase of growth of animals in which he implanted an extra pituitary as compared with controls. Other methods which might be expected to produce hyperpituitarism consist (1) in the addition of pituitary substance to the food, (2) in the subcutaneous injection of extracts at regular intervals during a prolonged period of time. The second method has been stated by some observers to produce a retardation of growth of the skeleton and of the body generally-a result exactly the contrary to what would be expected if, as there seems no reason to doubt, the symptoms of acromegaly, presently to be described, are due to hypertrophy of the gland, especially of the anterior part. A series of experiments by the first method which were carried out by me upon white rats and extended over several months showed no constant effect in facilitating the growth of young animalsalthough there was no sign of retardation. $R$. Wulzen records, on the contrary, a retardation of growth in chicks when pituitary was added to the food, the effect being more marked in males than in females. But the most remarkable result of feeding with pituitary substance (anterior lobe) is that described by L. N. Clark (Journ. Biol. Chem., Oct. 1915), who experimented on laying hens. In the first experiment, 35 White Leghorn hens, as well as 2 cockerels of the same breed with which they were mated, each received daily during eight days the equivalent of $20 \mathrm{mg}$. of fresh pituitary substance in addition to their usual food. By the fifth day the egg production of the batch was raised from an average of 18 per diem to 33 ; the beneficial effect, although diminishing, was maintained for several days after the pituitary had been taken off. And not only was the output of eggs largely increased as compared with the controls, but the fertility of the eggs and the hatching out of the chicks was extraordinarily enhanced. In order to test the matter further, a second experiment was performed with as many as 655 one-year-old White Leghorn hens (kept without males), the same dose as before being administered to each hen during four days. The average daily number of eggs laid by the batch during the four days preceding the pituitary feeding was 233, during the four days succeeding the administration, 352: These experiments were made at a time of year when the egg production of the hens was tending to diminish rather than to increase. 


\section{CHAPTER XIV}

\section{THE PITUITARY BODY (continued)}

\section{Clinical Evidence}

THE clinical symptoms due respectively to overgrowth of the gland and to deficiency of its secretion are very various. Although many of these symptoms have long been described, some of them have only recently been interpreted as the result of alterations in the pituitary, and certain affections which were previously obscure are gradually becoming elucidated. This advance in knowledge has mainly been due to the experiments on animals of which a description has just been given. The literature of the subject is rapidly becoming enormous. A large number of cases in which the pituitary probably played a causative part have been described by Harvey Cushing in The Pituitary Body and its Disorders, 1910, a work which marks an epoch in the study of this organ from the clinical aspect.

The course of many cases of disorder of the pituitary body (termed by Cushing dyspituitarism) is as follows: Starting with enlargement of the anterior lobe, they are heralded by symptoms of excessive function (hyperpituitarism). After a variable time-which may be greatly prolongeddegenerative changes in the enlarged organ supervene, and there results from this a gradual diminution (hypopituitarism), or even eventually an entire loss of function (apituitarism). The primary enlargement is usually first recognised by diminution of the visual field, caused by the pressure of the enlarging gland upon the optic chiasma; hence these affections generally come first under the notice of the ophthalmic surgeon. Although there is loss of vision, this may not be produced by actual destruction of nerve-fibres, for it has frequently been noticed that after operation for removal of the tumour or alleviation of the pressure produced by it the patient's vision is speedily restored. Accompanying or preceding the visual symptoms certain other signs are developed which point to the advent of a peculiar affection (figs. 73, 74), termed acromegaly ${ }^{1}$ by Marie (1886). The affection to which this name was given by him had been already described by others, and its association with enlargement of the pituitary body had been recognised. It is, nevertheless, to Marie-associated later with Marinescothat we owe the first complete account of the syndrome in question. The name which he bestowed upon it expresses its most prominent sign, "hypertrophie singulière non-congénitale des extrémités supérieures, in-

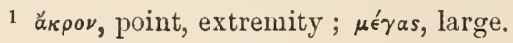


férieures et céphalique"-a marked non-congenital enlargement of the
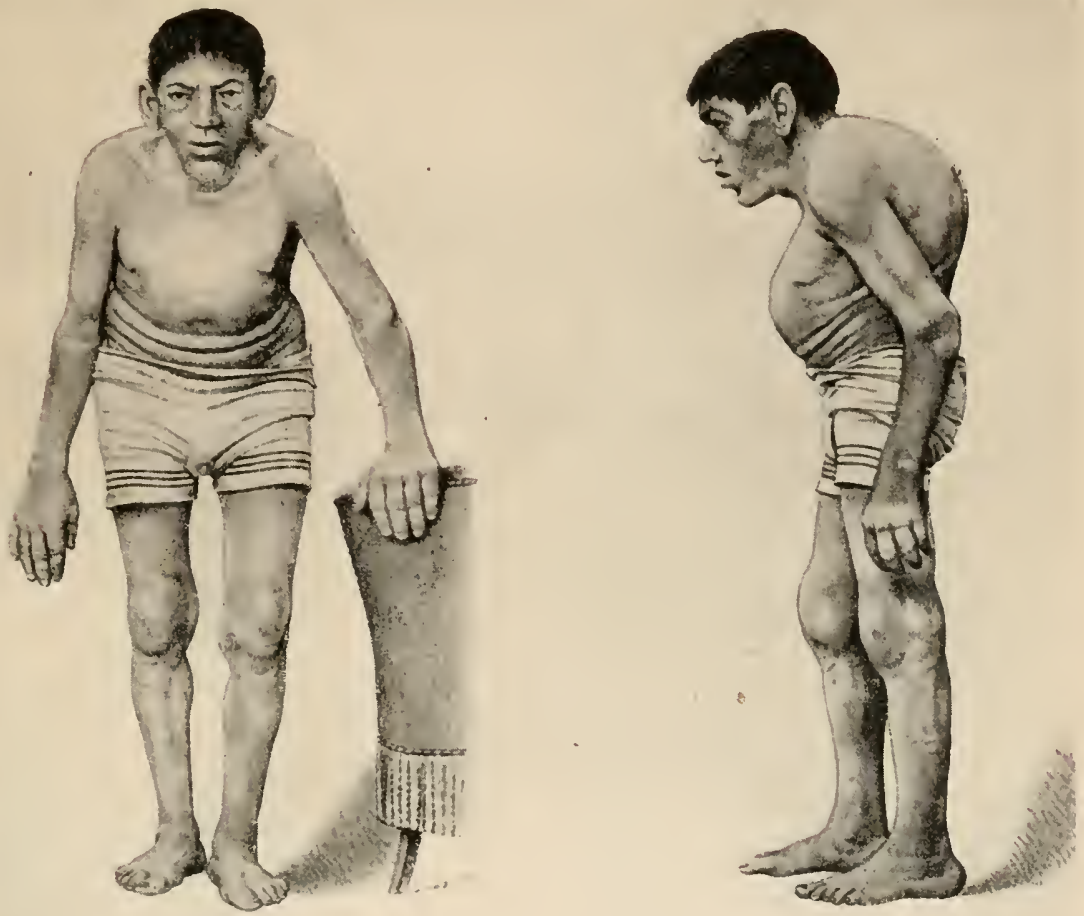

FIG. 73.-Case of acromegaly, front and side view. (From Klebs and Fritsche.) The illustration shows the enlarged hands, feet, and joints, the massive elongated face and thick lips, the dorsal curvature (kyphosis), the apathetic look.

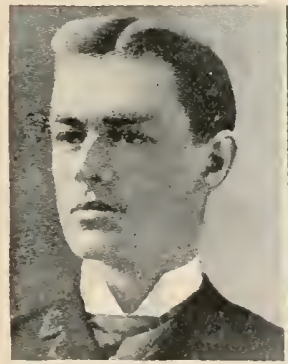

A

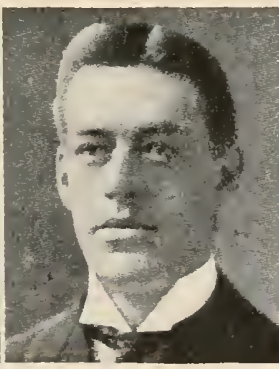

B

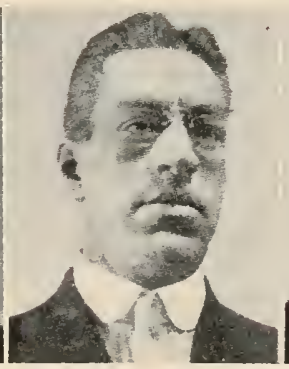

$\mathrm{C}$

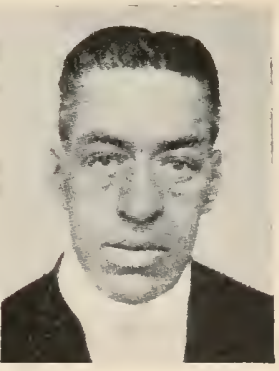

$\mathrm{D}$

FIG. 74.-Four photographs of the same person showing the gradual development of the facial appearance characteristic of the acromegalic. (Cushing.)

A, at 24 years of age (prior to the commencement of the disease); B, at 29 (onset of disease) ; $\mathrm{C}$, at $37 ; \mathrm{D}$, at 42 years of age.

limbs and head. The hands (fig. 75), feet, and face are especially hypertrophied, and X-ray photographs show a typical mushrooming of the ungual 
phalanges (fig. 76). But the enlargement is not confined to the bones of

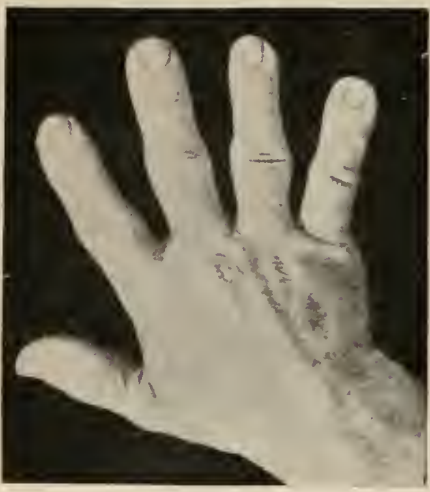

Fig. 75. - Typical hand of acrome. galic. (Cushing.) Notice the broad palm and digits and the relatively small nails, which lack lumulæ. the extremities; it affects the whole skeleton, which becomes thickened and hypertrophied. There is often considerable muscular development; the subject being abnormally strong. If the affection does not supervene until adult life is attained, i.e. until the epiphysial cartilages are ossified, the long bones do not grow in length and the height is but little affected, any increase of stature that is produced by increase of the vertebral column being usually more than compensated for by a kyphosis (fig. 73), which supervenes after the disease has made some progress. But if the hyperpituitarism commences whilst the cartilages are still unossified, there is a considerable growth in length of the long bones, so that the patient attains an unusual height. This condition is known as pituitary gigantism ${ }^{1}$ (fig. 77 ); it is of essentially the same nature and origin as acromegaly (Tamburini, Woods-Hutchinson, Lamois and Roy).

In acromegaly there is always enlargement of the pituitary. This increase in bulk often takes the form of a considerable tumour, which can usually be detected during life in skiagrams of the skull, the sella turcica showing a wellmarked enlargement. The tumour is usually found to affect mainly or entirely the anterior lobe, and if large is, as already mentioned, liable to affect vision and to produce headache and other symptoms of intracranial pressure.

In addition to the skeletal changes, others occur. The integument becomes thickened; there is increased activity of the skin glands and a tendency to an abnormal increase in the growth of the hair over the body (hypertrichosis). Diminution of sexual activity often supervenes early in the disease, although it nay be preceded by the opposite condition. There is often glycosuria or simple polyuria : ${ }^{2}$

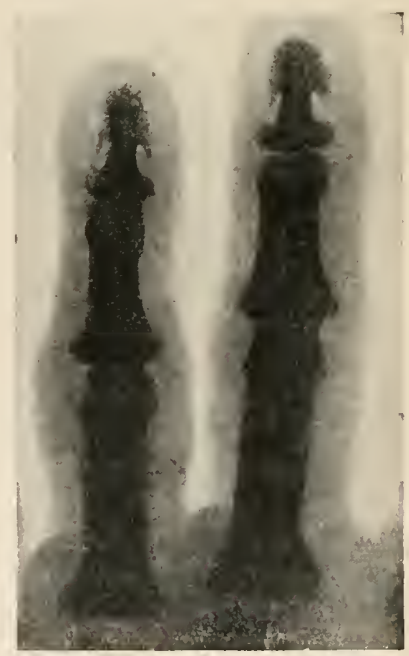

Frg. 76.-X-ray photograph of two digits of an acromegali: ratient (Cushing) showing the peculiar mushrooming of the ungual phalanx. when present these conditions are probably associated with hypertrophy of

1 There is another kind of gigantism, without pituitary enlargement, but associated with defective sexual derelopment and analogons to the increase of stature which occurs as the result of castration before puberty (see Byrom Bramwell, Clinical Studies IV., Edin. Med. Journ., June 1915).

2 Byrom Bramwell, Intracranuil Tumours, 1888, and op. cit., 1915. 
the pars intermedia rather than of the pars anterior. As the case advances they may be replaced by high degrees of sugar tolerance, due to a subsequent hypoplasia or degeneration of pars intermedia. According to André Levi, glycosuria occurs in 30 to 50 per cent. of cases of acromegaly. It is interesting to note that in pregnancy also-in which the pituitary is found to undergo enlargement-glycosuria not infrequently occurs.

Marie and Marinesco were originally inclined to the opinion that acromegaly is due to destructive disease of the gland, since in many cases it is found post-mortem that the tumour is of malignant character and that the substance of the gland has been destroyed. ${ }^{1}$ It was this idea which led to the carrying out by various investigator's of experiments for the removal or destruction of the organ in animals, in order to produce, if possible, a similar syndrome. But so far from producing increased growth, this operation led to the opposite result, the development of the skeleton and body generally being retarded and restrained. It is now recognised that the tumours of the gland which are associated with acromegaly are in the first instance of a glandular (adenoinatous) type; although they may later become of a malignant or of a cystic nature and lead to the destruction of the glandular tissue. It is therefore held by most authorities that the characteristic symptoms of acromegaly are originally due to hyperpituitarism, i.e. to increased function, although it may be that there is also some degree of

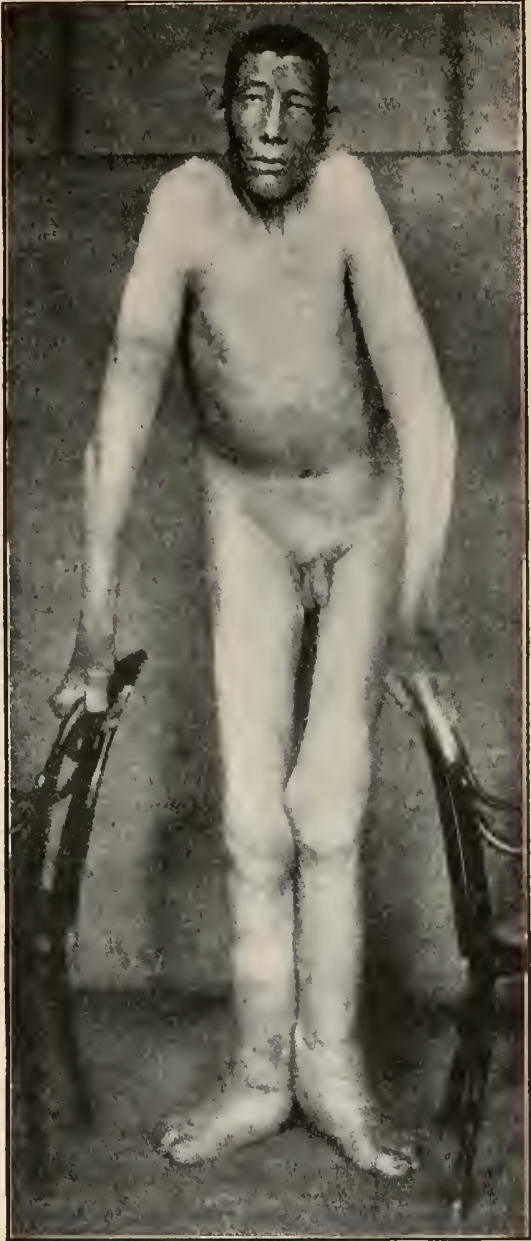

FIG. 77.-Case of pituitary gigantism. (Cushing.) The patient was 36 years of age and 8 feet 3 inches high. Notice the large elongated face, the dull heavy expression, the long limbs, narrow chest, enlarged joints, enormous hands and feet, and the deficiency of hair (hypotrichosis). The last is not a constant feature. perversion of function. In later stages effects of destruction may undoubtedly become apparent and supersede the symptoms of hypertrophy. Sometimes the tumour of the gland is from the first malignant, but

1 Marie appears more recently to have modified his views; inclining on the whole to the belief that it is a perversion and not a suppression of the secretion which leads to the abnormal growth. 
even then many of the cells tend to resemble those of the normal gland (malignant adenoma) and symptoms of acromegaly may still be produced. No one has yet succeeded in producing the effects of hyperpituitarism experimentally, either by operation or by feeding with the gland.

It must be stated that by no means every case of tumour of the pituitary is accompanied by the symptoms of acromegaly. For the disease may from the first be destructive and at once tend to the opposite condition, viz.

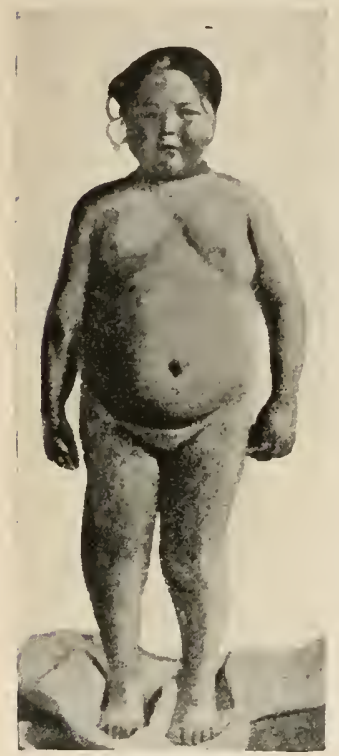

Fig. 78.-Case of bullet wound of pituitary. (Madelung.)

hypopituitarism. There is, as we have seen, evidence derived from the results of partial destruction in animals as to the symptoms which may result from such deficiency (p. 102). When similar symptoms occur in man, it is therefore natural to conclude that they have the same cause, viz., pituitary insufficiency; and in some cases it has been possible to obtain, by skiagrams or post-mortem examination, evidence of diminution in size of the organ.

Hypopituitarism, produced either by diminution in size or in activity of the gland, is probably the cause of the syndrome described by Fröhlich (1901) and termed by Bartels dystrophia adiposogenitalis. The symptoms of this affection closely simulate those of animals which have undergone partial or complete removal of the gland. A case in which such symptoms made their appearance was described by Madelung in 1904, in a girl of nine years of age (fig. 78) whose pituitary was destroyed by a bullet which lodged in the sella turcica.

The symptoms which are believed to be due to pituitary insufficiency are, as might be supposed, the reverse of those ascribed to hyperpituitarism. If the affection commence before adolescence, the stature (instead of becoming gigantic as in hyperpituitarism) remains small (fig. 79). This is generally associated with marked adiposity, so that the weight of the body may be large relatively to the height. Sexual development is delayed and may remain considerably in abeyance, producing a more or less permanent condition of sexual infantilism. In the female the menses are irregular or absent, and in both sexes there is deficient development of secondary sexual characters such as the hair on the face (in the male) and over the pubes in both sexes. Such hair as occurs in the last-mentioned situation in the male does not extend to the umbilicus as is usual in that sex, but assumes the disposition characteristic of the female, being limited to the mons veneris. On the other hand, the hair of the head is generally abundant. Nor is the character of the trichosis the only sign of feminism in subjects affected by hypopituitarism. They usually have a broad pelvis, a certain amount of genu valgum, rounded limbs, small feet and hands with tapering fingers, 
and occasionally well-marked mammary development. Skiagrams of the bones generally exhibit persistent epiphysial lines (fig. 80). The skin is smooth and delicate and free from moisture. The nails are small and thin, and the crescents at their base are absent.

The tendency to adiposity is attributable by Cushing to deficiency of posterior lobe secretion. This deficiency is usually associated with unusual tolerance to sugar and an excessive assimilative power for carbohydrates, which become transformed into fat and thus produce adiposity.

A subnormal body-temperature is generally present with the above symptoms, as well as low arterial tension and a slow pulse; there is also often drowsiness and torpidity. ${ }^{1}$ Sometimes evidences of psychic derangements and occasionally a tendency to epilepsy have been described.

Hypopituitarism and its accompanying symptoms may result from simple atrophy of the gland, as appears to have been the case in the instance of infantilism shown in the accompanying figure from Byrom Bramwell (fig. 79); in this subject the skiagram showed a small sella turcica. Or it may be caused by destruction of the gland, e.g. by the formation of a cyst, or as the result of pressure from a neighbouring tumour.

When the hypopituitarism comes on after adolescence certain of the above symptoms will be missed; but the lowered

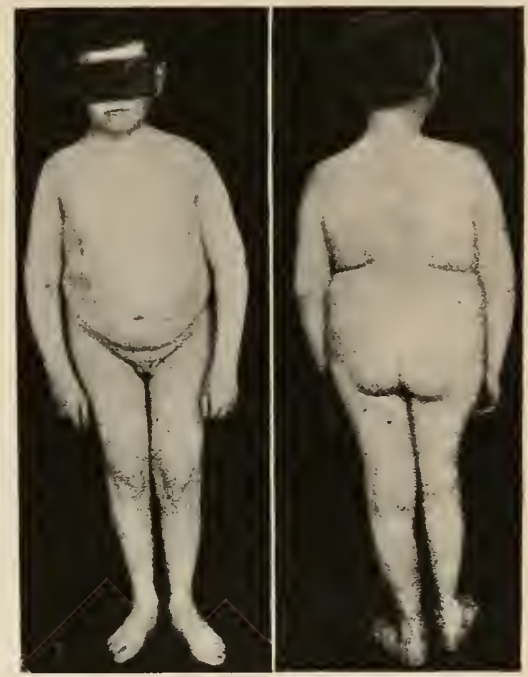

Frg. 79.-Case of pituitary infantilism. (Byrom Bramwell.) The patient was 27 when the photograph was taken. His height was 4 feet $1 \frac{3}{4}$ inches. Notice the arrested development of the sexual organs, the deficiency of hair, the adiposity, the slender limbs and digits, and the general approach to the feminine type of body. temperature, the tolerance to sugar, and the supervention of excessive adiposity are generally present, as well as dryness of skin and loss of hair, besides a tendency in the male to adopt the feminine type of trichosis, even in cases where the male type has already been established. According to Cushing, "pigmentation of the skin is a conspicuous feature of many of the adult states, and as it is apt to be associated with asthenia or a low blood-pressure it is natural to ascribe it to an associated adrenal insufficiency, though it hardly reaches the degree of bronzing seen in some of the Addisonian examples of adrenal tuberculosis."

As has already been stated, the history of some cases of affections of the pituitary shows symptoms characterising hypopituitarism following those characteristic of hyperpituitarism, although of course little or no

1 Cushing has pointed out that these symptoms closely resemble those which occur in animals about to undergo hibernation. 
retrogression in the growth of the skeleton and body can generally be expected. Thus the occurrence of hyperplasia and hyperpituitarism during adolescence leading to a general overgrowth of the body and unusual growth of hair, and sometimes accompanied by sexual precocity, may be followed by glandular hypoplasia and diminution of the sexual instinct even proceeding to impotence; as well as by excessive adiposity and the

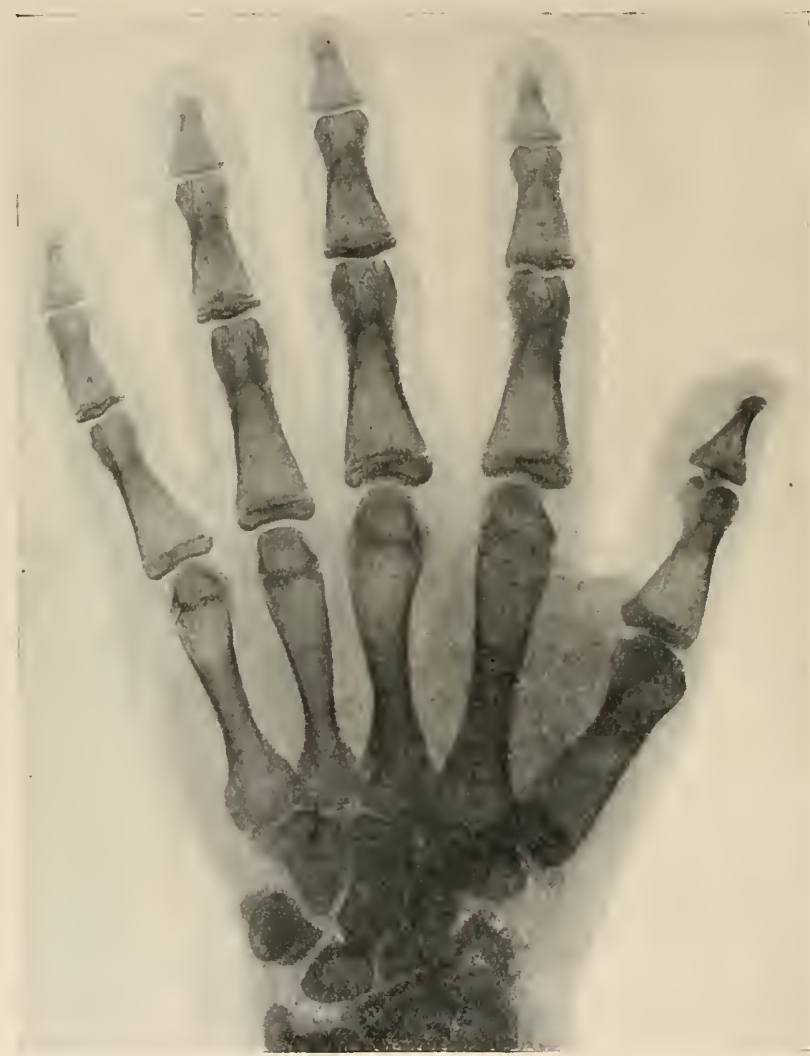

Fig. 80.-X-ray photograjh of hand from the case of infantilism shown in the preceding figure. (Byrom Bramwell.) Notice the slender phalanges and the still detached epiphyses. Reduced from $6 \frac{1}{2}$ inches.

assumption by the male of some of the feminine characteristics which have been above described as associated with hypopituitarism. This alteration in the signs of disease complicates the clinical features of many cases; the complications can only be unravelled by a careful study of the history of each case.

In many instances where the affection begins with hyperplasia of the gland and subsequent changes produce destruction or degeneration of the enlarged organ, leading eventually to apituitarism, these changes may occupy years in their development, but the patient ultimately loses strength and gradually wastes. Under such circumstances death results under 
conditions which are probably analogous to those of cachexia hypophyseopriva described by Paulesco, Cusling, and Biedl in the animals operated on by them (pp. 100-102). It seems likely that this is the usual course of the disease known as acromegaly. That the acromegalic skeletal growth is produced by hypertrophy and over-secretion of the anterior lobe is highly probable, both as the result of partial extirpations in animals and from the effect of operative removal of pituitary tumours in man. One case in particular has been described (by Hochenegg) as having shown within a few days of operation for removal remarkable amelioration of the symptoms, with gradual diminution in size of the enlarged extremities, and eventually complete cure. The thyroid gland both in this and in another instance which was also successfully operated upon by the same surgeon became permanently enlarged. In both, the pituitary tumour was a malignant adenoma. In other cases operated on by Hochenegg, Cushing, and others, in some of which an enlarged anterior lobe only was removed, the results have been less striking than in the above example, but the retrogression of the disease symptoms which resulted from the partial extirpation of the tumour has occasionally been well marked. We are therefore warranted in believing that the enlargement of the skeleton and the other signs which are characteristic of acromegaly are due to hypertrophy of the anterior lobe of the pituitary, whilst hypertrophy of the posterior lobe produces totally different effects.

The symptoms due to hypopituitarism vary according as the anterior or the posterior lobe of the gland is mainly affected. In the former case the chief effect seems to be upon the stature. When, however, it is the posterior lobe which is affected, a tendency to fat formation and to deficient sexual development are usually manifested, without being necessarily accompanied by diminution in stature; indeed, these conditions may be associated with increased growth of the body, although not especially affecting the skeleton, a characteristic infantile condition being retained. Rarely such symptoms of deficiency of posterior lobe occur along with acromegalic symptoms, and are then associated with concomitant enlargement of anterior lobe. That the adiposity is related to a deficiency of the posterior lobe is further indicated by the fact that, according to Strada, it is never accompanied by glycosuria or polyuria, symptoms which are almost certainly the result of increased activity of that lobe.

In connexion with the influence of the anterior part of the organ on growth, cases of dwarfs have been described in which the pituitary has been noticeably small and atrophied; although it must be stated that others have been recorded in which the contrary condition has been found. The supposition that in these latter cases the enlargement is not a true glandular growth as in acromegaly, but of an abnormal or destructive character, is attractive. We must, however, be careful not to adopt it too readily simply because it seems to fit in with what is believed to be the effect of overgrowth of the organ in producing giants and acromegalics. 
Nevertheless, it may be noted that in more than one such case of a dwarfish stature apparently associated with enlargement of pituitary, the tumour has been found to be really outside the gland and to exercise compression upon it. It must be remembered also that increased activity of the natural function of an organ may not necessarily accompany increase in volume: this is exemplified in cases of endemic goitre. There is, on the whole, reason to believe that a dwarfish habit of body is associated with diminution either in size or in activity of the anterior lobe of the pituitary. These changes may commence in infancy or even in the foetus.

Assuming, which there is no reason to donbt, that the two parts of the gland have different functions, it is obvious that as the result of increase or diminution of function of either part the clinical symptoms manifested in affections of this organ may take very various characters. Thus both anterior and posterior lobes, or the anterior lobe alone, or the posterior lobe alone, may exhibit either increased or diminished activity; and there is the further possibility of the one lobe having its activity increased whilst that of the other is diminished. Under all these conditions the clinical appearances would be different. The suprarenals and the thyroparathyroid apparatus may each, it is obvious, furnish clinical problems of similar complexity. 


\section{CHAPTER XV}

\section{THE PITUITARY BODY (continued)}

\section{Relations of the Pituitary with Other Endocrine Organs}

THE relationship of the pituitary to other internally secreting organs is extensive. Cow has recently shown that the secretion of the posterior lobe is excited by duodenal extract, which causes its hormones to be poured out in unusual amount into the cerebro-spinal fluid. The secretion of this lobe is also related to the glycogenic functions of the liver, and there seems to be a mutual interaction between its autacoids and those of the pancreas, suprarenals, thyroid and sexual glands. Further, Ascoli and Legnani found, in dogs which survived for a sufficient time the operation of removal of pituitary, a diminution in volume of the spleen, with disappearance of the Malpighian corpuscles, precocious retrogression of the thymus, enlargement of the thyroid due to accumulation of colloid within its follicles similar to that seen in endemic goitre, and an increase of lipoids in the cells of the cortex of the suprarenals. The relationship with certain of these organs may be considered more particularly.

With the Sexual Glands.-The relationship of the pituitary to the sexual glands and secondary sexual characters has been dealt with in considering the symptoms associated with hypo- and hyper-pituitarism. Besides the effect of these conditions on the state of development of the secondary sexual characters and on the activity of the essential organs of reproduction, the latter appear to have some reciprocal effect on the pituitary. Several observers have described enlargement of the gland and increase in the number of large oxyphil cells of the pars anterior as the result of castration. Livingston finds that in rabbits the effect is greater in the female than in the male. Further, Steinach and Scheidt aver that the changes in the pituitary which would result from castration are prevented by implantation of either ovary or testis in the castrated animal, and since the generative cells undergo atrophy under these circumstances they ascribe the result to the interstitial cells of the implanted organs. Moreover, it is found that both menstruation and pregnancy are associated with hypertrophy of the gland. Indeed, as the result of pregnancy it may attain to twice or three times its normal weight.

With the Thyroid and Parathyroids.-That after the removal of the thyroid the pituitary body becomes altered and enlarged was first shown by Rogowitsch in 1886 . His statements have been confirmed by all other 
observers. Degener finds the increase in weight directly proportional to the time which has elapsed after removal of thyroid (in rabbits). The hypertrophy produced by thyroidectomy affects all parts, but most the pars anterior, in which it is not uncommon to observe a development of colloidcontaining vesicles not unlike those of the thyroid: the same appearance is seen in myxcedema (Hale White) and other affections involving atrophic changes in the thyroid, or interference with its function, in the human subject. A. E. Livingston found thyroid feeding to prevent the increase in

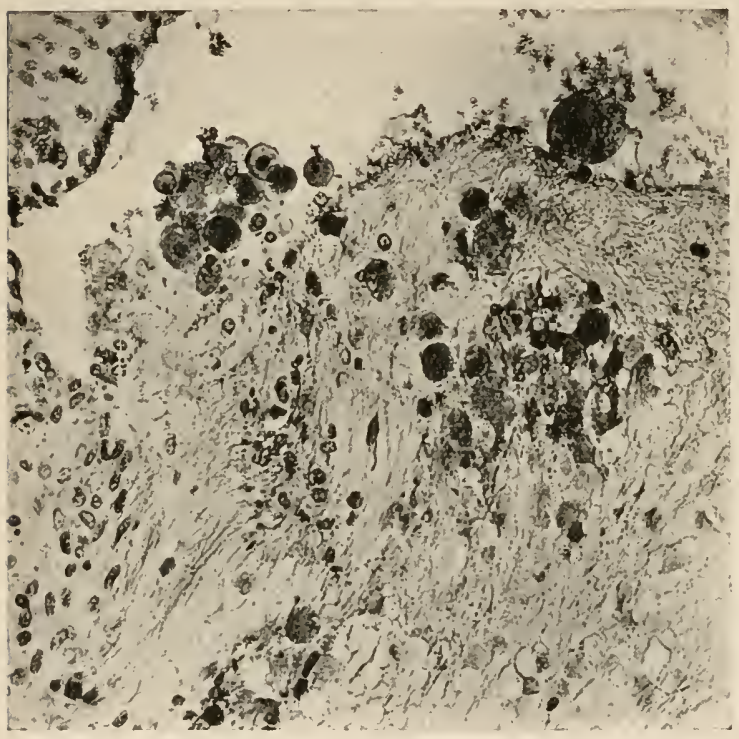

FIG. 81.-Section through infundibular recess and neck of posterior lobe of pituitary of a rabbit killed three months after removal of thyroids. Magnified 200 diameters. (Herring.) Cells and colloid bodies streaming through the pars nervosa and passing into the infundibular recess. size of the pituitary which would be caused by thyroidectomy.

Another striking effect of thyroidectomy upon the pituitary is increase of hyaline and granular masses in the pars intermedia, and their passage in large numbers through the pars nervosa into the infundibular extension of the third ventricle (fig. 81) (Herring). This denotes an increased activity of the pars intermedia. Whether the phenomenon also occurs in myxœedema has not been noted, but it will probably be found to be the case.

Halpenny and Thompson describe enlargement of the pituitary, and a considerable increase of colloid-containing vesicles in the pars intermedia, as the result of parathyroidectomy also.

The pituitary colloid is not identical with that of the thyroid. It is noteworthy that it does not contain iodine, which is a characteristic component of the thyroidal colloid in all animals. Even many wonths after thyroid removal Sutherland Simpson and Andrew Hunter were unable to detect the least trace of iodine in the sheep's pituitary. The pituitary cannot take the place of the thyroid in animals affected with cachexia thyreopriva, nor is pituitary extract able to take the place of thyroid extract in the treatment of goitre and myxoedema. There is, therefore, no evidence that these two organs act vicariously. The effect of the injection of their extracts is, moreover, entirely different. But that they have a certain similarity of function in relation to growth and development is shown by the results of their removal in young animals. In both cases 
growth is slowed or arrested, the development of the body generally and of the sexual organs in particular is checked, and that of the higher functions of the nervous system is interfered with. There is also a tendency to adiposity, which is particularly marked in cases of hypophysial deprivation, but is also seen after thyroidectomy and in myxœdema.

With the Suprarenals.-That there is some relationship between the pituitary and the suprarenals would appear from the fact that, as Gottlieb has shown, extracts of the posterior lobe of the pituitary and of the suprarenal medulla mutually facilitate one another's action upon the blood-vessels. Thus an immediately prior injection of even a small dose of adrenalin wili increase the effect of a dose of pituitrin, and vice versâ.

There is also some evidence that an excess of adrenalin is secreted into the blood as the result of injection of extract of the posterior lobe of the pituitary.

With the Pancreas and Other Organs concerned with Carbohydrate Metabolism.-Hypopituitarism, whether the result of disease or of surgical interference, is associated with an increased tolerance for sugar. This function is, as we have seen, connected with the posterior lobe. According to Cushing, animals which have suffered deprivation of this lobe will even bear removal of the pancreas without exhibiting glycosuria. But the result of removing the pancreas in causing glycosuria is produced through the liver, the glycogen of which becomes converted into sugar. And an effect similar to removal of the pancreas is produced by excess of adrenalin in the blood or by swabbing the exposed pancreas with adrenalin solution.

There seems, indeed, to exist a functional correlation between pituitary, suprarenal, pancreas, and liver, so that the disturbance of the function of any one of them may affect the metabolism of carbohydrates through its influence upon others. And to these we may add the thyroid, since, as has already been noticed, the mechanism of carbohydrate metabolism is also affected, in some manner as yet imperfectly understood, by variations in its secretion. For hypothyroidism, like hypopituitarism, raises the assimilation limit for sugar in the body. On the other hand, according to Asher and Flack, the presence of an unusual amount of thyroid secretion in the blood acts as an excitant to the suprarenals, causing an increased outpouring of adrenalin, and thus producing a lowering of the sugar assimilation limit. As we have seen, a deficiency in thyroid secretion is associated with increase of secretion of the posterior lobe of the pituitary.

Cushing states that after removal of the pancreas the amount of hyaline substance of the pars intermedia and pars nervosa is increased. 


\section{CHAPTER XVI}

\section{THE PINEAL GLAND}

\section{Structure of the Pineal}

THE pineal gland or epiphysis cerebri (conarium), which is present in nearly all vertebrates, is in man a small solid organ less than half the size of the pituitary body. It projects from the roof or dorsal wall of the third ventricle (fig. 82 , from the cat), and is connected on each side by a short stalk

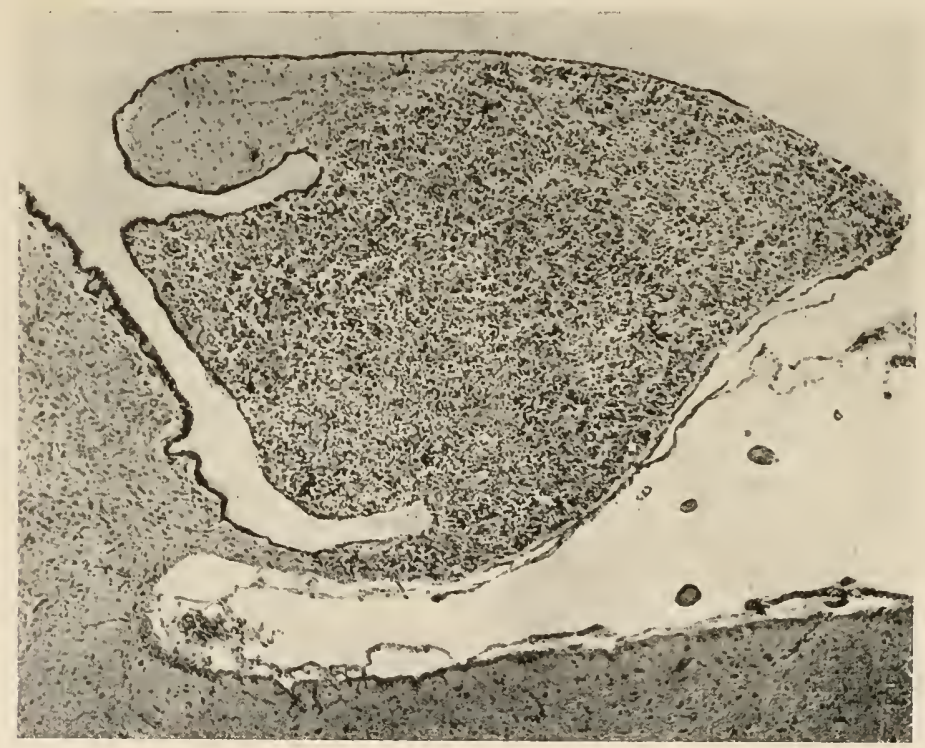

FIG. 82. - Sagittal section of pineal of cat. Magnified 50 diameters. I am indebted to Dr Kojima for the specimen from which this microphotograph was taken.

or peduncle to the habenular commissure. The base of the gland has a small infundibular depression (pineal recess) leading from the ventricle just above the entrance of the aqueduct. This recess is the remains of an evagination from the third ventricle, from which the pineal was originally developed. In some reptiles a median eye is developed as a secondary outgrowth from this evagination (Baldwin Spencer). The gland is proportionately larger in the child than in the adult, and in the female than in the male. Its average weight in man is 0.22 gramme. It lies between the anterior corpora quadrigemina, and is closely invested by pia mater, so 
that it usually becomes detached from the brain if the pia mater is torn away.

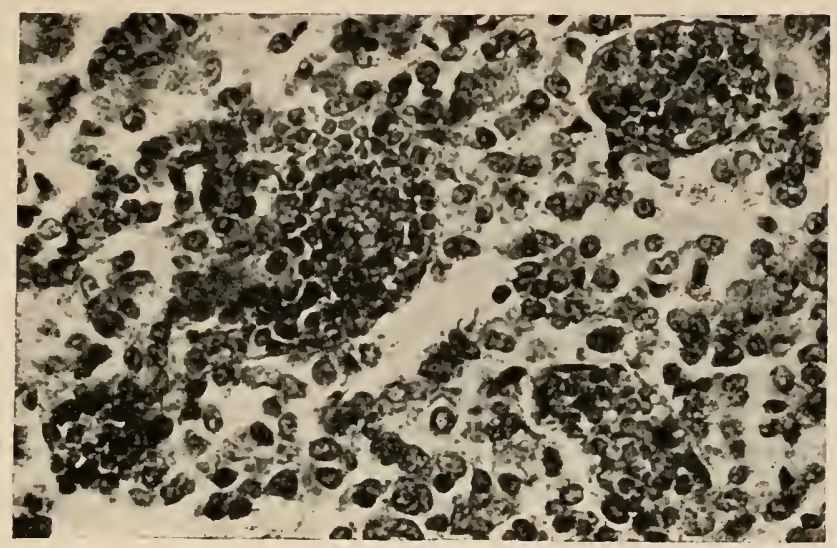

FIG. 83. -Section of pineal, new-born child. Magnified 400 diameters. Three or four large sinus-like vessels gorged with blood are included in the section.

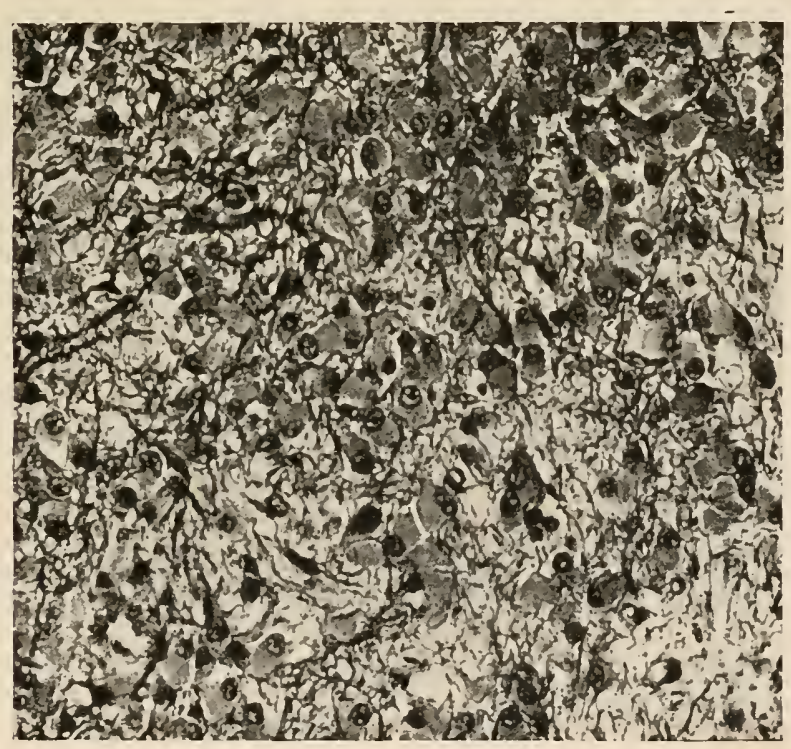

FIG. 84.-Section of pineal of ox, stained with iron-hæmatoxylin. Magnified 300 diameters. I am indebted to Mr Edgar Beard for the specimen from which this microphotograph was taken. The cell protoplasm and the reticular tissue between the cells are well shown.

Sections of human pineal show it to be composed of epithelium-like cells arranged in loosely disposed trabeculæ with large sinus-like blood-vessels between the trabecula (fig. 83). In some animals plain muscular tissue, and even striped muscle, has been described in the intertrabecular tissue. 
The blood-vessels are very numerous. There are no true nervous elements, with the exception of a few fibres perhaps destined for the blood-vessels, but neuroglia cells and fibres are present in abundance. Embedded both in the interstitial tissue and in the covering of the pia mater are small round globules of calcareous matter-corpora amylacea, brain sandwhich are much more common in man than in other animals, and more numerous in the adult than in the child. The cells of the organ are not uniform in character. Most have fine oxyphil granules in their protoplasm, but some possess basiphil granules. Cells with large oxyphil granules such as are seen in the anterior part of the pituitary are not found in the pineal. Vesicles containing colloid are also absent, but cysts are not infrequent: these may, however, be pathological. The gland undergoes retrogressive changes after puberty: there is marked hypertrophy of the intertrabecular tissue, which shows a characteristic reticular appearance resembling neuroglia and at the same time considerable diminution in the number of epithelial cells (fig. 84).

\section{Effects of Injecting Extracts of Pineal}

According to my own observations, extract of pineal injected intravenously produces a marked but temporary fall of blood-pressure accompanied by a diminution in volume of the kidney; the last is probably passive, for no effect is manifest on the flow of urine (fig. 85). The substance which produces these results is extracted from the gland by alcohol.

Ott and Scott state that the result of intravenous injection of extract of pineal is to produce a fall of blood-pressure followed by a prolonged rise with dilatation of kidney volume and diuresis. They describe some increase of contraction of the uterus. They also found a slight galactagogue action. These effects are similar to those produced by pituitary extract. They further obtained dilatation of the pupil on dropping the extract into the eye of an animal in which the superior cervical ganglion had been extirpated. Many of the above statements appear to require confirmation, but the galactagogue action has been noticed by Mackenzie (fig. 86). Previous workers, including Howell, Cyon, Dixon and Halliburton, and Jordan and Eyster, have obtained no definite result from pineal extracts so far as arterial pressure and kidney secretion are concerned; if we except the fall ir blood-pressure, which Dixon and Halliburton consider to be non-specific.

\section{Effects of Extirpation. Relations of the Pineal with the Sexual GLands}

Extirpation of the pineal is a difficult operation to carry through without provoking severe hæmorrhage, to which the animals operated on have generally succumbed. The most complete series of experiments as yet made are those of Foà on the domestic fowl, and those of Sarteschi on 
young rabbits and puppies. In pullets in which the pineal gland was destroyed no difference could be noted on comparison with controls, but in cockerels Foà describes not only a more rapid growth of the body, but an earlier development of the testicles and of the secondary sexual characters. The results obtained by Sarteschi agree generally with these.

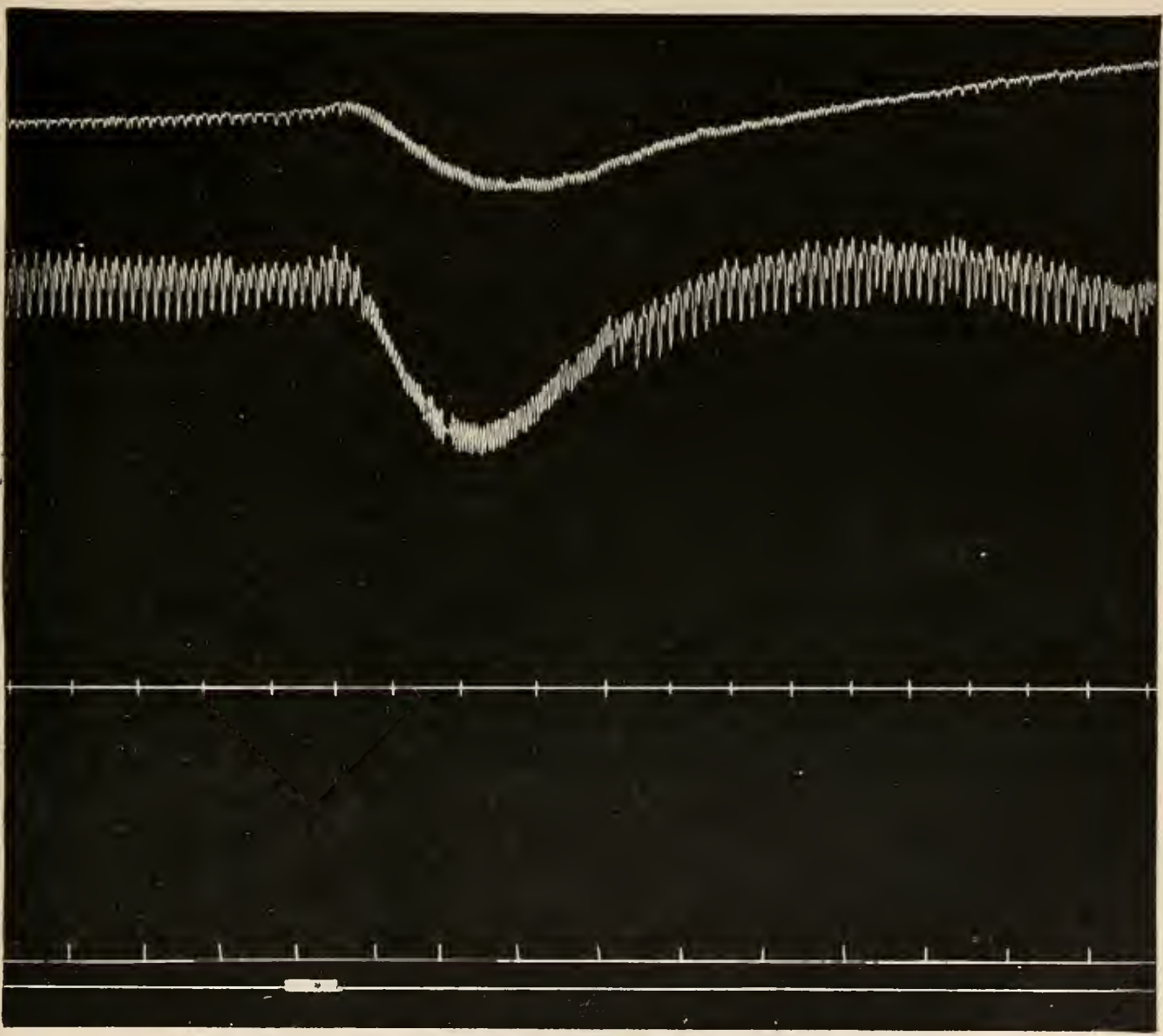

FIG. 85. - Effect on kidney volume and blood-pressure of intravenous injection of a solution in Ringer's Huid of dried alcohol extract of sheep pineal.

$a$, kidney volume; $b$, blood-pressure; $c$, urine drops ; $d$, tine iu ten seconds; $e$, sigual.

In connexion with this it is noteworthy that abnormal growth of the skeleton with sexual precocity and early development of secondary sexual characters have been observed in young boys affected by pineal tumour; although this is by no means true for all cases in which such tumours have been found. In some in which secondary sexual characters were present there was an unusually large amount of the interstitial tissue in the testicles, although these organs had otherwise remained small. It is pro- 


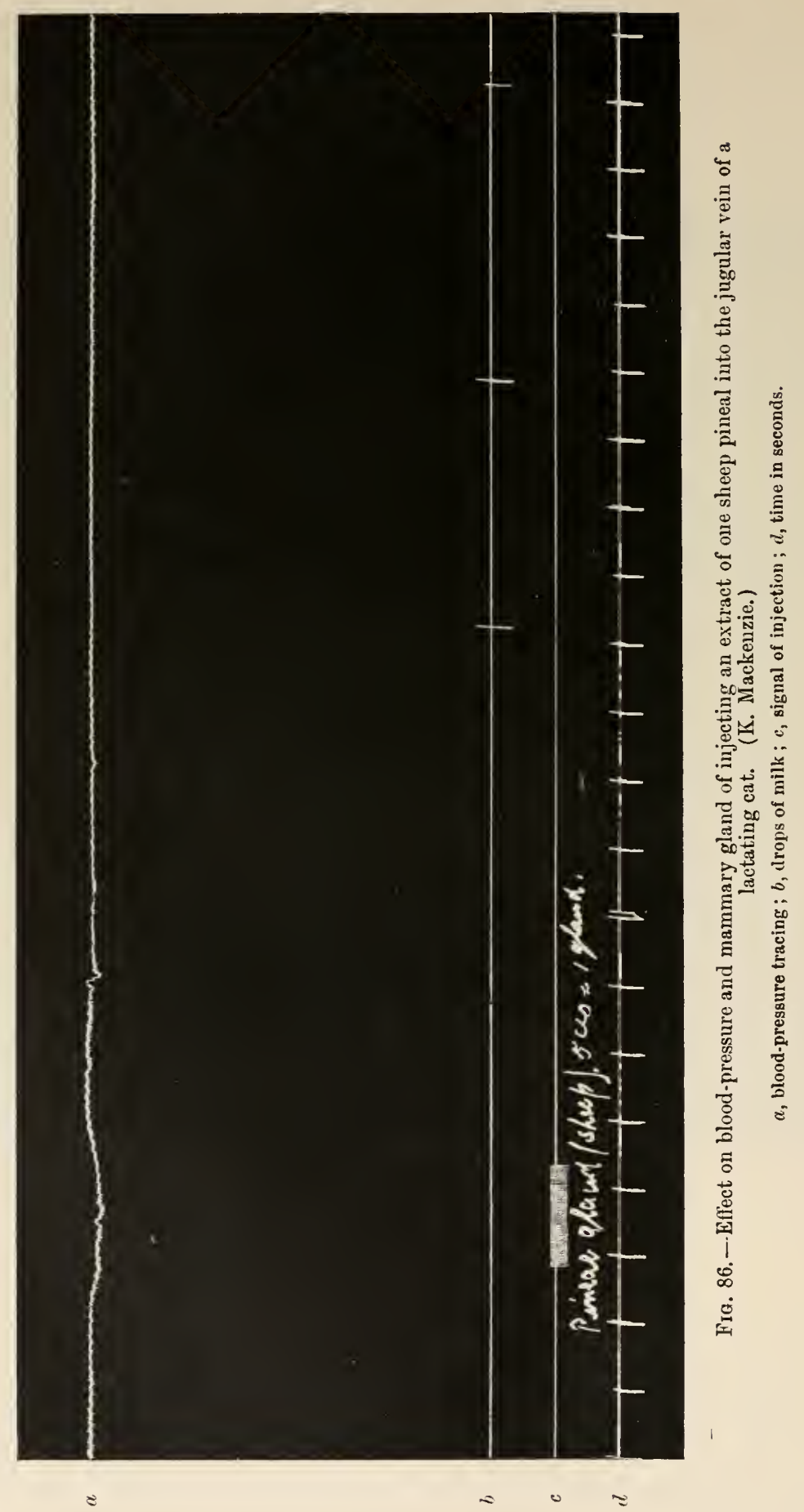


bable that the sexual precocity is associated with the development of this interstitial tissue (see p. 135). The symptoms resemble those described as the result of pineal removal, and have therefore been regarded as due to hypopinealism. On the other hand, it has been found (Dane and Berkeley, II'Cord) that the administration of pineal extract, both by feeding and by subcutaneous injection, is also followed in young animals by precocious sexual development, particularly but not exclusively in males. The rate of body growth of the pineal-fed animals is also greater than that of the controls. The addition of even a small amount of gland substance to the food is said to be sufficient to produce a marked result.

Another condition which has been sometimes observed to accompany pineal tumours is unusual adiposity of a nature somewhat similar to that accompanying hypopituitarism, although not, like that, associated with deficient development of the sexual organs. It is suggested that this may be caused by hyperpinealism.

The accounts of the effect on the pineal of removal of the generative glands have been conflicting. The experiments of Sarteschi on male animals of several different species proved negative: whereas Biach and Hulle described in cats, both male and female, the production of an atrophied condition of the pineal. In connexion with this it may, however, be mentioned that the pineal is often normally very small in the cat.

It must be admitted that the results of clinical observations and experimental work in animals are at present difficult to reconcile, and do not enable us to come to any definite conclusion regarding the functions of this organ and the nature and mode of action of its autacoids. 
CHAPTER XVII

\section{THE INTERNAL SECRETIONS OF THE ALIMENTARY MUCOUS MEMBRANE AND OF THE PANCREAS}

\section{SECRETINES}

BAYLISS and Starling discovered in 1902 that an extract of the duodenal mucous membrane, or even of its epithelium alone, if injected into the circulating blood, produces a rapid secretion of pancreatic juice (fig. 87). In Bayliss and Starling's experiments the active substance was obtained by boiling the mucous membrane with dilute hydrochloric acid and afterwards

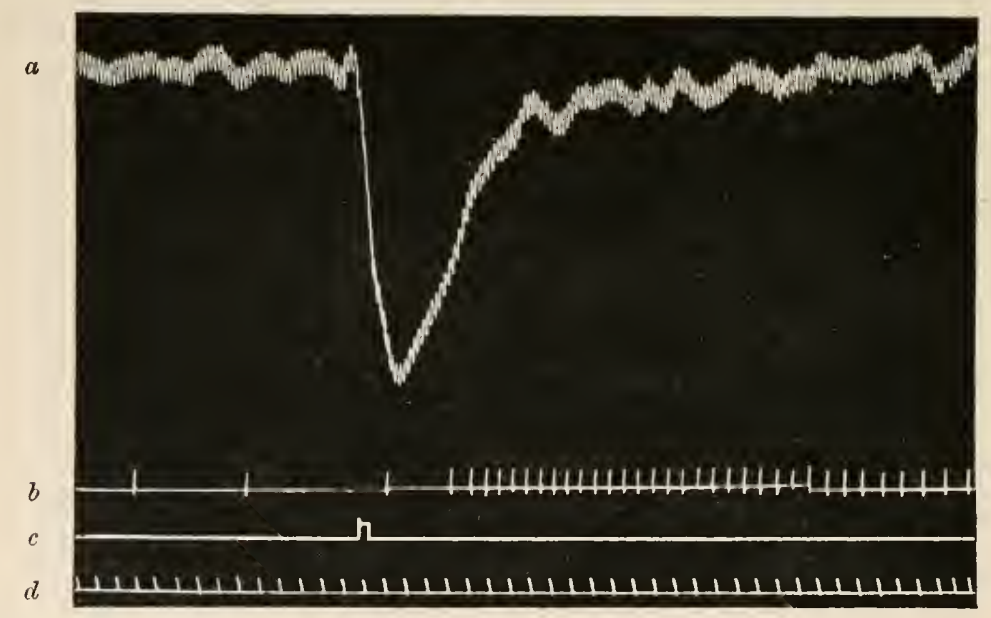

FIG. 87. - Elfect on blood-pressure and secretion of prancreatic juice of injecting into a vein extract of mucous membrane of dnodenum, made by boiling with dilute hydrochloric acid and subsequently neutralising. (Bayliss and Starling.)

$a$, blood-pressure : notice the sharp fall followed by return to normal; $b$, drops of pancreatic juice; $c$, signal; $d$, time in seconds.

neutralising and filtering: the autacoid (hormone) is contained in the filtrate. They observed little or no activity from extracts of membrane which had not been treated with acid, and concluded that the active substance (secretine) is present in the cells in an inactive form (pro-secretine), and becomes activated (converted into secretine) by the action of the acid. It had been previously found that rinsing the duodenum with dilute mineral acid ${ }^{1}$

1 According to Babkin and Ishikawa, fatty acids introduced into the duodenum have a similar effect. 
would provoke secretion of pancreatic juice. This had been put down to a reflex effect through nerves and nerve-centres, but the experiments of Bayliss and Starling made it clear that the effect is due to the formation and absorption into the blood of an organic chemical agent which is dialysable and not destroyed by boiling, and is presumably of a fairly simple chemical constitution.

Hustin finds that perfusion of pancreas with Locke's solution + secretine is without effect, but if blood + secretine is used an abundant secretion, containing all the ferments, is poured out by the duct.

That there is some mutual interaction between pancreas and duodenum would appear from the observations of Evans, who found that pro-secretine disappears from the duodenum after complete extirpation of pancreas, but not if enough pancreas is left to prevent the occurrence of glycosuria.

Duodenal extracts do not act only on the pancreas; they also increase the flow of bile and of succus entericus, but to a less extent.

Cow has made the interesting observation-already referred to in connexion with the pituitary body-that intravenous injection of duodenal extract produces a discharge of pituitary secretion into the cerebro-spinal fluid.

In 1906 Edkins announced that a substance of sinilar nature to secretine, but acting upon the glands of the stomach, can be extracted from the pyloric mucons membrane by boiling water or dilute hydrochloric acid, or by solutions of dextrin, maltose, or albumose. According to Edkins extracts of the mucous membrane of the fundus do not yield a similar substance. The hormone in question is termed gastric secretine or gastrine. It exists in the mucous membrane in the form of a precursor (pro-gastrine) which is activated by the above reagents. These observations have recently been confirmed by experiments in Pawlow's laboratory.

Atropine, which, in small doses, operates through the nerve endings of secreting organs, does not inhibit the action of these secretines. Their activity is therefore probably manifested directly upon the cells of the organ they stimulate and not through the nerve terminations.

\section{The Internal Secretion of the Pancreas. The Isletes OF LANGERHANS}

The pancreas contains, besides its alveoli and the ducts which conduct their secretion into the duodenum, a peculiar epithelial tissue occurring in most animals in the form of small isolated masses interspersed throughout the gland, and known from their discoverer (1869) as the islets of Langerhans (fig. 88). Although quite distinct in appearance and in the characters of their cells from the epithelium of the alveoli, the study of their development shows that they originally grew out from the budding ducts, and that their cells have therefore an origin in common with those of the alveoli. But they have no open communication with the ducts or alveoli. The number of islets in the pancreas is very variable, and this variability has led to inferences being drawn regarding their appearance 
and disappearance which in many cases are probably not justifiable. Thus Bensley found a variation in the guinea-pig in animals of different ages

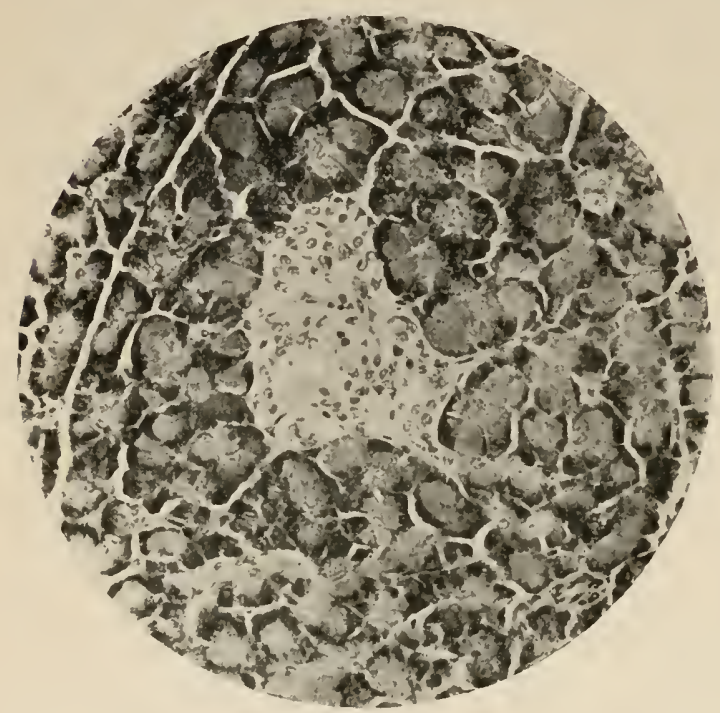

Fig. 88. - Section of pancreas of dog, showing an islet of Langerhans between the alveoli. Magnified 200 diameters. of from 10 to 189 islets per milligramme of pancreas: in the mature animal the variation was fiom 10 to 25 . The enumerations of Clerk led him to the conclusion that in the normal human pancreas there may average 10 to 20 islets in each milligramme of the gland, which roughly would give about three-quarters of a million to a million and a half for the whole pancreas.

In Teleostean fishes Rennie has shown that there is one very large mass of islet tissue which is encapsuled by connective tissue and practically forms a separate organ. But in other animals the islets are closely encircled by and in contact with the alveolar tissue, and sometimes appear to be continued into it. According to Pensa, they have an abundant supply of nerve fibres. Each islet has a specialised bloodsupply (fig. 89) in the form of a network of irregular-shaped sinus-like capillaries which are both larger and relatively more numerous than the capillaries of the alveoli (Kiihne and Lea).

The cells of the islets are generally much less stained by the ordinary dyes used in histology than are those of the alveoli. They are therefore usually described as chromophobe. But they have an especial affinity, as

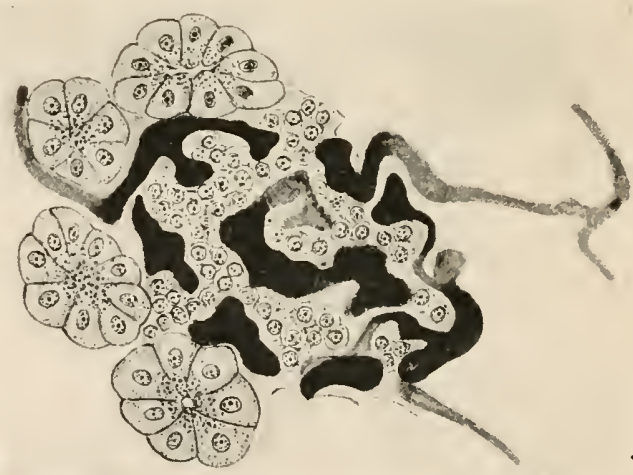

Fig. 89.-An islet of Langerhans of the pancreas, with its blood-ressels injected. (Kiihne and Lea.) Bensley has shown, for neutral red and janus green, employed as intravital stains. Although they contain granules, these are much finer than the zymogen granules of the alveolar cells. According to Lane, there are two kinds of cell in the islets, distinguishable from one another by the nature of their granules. The cells 
come into very close relation-indeed, in actual contact-ivith the walls of the blood capillaries. If the duct of the pancreas is tied, the ordinary alveolar tissue disappears after a time, although for a long while there are remains of the ducts. But most observers are agreed that the islet tissue does not-at least to any great degree-participate in the atrophy of the alveoli, and the statement that it persists under these circumstancesalthough denied by some authors-is generally accepted.

\section{Effect of Surgical Removal of Pancreas. Diabetes}

Since the discovery in 1889 by $v$. Mering and Minkowski that removal of the pancreas, or even of the greater part of the organ, is immediately followed by hyperglycæmia leading to severe and fatal diabetes, whereas this effect is not obtained from mere ligature of the duct (in spite of the disappearance of all the alveolar tissue and the complete cessation of formation of pancreatic juice), attention has been especially directed to the islet tissue as the probable source of an internal secretion which serves to regulate carbohydrate metabolism. For, as has just been stated, the cirrhosed and atrophied gland which remains after ligature of the duct contains none of the ordinary secreting epithelium, except perhaps that of a few remaining ducts, but does, in all probability, still contain the islets of Langerhans. Nevertheless, this atrophied gland is sufficient to furnish the internal secretion which regulates carbohydrate metabolism, so that this is maintained normal for an indefinite time. But if now the atrophied gland is removed, diabetes at once shows itself. Further, if a portion of pancreas, whether thus atrophied or not, be successfully transplanted to another site and the rest of the gland be then removed, diabetes does not occur-although on removal of the graft it immediately makes its appearance. The evidence for the action of an internal secretion which is yielded by the gland-and in all probability by its islet tissue,-and serves to maintain carbohydrate metabolism in a normal condition, is therefore very complete. In support of this conclusion it has frequently been noted in cases of diabetes in man that the cells of the islets have undergone some kind of degenerative change.

If the pancreas removal is complete, the percentage of sugar in the urine is very large, even during fasting or on carbohydrate free diet. Minkowski found the relation of dextrose to nitrogen in the dog under these circumstances to be $2 \cdot 8: 1$. With protein diet the sugar rises (and falls) with the nitrogen: with fatty foods there is an increase in the quotient: while carbohydrates of the food are almost wholly passed out by the urine as dextrose. Lævulose is, however, utilised in the body to a considerable degree, and the glycogen which had disappeared from the liver and muscles may to some extent reappear when this sugar is given with the food.

The glycosuria is accompanied by hyperglycæmia, which is indeed the actual cause of the glycosuria; but according to de Meyer the latter is 
augmented by the fact that the permeability of the kidneys to blood-sugar seems also to be somewhat increased by absence of the pancreas. The hyperglycæmia is produced in the first instance by transformation of the liver glycogen into sugar, which is passed into the blood; while the glycogen of the muscles is also diminished. ${ }^{1}$ The sugar thus prorluced from the liver glycogen is not utilised in the body, but is for the most part at once got rid of by the kidneys. Since, therefore, the carbohydrates of the food are not used for nutrition, there is a comparatively greater call upon the proteins and fats both of the food and of the body, so that the animal loses flesh rapidly and death may ultimately result from inanition, unless the end has arrived sooner as the result of the accumulation in the body of abnormal by-products of the metabolism of proteins and fats (such as the acetonebodies) tending to acidosis and the production of diabetic coma.

Kausch, and independently Noël Paton, have shown that in birds removal of the pancreas does not cause glycosuria although hyperglycæmia is produced; on subsequently administering adrenalin, glycosuria supervenes.

\section{Nature of the Pancreatic Autacoid}

The results of pancreas extirpation and pancreas grafting can, as we have seen, be best explained by supposing that the islet tissue produces an autacoid which passes into the blood and affects carbohydrate metabolism and carbohydrate storage in such a manner that there is no undue accumulation of glucose in the blood. Provisionally, it will be convenient to refer to this hypothetical autacoid as insuline. It must, however, be stated that it has yet to be determined whether the active substance is present as such in the pancreas or whether it exists there as pro-insuline, which becomes elsewhere converted into the active autacoid. It is not found that pancreas extracts have the effect of antagonising the results of pancreas extirpation: in this respect they offer a parallel to the negative results of suprarenal extracts in antagonising the effects of adrenal deprivation. On the other hand, it has been shown by Hédon and others that the blood of a normal dog contains substances which, when allowed to circulate through the system of a depancreatised dog, prevent the occurrence of glycosuria. It has also been shown by Carlson and Drennan that if a pregnant bitch be deprived of the pancreas she does not suffer from glycosuria as long as her foetuses remain in utero. This experiment indicates that the autacoids produced by the foetal pancreas can pass to the maternal circulation through the placenta; and both experiments afford a clear indication that the influence of the pancreas upon carbohydrate metabolism is due to a chemical agent circulating in the blood. Later experiments of Hédon seem to show that the autacoid is inactive whilst within the pancreatic vein, and only becomes activated on passing through the liver.

${ }^{3}$ Ehrlich found the glycogen of the blood-leucocytes to be markedly increased in amomit in pancreatic diabetes. 
There are various ways in which the prevention of an undue accumulation and mobilisation of glucose and the consequent appearance of hyperglycæmia might be supposed to be effected by an internal secretion of the pancreas islets.

(1) The active agent may itself be a glycolytic ferment (Lépine) and may be the source of the glycolytic ferment which is known to be present in blood. If so, removal or disease of pancreas would tend to produce glycosuria in consequence of the absence of sufficient of this ferment to effect the splitting of glucose, so that the sugar of the body would not be metabolised further and would be passed out as such by the urine. As against this theory, it is found that in diabetes the glycolytic power of the blood is not diminished, and although in support of it the fact has been urged that a glycolytic ferment can be got from the pancreas, it must be pointed out that this is by no means peculiar to that organ, for a similar enzyme is yielded by most organs and tissues of the body.

(2) It may be of the nature of a kinase, the function of which is to convert a pro-ferment into ferment, or perhaps to promote the activity of an already existing ferment which serves to break down the molecule of glucose and prepare it for ultimate oxidation in the muscles, liver, etc. In support of this hypothesis it is stated by O. Cohnheim that a combination of muscle juice with pancreas juice (obtained from the cells by hydraulic pressure) is far more active glycolytically than either of the two employed singly; although, as Levene points out, the disappearance of sugar which is caused cannot be definitely regarded as glycolysis. According to De Meyer, a glycolytic pro-ferment which is activated by pancreas extract is contained in the blood-leucocytes. Anything which tends to prevent the formation of insuline, such as disease of the islet tissue, the entire removal of the pancreas, and perhaps the action of adrenalin, would therefore necessarily interfere with the glycolysis and prevent the utilisation of glucose by the tissues, so that hyperglycæmia and glycosuria would be produced. According to this theory, the tissues of a depancreatised dog should be unable or less able to utilise glucose for the production of muscular work. Experiments on heart muscle which seemed to support this were published by Knowlton and Starling. But other experiments by Porges and Salomon (on skeletal muscle) gave a contrary result, and Starling has since come to the conclusion that his results with Knowlton were within the limits of individual variations of the normal heart muscle.

(3) The substance (insuline) produced by the pancreas islets may be a chalonic autacoid which tends to inhibit the formation of glucose from glycogen, and incidentally to promote the storage of glycogen, so that in its absence the glycogen which is present in the liver is rapidly converted into glucose and the sugar absorbed from the alimentary canal or formed in the body is not stored by the liver. The result again will be hyperglycæmia and glycosuria. The fact that the conversion of glycogen into glucose occurs rapidly in the excised liver seems to indicate that there is 
something which under ordinary circumstances acts as an inhibitory agent, and we may suppose this to be present in the blood, and that it has been furnished by the pancreas.

The hypothesis that there exists a chalonic or inhibitory agent in the internal secretion of the pancreas which affects carbohydrate metabolism is probably the correct one. Whether this is of the nature of an autacoid or of an enzyme cannot be definitely stated, although the supposition that it is an autacoid is most in accordance with what is known regarding the effective agents of other internal secretions.

\section{Relation of Internal Secretion of Pancreas with Other ENDOCRINE ORGANS}

Hyperglycæmia is produced not only by extirpation of the pancreas, but in various other ways, such as by Bernard's sugar-puncture of the medulla oblongata, by stimulation of the splanchnics, and by the introduction of an excess of adrenalin into the blood.

We have seen that brushing the pancreas with adrenalin provokes marked hyperglycæmia and glycosuria, and that this is not merely due to absorption of the autacoid into the general circulation is shown by the fact that the excess of sugar is far greater than when other organs are so treated. It is not, however, only through the pancreas that adrenalin glycosuria is produced, for it has been shown by various observers that there is an increase of sugar in depancreatised animals (also in cases of pancreatic diabetes in man) as the result of adrenalin injection. Moreover; the effect of adrenalin is produced immediately both in normal and in depancreatised animals, whereas it takes some hours for the effect of depancreatisation upon carbohydrate metabolism to show itself. On the other hand, Zuelzer and others have found that adrenalin glycosuria is prevented by pancreas extracts and even by pancreatic juice; this effect is, however, according to De Meyer, not due to an antagonising autacoid, but to the effect of the extracts upon the permeability of the kidney for sugar. The result of administering pilocarpine, which produces marked secretion from the pancreas by exciting the secreting endings of the vagi, is also to prevent adrenalin glycosuria; possibly it acts by stimulating nerve-endings to the islet cells as well.

Loewy finds that after removal of the pancreas, adrenalin causes dilatation of the pupil when dropped into the eye; this does not occur in the normal animal. The same observation has been made in cases of diabetes in man-presumably these cases are of pancreatic origin.

With regard to the relations between the pancreas and the thyroid and parathyroids, it is found that removal of the thyroid tends to prevent, and removal of the parathyroids to facilitate, both pancreatic and bulbar glycæmia and glycosuria. The thyroid autacoid may therefore be regarded as in this matter antagonistic to that of the pancreas, whilst the parathyroid 


\section{Relation of Pancreas with Other Endocrine Organs}

assists it. It may be that the increased tolerance to sugar which is associated with diminished activity of the thyroid, the posterior lobe of the pituitary, and the medulla of the suprarenals respectively, is brought about through the effect of the changes in those organs upon the pancreas.

The mode of production of pancreatic diabetes is in need of further elucidation. It would appear, however, from what has been above stated, that, apart from the liver, which acts as the main storehouse for carbohydrates, a number of organs are concerned in governing the metabolism and mobilisation of those bodies, all these organs being mutually interdependent. Of such organs the pancreas, probably by virtue of the internal secretion of its islet tissue, may be regarded as occupying the central position.

The interrelations of these endocrine organs (particularly the thyroid, pancreas, and suprarenals) in connexion with the production of glycæmia and glycosuria have been especially dwelt upon by Eppinger, Falta, and Rudinger. The relations of the internal secretion of the pancreas with glycogenic functions of the liver are dealt with at length by De Meyer, Sécrétion interne du pancreas, 1910. 


\section{THE INTERNAL SECRETIONS OF THE GENERATIVE GLANDS IN THE MALE ${ }^{1}$}

\section{The Interstitial Cells of the Testicle}

IT was noticed by Leydig in 1850 that the intertubular connective tissue of the testicle is characterised by the presence of strands of epithelium-like cells; these have been termed the cells of Leydig, and, collectively, the

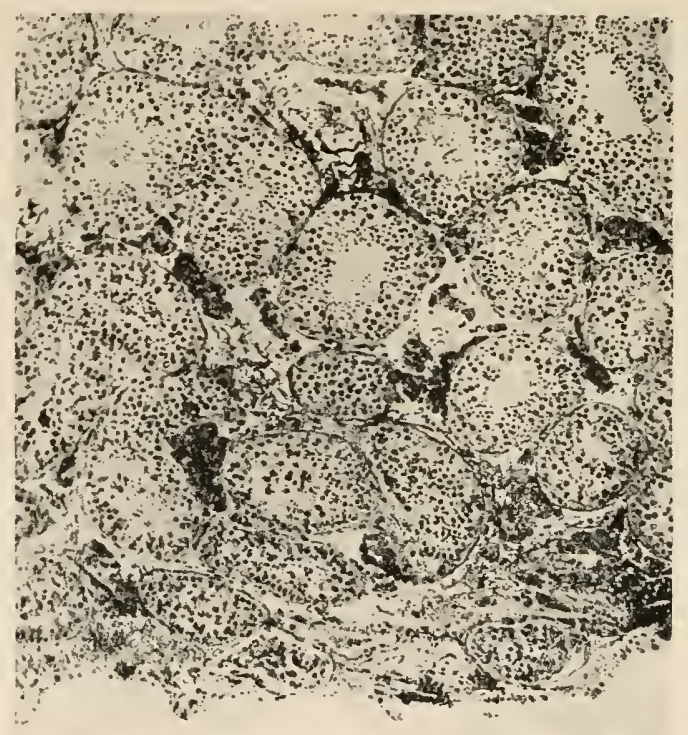

FIG. 90. - Section of testicle, human, showing groups of interstitial cells between the tubules. Magnified 50 diameters.

interstitial gland of the testis. They vary in development in different species of animals, being very well marked in the cat (fig. 92), less so in the dog and mouse, and still less in the rat and rabbit: in man they may be quite conspicuous (figs. 90, 91). The cells are always present to some extent, and Tandler and Grosz have shown that in animals which undergo seasonal changes in sexual activity the interstitial cells may be even better developed when the seminiferous tubules are inactive than during the time

1 For a fuller discussion of the subject of internal secretion in connexion with the sexual organs, F. H. A. Marshall's Physiology of Reproduction may be consulted. 
of their activity, their increased development generally immediately preceding that of the seminiferous epithelium. The tissue may also be found well developed in cases where there is atrophy of the contents of the seminiferous tubules, as in cases of cryptorchidism and after ligature of the vas deferens; although if the whole of the spermatic cord be included in the ligature, so that the circulation and nerve-supply to the testicle is interfered with, the interstitial cells share in the general atrophy of the organ which ensues, and the result is the same as castration (Vincent and Coleman).

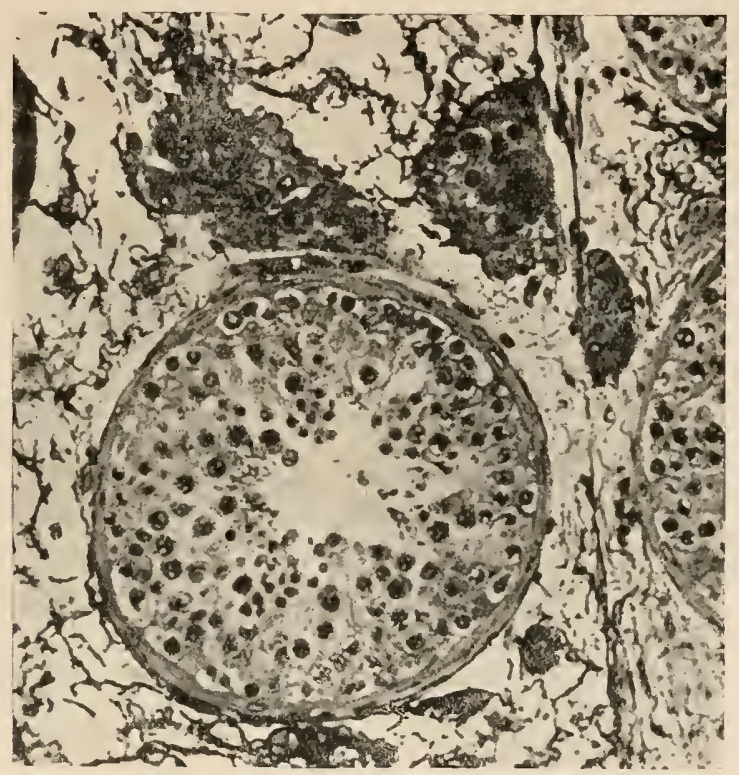

Fig. 91.-Interstitial cells of testicle, human. Magnified 200 diameters. One tubule and parts of two others are shown. The groups of interstitial cells lie in the loose intertubular reticular tissue. (Figs, 90 and 91 are from an iron-hæmatoxylin preparation given me by Professor dlartin Heidenhain.)

These interstitial cells are polygonal in shape with spherical nucleus, a well-marked nucleolus, and a double centrosome. The cytoplasm often contains lipoid granules of a yellowish colour, which are blackened by osmic acid; besides other granules of protein nature, which may be either oxyphil or basiphil. Frequently there are crystals within the cells, but the exact nature of these has not been determined.

\section{EFFECTS OF CASTRATION}

The results of removal of the testes are well known. If the operation is performed in the child the secondary sexual organs-especially the prostate and seminal vesicles-remain in an undeveloped condition, and the special secondary sexual characters, such as the growth of hair on the face, the enlargement of the larynx, and the development of the male characters 
of the skeleton, are not seen. In such animals as birds and deer, in which the external characteristics of the male sex are well marked, these characteristics fail to show themselves, the general features of development approaching those usual to the female sex. In the skeleton, the epiphyses long remain separate; the limb bones are longer and more delicate than usual, and the sutures of the skull slower in ossifying. The mental character also tends to retain a more infantile type. Most of the ductless glands are in some way affected, the growth of the thyroid being diminished, that of the suprarenal cortex, pituitary, and thymus increased : the last-named organ shows arrest of its normal retrogressive changes.

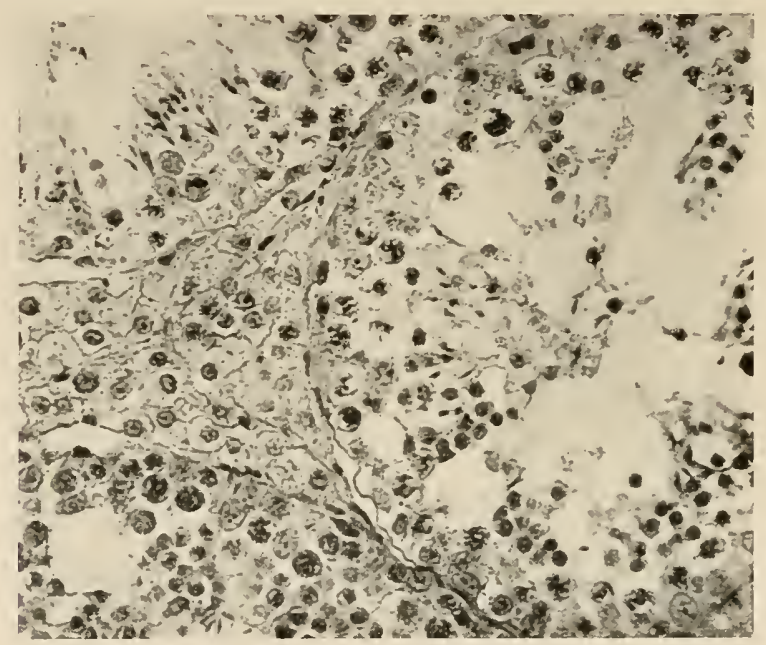

FIG. 92.-Interstitial cells of testicle, cat. Magnified 200 diameters. Parts of three tubules are included in the photograph.

If castration is performed in the mature animal, and therefore after the secondary sexual characters have become developed, there may be some retrogression of these, and such accessory generative glands as the prostate tend to undergo atrophic changes. But the effects are now mainly upon metabolism, and are shown in a tendency to increased formation of fat, although the limit of assimilation of carbohydrates is lowered and alimentary glycosuria is more easily produced. How far these effects on metabolism are direct or how far indirect, through other endocrine organs, it is not possible to say, but the fact seems to be well established that the pituitary body becomes hypertrophied after castration (Fichera, Cimorini). The increased length of limb bones which occurs when the operation is performed before adolescence may be associated with this change in the pituitary (Tandler).

In certain animals which undergo seasonal variations in sexual activity the secondary sexual characters which generally accompany these variations are also abolisherl or modified by castration. Thus if a stag is castrated, the antlers 
either remain undeveloped or if developed are shed prematurely and are not replaced, or replaced ouly by incomplete growths. But structures which are common to both sexes-in species, for instance, in which both sexes possess hornsare not modified by castration. In Arthropoda the correlation between the generative glands and the secondary sexual characters (which in many species are even more marked than in Vertebrata) does not hold good. Experiments upon caterpillars show that removal of the generative glands has no influence on the development of the male sexual characters of the imago; nor do the glands, if transplanted into individuals of the other sex, affect the secondary sexual characters or instincts of the host. This need not be taken to mean that the secondary sexual characters in these animals are not the result of an internal secretion, but may be interpreted by supposing that some organ other than the generative glands furnishes the internal secretion which produces those characters.

In Vertebrata, at any rate, there can be little doubt that the internal secretions of the generative glands are an important if not the chief factor in determining the development of the secondary sexual characters. And that this development is independent of the normal functions of the generative glands is shown by the fact that ligature of the vas deferens has no effect in preventing it. Moreover, transplanted testes and portions of testis (in which the generative cells themselves may completely disappear) have been found capable (in birds) of preventing the results of castration: the comb, wattles, spurs, etc., of the cock being developed in the usual way (Shattock and Seligmann and others). Nussbaum's experiment on the effect upon the development of the thumb-pad of grafting pieces of testis from another frog into the dorsal lymph sac of a castrated male frog also points to the existence of an internal secretion of the testicles in these animals.

\section{The Nature and Source of the Testicular Autacoid}

It seems certain, therefore, that the development of the secondary sexual characters in the male sex is dependent upon an internal secretion of the testicle, and it is highly probable that it is yielded not by the generative cells (gonads) but by the interstitial cells. In cryptorchids, and also after experimental ligature of the vas deferens, in both of which, as we have seen, the seminiferous epithelium is atrophied but the interstitial tissue is well developed, the secondary sexual characters and sexual desire are normal. Successful implantation of the whole or part of a testicle in a young castrated animal is also followed by development of those characters, although in most cases the seminiferous epithelium of the graft disappears. Loewy found male secondary characters developing in caponised cockerels fed with testicle-substance. Bouin and Ancel state that extract of testicle freed from all morphological elements may, when injected, produce a similar result. In support of the theory that an autacoid which affects the development of the secondary sexual organs and characters is formed by the interstitial cells, they have found that if one testicle is removed from a rabbit and the remaining one has the vas ligatured its interstitial tissue becomes hypertrophied. Further, it is known that if the testicles are exposed to the action of $\mathrm{X}$-rays the seminiferous epithelium undergoes 
degeneration, although the interstitial tissue is not, at first at any rate, attacked. Young animals so treated develop normal secondary sexual characters. Moreover, remarkable cases have been described, in both the male and female sex, in which tumour's of the testicle and ovary, apparently malignant in character, occurring in children, have been accompanied by a general growth of stature and by premature appearance of secondary sexual characters, such as growth of hair on the face in the male and in the armpits and on the pubes in both sexes, development of breasts and external generative organs: in short, all the signs of puberty; which, on removal of the tumour, have been found to disappear. These seem to be cases of tumour cells taking on the functions of normal cells (in this case interstitial cells) from which they have developed (see p. 33).

\section{Effects of Extracts of Testicle}

Brown-Séquard was of opinion that subcutaneous injection of testicular extracts has the effect of producing a bodily and even more a mental rejuvenation, and he ascribed this to the occurrence in such extracts of certain principles which are taken up into the blood, and through this act upon the nervous system. $\mathrm{He}$ supposed that similar principles are produced also in the ovaries, but to a less extent. The results he announced nave not, however, been obtained by others who have tested the physiological effects of such extracts, and the views he enunciated have not obtained general assent, although certain observers claim to have obtained positive effects on the growth and development of young castrated animals, and also of immature entire animals.

Intravenous injections of testicular extracts produce no immediate results except a fall of blood-pressure, due, according to Dixon, to cardiac inhibition. 
CHAPTER XIX

\section{THE INTERNAL SECRETIONS OF THE GENERATIVE ORGANS IN THE FEMALE}

\section{The Interstitial Cells of the Ovary}

The ovary contains-besides the Graafian follicles with their ova, follicular epithelium and liquor folliculi and the corpora lutea-a highly vascular stroma formed of a peculiar connective tissue, firm in texture and containing

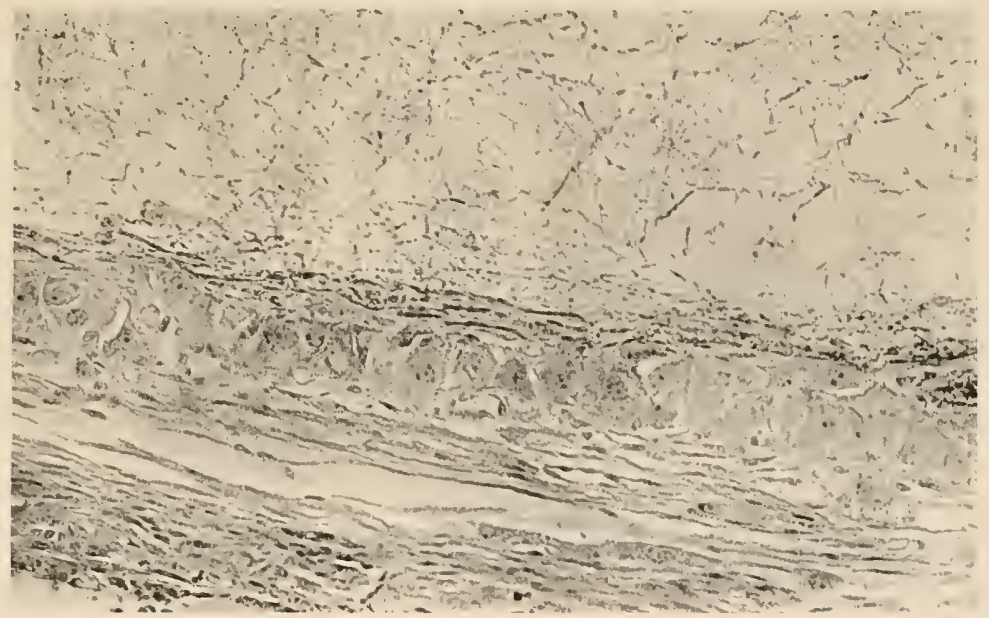

Fig. 93.-Section of the wall of a Graafian follicle of the rabbit, from which the ovum and follicular epithelium have just been discharged. The cavity is occupied by a blood-clot of which part of the fibrin-network is shown in the photograph. Notice the large cells in the wall of the follicle (theca) from which the luteal cells become developed. Magnified 200 diameters.

numerous spindle-shaped cells. In some animals it is possible to discover in the stroma groups of cells of a different appearance from that of the ordinary stroma cells. These have been named the interstitial cells of the ovary, and have been thought to be analogous to the interstitial cells of the testicle. But the interstitial cells of the ovary do not form so distinct a tissue as those found in the testicle; they are, moreover, said to be destroyed by the $\mathrm{X}$-rays, whereas those of the testicle are not so affected: they appear therefore not to be of identical nature. As the Graafian follicles mature, their wall (theca) is found to contain peculiar large epithelium-like cells (fig. 93) (theca cells), derived from the stroma and not improbably 
from the interstitial cells. It is from these theca cells that the cells of the corpora lutea are derived; while, on the other hand, as the latter disappear, many of their cells tend to lose themselves in the substance of the stroma.

\section{The Corpora Lutea}

The manner of development of the corpora lutea appear's to be as follows:-The larger follicles become gradually more distended with liquor

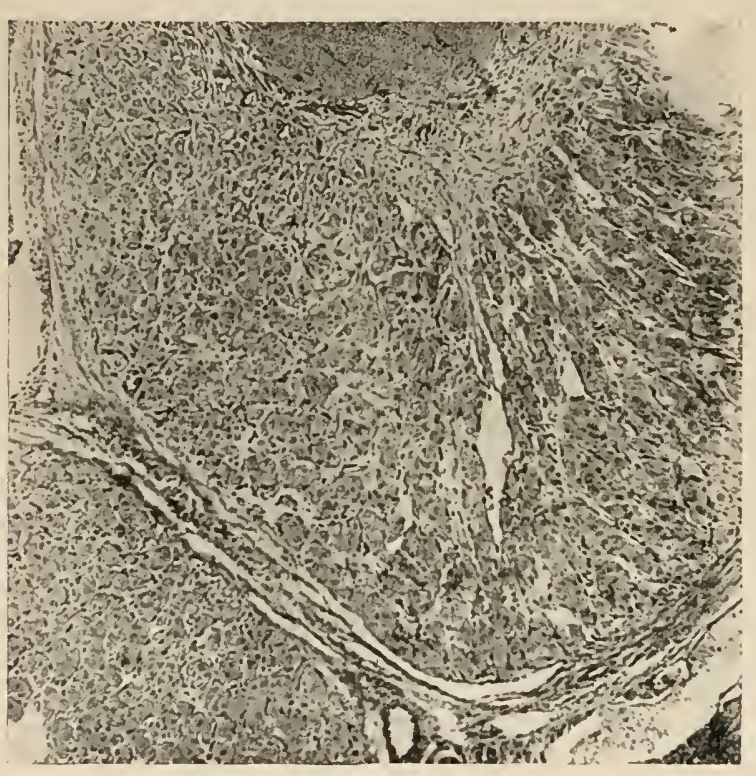

Fig. 94. - A stage in the development of a corpus luteum of the rabbit in which the cells form trabecula converging towards the remains of the blood-clot which originally occupied the cavity of the Graafian follicle. Magnified 60 diameters. folliculi, and ultimately split open at the thinnest and most prominent part. When the follicle bursts, the ovum and discus proligerus escape, and the rest of the follicular epithelium also becomes detached from the follicular wall and extruded or disintegrated. The cavity of the follicle is now usually occupied by a bloodclot (fig. 93), derived from vessels at the point of rupture of the follicle. The enlarged cells in the wall of the theca multiply and grow into the cavity, displacing the clot towards the hilum of the follicle. They are filled with lipoid droplets which give the structure the yellowish colour from which the name corpus luteum is derived. The cells are now known as luteal cells; in most animals they arrange themselves in trabeculæ converging towards the remains of the clot (figs. 94, 95), which becomes gradually organised, its place being taken by fibrous or cicatricial tissue. Sinus-like blood-vessels grow in from the theca along with the luteal cells, and the whole structure eventually forms, in most animals, a solid gland-like vascular mass, which is usually much larger than the follicle it replaces. In animals which have several young at a birth, and in which therefore several follicles come to maturity at about the same time, the resulting corpora lutea may appear to occupy almost the whole ovary, which becomes greatly enlarged as they develop.

From the above account, which is based upon observations in the rabbit and corresponds with that originally furnished by von Baer, since confirmed by many 
histologists, it seems clear that the corpus luteum is developed entirely from the theca cells of the burst follicle: these cells are themselves derived from stroma cells, so that the follicular epithelium takes no part in the formation of the corpus luteum.

Sone authorities hold, however, that the follicular epithelium is not lost when the follicle bursts, but that its cells undergo proliferation and become enlarged and transformed into luteal cells, so that a part if not the whole of the corpus luteum is formed from the epithelium which originally lined the Graafian follicle.

In the human subject, as in the lower mammals, the luteal cells at first form a layer lining the wall of the follicle. Presently this layer becomes plaited into thick folds tending to converge towards the cicatrix of the follicle. After a time the cells forming the folds undergo a peculiar change; they lose their distinct outlines, become stained with great difficulty, and are closely clumped together in thick trabeculæ, the whole having a characteristic appearance and distinct yellow colour.

The corpus luteum is well marked throughout pregnancy, although towards the end it becomes less sharply defined from the ovarian stroma. Similar

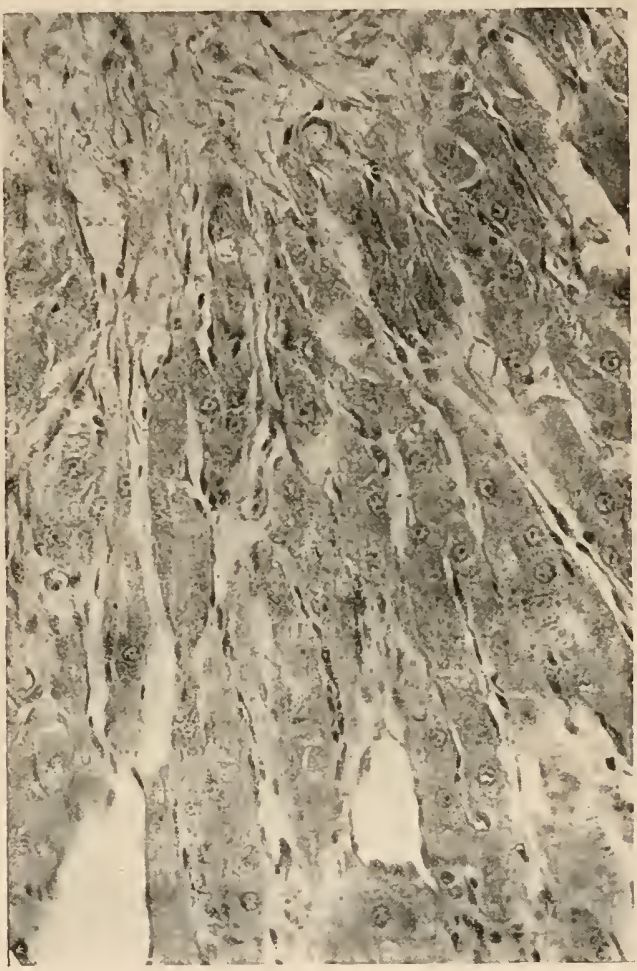

F1G. 95. - Part of the section shown in fig. 94 . Magnified 200 diameters. changes occur-but with far less increase in size-in burst follicles where pregnancy has not supervened. The corpora lutea thus produced have been termed corpora lutea spuria to distinguish them from the corpora lutea verch of pregnancy.

\section{Effects of Removing and Remplanting Ovaries}

The effects resulting from removal of both ovaries (oöphorectomy; spaying) are externally not so striking as with the similar operation in the male sex. If the operation is performed in young animals, or if the ovaries are congenitally atrophic, it is not infrequently found that characters distinctive to the male are to some extent assumed. In the human subject, as well as in animals, a constant result is that the uterus remains small: 
the external changes characteristic of puberty either do not occur or are greatly modified: there is absence of menstruation. A tendency to the male type of trichosis is often also exhibited. When the operation is performed subsequently to puberty the results are less marked-but menstruation ceases, and there is sometimes atrophy of the mammæ; in animals a diminution in size of the uterus and Fallopian tubes has been substantiated (Carmichael and Marshall, in rabbit; Marshall and Jolly, in white rat). According to Hatai the suprarenal capsules are diminished in size in the female white rat, whereas in the male castration causes a marked increase of those organs: the same author states that although there is an increase in size of the pituitary, it is very slight as compared with the effect of castration in the male. Metabolism is affected mainly, as in males, in the direction of a tendency towards adiposity. This, however, may be indirect and through other ductless glands, which are affected much in the same way as they are in the male sex by removal of the testicles (p. 134).

Doubtless, as in the male sex, the effects which are produced by the ovaries in determining the female secondary sexual characters are due to an internal secretion. And reasoning from analogy one would be disposed to refer the production of this not to the generative epithelium but to special cells, like the interstitial cells above referred to. The periodical changes (heat, menstruation) which occur in the female appear to be due neither to the Graafian follicles nor to the corpora lutea. For heat in animals still occurs if the corpora lutea are destroyed, or if none are present in the ovary. Moreover, the changes which follow spaying can be prevented by ovarian grafts, and these may contain no corpora lutea. The grafts may also show after a time no Graafian follicles-these having undergone degeneration and disappearance. ${ }^{1}$ And even in the absence of Graafian follicles from the implanted ovarian tissue, Marshall and Jolly and A. L. M'Tlroy have shown that the atrophic changes in the uterus which ordinarily follow spaying are prevented by the graft.

1 This is not, however, a necessary consequence of reimplantation, for instances are recorded of development of Graafian follicles and formation of corpora lutea, or even of the supervention of pregnancy, after reimplantation of ovaries in spayed animals. Such an occurrence in the case of a woman has been reported by Halliday Croom. 


\section{CHAPTER XX}

\section{THE INTERNAL SECRETIONS OF THE GENERATIVE ORGANS IN THE FEMALE (continued)}

\section{Effects of Orarian Extracts}

On the Uterus. - Extracts of ovary influence the contractions of the uterus and of plain muscular tissue in general. These effects, which have recently been worked out in my laboratory by Dr M. Itagaki, of Kyushu University, but are as yet unpublished, are illustrated by the accompanying tracings (figs. 96 to 101).

The methods employed to obtain these tracings have been (1) immersion of a length of uterine cornu, or of a strip of uterine muscle, in warmed and oxygenated Locke's solution, the Locke's solution being replaced for a short period of time by the extract to be investigated, which is itself made with Locke ; (2) injection of the extract into the circulation, and recording the effect upon the uterus or intestine, and at the same time the blood-pressure and kidney volume. The extracts have been made separately from corpora lutea, Graafian follicles, liquor folliculi, and hilum ovarii (i.e. stroma without corpora lutea or Graafian follicles, but presumably containing interstitial cells), and always by boiling the tissue, either fresh or dried, with Locke's solution (without glucose). The ovaries of the sheep and cow were used for preparing the extracts, and the testing was performed on the tissues of the rat, guinea-pig, rabbit, cat, and dog. Occasionally the desiccated organ was extracted first with chloroform and then with absolute alcohol ; these extracts were evaporated down and the dry residue extracted with Locke; the remainder of the gland which was left after the chloroform and alcohol had acted upon it being also extracted with Locke.

A striking effect of intravenous injection is obtained with extracts of hilum (interstitial cells). This usually causes inhibition of the normal rhythmic movements, if present, and diminution of tone of the uterine muscle, which may be preceded by an increase (fig. 96). Accompanying this change there is a considerable fall in blood-pressure, even in atropinised animals, and a diminution in volume of the kidney. Corpus luteum extract injected into the veins causes the uterus if quiescent to begin contracting, if already contracting to increase its contractions and to assume an increased tone. Little or no effect on blood-pressure or kidney volume is produced by this extract.

The result of immersing portions of uterus or strips of uterine and most other plain muscle in extract of follicular tissue or liquor folliculi is 


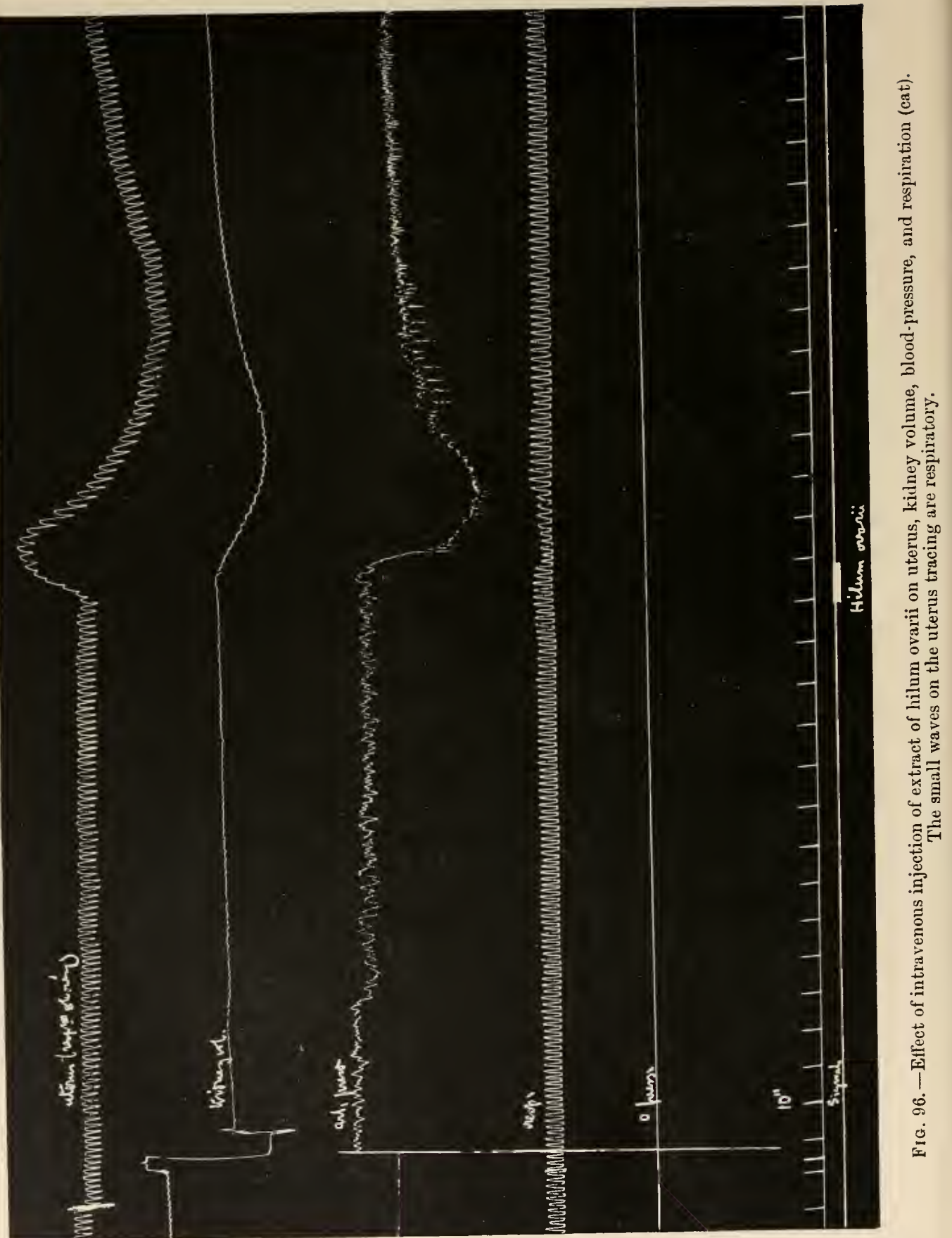


generally to cause an increase of force and rate of the rhythmic movements, and increased tone of the muscle. With hilum ovarii the effect is inhibition

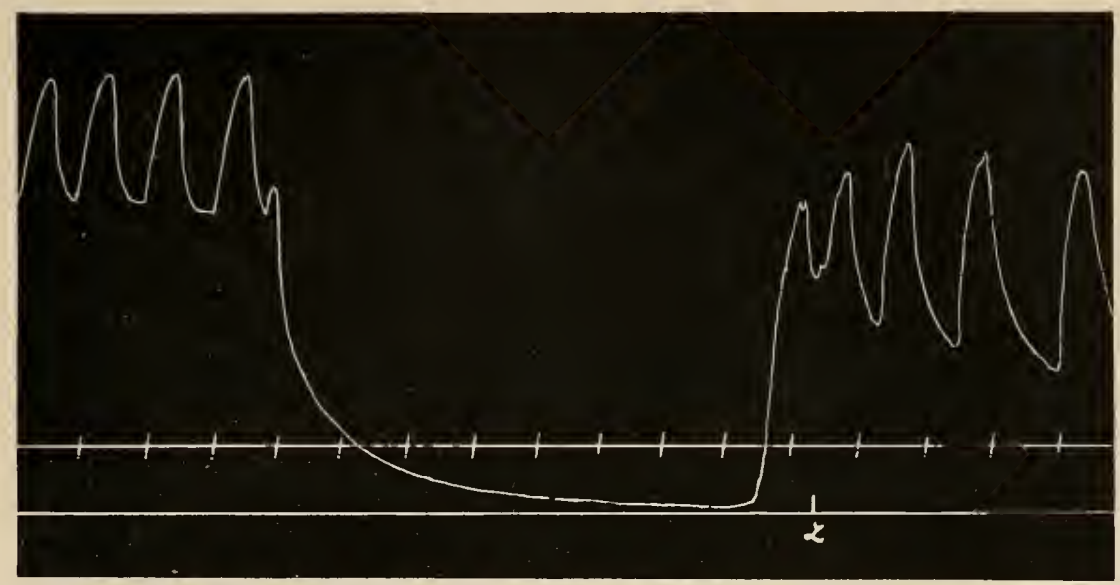

Frg, 97.-Effect of addition of extract of hilum ovarii of cow to Locke's solution in which a cornu of uterus of rat was suspended. Notice the cessation of rhythmic contractions and diminution of tone.

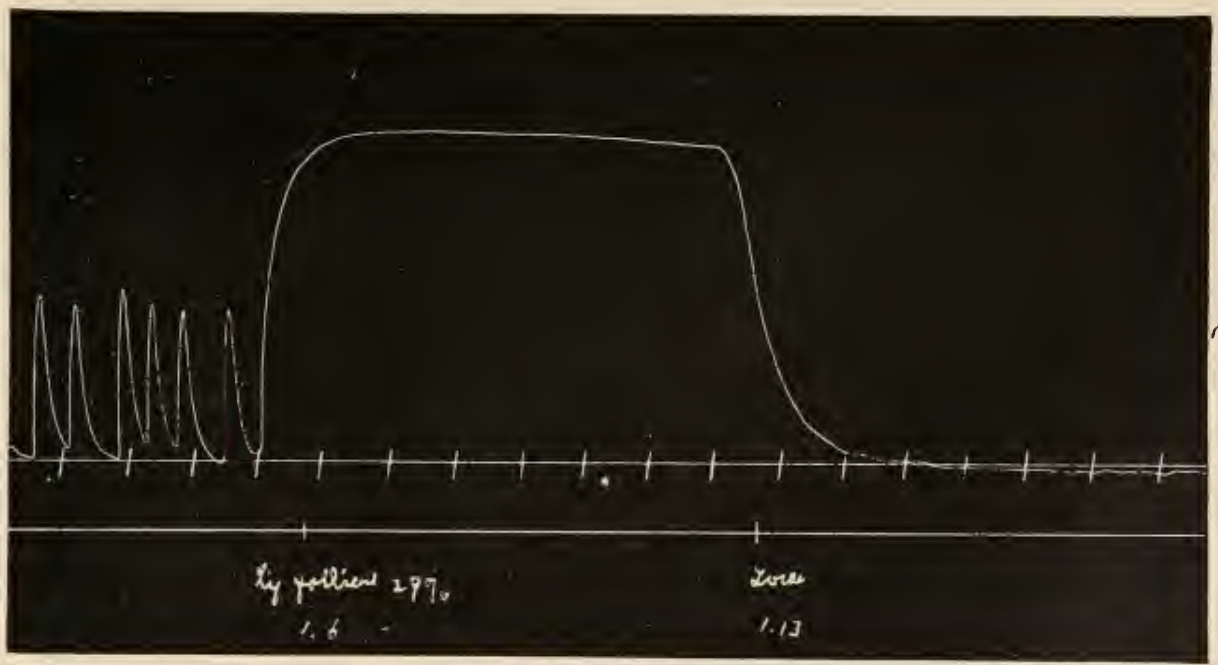

FIg. 98.-Effect of addition of liquor folliculi of cow to Locke's solution in which a cornu of rat uterus was suspended. Notice the increase of tone with cessation of rhythmic movements. At "Locke" the liquor folliculi was removed and Locke's solution substituted.

with marked diminution of tone. Rarely this inhibitory effect rather than increased contraction is obtained with the other extracts.

It appears probable from these observations that ovarian extracts contain two different kinds of autacoid acting upon plain muscle, especially upon 
that of the uterus. One of these is a hormone, and either excites the muscle to contraction or renders it more excitable to the natural stimuli which are producing the contractions; the other is a chalone, tending to prevent or diminish the contractions. The difference of result obtained would depend

uterus

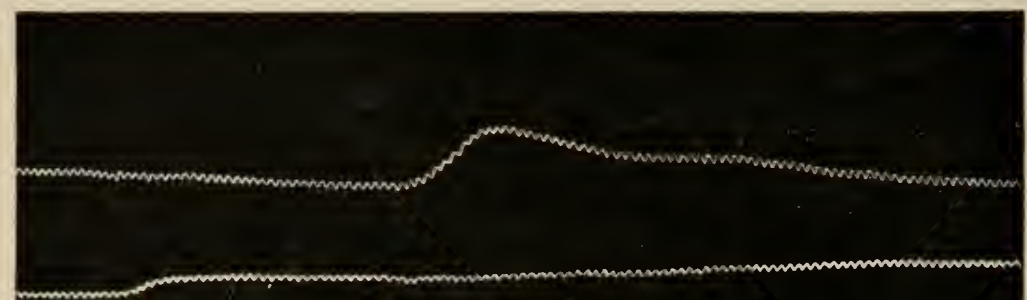

kidney

carotid

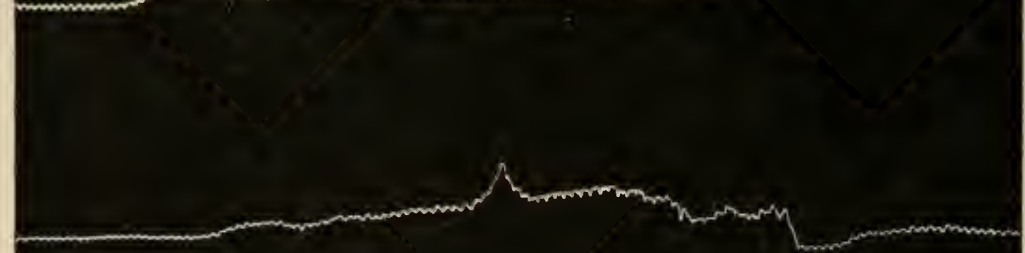

respira. tions

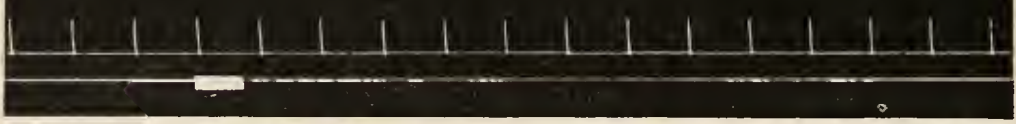

signal

FIG. 99.-Effect of intravenous injection of extract of corpus luteum on uterus, kidney volume, blood-pressure, and respirations of cat. The small waves on the uterus curve are caused by the respirations.

upon the relative amount of one or other autacoid in a particular extract, and on the sensitiveness of the tissue under examination to the effects of excitatory or inhibitory agents. Whether the action is exercised through nerve end-organs, or whether it is a direct effect upon the contractile tissue, is a point which it has not been easy to determine.

On Milk Secretion.-One of the effects of intravenous injection in lactating animals of extract of corpus luteum is to provoke an outpouring 
of milk (Ott and Scott). This galactagogue action was found by Mackenzie to be absent in extracts of ovary minus corpus luteum. It resembles that

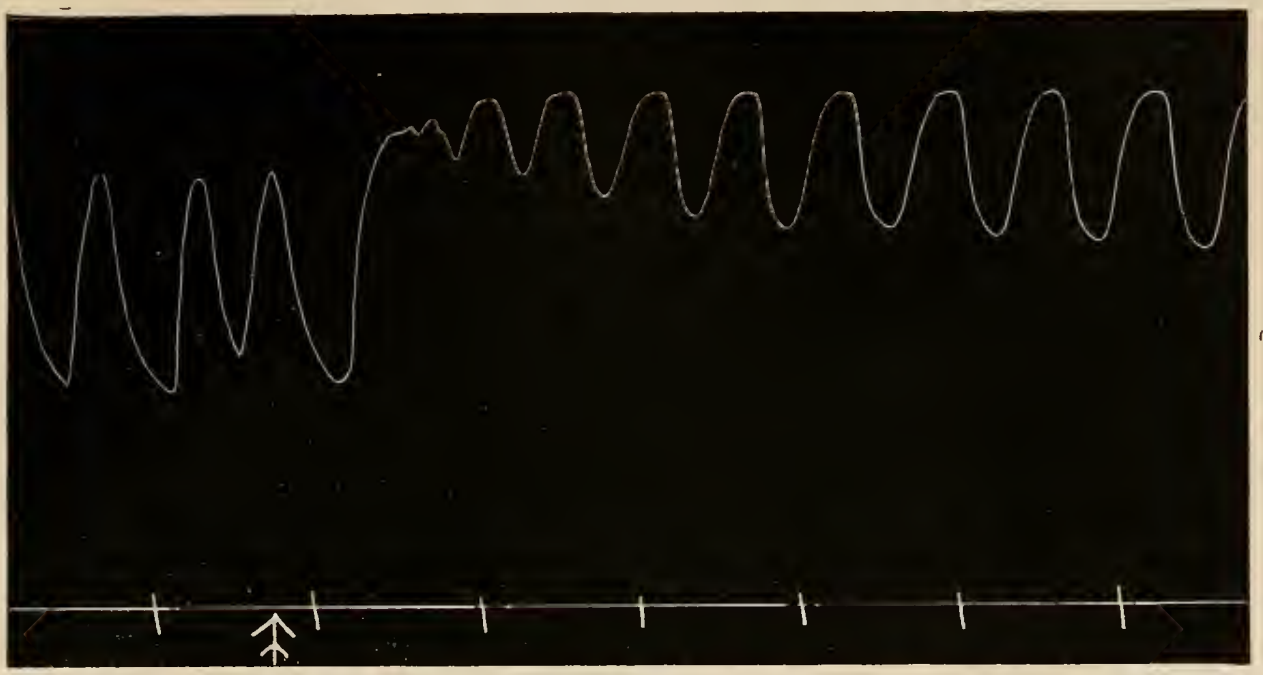

FIG. 100. -Effiect of extract of corpus luteum of cow on isolated cornu uteri of rat. Marked increase of tone is produced.

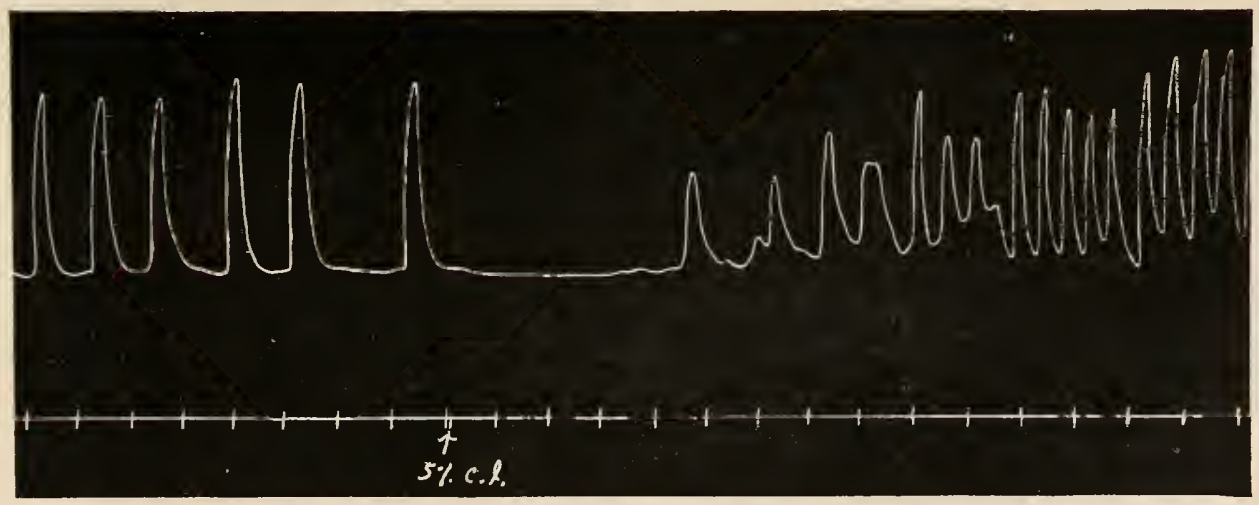

FIG, 101.-Effect of extruct of corpus luteum of cow on isolated cornu uteri of rabbit. Inhibition, followed by increased rapidity of rhythm, is produced. (I am indebted to Dr MI. Itagaki for the tracings shown in figs. $97,98,100$, and 101.)

of pituitrine, and seems to be the result of stimulation of plain muscle in the walls of the mammary alveoli (see p. 94).

\section{Metabolic Effects produced by Corpus Luteui}

Th. Sack found that if corpus luteum be added to the food of white rats it promotes retention of nitrogen, i.e. laying on of flesh, in females; 


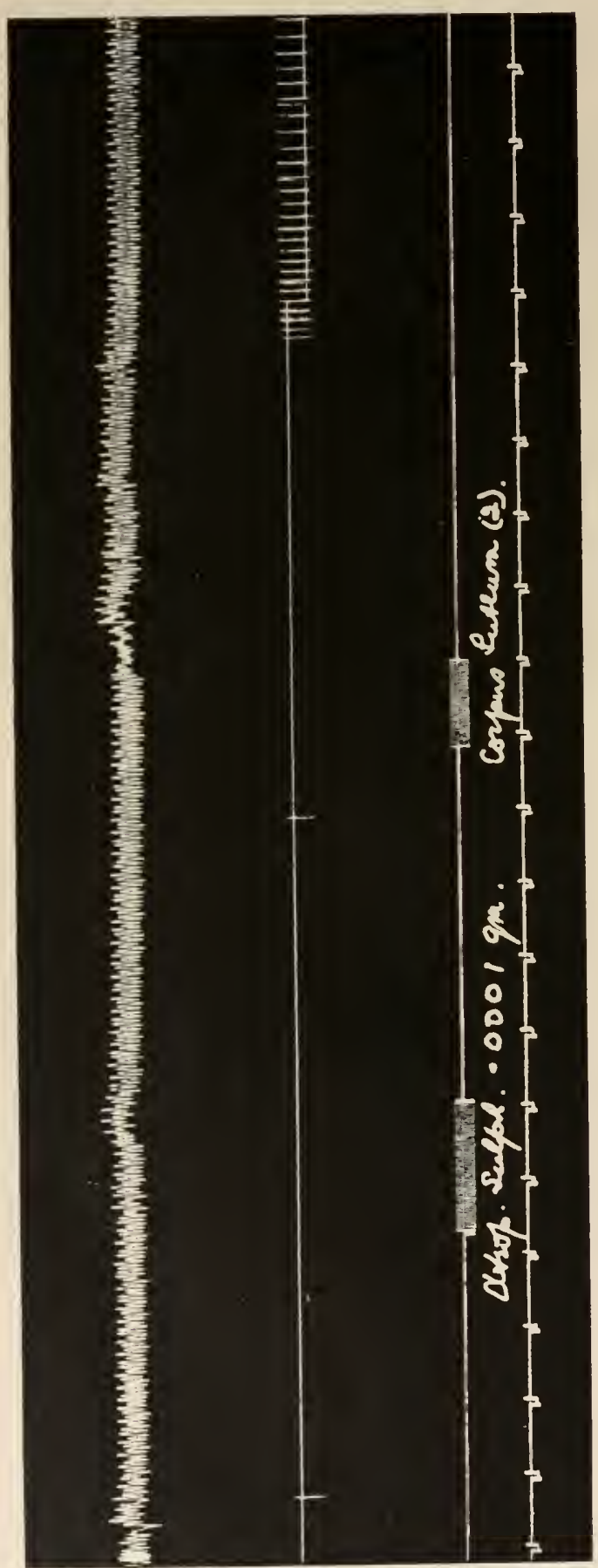

$\approx$

\section{virin rabbita Graatian} follicle be ruptured (even by mechanical means) so that a corpus luteum develops, the mammæ undergo evolution; whereas if a corpus luteum fails to form there is no such evolution. Hammond and Marshall state that under these circumstances the development of the mammæ may even proceed so far as to produce free secretion of milk. Ott and Scott have obtained marked development of the mammæ, and even secretion of milk, in young virgin rabbits injected subcutaneously at frequent intervals for a month with extract of corpus luteum.

It is further stated by Ancel and Bouin that if all the corpora lutea are destroyed in a pregnant rabbit the development of the mammary gland is 


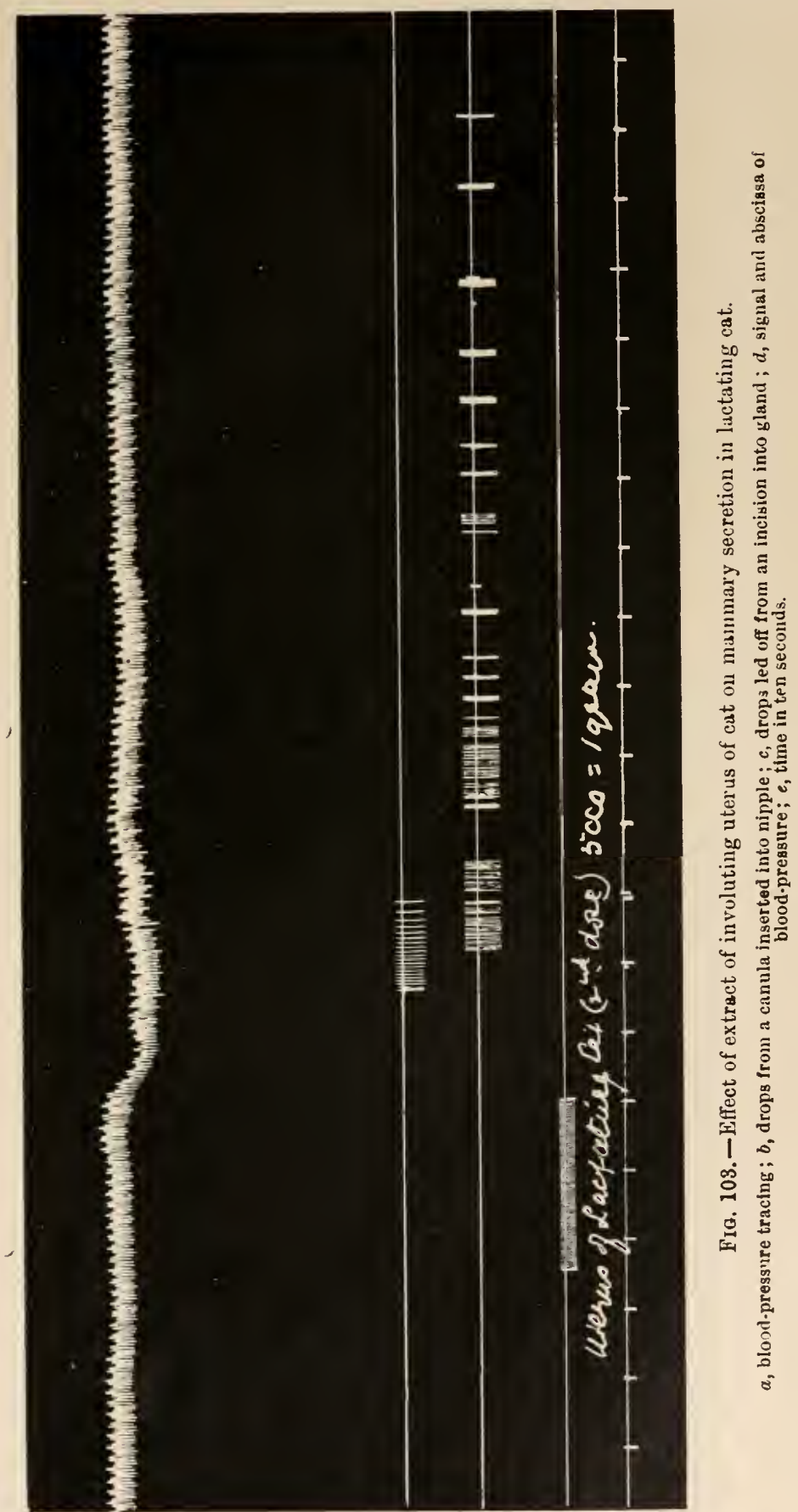


arrested, and it is inferred that their secretion is necessary for such development. It must, however, be pointed out that it is next to impossible to destroy the corpora lutea without practically destroying all the ovarian tissue, for the corpora lutea of the pregnant rabbit form by far the greater mass of the ovary. This applies also to Fraenkel's experiments (see below).

An important function of the internal secretion of the ovary-perhaps of the corpus luteum-relates to the formation of the uterine decidua and the fixation of the embryo. Fraenkel-working upon a hypothesis suggested by Born-found that if in rabbits the corpora lutea are destroyed at an early period of pregnancy the embryo does not become adherent to the mucous membrane of the uterus, and ceases to develop. Marshall and Jolly, working with dogs and rats, obtained similar results from double ovariotomy in early pregnancy. L. Loeb observed that mechanical stimuli are able to produce the formation of decidual membrane and uterine hyperplasia if corpora lutea are present in the ovary, but that there is no such change in their absence. Extracts of corpus luteum are not in this respect able to replace the functions of the removed organs.

Loeb has shown that in the guinea-pig extirpation of the corpora lutea accelerates bursting of the ripe Graafian follicles, i.e. is conducive to ovulation; this suggests that their presence militates against ovulation.

\section{INTERNal SECRETION OF Uterus}

There is some evidence that in certain states the uterus itself may yield an internal secretion. Blair Bell has suggested that menstruation and ovulation depend on such a secretion, and Bond has described experiments which appear to indicate that an internal secretion from the uterus promotes the growth of the corpus luteum. But these views find no support in the experiments of Carmichael and Marshall, who obtained typical development of the ovaries, with ovulation and formation of corpora lutea, in animals (young rabbits and adult rats) from which the uterus had been completely removed. Bouin and Ancel have described an epithelium-like formation in the muscular coat of the uterus of the rabbit and guinea-pig during the latter half of pregnancy which they consider to be related to the development of the mammary glands during the final period of gestation and the production of milk. To this formation they have given the name of "glande myométricale endocrine." Mackenzie found that extracts from the involuting uterus of the cat shortly after parturition cause a free flow of milk from the incised nipple of lactating animals (fig. 103). He obtained no such results with extracts made from the non-pregnant uterus, or from the pregnant uterus at other times. He infer's, therefore, that the uterus contains a galactagogue hormone only at this period. 


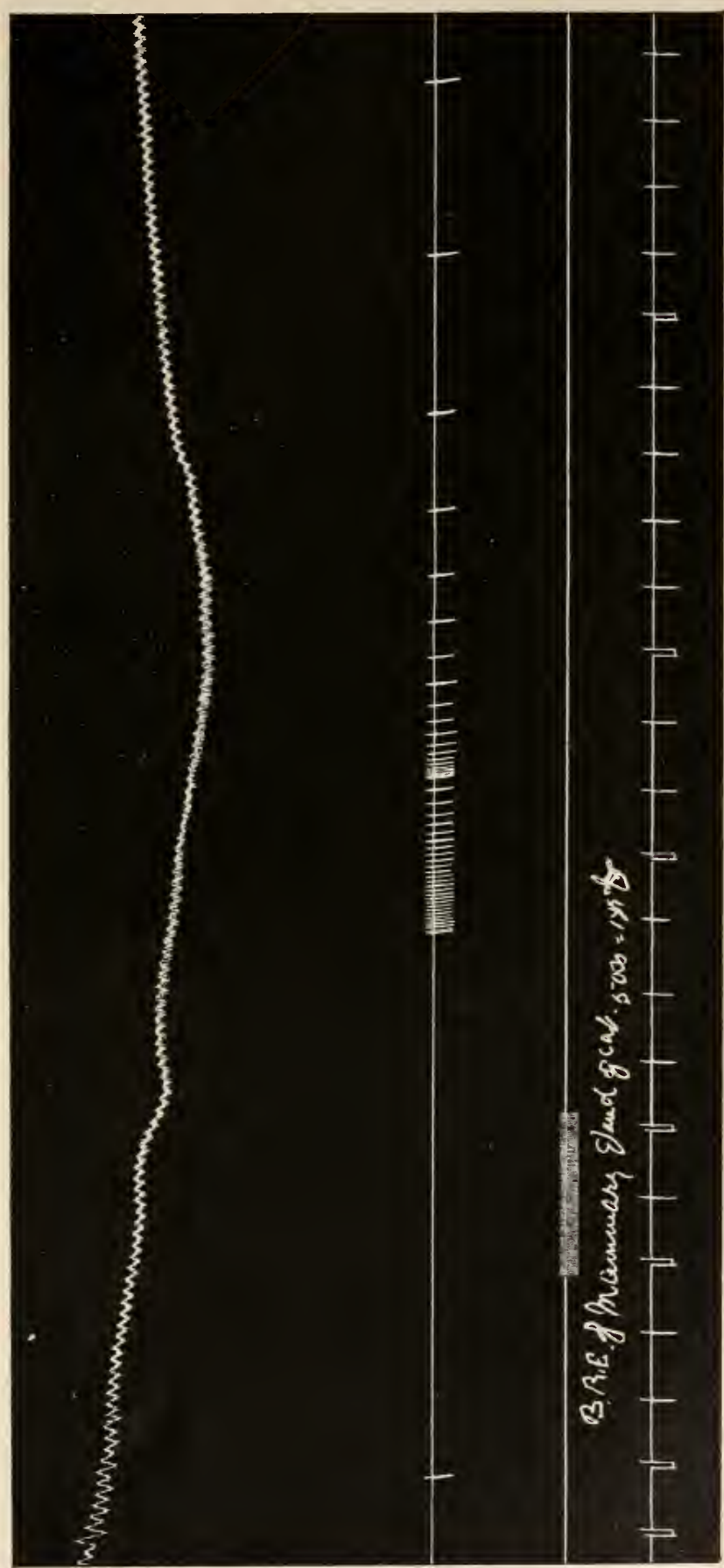




\section{Internal Secretion of Mammary Gland}

A similar galactagogue effect was obtained by Mackenzie as the result of intravenous injection of extract of lactating mammary gland (fig. 104): no result was obtained from the gland of non-lactating animals.

Adler found subcutaneous injection of extract of mamniary gland to produce enlargement of the suprarenals and increase of adrenalin in the blood, sometimes sufficient to cause glycosuria. He also found it to arrest the development of the embryo, and even to produce abortion in pregnant animals. These observations require confirmation.

\section{Internal Secretion of Placenta}

Halban has suggested that the placenta furnishes the stimulus for the development and growth of the mammary glands, whilst inhibiting the pouring out of their secretion. That the former is improbable is indicated by the fact that the mammæ may become developed in exceptional cases in the virgin, and even in the male sex. ${ }^{1}$ The second suggestion has received some support from the experiments of Mackenzie, who found that injection of placental extract tends to inhibit the effect of such galactagogue extracts as pituitary or corpus luteum. A similar result was obtained by Mackenzie with extract of fotus, which also has been described as promoting mammary development. ${ }^{2}$ It would seem, therefore, that both placenta and fotus produce chalonic autacoids which have an inhibitory effect on milk secretion. As a commentary on this, it may be noted that secretion by the mammary gland does not begin until the removal of any influence which might be derived from placenta or fœetus.

1 As W. Heape has pointed out, this objection is also applicable to the fœtal hormone theory of Starling and Lane-Claypon (see below).

2 By Starling and Lane-Claypon, and by Foà. There seems to be some doubt whether the changes described were a specific effect of the foetal extract. 


\section{INDEX}

Acetonitrile, resistance to poisonous action in mice, 38 .

Acromegaly (see also under Pituitary), 106. causation, 109.

symptoms of, $107,109$.

Addison's disease (see also under Suprarenal), 49. administration of suprarenal extract in, 57 . pigmentation in, 49 . prognosis of, 49 . suppression of functions of suprarenal in, 57 . symptoms of, 49 .

Adiposity, relation to pituitary, 101, 102, 111, 112.

relation to sexual organs, 134,140

to thyroid, 31.

Adrenalin (see also Suprarenal capsules), chemistry of, 58 .

chromaphil reaction, 50 .

in diphtheria, 57.

disappearance of, in the body, 67 .

inactivation of, by cerebro-spinal fluid, 67 .

by formaldehyde, 67 .

medulla of, 58 .

occurrence in skin glands of $B u f o, 51$.

painting pancreas with, 66, 130.

passage into blood, 68 .

physiological effects of, 58 .

production of hyperglycæmia and glycostria by, $66,70,72,128,130$.

relation to melanin, 49 .

synonyms, 58.

synthesis of, 58 .

Adrenals (see Suprarenal capsules).

Adrenine (see Adrenalin).

Amines, syrapatho-mimetic action of, 65 .

Animal extracts (see also under the various organs), 8, 10.

Apituitarism, 101, 106.

Apocodeine, effect on action of adrenalin, 65 .

Arteries, as test for adrenalin, 62 .

A theroma, caused by suprarenal extract, 65 .

Atropine, eflect on action of adrenalin, 59, 71, 72.

effect on milk secretion, 94.

on pituitary activity, 90 .

on secretine, 125.

Autacoids or autacoid substances (see also under the various organs), 6 .

in blood, 2, 5, 6, 24, 40, 95, 128.

classification of, 6 .

compared with drugs, $6,8,90$.

definition of term, 6 .

Autotherapy, 10.

Basedow's disease (see Exophthalmic goitre).

Blood, action on adrenalin, 67 .
Blood, adrenalin in, 68.

autacoids in, 2, 5, 6, 24, 125 .

galactagogue in, 95 .

glycolytic ferment in, 129.

passage of internal secretions into, 2.

secretine in, 125.

Branchial organs (see Cleft organs).

Cachexia, hypophyseopriva, 101, 113.

strumipriva vel thyreopriva, 32.

Calcium metabolism, affected by thyroidectomy, 47.

in tetany, 26.

salts, administration in tetany, 26.

Cancer cells and internal secretions, 33 .

Carbolydrate metabolism (see Metabolism, carbohydrate).

Carotid gland, 51.

Castration, effects of, 108, 133 .

Cells, chromaffine, 51 .

chromaphil, 51 .

internally secreting, 2.

interstitial, of ovary, 137.

of testicle, 132.

of islets of Langerhans, 126.

luteal, 138.

of parathyroid, 17 .

of pineal, 119.

of pituitary, pars anterior, 79 .

pars intermedia, 80.

pregnancy cells, 79 .

of suprarenal cortex, 51 .

of suprarenal medulla, 54 .

of thymus, 46.

of thyroid, 12.

Cerebro-spinal fiuid, effect on, of extracts of pituitary, 90.

effect on, of intravenous injection of duodenal extract, 82 .

secretion into, of pars intermedia of pituitary, 81.

Chalones, origin and meaning of term, 5 .

Chalonic autacoids, 6 .

Chemical messengers, 5.

Chromaffine bodies. 51 . cells, 51 .

Chromaphil bodies, 51

development of, 50 .

reaction, 50 .

substance, 58 .

Cleft organs, 12.

Coccygeal gland, 51.

Colloid of parathyroid, 20.

of pituitary, 75 .

of thyroid, 14

Conarium (see Pineal glanđ). 
Corpuscles, concentric, of Hassal, 46. of Stannius in Teleostei, 58.

Corpus luteum or corpora lutea, spuria, 139. vera. 139. cells of, 138 .

development of, 138 .

extracts of, 141

influence of, on tixation of embryo, 148. on mammary growth, 146.

on ovulation, 148 .

on secretion, 146 .

on uterus, 148.

metabolic effects cuused by, 145 .

Cretinism, association with thyroid, 32.

endemic, 30 .

sporadic, 30 .

Diabetes (see cilso Glycosuria).

insipidus, produced by pituitary lesions, 103.

Langerhans' islets in, 127.

paucreatic, 127.

Diphtheria, disappearance of adrenalin in, 57 .

Drugs, internal secretions compared with, 5 .

Ductless glands, 1 .

Duodenum, autacoid of, 124.

epithelium of, 3 .

extract of, 3,124 .

action on bile, 125 .

on prancreas, 124.

on pituitary, $8:, 125$.

on succus entericus, 125 .

interaction with pancreas, 125.

internal secretion of, 73 .

Dwarfism, in connexion with pituitary, 113.

Dysparathyroidism, 24.

Dyspituitarism, 106.

Dystrophia adiposogenitalis, 110.

Elasmobranch fishes, suprarenuls of, 57, 58.

Endocrine glands, groupings of, 7 .

organs, definition, 2.

extracts of, 8 .

methods of determining functions of, 8 .

Enzymes, compared with active principles of endocrine organs, 4.

Epinephrectomy, 56.

Epinephrin (see also Adrenalin), 58.

Epiphysis (see Pineal gland).

Ergotoxine, effect on action of adrenalin, 64 .

Extracts (see Animal extracts, and under the several organs).

Fatigue, effect of suprarenal extract upon, 65.

Fecundity in fowls, effect of pituitary feeding upon, 105 .

Feminism, due to pituitary insufficiency, 110.

Fish, pancreas of, 126.

pituitary of, extructs of, 99.

suprarenals of, $7,57,58$.

Fotus, extract of, influence on growth of mamma, 150.

influence on milk secretion, 150 .

pancreas of, influence on mother, 128

parathyroids of, influence on mother, 23.

suprarenal of, 51 .

chemistry of cortex, 53 .

structure of cortex, 51 .

Formaldehyde, effect of, on adrenalin, 67.
Fröhlich's disease (see Dystrophia udiposogenitalis).

Galactagogue action of blood-serum, 95 .

of extract of corpus luteum, 144.

of mammary gland, 148.

of pineal, 120.

of pituitary, 90 .

Gastric secretion, 125 .

Gastrine, 125.

Generative glands or organs, female, internis secretions of, 137. (See also Ovary, Corpus luteum, etc.)

male, internal secretions of, 132. (See also Testicle.)

relations with pineal, 121 .

with pituitary, 110, 112, 115.

with suprarenal cortex, 53 .

with thyroid, $37,41$.

Gigantism, pituitary, 108.

relation to acromegaly, 108.

to defective sexual development, 108.

Glands, ductless, 1 .

endocrine or internally secreting, 1. (See also Endocrine glands).

externally secreting, 2 .

generative (see Generative glands).

Glycæmia (see Hyperglycæmia).

Glycolysis (and glycolytic ferment) in relation to internal secretion of pancreas, 129.

Glycosuria, caused by adrenalin, $65,70,72,130$. by injury of pituitary, 103, 104.

by mammary gland extract, 150 .

by removal of pancreas, 72, 127, 128, 129.

in acromegaly, 108, 109.

alimentary, affected by exophthalmic goitre, 37.

affected by hypopituitarism, 111.

by pituitary extracts, 96 .

by pituitary removal, 102 .

by thyroid atrophy, 36 .

by thyroidectomy, 32 .

by thyroid extracts, 36 .

Goitre, 33.

endemic, remedial effect of thyroid feeding, 32 . structure of thyroid in, 33 .

symptoms, 33.

exophthalmic, 36 . adrenalin in blood in, 41, 43 .

conaition of blood in, 39 .

of thymus in, 37.

hypersecretion in, 37 .

metabolism in, 37 .

structure of thyroid in, 37 .

symptoms of, 37 .

Grafting of internally secreting organs, 4.

ovary, 139.

pancreas, 127, 128.

parathyroid, 23.

pituitary, 104.

suprarenal, 57 .

testicle, 135 .

thyroid, 32.

Graves' disease (see Goitre, exophthalmic).

Hair (see also Trichosis).

in parathyroidectomy, 22.

in thyroid extirpation and atrophy, 29. 
Harmazones, 5.

Hormone or hormones, definition, 6. examples of, 6 . origin and meaning of term, 5 .

Hormonic autacoids, 6.

Hyperglycæmia, 130.

caused by adrenalin, 66, 72,130 .

by Bernard's puncture, 70,72 .

by pancreas removal, 127, 128, 129.

Hyperparathyroidism, 24.

Hyperpituitarism, 106.

Hyperthyroidism, caused by extract of thyroid, 36.

in exoplithalmic goitre, 38 .

Hypertrichosis, in acromegaly, 108.

Hypoparathyroidism, 24.

Hypophysectomy (see Pituitary, removal of).

Hypophysin, 84 .

Hypophysis, 74. (See also Pituitary body.) pharyngeal, 75 .

Hypopituitarism, 101, 106, 110, 111.

Hypothyroidism, in endernic goit:e, 33 .

in myxœdema, 31.

after thyroidectomy, 32 .

Infantilism, connectel with hypopituitarism, 111 .

relation to pituitary, 102, 110 .

sexual, thyroid in, 42 .

Infundibulum (see Hypophysis).

Insuline, 128.

Internal secretions, classification of, 5 .

definition, $1,2$.

materials of, 5 .

mode of action of, 7 .

Interrenal body of Elasmobranchs, 7 .

Interstitial cells (see Generative glands, Testicle, Ovary).

Iodine, absence in pituitary even after thyroidectomy, 116 .

in thyroid, 40 .

Iodo-thyrin, 40 .

Iodo-thyro-globulin, 40.

Islets of Langerhans (see Langerhans).

Kidney, permeability of, affected by absence of pancreas, 128, 130.

affected by pituitary extract, 89 .

Langerhans, islets of, in pancreas :-

cells of, 126.

changes in diabetes, 127 .

internal secretion of, 127 .

nerves of, 126.

origin of, 125 .

structure of, 126 .

in Teleostei, 126.

variations in, 125 .

vascular supply of, 126.

Leucocytes, glycogen in, 128.

glycolytic pro-ferment in, 129.

Mammary gland, electrical changes in, during secretion, 95 .

extracts of, effect on development of embryo, 150.

effect on suprarenals, 150.

galactagogue action of, 148
Ianmary gland, growth of, influenced by corpus luteum, 146.

influenced by fœtus extract, 150 .

by ovary, 140 .

by placenta extract, 150 .

internal secretion of, 148 .

plain muscle in walls of alveoli of, 91,145 .

secretion of, effect on :-

of blood-serum, 95 .

of extract of corpus luteum, 144.

of ovary, 143 .

of pineal, 120 .

of pituitary, 90 .

Melauin, formation of, in relation to adrenalin, 49.

Menstruation, affected by extirpation of ovaries, 140.

attecting size of thyroid, 41 .

Metabolism, action of internal secretions on, 5, 9.

affected by corpus luteum, 145 .

carbohydrate, influenced by castration, 134 .

by pancreas removal, 127, 123 .

by parathyroid removal, 25 .

by pituitary extirpation and disease, 102 .

by thyroid extracts, 9,36 .

by thyroid removal, 29.

in exophthalmic goitre, 37 .

in myxœdema, 32 .

Morphogenetic substances, 5 .

Myoneural junction, acted on by drugs and autacoids, 64 .

Myxodema, effect of thyroid administration in, 32.

history of, 31.

metabolism in, 32.

post-operative, 32 .

relation to thyroid atrophy, 31.

to thyroid extirpation, 32 .

Oöphorectomy (see Ovaries, removal of).

Opotherapy, 10.

Organotherapy, 10.

Ovary or ovaries, autacoids of, 143 .

corpora lutea (see Corpus luteum).

effect of grafting, 139.

extracts of, eflects on uterus, 141.

interstitial cells of, 137 .

effect of X-rays on, 137.

influence on development of secondary sexual characters, 180.

liquor folliculi of, action of, 141 .

relation to inammary developinent, 140 .

to puberty, 140.

removal of, 139.

effects on menstruation, 140 .

on metabolism, 139.

on uterus, 139.

Paired bodies of Elasmobranchs, 7, 58.

Pancreas, autacoids of, 128,129 .

diseases of, and diabetes, 127.

exterual secretion of, 1.5.

extiruation of, 2,127 .

effect on dilatation of pupil cuused by adrenalin, 130.

of pregnancy on, 128.

grafting, 127, 128.

internal secretion of, $2,125,128$. 
Pancreas, islets of Langerhans, 3, 125, 126. (See also Langerhans.)

relation to carbohydrate metaholism, 2, 127, 129.

Pancreatic duct, ligatnre of, 127.

juice, secretion of, excited by acid in duodenum, 125.

excited by secretine, 125 .

Parahypophysis, 75 .

Parathyrine, 27.

Parathyroid or parathyroids, accessory, 12. anatomy of, 16.

in animals, 12.

autacoids of, $24,27$.

blood-vessels of, 21 .

colloid in, 20.

development of, 21.

in disease, 25.

external or lower, 11.

extirpation of, 22.

differences, 24 .

effects of, 22.

on metabolism, 24.

on thyroid, 24.

tetany from, 23.

extracts of, 26.

grafting of, 23.

history of, 16.

internal or upper, 11.

position of, 11 .

relation to pancreas, 130 .

to pituitary, 28.

to thyroid, $20,27$.

to other endocrine organs, 28.

structure of, 17.

Parathyroidectomy, 22.

influence on liver cells, 28.

Pigmentation, in Addison's disease, 49.

in hypopituitarism, 111.

after suprarenal removal, 50.

Pineal or pineal gland, anatomy of, 118.

extirpation of, 120 .

extracts of, 120, 123 .

galactagogue action of, 120 .

feeding with, 123.

relation of, to generative organs, 121.

structure of, 119 .

tumours of, 121.

Pineal eye, 118.

Pituitary body, 74.

accessory glandules, 100.

anterior lobe of, 77 .

effect of deficiency of, 106, 110, 111.

of increase of secretion of, 106.

relation to acromegaly, 100, 109 .

autacoid or autacoids of, $84,86,96$.

compared with suprarenal, $84,85,88$.

blood-vessels of, $77,78,83$.

cells of, $78,79,80$.

clinical evidence relating to, 106 .

colloid in, 75, 80 .

development of, 75 .

feeding with, 96, 104.

effect on egg production in hens, 105.

on fertility of eggs, 105.

on growth, 105.

grafting of, 104.

hyaline bodies in, 80 .
Pituitary body, injury of, 103.

intraglandular cleft of, 74 .

iodine in, 116.

operations on, 113.

pars anterior seu glandularis, 77 .

blood-vessels of, 78 .

cells of, 78 .

colloid vesicles in, 80 .

pars intermedia of, 80 .

action of extracts, 98 .

cells of, 80 .

colloid vesicles in, 80 .

pars nervosa of, 83 .

effect of thyroidectomy on, 83, 116 .

extracts, action of, 98 .

hyaline and granular substances in, 83 . passage into third ventricle, 81.

posterior lobe of, 77 .

extracts of :-

administration of, in disease, 96.

effects of, on bladder, 87.

on blood pressure, 84 .

in birds, 87 .

on heart, 84,87 .

in birds, 84 .

ou intestine, 87.

on kidney, 88,89 .

on metabolism, 96 .

on milk secretion, 90 .

on plain muscle, 84.

on pupil, 87.

on stomach, 87 .

on urine, 88.

on uterus, 87 .

in pregnancy, 79 .

puncture of, effect in causing glycosuria, 104. relation to acromegaly, 106.

to Bernard's sugar puncture, 104.

to carbohydrate metabolism, 102, 117 .

to dystrophia adiposogenitalis, 110 .

to fat formation, $101,102,110,112,113$.

to feminism, $110,112$.

to gigantism, 108.

to growth, 102.

to menstruation, 110,115 .

to pancreas, 117.

to parathyroid, 116 .

to pregnancy, 101, 109, 115.

to respiration, 101.

to sexual organs, 101, 110, 115.

to suprarenals, 117.

to thyroid, 113,115 .

removal or extirpation of, complete, 100 .

methods, 100.

partial, 102.

secretion of, into third ventricle, 81, 83, 115.

structure of, 74.

after thyroidectomy, 116.

tumours of, 106, 109, 110.

Pituitrin, 84.

Polyuria, resulting from pituitary lesions, 103.

Post-branchial bodies, 16 .

Pregnancy, affected by parathyroidectomy, 23.

cells, in pituitary, 79 .

relation to corpus luteum, 148.

to exoph thalmic goitre, 37 .

to pituitary, 79, 101, 109, 115.

Progastrine, 125. 
Prosecretine, 3, 124.

affected by removal of pancreas, 125 .

Receptive substance, acted on by drugs and autacoids, 64 .

Secretine, action on, of atropine, 125.

gastric, 4, 125.

history of, 3 .

production of, 3,124 .

Secretion or secretions, external, 2.

internal, classification, $\mathbf{5}$.

definition, 1, 2.

history, 2.

methods of investigating, 8 .

mode of action of, 7 .

nature of active principles of, 4,5 .

(See also under the various organs.)

Sexual characters, secondary, influence on, of interstitial cells of generative glands, $135,140$.

organs (see Generative glands or organs).

Spaying (see Ovary, extirpation of).

Spleen, 1 .

affected by thyroidectomy, 47 .

Stannius, corpuseles of, $5 \mathrm{~S}$.

Substitution therapy, 10.

Sugar in blood and urine (see Diabetes, Glycosuria, Hyperglycæmia).

Suprarenal capsules or suprarenals :accessory, 50, 57.

action of drugs through suprarenals, 70 .

activity of, due to adrenalin, 50 .

in Addison's disease, 49.

autacoid of, 58.

blood-supply of, 55 .

buccal administration of, 65 .

cortex, chemistry of, 53 .

in fotus, 51 .

functions of, 52 .

lipoids of, 53 .

relationship to sexual organs, 53 .

structure of, 51 .

effects of extirpation, $56,57$.

of transplantation, 57 .

medulla, extracts of (see also Adrenalin) :-

action in Addison's disease, 57.

effect of nerve section on, 60 .

seat of, in niyoneural junction or receptive substance, 64 .

on arteries, 58 .

on bladder, 63 .

on carbohydrate metabolism, 66 .

on eye, 63 .

on hair-muscles, 64 .

on heart, 59.

on intestine, 62 .

on lacrimal glands, 64 .

on membrana nictitans or third eyelid, 63 . on muscle, 64,65 .

on pupil, 60,63 .

on respiration, 59.

on retractor penis, 62 .

on salivary glands, 64 .

on sweat glands, 64 .

on urine, 64.

on uterus, 62 .

on vas deferens, 64 .
Suprarenal capsules or suprarenals :-

medulla, extracts of, action on veins, 60 . subeutaneous administration of, 65 . morphology, 50 .

relations to generative glands, 71 .

to liver, 66, 71 .

to metabolism, 66 .

to pancreas, 66,72 .

to salivary and lacrimal glands, 71 .

to sympatlietic nervous system, 64 . effects of apocodeine, 65 . of ergotoxine, 64 .

secretion of, influence of drugs, 79 .

influence of fright, 69 .

of nerves, 69,72 .

structure of, 54 .

vessels and nerves of, 55 .

Suprarenin, 58.

Tachyphylaxis, in connexion with pituitary extract, 86

meaning of term, 86 .

Testicle, autacoid of, 135 .

effect of X-rays on, 135.

extracts of, 136.

grafting of, 135.

influence of, on secondary sexual characters, 134.

internal secretion of, 132.

interstitial cells of, 132.

removal of, 133. (See also Castration.)

tumours of, 136.

Tetania parathyreopriva, 23.

Tetany, caused by extir pation of parathyroids, 23 . toxin, 27.

Thymectomy (see Thymus, extirpation of).

Thymus, development of, 45 .

effect of inanition upon, 47 .

in exophthalmic goitre, 37.

extirpation of, 47 .

functions of, 47 .

relationship to generative organs, 47.

to thyroid, 43.

result of feeding with, 47 .

structure of, 45 .

in thyroid, 11,47 .

Thyrine, 40.

Thyro-globulin (see Iodo-thyro-globulin).

Thyroid or thyroid gland, 11.

accessory, 12.

atrophy of, 29,31 .

autacoids of, 32,40 .

blood-vessels of, 13.

chemistry of, 40 .

colloid of, 14 .

comparative anatomy of, 12.

development of, 15 .

effect of parathyroidectomy on, 20 .

in endemic goitre, 33.

in exophthalmic goitre, 36 .

extirpation of, 29 .

extracts of, administration by mouth, 32,36 .

effect on excitability of nerves, 36 .

intravenous injection, 35.

grafting of, 32 .

internal secretion of, 40 .

influence of nervous system on, 44 .

iodine in, 40. 
Thyroid or thyroid gland, in myxœdema, 31. position of, 11.

relation to carbohydrate metabolism, 42 . to generative organs, $29,41$.

to liver, 42.

to pancreas, 42, 130.

to parathyroiits, 24,27 .

to pituitary, $43,113$.

to suprarenals, 42 .

to thymus, 41,43 .

structure of, 12 .

theories regarding connexion with cretinisu, 30.

with exophthalmic goitre, 37 .

with myxœdema, 31 .

Thyroidectomy (see Thyroid, extirpation of).

Transplantation (see Grafting).
Trichosis, sexual characteristics of :affected by pituitary insufficiency, 110 .

by removal of generative glands, 133, 140.

Tumours, malignant, relation to internal secretions, 33 .

of pineal, 121 .

of pituitary body, 106, 108.

of testicle, 136 .

of thyroid, 33 .

Uterus, elfect of extracts on milk secretion, 148.

effect of pituitary extracts on, 87 . of removing ovaries on, 140.

of suprarenal extracts on, 62 .

inthence on growth of mammary gland, 148. internal secretion of, 148 . 





